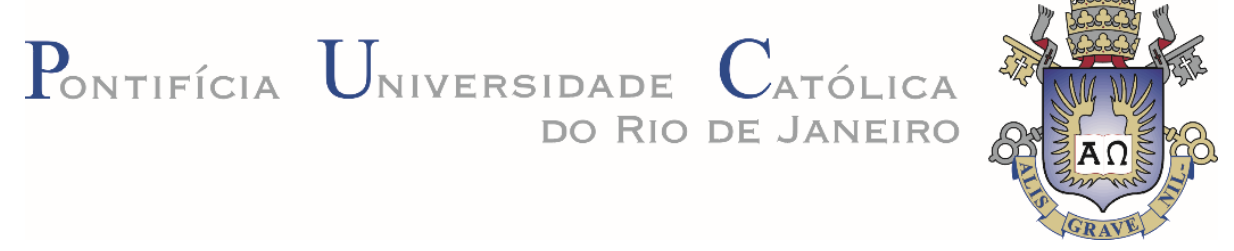

José Filho da Costa Castro

Planejamento da Reserva Operativa em Sistemas Multiárea
com Fontes Renováveis via Método da Entropia Cruzada

Tese de Doutorado

Tese apresentada ao Programa de Pós-Graduação em Engenharia Elétrica da PUC-Rio como requisito parcial para obtenção do grau de Doutor em Engenharia Elétrica.

Orientador: Prof. Armando Martins Leite da Silva

Rio de Janeiro

Abril de 2018 


\section{Planejamento da Reserva Operativa em Sistemas Multiárea com Fontes Renováveis via Método da Entropia Cruzada}

Tese apresentada como requisito parcial para obtenção do grau de Doutor pelo Programa de Pós-Graduação em Engenharia Elétrica da PUC-Rio. Aprovada pela Comissão Examinadora abaixo assinada.

Prof. Armando Martins Leite da Silva

Orientador

Departamento de Engenharia Elétrica - PUC Rio

Prof. Ricardo Bernardo Prada

Departamento de Engenharia Elétrica - PUC Rio

Prof. Marcus Theodor Schilling

UFF

Prof. Mauro Augusto da Rosa

UFSC

Prof. Dan Abensur Gandelman

EPE

Prof. Márcio da Silveira Carvalho

Coordenador Setorial do Centro

Técnico Científico - PUC-Rio

Rio de Janeiro, 11 de Abril de 2018 
Todos os direitos reservados. Proibida a reprodução total ou parcial do trabalho sem autorização da universidade, do autor e do orientador.

\section{José Filho da Costa Castro}

Analista de Pesquisa Enérgica na EPE - Empresa de Pesquisa Energética. Possui graduação em Engenharia Elétrica pela UFMA e mestrado em Sistemas Elétricos de Potência pela UNIFEI.

Ficha Catalográfica

Castro, José Filho da Costa

Planejamento da reserva operativa em sistemas multiárea com fontes renováveis via método da entropia cruzada / José Filho da Costa Castro ; orientador: Armando Martins Leite da Silva. - 2018. 201 f. : il. color. ; $30 \mathrm{~cm}$

Tese (doutorado)-Pontifícia Universidade Católica do Rio de Janeiro, Departamento de Engenharia Elétrica, 2018.

Inclui bibliografia

1. Engenharia Elétrica - Teses. 2. Confiabilidade de sistemas de energia. 3. Reserva girante. 4. Reserva operativa. 5. Risco de corte de carga. 6. Simulação Monte Carlo Quase Sequencial. I. Silva, Armando M. Leite da. II. Pontifícia Universidade Católica do Rio de Janeiro. Departamento de Engenharia Elétrica. III. Título. 
Dedico esta tese aos meus pais,

Pelo exemplo de vida 


\section{Agradecimentos}

Gostaria de expressar meus sinceros agradecimentos a todos que de alguma forma contribuíram para realização deste trabalho. Primeiramente a Deus, pela vida e pelas oportunidades.

Ao meu orientador, professor Armando Martins Leite da Silva, pelo excelente trabalho de orientação, pelos ensinamentos de vida e exemplo de dedicação, pelas oportunidades que me proporcionou e pela confiança. Agradeço por todo o tempo que dedicou para a realização deste trabalho, ao longo dos últimos anos foram muitas horas de discussões técnicas e ensinamentos, sem dúvida levo comigo, com muita humildade, alguns traços de sua personalidade.

A minha mãe, pelo apoio incondicional e incentivo para realização deste trabalho. Pelos ensinamentos e exemplo de superação, humildade e resiliência, que têm me servido de inspiração para vencer os obstáculos da vida. Ao meu pai, que embora tenha partido muito cedo, foi meu primeiro mentor e incentivador. Teve uma contribuição essencial para que eu perseguisse o caminho dos estudos. Agradeço a todos da minha família, pelo apoio moral, pela presença e união.

A Vittória Andrade, pelo carinho e compreensão. Por ter apoiado minhas decisões, incentivado que eu perseguisse minhas aspirações e por ter pacientemente gerenciado minha ausência. Agradeço por ter compartilhado comigo, sempre com muito companheirismo, os diversos momentos ao longo dos últimos anos.

A todos os colegas e amigos da PUC Rio, UNIFEI e EPE, pelo acolhimento, companheirismo e pelo compartilhamento de suas experiências de vida. Em especial ao meu amigo Fernando Assis, pela inestimável amizade, pelas suas valiosas dicas e contribuições para este trabalho e pelos ensinamentos compartilhados e lições de vida. Ao amigo Lucas Ramalho, pela amizade e pelas discussões conceituais que contribuíram para este trabalho. Ao Reinaldo Andrés González-Fernández pela ajuda na elucidação de alguns conceitos. Ao Pedro César e ao Mauro Rosa, pelas discussões no âmbito do projeto Mora.

A todos os que contribuíram para minha formação profissional.

À PUC Rio pela oportunidade. A CAPES, ao CNPQ e ao INESC P\&D Brasil pelo apoio financeiro. 


\section{Resumo}

Castro, José Filho da Costa; Leite da Silva, Armando Martins. Planejamento da Reserva Operativa em Sistemas Multiárea com Fontes Renováveis via Método da Entropia Cruzada. Rio de Janeiro, 2018. 201p. Tese de Doutorado - Departamento de Engenharia Elétrica, Pontifícia Universidade Católica do Rio de Janeiro.

A reserva girante é a parcela da reserva operativa provida por geradores sincronizados, e interligados à rede de transmissão, aptos a suprir a demanda na ocorrência de falhas de unidades de geração, erros na previsão da demanda, variações de capacidade de fontes renováveis ou qualquer outro fator inesperado. Dada sua característica estocástica, essa parcela da reserva operativa é mais adequadamente avaliada por meio de métodos capazes de representar as incertezas inerentes ao seu dimensionamento e planejamento. Por meio do risco de corte de carga é possível comparar e classificar distintas configurações do sistema elétrico, garantindo a não violação dos requisitos de confiabilidade. Sistemas com elevada penetração de fontes renováveis apresentam comportamento mais complexo devido ao aumento das incertezas envolvidas, à forte dependência de fatores energético-climáticos e às variações de capacidade destas fontes. Para avaliar as correlações temporais e representar a cronologia de ocorrência dos eventos no curto-prazo, um estimador baseado na Simulação Monte Carlo Quase Sequencial é apresentado. Nos estudos de planejamento da operação de curto-prazo o horizonte em análise é de minutos a algumas horas. Nestes casos, a ocorrência de falhas em equipamentos pode apresentar baixa probabilidade e contingências que causam corte de carga podem ser raras. Considerando a raridade destes eventos, as avaliações de risco são baseadas em técnicas de amostragem por importância. Os parâmetros de simulação são obtidos por um processo numérico adaptativo de otimização estocástica, utilizando os conceitos de Entropia Cruzada. Este trabalho apresenta uma metodologia de avaliação dos montantes de reserva girante em sistemas com participação de fontes renováveis, em uma abordagem multiárea. O risco de perda de carga é estimado considerando falhas nos sistemas de geração e transmissão, observando as restrições de transporte e os limites de intercâmbio de potência entre as diversas áreas elétricas.

\section{Palavras-Chave}

Confiabilidade de sistemas de energia; reserva girante; reserva operativa; risco de corte de carga; simulação Monte Carlo Quase Sequencial; método da Entropia Cruzada; planejamento da operação. 


\section{Abstract}

Castro, José Filho da Costa; Leite da Silva, Armando Martins (Advisor). Operating Reserve Assessment in Multi-Area Systems with Renewable Sources via Cross Entropy Method. Rio de Janeiro, 2018. 201p. Tese de Doutorado - Departamento de Engenharia Elétrica, Pontifícia Universidade Católica do Rio de Janeiro.

The spinning reserve is the portion of the operational reserve provided by synchronized generators and connected to the transmission network, capable of supplying the demand considering generating unit failures, errors in load forecasting, capacity intermittency of renewable sources or any other unexpected factor. Given its stochastic characteristic, this portion of the operating reserve is more adequately evaluated through methods capable of modeling the uncertainties inherent in its design and planning. Based on the loss of load risk, it is possible to compare different configurations of the electrical system, ensuring the non-violation of reliability requirements. Systems with high penetration of renewable sources present a more complex behavior due to the number of uncertainties involved, strong dependence of energy-climatic factors and variations in the capacity of these sources. In order to evaluate the temporal correlations and to represent the chronology of occurrence of events in the short term, an estimator based on quasi-sequential Monte Carlo simulation is presented. In short-term operation planning studies, the horizon under analysis is from minutes to a few hours. In these cases, the occurrence of equipment failures may present low probability and contingencies that cause load shedding may be rare. Considering the rarity of these events, risk assessments are based on importance sampling techniques. The simulation parameters are obtained by an adaptive numerical process of stochastic optimization, using the concept of Cross Entropy. This thesis presents a methodology for evaluating the amounts of spinning reserve in systems with high penetration of renewable sources, in a multi-area approach. The risk of loss of load is estimated considering failures in the generation and transmission systems, observing the network restrictions and the power exchange limits between the different electric areas.

\section{Keywords}

Reliability of power systems; spinning reserve; operating reserve; loss of load risk; Monte Carlo Simulation; Cross-Entropy method; operation planning. 


\section{Sumário}

$\begin{array}{ll}1 \text { Introdução } & 16\end{array}$

$\begin{array}{ll}\text { 1.1. Reserva Girante } & 18\end{array}$

1.2. Transporte da Reserva Operativa via Sistema de Transmissão 20

1.3. Estimação do Risco via Simulação Monte Carlo 21

1.4. Amostragem por Importância e o Método da Entropia Cruzada 22

1.5. Sistemas com Fontes Renováveis $\quad 24$

1.6. Revisão Bibliográfica $\quad 25$

1.7. Estrutura da Tese $\quad 29$

2 Confiabilidade de Sistemas de Energia Elétrica 32

2.1. Índices de Confiabilidade 33

2.2. Confiabilidade da Capacidade de Geração 35

2.3. Métodos de Avaliação da Confiabilidade 36

2.3.1. Avaliação da Confiabilidade pelo Método Analítico 38

2.3.2. Avaliação da Confiabilidade via Simulação Monte Carlo 40

2.3.3. Avaliação da Confiabilidade via Método da Entropia Cruzada 45

2.4. Conclusões 52

3 Requisitos de Reserva Operativa em Sistemas de Geração 53

3.1. Serviços Ancilares

3.2. Reserva Operativa 55

3.2.1. Classificação dos Tipos de Reserva 56

3.2.2. Reserva Girante 58

3.2.3. Método PJM (Pennsylvania - New Jersey - Maryland) 59

3.3. Dimensionamento da Reserva usando SMC via Método CE 63

3.4. Conclusões $\quad 68$

4 Reserva Girante Considerando Restrições de Transmissão 70

4.1. Confiabilidade de Sistemas de Geração e Transmissão 72

4.1.1. Modelos de Rede 74

4.1.2. Fluxo de Potência Linear 76 
4.2. Estimação dos Índices de Risco via Método CE cons.a Transmissão 81

4.3. Avaliação da Reserva Girante considerando a Rede de Transmissão 84

4.4. Avaliações Numéricas $\quad 89$

4.4.1. Comparação dos Métodos de Avaliação do Risco 91

4.4.2. Impacto da Estratégia de Corte de Carga 93

4.4.3. Restrições de Capacidade das Linhas de Transmissão 95

4.4.4. Efeito das Falhas em Linhas de Transmissão 97

4.5. Requisitos Mínimos de Reserva Girante em Função do Risco 99

4.5.1. Dimensionamento da Reserva via Modelo Barra Única 100

4.5.2. Reserva Considerando o Sistema de Transmissão e Redesp. de Geração 101

4.5.3. Reserva Considerando o Sistema de Transmissão e sem Redespacho 102

4.6. Impacto das Perdas no Sistema de Transmissão 104

$\begin{array}{ll}\text { 4.6.1. Perdas de Transmissão no Modelo Linearizado } & 104\end{array}$

4.6.2. Montante de Perdas - Sistema IEEE RTS 106

4.7. Aplicação do Método CE para identificação de Equipamentos Críticos 109

4.8. Conclusões 111

5 Planejamento da Reserva via Simulação Monte Carlo Quase Sequencial com $\begin{array}{ll}\text { Fontes Renováveis } & 113\end{array}$

$\begin{array}{ll}\text { 5.1. Introdução } & 114\end{array}$

5.2. Avaliação do Risco via Simulação Monte Carlo 117

5.3. Reserva Girante Considerando Fontes Renováveis 119

$\begin{array}{ll}\text { 5.4. Critério de Segurança } & 120\end{array}$

5.5. Representação da Geração Eólica no Curto Prazo 121

5.6. SMC Quase Sequencial via Método da Entropia Cruzada 123

5.7. Estratégia de Inicialização 125

5.8. Algoritmo da SMC Quase Sequencial 126

5.9. Resultados Numéricos - PARTE I 127

5.9.1. IEEE RTS - Geração Eólica e Cenários de Carga 128

5.9.2. Avaliações de Risco de Não Suprimento e Segurança Sistêmica 130

5.10. Resultados Numéricos - PARTE II: Restrições de Transmissão 135

5.11. Resultados Numéricos - Parte III: Classificação dos Equipamentos 138

5.11.1. Comparação dos Índices de Risco 138 
5.11.2. Classificação dos Equipamentos via Amostragem por Importância

5.11.3. Avaliação do Critério de Segurança Cons. o Sistema de Transmissão 142

5.12. Conclusões

6 Requisitos de Reserva em Sistemas Multiárea

6.1. Reserva Operativa no Sistema Multiárea

6.2. Método da Entropia Cruzada Aplicado ao Problema Multiárea

6.3. Resultados - Sistema IEEE RTS

6.3.1. Cenário 1: Sem Restrições de Cap. e sem Falha em Linhas

6.3.2. Cenário 2: Sistema de Trans. com Falhas, com Capacidade Ilimitada

6.3.3. Cenário 3:Considerando as Cap. Nominais das Linhas de Transmissão

6.3.4. Cenário 4: Sistema de Transmissão - Sem redespacho de Geração 160

6.3.5. Cenário 5: Efeito das Restrições de Transporte entre as Áreas

6.4. Resultados - Sistema Norte-Nordeste Brasileiro

6.4.1. Áreas do Sistema Elétrico

6.4.2. Áreas de Controle da Geração

168

6.4.3. Áreas de Controle da Transmissão

6.5. Conclusões

7 Conclusões e Propostas

175

7.1. Proposta de Trabalhos Futuros

7.2. Publicações Técnicas 


\section{Lista de Figuras}

Figura 1.1: Capacidade instalada de geração eólica - 2006 a 2018 [30]............... 25

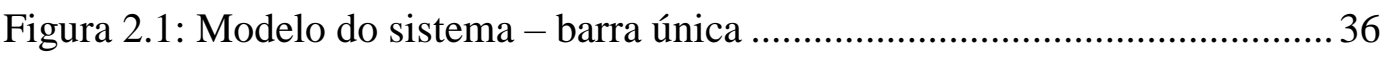

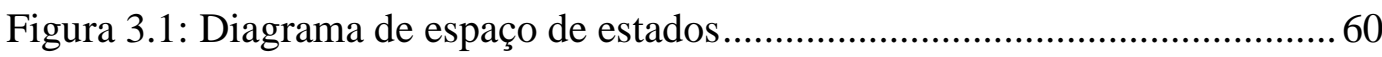

Figura 3.2: Características de capacidade e carga do sistema PJM [16] ............... 61

Figura 3.3: Representação do sistema - modelo barra única ................................ 66

Figura 4.1: Níveis hierárquicos e zonas funcionais ............................................. 73

Figura 4.2: IEEE Reliability Test System - RTS [87]. ......................................90

Figura 4.3: Tempo de simulação: SMC convencional × SMC-CE ......................93

Figura 4.4: Impacto da estratégia de corte de carga no risco. .............................. 95

Figura 4.5: Índices de risco em função da ORR da transmissão ........................... 98

Figura 4.6: Impacto das medidas corretivas nos índices de risco....................... 103

Figura 4.7: Impacto das perdas de transmissão no índice de risco...................... 108

Figura 4.8: Impacto das perdas de transmissão no montante de reserva .............. 108

Figura 5.2: Geração eólica no SIN (média diária) [30] ........................................ 116

Figura 5.3: Geração eólica no SIN (média horária) [30] ..................................... 116

Figura 5.1: Fator de capacidade médio mensal ................................................... 116

Figura 5.4: Modelo multiestados de curto-prazo - Geração eólica....................... 123

Figura 5.5: Modelo multinível geração-carga tempo-sequencial ........................ 124

Figura 5.6: IEEE RTS-79 com geração eólica .................................................. 128

Figura 5.7: Sequência de cenários de vento e níveis de carga.............................. 130

Figura 5.8: Variações do índice de risco nas séries eólicas .................................. 131

Figura 5.9: Variações do índice de risco nos cenários de geração eólica............. 133

Figura 5.10: Histograma do risco para os critérios: $10^{-2}$ (a) e $10^{-4}$ (b) ................ 133

Figura 5.11: Número de unidades geradoras .................................................... 134

Figura 5.12: Cenários de geração .................................................................. 136

Figura 5.13: Reserva disponível em cada cenário de geração ............................. 137

Figura 5.14: Índices de risco para cada cenário de geração ................................ 138

Figura 5.15: Índices de risco para o cenário "Normal" ........................................ 139 


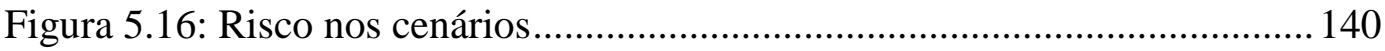

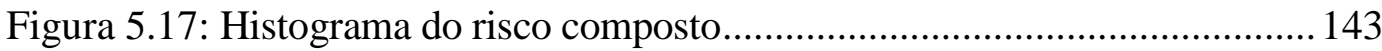

Figura 5.18: Risco e reserva como percentual da carga ........................................ 144

Figura 5.19: Risco em função do número de unidades............................................. 145

Figura 5.20: Risco desconsiderando as falhas e restrições de transmissão .......... 146

Figura 6.1: Sistema com interligações entre áreas elétricas ................................. 150

Figura 6.2: Áreas do sistema IEEE RTS-79 ....................................................... 153

Figura 6.3: Índices de Risco do sistema e das áreas ...............................................162

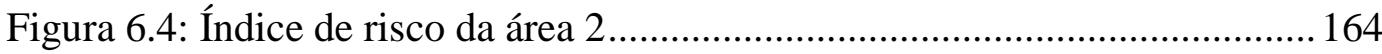

Figura 6.5: Diagrama do Sistema Elétrico Brasileiro - ONS [93] ........................ 166

Figura 6.6: Áreas de controle da geração - Centros Regionais ONS - [94]......... 169

Figura 6.7: Áreas de controle da transmissão ONS- [95] ..................................... 170

Tabela 11.1: Tempos computacionais [em segundos] ………………………...... 195

Tabela 11.2: Tempos computacionais [em segundos] considerando restrições .. 195

Figura 12.1: Curva de Lorenz e o índice de Gini [97]......................................... 197 


\section{Lista de Tabelas}

Tabela 2.1: Classificação do índice de Severidade...................................................35

Tabela 4.1: Resultados para o sistema IEEE-RTS 79 ......................................... 92

Tabela 4.2: Efeito da política de corte de carga .................................................. 94

Tabela 4.3: Índice de risco em função da capacidade de transmissão................... 96

Tabela 4.4: Impacto da $\mathrm{ORR}_{T}$ no índice de risco ............................................... 97

Tabela 4.5: Índice de risco desconsiderando falhas nas LTs................................99

Tabela 4.6: Dimensionamento da reserva - Modelo barra única ......................... 100

Tabela 4.7: Reserva - Considerando risco G\&T com redespacho ...................... 102

Tabela 4.8: Reserva - Considerando risco G\&T sem redespacho ...................... 103

Tabela 4.9: Risco no sistema IEEE RTS sem perdas na transmissão.................. 107

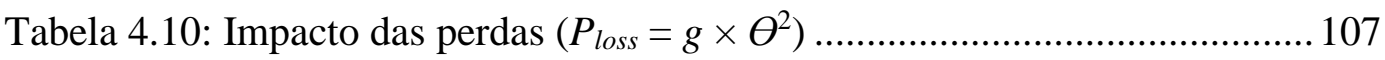

Tabela 4.11: Classificação dos equipamentos - IEEE RTS ................................. 110

Tabela 5.1: Dados cronológicos: Geração eólica e carga .................................... 129

Tabela 5.2: Avaliação do risco das séries eólicas................................................. 132

Tabela 5.3: Geração Despachada (794 U) [MW] .............................................. 135

Tabela 5.4: Reserva Disponível [MW] com as 794 unidades despachadas* ..... 136

Tabela 5.5: Reserva Disponível [\% Carga] com as 794 unidades despachadas.. 137

Tabela 5.6: Índices de Risco - IEEE RTS Wind: Cenário Normal ..................... 139

Tabela 5.7: FDR para classificação dos equipamentos - IEEE RTS Wind: ....... 141

Tabela 5.8: FDR para classificação dos equipamentos - IEEE RTS Wind: ....... 142

Tabela 6.1: Características do sistema de geração - IEEE RTS ......................... 154

Tabela 6.2: Geração, carga e reserva de cada área .............................................. 154

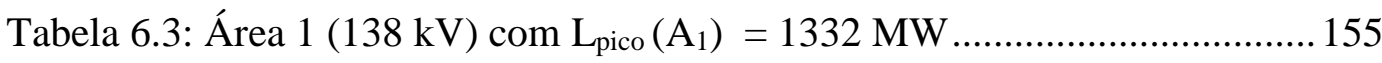

Tabela 6.4: Área $230 \mathrm{kV}$ com $\mathrm{L}_{\text {pico }}\left(\mathrm{A}_{2}\right)=1518 \mathrm{MW}$.................................. 155

Tabela 6.5: Risco por área - Modelo Barra Única $\left(\beta_{\max }=1 \%, \forall \mathrm{A}_{\mathrm{i}}\right) \ldots \ldots \ldots \ldots \ldots . . . . .156$

Tabela 6.6: Risco por área - Modelo Barra Única $\left(\beta_{\max }=5 \%, \forall \mathrm{A}_{\mathrm{i}}\right) \ldots \ldots \ldots \ldots \ldots . . . . . .157$

Tabela 6.7: Sistema de transmissão sem restrições - com redespacho ................ 158

Tabela 6.8: Sistema de transmissão sem restrições - sem redespacho................. 158

Tabela 6.9: Representação das restrições e falhas - com redespacho ................. 159 
Tabela 6.10: Transmissão representada e geração sem redespacho 160

Tabela 6.11: Transmissão representada e geração sem redespacho 161

Tabela 6.12: Região de fronteira com $90 \%$ de capacidade 163

Tabela 6.13: Região de fronteira com 80\% de capacidade.................................. 163

Tabela 6.14: Região de fronteira com 70\% de capacidade................................. 164

Tabela 6.15: Áreas Elétricas do PDE2026 - Sistema NNB ............................... 167

Tabela 6.16: Risco sistema NNB - Modelo Barrra Única ...................................171

Tabela 6.17: Risco por área - com restrições de capacidade .............................. 172

Tabela 6.18: Risco por área - com restrições de capacidade e falhas nas LTs ... 173

Tabela 9.1: Lista de unidades de geração segundo ordem de mérito. .................. 192

Tabela 10.1: Índices de Risco - Cenário Favorável ............................................ 193

Tabela 10.2: Índices de Risco - Cenário Normal ................................................ 193

Tabela 10.3: Índices de Risco - Cenário Desfavorável ....................................... 194

Tabela 10.4: Índices de Risco - Cenário Decrescente.......................................... 194

Tabela 10.5: Índices de Risco - Cenário Crescente 194

Tabela 12.1: Riscos no sistema IEEE RTS........................................................ 198

Tabela 12.2: Renda das áreas do sistema .......................................................... 199

Tabela 12.3: Parâmetros normalizados................................................................... 200

Tabela 12.4: Parâmetros da curva de Lorenz ........................................................ 200

Tabela 12.5: Índice de Gini das áreas .............................................................. 201 
Keep your thoughts positive 6ecause Your thoughts become your words. Your words become your actions. Your actions become your habits. Your habits become your values. Your values become your destiny. 


\section{Introdução}

Os sistemas de potência são planejados e operados para fornecer energia elétrica aos seus consumidores de forma econômica e dentro dos níveis requeridos de confiabilidade [1], [2]. Assim, é necessário manter um equilíbrio contínuo entre a energia gerada e o consumo de modo a evitar interrupções no fornecimento. No entanto, a energia elétrica é produzida e fornecida aos consumidores praticamente em tempo real e ainda não há um método adequado e seguro para armazená-la em larga escala de forma economicamente viável [3].

Para garantir o equilíbrio eletro-energético, mantém-se certa margem de geração acima da demanda prevista. Essa margem é denominada reserva de geração sendo essencialmente dividida em duas partes: reserva de capacidade estática e de capacidade operativa, de acordo com o horizonte do planejamento [4].

A reserva de capacidade estática está relacionada à avaliação de longo prazo das necessidades do sistema em termos globais. A capacidade operativa está relacionada à avaliação em curto prazo da capacidade real necessária para atender um dado nível de carga [2], [5], [6], [7], sendo fornecida por unidades que ficam de prontidão e podem ser rapidamente utilizadas caso ocorra insuficiência de geração [3].

O dimensionamento adequado da reserva de geração é essencial para que o sistema elétrico seja capaz de desempenhar sua função, mesmo na ocorrência de aumentos inesperados dos níveis de carga, falhas nos seus geradores, saídas não programadas de linhas de transmissão, indisponibilidade de recursos energéticos de fontes renováveis, entre outros eventos. Desta forma, um dos objetivos do planejamento de sistemas elétricos de potência é determinar os montantes de reserva, tanto estática quanto operativa, necessários para atender apropriadamente os requisitos do sistema.

Em estudos de planejamento da expansão são determinados os reforços (i.e., unidades de geração, linhas de transmissão, funções de transformação, etc.), onde e quando devem ser adicionados para assegurar os requisitos de reserva estática [8]. 
No curto prazo, dada a configuração do sistema existente, o objetivo é determinar o montante de geração que deve ser programado para atender a demanda prevista, assegurando os níveis adequados de confiabilidade e economicidade [9].

Em estudos de planejamento da operação de sistemas elétricos, para que seja possível dimensionar coerentemente a reserva, é necessário o emprego de metodologias capazes de quantificar a confiabilidade de diversas configurações do sistema, de forma a escolher dentre elas a mais adequada, com o objetivo de mitigar o risco de não suprimento da demanda.

No curto prazo, o risco de insuficiência de geração pode ser minimizado sincronizando um número apropriado de unidades; uma quantidade de reserva é mantida para garantir o suprimento com confiabilidade. No entanto, um montante elevado de reserva pode levar a altos investimentos, o que seria refletido na tarifa de energia do consumidor. Por outro lado, uma pequena margem pode levar a baixos níveis de segurança sistêmica, o que aumentaria o risco de interrupção do fornecimento [10].

Em geral, os padrões de confiabilidade são obtidos provendo um grupo de serviços denominados "ancilares", necessários para proteger a integridade da rede e garantir a continuidade do fornecimento. Esses serviços auxiliares incluem a coordenação da operação, regulação de frequência, balanço de energia, suporte de tensão, reserva de geração, entre outros [3]. A reserva de geração pode ser considerada um dos serviços mais importantes [11], pois tem a função de garantir o equilíbrio energético de forma a mitigar o risco de corte de carga.

A reserva operativa, que no âmbito dos serviços ancilares faz parte do grupo de reserva de geração, é normalmente decomposta em quatro partes: reserva de regulação, girante, não girante e reserva de reposição [7].

As reservas de regulação e girante são providas por unidades sincronizadas. Enquanto a reserva de regulação destina-se, basicamente, ao controle de frequência por meio da atuação das unidades que participam do Controle Automático da Geração (CAG), a reserva girante visa cobrir a perda de unidades ou a ocorrência de qualquer distúrbio inesperado que ocasione déficit de geração.

A reserva não girante compreende as unidades de partida rápida (e.g. hidráulica), e destina-se à recomposição da reserva girante. A reserva de reposição pode 
ser provida por unidades com maior tempo de partida sendo empregada para recompor a reserva girante no caso da perda de um grande bloco de geração sincronizada.

Usualmente unidades síncronas podem ser empregadas para substituir outros tipos de reserva de resposta mais lenta. Unidades de partida rápida e cargas interruptíveis são considerados casos especiais de reserva de geração. Definições específicas e classificações de serviços ancilares têm sido realizadas de acordo com as características do sistema elétrico e das diretrizes dos órgãos de regulamentação. Uma descrição das definições e características técnicas desses serviços em diversas partes do mundo pode ser encontrada em [12].

Esta Tese de Doutorado concentra-se na avaliação e planejamento dos requisitos de reserva de geração para o curto prazo. Desenvolve-se um novo método de dimensionamento e planejamento da operação considerando o risco de não suprimento da demanda devido a falhas nos sistemas de geração e transmissão. Adicionalmente, propõe-se uma metodologia para avaliação dos requisitos de reserva em sistemas com elevada penetração de fontes renováveis e também uma abordagem analisando as múltiplas áreas eletroenergéticas do sistema.

\section{1. Reserva Girante}

A reserva girante é, fundamentalmente, a parcela da geração que deve estar sincronizada, ou que seja possível sincronizar em tempo hábil, de forma a repor a perda de unidades de geração ou suprir acréscimos de demanda devido a erros de previsão ou qualquer outro fator externo inesperado [4].

Embora haja na literatura diversos critérios determinísticos de avaliação da reserva girante (e.g., critério da maior máquina, percentual da carga, etc.), esses métodos geralmente desconsideram a natureza estocástica do problema.

A inadequação da aplicação de métodos determinísticos em problemas com elevado número de incertezas é um fato que tem sido amplamente reconhecido [2], [4], [8], [13], [14]. Ao desprezar os parâmetros estocásticos dos componentes do sistema (tais como taxa de falha e indisponibilidade), o uso de métodos determinísticos pode produzir resultados pouco confiáveis ou não econômicos. 
Fatores como o reconhecimento da natureza estocástica dos eventos envolvidos, o desperdício oriundo de decisões tomadas com base em critérios determinísticos e, principalmente, escassez de recursos financeiros contribuem para o aumento da necessidade de uma avaliação mais detalhada do comportamento do sistema através de técnicas probabilísticas [14].

O dimensionamento da reserva operativa envolve a programação e o despacho das unidades de geração considerando o risco do sistema. Durante a fase de programação o operador decide quais unidades deverão ser despachadas. No despacho define-se a quantidade de potência de reserva a ser alocada por máquina ou grupos de máquinas [7].

No planejamento da reserva o objetivo é definir os requisitos de reserva em um horizonte de interesse; no âmbito da operação esse intervalo normalmente é de algumas horas. Em sistemas com elevada penetração de fontes renováveis, a avaliação dos requisitos de reserva deve ser realizada em intervalos ainda menores, uma vez que a capacidade de geração de fontes voláteis pode variar significativamente em curtos períodos (da ordem de minutos).

O método PJM (aplicado ao sistema Pennsylvania-New Jersey-Maryland, USA) [15] foi um dos primeiros a utilizar índices de risco na determinação do montante de reserva. Basicamente, determinam-se as probabilidades de suprir a demanda em um intervalo de tempo no qual não seja possível sincronizar máquinas, caso ocorra a saída inesperada de geradores. Acrescenta-se, na fase de programação, uma quantidade de máquinas com potência suficiente para que a probabilidade de perda de carga, ou risco probabilístico de não suprimento da demanda, torne-se inferior a um valor definido como aceitável.

Mesmo simplificando a representação do sistema, desprezando o sistema de transmissão e considerando falhas apenas no sistema de geração, o método PJM foi importante por introduzir a ideia de utilizar o índice de risco para avaliar os requisitos de reserva.

Algumas das ideias do método PJM foram expandidas em vários trabalhos. Os conceitos do método PJM são aplicados até hoje no planejamento da Margem de Reserva Instalada (IRM - Installed Reserve Margin) do sistema interligado Pennsylvania-New Jersey-Maryland [16]. 


\section{2.}

\section{Transporte da Reserva Operativa via Sistema de Transmissão}

A transmissão desempenha um papel crítico nos sistemas elétricos [8], uma vez que a ocorrência de falhas nesse sistema inviabiliza o atendimento da demanda mesmo em situações de disponibilidade de geração. $\mathrm{O}$ impacto de falhas e restrições de limite de capacidade têm se tornado cada vez mais relevante, uma vez que a busca por eficiência econômica impõe que os equipamentos operem cada vez mais carregados.

No âmbito do dimensionamento da reserva girante, ao avaliar a confiabilidade do fornecimento é comum considerar apenas o sistema de geração, os índices de risco calculados são otimistas [17] e, dependo da confiabilidade do sistema de transmissão, podem não refletir a realidade e as incertezas inerentes à operação sistêmica de curto e longo prazo.

O acréscimo de reserva de geração, em uma área em que o sistema de transmissão está próximo dos seus limites ou em regiões onde possam ocorrer gargalos de transmissão, pode resultar em pouco ou mesmo nenhum benefício para o sistema [1], [18]. Uma maneira coerente de avaliar os requisitos de reserva é, além de utilizar métodos que aferem adequadamente as incertezas do sistema de geração, considerar também as características estocásticas dos elementos dos sistemas de transmissão, i.e., suas falhas e restrições de capacidade de transporte.

Linhas de transmissão são elementos críticos para a conexão entre a geração e os centros de consumo. Com o crescimento da demanda e as estações geradoras sendo construídas cada vez mais distantes dos núcleos de concentração de carga, a tendência é que operem cada vez mais carregadas e que os sistemas de transmissão sejam, portanto, cada vez mais solicitados [19].

Tradicionalmente os métodos de determinação dos montantes de reserva girante consideram o sistema de transmissão robusto o suficiente a ponto de ser desprezado [15]. Uma das dificuldades que surge ao incluir a rede de transmissão é representar corretamente a política de corte de carga durante a análise da adequação do sistema, pois os índices de risco por barra/área podem ser alterados dependendo das premissas e critérios adotados.

Diferentemente da análise em que apenas o sistema de geração é considerado, através de um modelo "barra única", as políticas de corte de carga devem priorizar 
o corte/rejeição de carga na região em que ocorre alguma inadequação. Esse tipo de observação, apesar de representar a operação do sistema da forma como é realizada por meio dos esquemas de corte de carga, apenas torna-se visível quando a rede de transmissão é incluída na avaliação do risco no problema de planejamento da reserva girante.

A estimação do risco torna-se mais complexa ao representar a transmissão. Para verificar a adequação do sistema necessita-se avaliar a rede e, dependendo do tipo de análise, adotar medidas corretivas, tais como redespacho de geração, corte de carga, etc. O risco, neste nível hierárquico, pode ser apropriadamente avaliado por meio de ferramentas de simulação computacional [8]. Em sistemas de grande porte, a estimação dos índices de confiabilidade composta (confiabilidade da geração e transmissão) por meio de simulação Monte Carlo (SMC) é mais atrativa que por métodos de enumeração [8], [20].

Em resumo, as interrupções de fornecimento devido às restrições e falhas de capacidade de transporte impactam os índices de risco, uma vez que o corte de carga pode ocorrer não apenas devido à insuficiência de geração, mas também devido às restrições do sistema de transmissão. Há, portanto, um impacto do sistema de transmissão nos requisitos de reserva e nos pontos adequados para alocação. Tais constatações são ainda mais evidentes em sistemas com fontes com capacidades intermitentes, uma vez que há variação significativa da adequação do sistema em função dos recursos energéticos e da capacidade de transportar/intercambiar potência.

\section{3.}

\section{Estimação do Risco via Simulação Monte Carlo}

A Simulação Monte Carlo é um processo iterativo que permite estimar probabilidades e, portanto, riscos, através do sorteio ou amostragem de eventos. O procedimento básico consiste em, dadas as funções densidade de probabilidade dos estados representativos dos componentes do sistema, amostrar eventos um número de vezes até que os resultados obtidos apresentem valores dentro de um determinado intervalo de confiança [2], [21]. Essa técnica de simulação computacional tem sido uma importante ferramenta em uma variedade de aplicações em engenharia. 
Para sistemas de geração e transmissão as estimativas dos índices de perda de carga são obtidas através de algoritmos baseados em duas representações distintas: espaço de estados e cronológica. A enumeração de estados, ou método analítico, e a simulação Monte Carlo (SMC) não sequencial (ou não cronológica) são exemplos de algoritmos baseados na representação a espaço de estados [6].

Nos métodos baseados em espaço de estados, diferentemente da abordagem cronológica ou sequencial, os estados são selecionados e avaliados sem qualquer conexão cronológica ou memória, o que diminui o custo computacional de métodos não cronológicos se comparados aos cronológicos. Assim, métodos não sequenciais são ferramentas de extrema utilidade na avaliação da confiabilidade de sistemas de geração e/ou transmissão de grande porte [8], [22], [23], [24], [25].

Apesar da robustez e capacidade de avaliar sistemas de grande porte, a grande desvantagem da SMC é o seu alto custo computacional ao simular eventos com baixa probabilidade (ditos raros, i.e., com probabilidades menores que $10^{-5}$ ), pois, devido sua estratégia de amostragem para obter um nível de precisão aceitável, um elevado número de simulações deve ser realizado. Em situações deste tipo, com o intuito de diminuir o esforço computacional, técnicas de redução de variância (VRT - Variance Reduction Techniques) [21], [26] devem ser empregadas.

Uma VRT que apresentou resultados bastante significativos quando aplicada à análise de confiabilidade de sistemas elétricos de potência é a técnica baseada em Amostragem por Importância (IS - Importance Sampling), usando os conceitos estatísticos do Método da Entropia Cruzada (Método CE - Cross Entropy) [22], [27], [28].

\section{4.}

\section{Amostragem por Importância e o Método da Entropia Cruzada}

Técnicas de redução de variância (VRT) são métodos cujo objetivo é diminuir a variância, i.e., a dispersão associada às variações dos parâmetros sendo avaliados (variáveis aleatórias). O uso de uma VRT possibilita reduzir a variância para um mesmo número de amostras ou diminuir o número de amostras para obter a mesma variância. Assim, pode-se diminuir o esforço computacional da simulação ou mesmo obter resultados com menor intervalo de confiança [2], [6]. 
No âmbito do dimensionamento probabilístico da reserva girante usando técnicas de SMC, o uso de VRT é necessário devido à ocorrência de pequenos valores de risco de corte de carga em algumas configurações simuladas. Isto é consequência do pequeno intervalo de tempo considerado, que é de apenas algumas horas em análises de curto-prazo [29].

Os avanços recentes em estratégias de simulação, disponibilidade de software, análise de sensibilidade e otimização estocástica, combinados com o crescimento constante tanto em dimensões quanto em complexidade dos sistemas reais têm feito com que técnicas de simulação sejam ferramentas cada vez mais utilizadas e aceitas [21]. Observando essa tendência e dadas as características de complexidade dos sistemas elétricos atuais e a necessidade de uma modelagem adequada, neste trabalho os índices de risco são estimados usando SMC em conjunto com técnicas de amostragem por importância baseadas no método CE.

Metodologias de avaliação de risco via simulação estocástica são robustas para lidar com problemas de elevado número de estados, como em sistemas de grande porte e/ou com múltiplos níveis de carga e geração, tais como a maioria dos sistemas reais [22]. O uso de técnicas de amostragem por importância em conjunto com a otimização dos parâmetros via método CE torna possível a avaliação de forma computacionalmente eficiente, mesmo em configurações altamente confiáveis ou com fontes renováveis.

Com o intuito de melhorar as propriedades de convergência, algumas VRT exploram a possível correlação entre as variáveis aleatórias que apresentam a mesma distribuição de probabilidade para reduzir a variância do estimador. Em Amostragem por Importância (IS), entretanto, utiliza-se uma nova distribuição de probabilidade para gerar amostras dos eventos de interesse. Assim, os eventos que são considerados mais importantes são amostrados mais frequentemente. Porém, ao utilizar uma distribuição de probabilidade diferente da original, são geradas amostras tendenciosas. $\mathrm{O}$ estimador deve então ser compensado através de algum fator de correção, que deve ser obtido considerando as distorções no espaço amostral devido à utilização da nova função de distribuição [21], [26].

Um dos aspectos críticos de metodologias baseadas em IS é a determinação da nova função de distribuição, uma vez que esta será utilizada para obter as amostras dos eventos importantes [28]. A correta identificação, através de uma medida 
estatística, da região mais adequada a ser amostrada é considerado um dos maiores problemas da IS [4].

Técnicas de otimização estocástica em conjunto com conceitos de Entropia Cruzada têm sido utilizadas com esse intuito [21], [22]. Por meio do método CE pode se estimar os parâmetros de referência ótimos, ou quase ótimos, da amostragem. Isto é possível minimizando a distância entre as funções massa de probabilidade das amostras [21], [26].

O desempenho computacional da Simulação Monte Carlo pode ser consideravelmente melhorado aplicando técnicas de redução de variância, tornando a simulação estatisticamente eficiente e possibilitando obter os intervalos de confiança mais estreitos, principalmente na estimação da probabilidade de eventos raros [21].

\section{5 . \\ Sistemas com Fontes Renováveis}

Nos últimos anos, a participação de fontes renováveis na matriz energética de vários países tem crescido de forma acelerada. No Brasil, em função dos leilões de energia renovável coordenados pela EPE (Empresa de Pesquisa Energética), a capacidade instalada da geração eólica cresceu de forma acentuada nos últimos dez anos, como mostrado na Figura 1.1 [30].

A inserção de geração eólica traz impactos na segurança, confiabilidade e eficiência da operação. O emprego massivo de fontes renováveis, especialmente a geração eólica, traz novos desafios aos operadores e planejadores dos sistemas de potência [31].

A avaliação dos requisitos de reserva em sistemas com elevada penetração de fontes voláteis/variáveis é mais complexa, uma vez que o impacto das incertezas, tal como a variação dos ventos ou irradiação solar, pode ser significativo.

Em geral, do ponto de vista construtivo, as especificações de projeto (inércia, estatismo, etc.) de geradores hidráulicos e térmicos permitem que contribuam com a provisão de serviços ancilares, tais como o controle de tensão e a regulação de frequência. Por outro lado, nem todos os tipos de turbina eólica, por critérios econômico-construtivos, são capazes de fornecer esses serviços de suporte à operação do sistema [19]. 


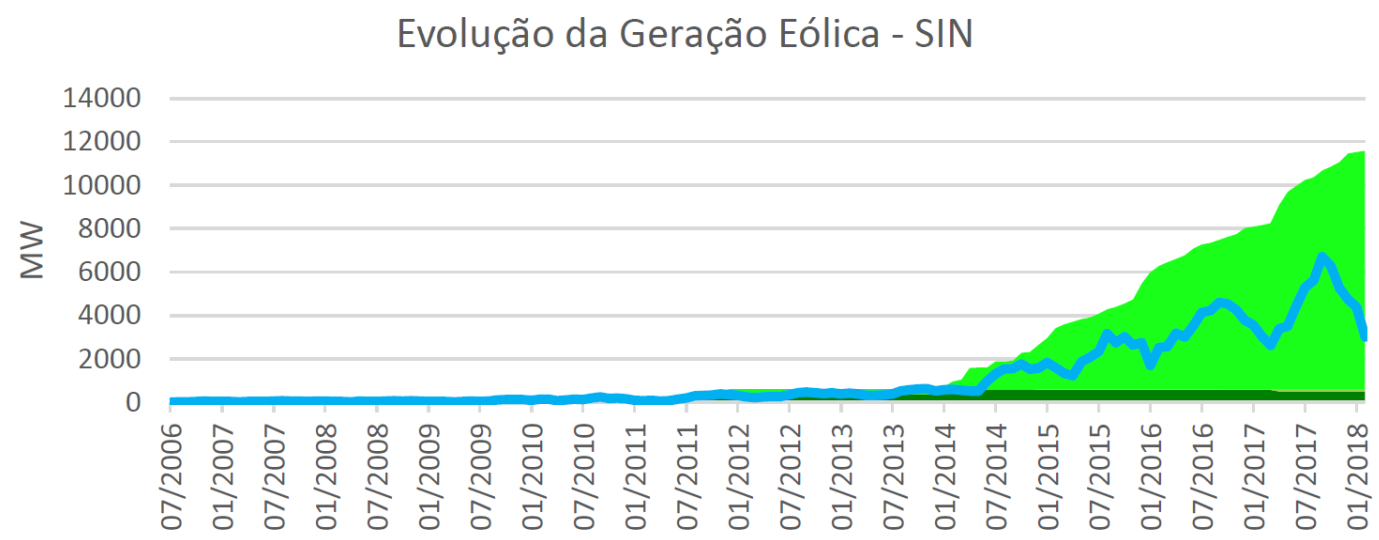

Figura 1.1: Capacidade instalada de geração eólica - 2006 a 2018 [30]

Do ponto de vista da segurança energética no curto-prazo, a geração eólica impõe requisitos adicionais, principalmente devido às variações de velocidade do vento. Em sistemas com elevada penetração de fontes intermitentes, a reserva precisa lidar com a incerteza associada à produção de energia eólica, uma vez que a capacidade de geração dos aerogeradores varia devido à característica de flutuação da energia em sua forma primária (vento/sol). Além disso, a variabilidade da geração pode também impor mais requisitos de flexibilidade dos geradores convencionais (hidro e térmicas), a fim de fornecer serviços de suporte ao sistema [31].

O Brasil se apresenta como um dos mercados mais promissores para a expansão das fontes de renováveis que utilizam o vento como energia primária, pois possui um dos maiores fatores de capacidade de geração eólica no mundo. Em 2016 o ONS propôs uma revisão em sua metodologia de dimensionamento da reserva de potência operativa, em função do significativo aumento da participação dessa fonte na matriz energética brasileira nos últimos anos [32].

\section{6. \\ Revisão Bibliográfica}

O planejamento da operação tem um papel fundamental em estudos de sistemas elétricos de potência [1]. A necessidade de assegurar que haja um nível apropriado de confiabilidade, tanto do ponto de vista da adequação estática quanto do 
ponto de vista da segurança dinâmica, na operação de sistemas de potência é um fato há muito tempo reconhecido [2], [4].

Há cerca de mais de 70 anos já se discutia a necessidade de adotar metodologias capazes de lidar com a natureza estocástica dos sistemas de potência [4], [7], como pode ser comprovado através de vários trabalhos publicados sobre o tema. Ao longo dos anos, alguns desses trabalhos foram organizados em bibliografias publicadas em 1966 [33], 1972 [34], 1978 [35], 1984 [36], 1988 [37], 1990 [38], 1994 [39] e 2001 [40].

Em 1963 um grupo de engenheiros responsáveis pelo sistema interligado Pennsylvania-New Jersey-Maryland publicou um dos primeiros trabalhos a utilizar técnicas probabilísticas para dimensionar a reserva girante [15], tendo a metodologia proposta ficado conhecida como método PJM [4]. Basicamente, o método proposto consistia em comissionar unidades no início do período de operação, considerando que dentro de um determinado intervalo de tempo (denominado em inglês por lead time) não seria possível adicionar novas unidades de geração, na ocorrência de saída inesperada de alguma máquina ou uma elevação não prevista da demanda.

No método PJM as unidades de geração são despachadas até que um critério de risco pré-estabelecido seja satisfeito. O risco é obtido analiticamente por inspeção observando as linhas de uma tabela semelhante à COPT (Capacity Outage Probability Table), com a diferença que é utilizado o parâmetro ORR (Outage Replacement Rate) e não a FOR (Forced Outage Rate) no cálculo do risco de curto-prazo do sistema [4]. O sistema de transmissão é considerado totalmente confiável e com capacidade de transporte ilimitado.

Após a publicação do Método PJM, vários trabalhos foram publicados propondo novas considerações e fazendo análises adicionais [4], [17], [41], [42], [43]. Em [42], a ORR foi modificada para possibilitar a modelagem de perdas parciais de capacidade das unidades devido ao adiamento da manutenção. O efeito da inclusão de unidades com diferentes lead times (tais como as unidades de partida rápida e as unidades de reserva quente) foi analisado em [43].

Em [44] são exploradas as metodologias básicas de estabelecimento da reserva operativa e os aspectos que influenciam no seu cálculo, comparando as abordagens determinísticas e probabilísticas. São apresentados resultados para sistemas de grande porte, tal como o sistema Sul/Sudeste/Centro-Oeste Brasileiro explorado no trabalho. 
Em [16], o sistema interligado Pennsylvania-New Jersey-Maryland é revisitado e são discutidas as especificações da metodologia de dimensionamento da Margem de Reserva Instalada (IRM). O risco (LOLE) é avaliado para horizontes semanais, por estação e por ano. O nível de confiabilidade considerado aceitável para o índice de corte de carga anual é dado pela regra "1 em 10", um dia em dez anos [16].

Em [41], propõe-se uma metodologia para a determinação dos montantes de reserva girante em sistemas interligados. Essa metodologia sugere que sejam usados dois índices de risco para o dimensionamento da reserva girante: um índice de risco para o sistema independente e o outro para o sistema interligado. A ideia de utilizar diferentes índices de risco foi revisitada em [17], desta vez para considerar as restrições de capacidade e as falhas entre a interligação de dois sistemas isolados. Ao considerar a interligação foram obtidos diferentes riscos, demonstrando, ainda que de forma indireta, que a inclusão das restrições de transmissão nas linhas de interligação apresenta impactos significativos nos índices de risco.

Ao utilizar métodos de enumeração para obter o risco, esses trabalhos, apesar de terem apresentado conceitos e ideias relevantes, podem ser ineficientes para a aplicação em sistemas de grande porte devido ao elevado número de estados que devem ser avaliados [22].

Técnicas de SMC, por outro lado, apresentam relativa independência em relação ao número de estados do sistema, como descrito em [8], [24]. Métodos de Enumeração, ao contrário, mesmo aqueles mais eficientes como o proposto em [45], apresentam dificuldades em sistemas de grande porte devido à explosão combinatória.

A avaliação de risco via SMC e VRT, em sistemas de grande porte, é computacionalmente mais atrativa que técnicas de enumeração [5], [6], [22], [27]. Em [23], descreve-se a aplicação de técnicas de SMC na avaliação da confiabilidade de sistemas elétricos de potência.

Uma das considerações utilizadas na modelagem do sistema elétrico no método PJM é que o sistema de transmissão é perfeitamente confiável e com capacidade de transmissão infinita [15]. No entanto, como já foi mencionado, os sistemas de transmissão operam cada vez mais carregados. Desta forma, falhas em sistemas de transmissão apresentam impacto cada vez maior. Ao estimar índices de risco desconsiderando as incertezas na transmissão são gerados resultados otimistas, uma 
vez que as falhas do sistema em decorrência de contingências no sistema de transmissão não são contabilizadas [17].

A avaliação da confiabilidade de sistemas considerando falhas na geração e na transmissão, ou confiabilidade composta, vem sendo amplamente discutida há algum tempo. Só entre os anos 1964 e 1988 mais de 272 trabalhos (livros, artigos e relatórios) já haviam sido publicados, como descrito em [46]. Um resumo das principais metodologias e técnicas pode ser encontrado na referência [8].

Algumas das aplicações da confiabilidade composta no planejamento da operação no Brasil são apontadas em [14]. Uma discussão detalhada sobre o importante papel do sistema de transmissão na operação confiável, segura e econômica pode ser encontrada em [47].

Uma metodologia para o dimensionamento da reserva girante considerando os sistemas de geração e transmissão é proposta em [48]. Por meio de um algoritmo de análise de contingências o impacto das restrições do sistema de transmissão no índice de risco é avaliado. Neste artigo propõe-se também a alocação de reserva distribuída proporcionalmente ao índice de risco escolhido pelo consumidor. Assim, uma maior quantidade de reserva é alocada nas regiões onde há maior carência por confiabilidade.

A avaliação do risco torna-se muito mais complexa ao adicionar o sistema de transmissão na análise. O custo computacional da avaliação por SMC pode tornarse proibitivo, uma vez que um elevado número de amostras deve ser processado e para cada amostra uma análise de adequação deve ser executada [8]. Para superar o problema do custo computacional diversos métodos têm sido propostos na literatura [49], [50], [51]. Entre esses métodos estão as Técnicas de Redução de Variância [52] por meio de Amostragem por Importância via método da Entropia Cruzada.

$\mathrm{O}$ conceito de entropia remonta a meados do século XX, sendo atualmente utilizada em diversas áreas do conhecimento, como termodinâmica, estatística, economia, pesquisa operacional, reconhecimento de padrões, planejamento, dentre muitas outras aplicações [21]. Em Teoria da Informação, o conceito de entropia, como proposto por Shannon, está associado à incerteza de uma distribuição de probabilidade. Entre os trabalhos precursores nesse campo estão o de Shannon, em 1948, que definiu entropia e uma forma de quantificá-la, Jaines, em 1957, e Kullback, em 1959, que propuseram métodos de otimização da entropia [53]. 
O método CE tem suas origens em um algoritmo adaptativo para a estimação de eventos raros baseado em minimização da variância [21]. A aplicação do método CE na resolução de problemas de otimização combinatória e obtenção de probabilidades de eventos raros é atribuída a R.Y. Rubinstein [21]. Uma aplicação do método na estimação dos índices GCR (Generation Capacity Reliability) de sistemas elétricos foi proposta em [22].

Uma versão simplificada para o cálculo das distorções ótimas utilizando os conceitos de Entropia Cruzada foi apresentada em [28]. A metodologia propôs um procedimento analítico simples e de fácil implementação para determinar a distribuição ótima a ser utilizada na avaliação GCR através de uma SMC baseada em Amostragem por Importância (IS). Recentemente, em 2013, o método CE foi aplicado na estimação dos índices de confiabilidade composta [27].

Por meio da simulação Monte Carlo Quase Sequencial [20] é possível representar cronologicamente as variações de geração e suas correlações temporais. Mantendo a representação completa da rede de transmissão e avaliando as variações de capacidade das fontes renováveis.

\section{7. Estrutura da Tese}

O objetivo deste trabalho é propor uma metodologia para o dimensionamento e planejamento da reserva girante, usando técnicas de simulação com amostragem por importância via método CE, considerando inserção de fontes renováveis e restrições de transmissão em sistemas multiárea. Índices de risco são estimados de forma a refletir as incertezas associadas ao planejamento da operação de curtoprazo.

Os conceitos formulados no método PJM são incorporados e expandidos para possibilitar a análise de sistema de grande porte. Mantendo-se a representação dos geradores térmicos e hidráulicos do sistema através do modelo de dois estados e também a premissa da impossibilidade de reparação das unidades que falharem (seja por manutenção ou substituição) no curto-prazo. O risco de corte de carga é 
estimado por meio da Simulação Monte Carlo Quase Sequencial, possibilitando a representação de fontes renováveis e de eventos com correlação temporal.

Por tratar-se de uma análise de curto prazo, o risco pode resultar em valores muito pequenos. Assim, são usadas estratégias de amostragem dos eventos de forma que sejam priorizados os eventos mais importantes e não os de maior probabilidade de ocorrência, de forma a reduzir o esforço computacional.

O método da Entropia Cruzada é utilizado para determinar os parâmetros que otimizam o processo de amostragem. Como resultado da integração da SMC com técnicas de Redução de Variância, obtém-se uma metodologia robusta e eficiente, sem perder a simplicidade do método PJM.

Este trabalho foi divido preliminarmente em seis capítulos. Neste capítulo introdutório são apresentadas as considerações iniciais. Alguns conceitos e métodos utilizados foram brevemente comentados.

Algumas ferramentas estatísticas, tal como a SMC, bem como alguns métodos de redução de variância foram também brevemente citados. Foi apresentado um histórico do desenvolvimento das metodologias e uma revisão bibliográfica descrevendo técnicas tradicionais e o estado da arte, dentro do contexto do problema da avaliação da reserva de geração.

No Capítulo 2, são apresentados os conceitos e discussões no tocante à análise da confiabilidade de sistemas elétricos. Há uma descrição sucinta dos principais índices de confiabilidade e dos métodos para avaliá-los.

No Capítulo 3, são descritos os principais conceitos relativos ao dimensionamento da reserva considerando as incertezas associadas aos sistemas de geração, abordando com mais detalhes o método PJM e a avaliação do risco de curto-prazo via SMC com o método CE.

Discute-se no Capítulo 4 o importante papel da inclusão das características do sistema de transmissão na análise. Muitas vezes seu efeito é negligenciado devido ao expressivo aumento da complexidade de avaliação do sistema [8], que requer o uso de uma ferramenta de análise de rede. Ao considerar as restrições de capacidade do sistema de transmissão, bem como a falha de suas linhas de transmissão, obtêm-se resultados que demonstram claramente o impacto desse sistema nos índices de risco e nos montantes requeridos de reserva girante. São apresentados alguns resultados com o sistema IEEE-RTS. 
No Capítulo 5, propõe-se um método para dar subsídio ao planejamento da operação de sistemas com alta penetração de fontes renováveis. As fortes correlações com variáveis climáticas e as flutuações na capacidade em curtos intervalos de tempo aumentam a complexidade de avaliação desses sistemas. Ao integrar ferramentas como a SMC Quase Sequencial e o método CE, a abordagem inovadora desenvolvida se mostra eficiente e robusta.

São apresentados resultados com o sistema IEEE RTS Eólico, demonstrando que é possível representar cronologicamente as variações de geração e suas correlações temporais. Todas essas incertezas associadas à capacidade de suprir a demanda são apropriadamente capturadas nos índices de risco e são refletidas no dimensionamento da reserva de geração. A avaliação dos requisitos de reserva, no planejamento da operação, considera a sequência temporal de ocorrência dos eventos. São utilizadas, no método proposto no Capítulo 5, séries históricas de capacidade de fontes eólica e os valores previstos de variação horária da demanda.

Os sistemas elétricos apresentam como tendência natural, em virtude da busca pela eficiência técnica e econômica, a operação interligada. De fato, a otimização energética só é garantida quando é possível transportar a potência das estações geradoras de menor custo sem restrições de fluxo. No entanto, para garantir o suprimento confiável, deve-se alocar adequadamente a reserva de geração em cada área de forma que as diversas áreas elétricas possam sobreviver à saída das linhas de interligação. No Capítulo 6 são discutidos aspectos relativos ao efeito da alocação da reserva em diferentes áreas elétricas considerando a capacidade de intercambio em sistemas numa abordagem multiárea.

Finalmente no Capítulo 7 são resumidas as principais conclusões obtidas na tese e feitas propostas de continuidade do trabalho apresentado. 


\section{2 \\ Confiabilidade de Sistemas de Energia Elétrica}

Confiabilidade é a probabilidade de um componente, equipamento ou sistema exercer sua função sem falhas, num período de tempo previsto, sob condições especificadas [2]. Em sistemas elétricos, a confiabilidade representa suas características inerentes por meio de medidas numéricas específicas, que descrevem a capacidade de um sistema desempenhar a função para a qual foi planejado.

A avaliação da confiabilidade de um sistema consiste, essencialmente, no cálculo de um conjunto de indicadores de desempenho relativos à adequação (estática) e segurança (dinâmica). Estes índices, medidas quantitativas das características de uma barra, área ou do sistema como um todo, podem ser utilizados na análise das condições operativas e na determinação e previsão do comportamento futuro das partes correspondentes.

Em geral, estudos de confiabilidade dão subsídios técnicos para análises de alternativas de expansão/operação, cada uma com seu custo associado. A eficiência econômica é obtida quando há um equilíbrio entre benefícios do aumento da confiabilidade e os recursos financeiros adicionais para provê-lo, considerando as incertezas inerentes ao problema, tais como as flutuações de geração/carga e a indisponibilidade de equipamentos [8], [54].

No Brasil, os estudos de confiabilidade relativos ao Sistema Interligado Nacional (SIN) são de responsabilidade da Empresa de Pesquisa Energética - EPE, que tem por finalidade prestar serviços na área de estudos e pesquisas destinados a subsidiar o planejamento estratégico do setor energético [55]. O Operador Nacional do Sistema - ONS também realiza análises de confiabilidade nos ciclos do PAR (Plano de Ampliações e Reforços) da Rede Básica Brasileira.

Neste capítulo são descritos alguns índices de confiabilidade e os principais métodos para obtê-los. São discutidos os métodos analíticos e de simulação. No âmbito do dimensionamento dos requisitos de reserva, os índices de confiabilidade são medidas quantitativas dos riscos associados aos eventos operativos em análise, 
tal como o risco de não suprimento da demanda ou risco de perda de carga, que é o índice LOLP estimado para o horizonte de algumas horas.

\section{1. Índices de Confiabilidade}

A análise de confiabilidade de sistemas de energia elétrica pode ser realizada por meio de índices, ou indicadores de risco, que são estimativas numéricas de eventos ou grandezas que se deseja quantificar [4], [56].

Os índices de confiabilidade podem estar relacionados à frequência, duração e severidade de eventos. Podem ser estimados por meio de duas abordagens, avaliando a probabilidade de problemas no sistema e a probabilidade de corte de carga, de acordo com a maneira pela qual se mede a severidade dos eventos [55].

Índices de problemas no sistema são obtidos desconsiderando a atuação de medidas corretivas (redespacho, atuação de controles, chaveamento de LTCs, etc.). Por outro lado, índices de corte de carga são estimados contabilizando eventos de não suprimento que persistem mesmo após a atuação de medidas corretivas prédefinidas.

Os índices associados à perda de carga (Loss of Load indices) são obtidos analisando conjuntamente o modelo de carga e de capacidade de geração no período em consideração. Os principais índices de perda de carga são:

- LOLP: Probabilidade de Perda de Carga (Loss of Load Probability). É também conhecido pela sigla PPC, i.e., Probabilidade de Perda de Carga.

- LOLE: Expectativa de Perda de Carga (Loss of Load Expectation). É obtido multiplicando a LOLP pelo número de horas do ano $(\Delta T)$ e reflete o número médio de horas, durante o período de tempo total, em que o sistema permanece em estados de falha,

$$
\mathrm{LOLE}=\mathrm{LOLP} \times \Delta T
$$


- EPNS: Valor Esperado da Potência Não Suprida (Expected Power Not Supplied). Trata-se de uma indicação do valor médio da potência, usualmente em MW, não fornecida durante o período devido à indisponibilidade do sistema.

- EENS: Valor Esperado da Energia Não Suprida (Expected Energy Not Supplied). É obtido multiplicando o índice EPNS pelo número de horas do horizonte de estudo (e.g., um ano), usualmente em MWh/ano,

$$
\mathrm{EENS}=\mathrm{EPNS} \times \Delta T
$$

- LOLC: Valor Esperado do Custo de Interrupção (Loss of Load Cost). É o valor médio do custo associado às perdas monetárias devido à interrupção do fornecimento, usualmente em \$/ano (e.g., US\$/year, R\$/ano).

- LOLF: Frequência Média de Perda de Carga (Loss of Load Frequency). Quantifica o número médio de ocorrências de não suprimento no período, usualmente em ocorrências/ano (oc./ano).

- LOLD: Duração Média da Perda de Carga (Loss of Load Duration). Quantifica a duração média (geralmente em horas), em um determinado período, do modo de falha. Este índice pode ser obtido, como demonstrado em [2], pela relação:

$$
\text { LOLD }=\text { LOLP/LOLF }
$$

- SEV: Severidade. Exprime um tempo de um distúrbio que seria necessário para acumular uma energia não suprida exatamente equivalente àquela associada à perturbação caso a carga afetada fosse idêntica à ponta de carga do próprio sistema. O índice SEV é usualmente expresso em minutos, podendo ser estimado por:

$$
\mathrm{SEV}=\frac{\mathrm{EENS}}{\mathrm{P}_{\mathrm{BASE}}} \times 60,
$$

onde $\mathrm{P}_{\mathrm{BASE}}$ é uma base de potência. $\mathrm{O}$ índice de Severidade é calculado pela divisão de um valor estimado de energia não suprida (MWh/ano) por uma base de potência (MW) que geralmente é pico de carga do sistema, da área ou região 
monitorada. $\mathrm{O}$ valor numérico é multiplicado por 60 para a conversão em minutos.

Uma das vantagens da Severidade é ser um índice normalizado, permitindo assim a comparação de sistemas de tamanho, complexidade e naturezas distintas. Além disso, há uma escala internacional de valoração do índice e sua interpretação, apresentada na Tabela 2.1 [55], [57].

Tabela 2.1: Classificação do índice de Severidade

\begin{tabular}{|c|c|c|c|}
\hline Classificação & $\begin{array}{c}\text { Severidade S } \\
\text { (Sistema Minuto) }\end{array}$ & Interpretação & Comentário \\
\hline Grau 0 & $\mathrm{S}<1$ & Favorável & Condição operativa de baixíssimo risco \\
\hline Grau 1 & $1 \leq \mathrm{S}<10$ & Satisfatório & Condição operativa de baixo risco \\
\hline Grau 2 & $10 \leq \mathrm{S}<100$ & Limítrofe & Condição operativa de risco médio \\
\hline Grau 3 & $100 \leq \mathrm{S}<1000$ & Grave & $\begin{array}{c}\text { Sério impacto para vários } \\
\text { agentes consumidores }\end{array}$ \\
\hline Grau 4 & $\mathrm{S} \geq 1000$ & Muito Grave & $\begin{array}{c}\text { Sério impacto para muitos agentes consumi- } \\
\text { dores, colapso do sistema. }\end{array}$ \\
\hline
\end{tabular}

Os valores de alguns desses índices para o sistema elétrico brasileiro, bem como discussões adicionais associadas aos métodos de avaliação usando o aplicativo NH2 do CEPEL, podem ser encontrados em [55] e [58].

\section{2.}

\section{Confiabilidade da Capacidade de Geração}

Em estudos de confiabilidade os sistemas de potência podem ser divididos em três áreas funcionais: Geração, Transmissão e Distribuição [59], [8]. Em avaliações da confiabilidade da capacidade de geração, ou GCR (Generating Capacity Reliability) [22], supõe-se que toda a carga e a geração estão concentradas em uma única barra (modelo "barra única"), como mostrado na Figura 2.1.

As restrições no transporte de energia impostas pela rede de transmissão e de distribuição podem ser ignoradas, assumindo-se que os equipamentos dos sistemas de transmissão e distribuição são totalmente confiáveis e capazes, sem quaisquer restrições, de conduzir a energia produzida nas usinas até os pontos de consumo. 
Sendo assim, o desempenho do sistema é medido pela simples comparação entre a geração disponível e a carga momentânea [7].

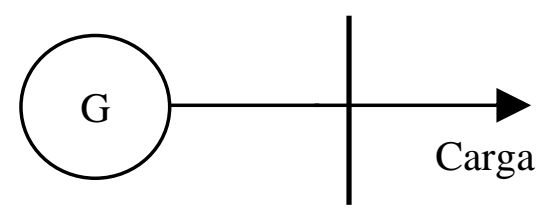

Bus

Figura 2.1: Modelo do sistema - barra única

O procedimento de obtenção dos índices de risco, ao usar considerações simplificadoras, tende a gerar índices otimistas, uma vez que qualquer evento de perda de carga devido a um fator externo ao sistema de geração não será contabilizado. Apesar de simplificada, os índices das avaliações GCR refletem a adequação da capacidade de geração em suprir a demanda especificada.

\section{3. Métodos de Avaliação da Confiabilidade}

Em termos gerais, a avaliação da confiabilidade de sistemas pode ser realizada, basicamente, utilizando métodos analíticos ou simulação computacional estocástica [2]. A diferença básica entre os métodos analíticos e os métodos de simulação estocástica é a estratégia de avaliação dos índices.

Técnicas analíticas representam o sistema através de um modelo matemático, e.g., modelos Markovianos, que usualmente é simplificado, e obtêm os índices de confiabilidade usando soluções matemáticas diretamente das equações do modelo, sendo assim métodos computacionalmente muito eficientes para avaliar sistemas com poucos estados representativos.

Técnicas de simulação, por outro lado, estimam os índices de confiabilidade simulando as características reais e o comportamento estocástico do sistema. As probabilidades são estimadas realizando uma série de experimentos aleatórios, simulações, e contando o número de ocorrências do evento de interesse [2]. 
Os sistemas em estudo podem ser representados por meio de um diagrama de estados. Dado o estado definido pelo vetor $\mathbf{X}=\left(x_{1}, x_{2}, \ldots, x_{j}, \ldots, x_{m}\right), x_{j}$ representa o estado do $j$-ésimo componente, com $x \in \Omega$, em que $\Omega$ é o conjunto de todos os possíveis estados dos componentes do sistema. Os índices de confiabilidade correspondem ao valor esperado de uma função teste, $E(F)[8]$ :

$$
E(F)=\sum F(\mathbf{X}) P(\mathbf{X})
$$

$F(\mathbf{X})$ é a função teste e $P(\mathbf{X})$ é a probabilidade associada à ocorrência do estado $\mathbf{X}$.

A função teste avalia numericamente a ocorrência do evento de interesse. Por exemplo, a função de teste do índice LOLP assumirá valor "1" caso a variável aleatória $x$ indique um estado de perda de carga e valor " 0 " caso contrário:

$$
F_{\text {LOLP }}(x)=\left\{\begin{array}{lll}
1 & \text { se } & x \in \Omega_{\text {Down }} \\
0 & \text { se } & x \in \Omega_{U p}
\end{array}\right.
$$

Em geral, algoritmos baseados em espaço de estados seguem três passos principais [8], [22]. O primeiro consiste em selecionar um estado do sistema (i.e., disponibilidade dos equipamentos e nível de carga). No segundo, analisa-se o desempenho do estado selecionado (i.e., verificar se a geração total disponível é capaz de satisfazer a carga associada sem violar nenhum limite operativo; se necessário, ativar medidas corretivas como, por exemplo, corte de carga). Finalmente no terceiro, estimam-se os índices de confiabilidade (i.e., LOLP, EPNS, etc.). Se as precisões das estimativas são aceitáveis, encerra-se o algoritmo; caso contrário, repete-se o processo reiniciando no primeiro passo.

O método conhecido como abordagem da LOLE, devido sua flexibilidade e simplicidade de aplicação, é um dos métodos analíticos mais utilizados. Este método consiste, basicamente, em "convolucionar" os estados individuais dos grupos de unidades de geração e combiná-los com o modelo de carga para gerar uma tabela de probabilidades, a COPT, a partir da qual os índices de confiabilidade LOLP, LOLE, EPNS e EENS podem ser obtidos [22].

Apesar de simples, o método LOLE original não apresenta indicações sobre a frequência e duração das ocorrências de insuficiência de capacidade. Assim, o método da Frequência e Duração (F\&D), que é capaz de calcular a LOLF e a LOLD, 
é uma abordagem mais completa e, tal como proposto em [45], computacionalmente mais eficiente.

Entre os métodos de simulação estocástica utilizados em avaliação de confiabilidade, a simulação Monte Carlo (SMC) vem recebendo considerável atenção pela capacidade de análise generalizada, irrestrita a modelos com taxas de transição constantes ou com tempos de residência em cada estado exponencialmente distribuídos [60]. Indubitavelmente, a SMC apresenta enorme eficiência e robustez computacional ao lidar com sistemas complexos de grande porte, se comparada aos métodos baseados em enumeração [22].

Apesar de extremamente robusta, principalmente para sistemas de médio e grande porte, a avaliação GCR via SMC, devido à estratégia de amostragem baseada na probabilidade histórica de ocorrência dos eventos, apresenta dificuldades em termos de tempos de execução para configurações altamente confiáveis. Em outras palavras, se os eventos são raros a eficiência do processo de estimação via SMC pode ser prejudicada [61]. Desta forma, neste tipo de problema, deve-se aplicar alguma VRT para diminuir o tempo de simulação e aumentar a eficiência computacional.

\subsection{1. \\ Avaliação da Confiabilidade pelo Método Analítico}

Ao longo dos anos, diversos métodos analíticos, também conhecidos como métodos de Enumeração, foram sendo desenvolvidos para solucionar os problemas surgidos devido à evolução natural dos sistemas; cada um desses métodos com suas respectivas vantagens, desvantagens e tipos de aplicação. Esses métodos diferenciam-se, basicamente, em relação ao nível de detalhamento dos modelos em espaço de estados, hipóteses assumidas [6] e nas estratégias de seleção dos estados [8]. Uma descrição da aplicação de alguns desses métodos na avaliação da confiabilidade de sistemas de potência pode ser encontrada em [4].

O procedimento fundamental utilizado nos métodos analíticos é enumerar os estados do sistema para obter tabela de dados de capacidades, probabilidades e/ou frequências dos estados a partir da qual os índices de confiabilidade são obtidos. 
Descreve-se o sistema em termos dos modelos equivalentes de capacidade de geração e carga. Comparando o nível de capacidade de geração total e de carga, determina-se o nível de reserva.

No método F\&D proposto em [45], cada unidade de geração pode ser representada em termos dos seus estados de capacidade $C_{k}$, das probabilidades, $p_{k}$ e das frequências incrementais, $f_{k}$, associadas a tais estados. A unidade de geração equivalente $G$ pode ser expressa pela soma de variáveis $N_{G}$ aleatórias independentes $G_{k}$ representando cada unidade geradora. Sejam $G_{1}=\left\{C_{1} ; p_{1} ; f_{1}\right\}$ e $G_{2}=\left\{C_{2} ; p_{2} ; f_{2}\right\}$ a representação de dois grupos de unidades, os parâmetros representativos da unidade equivalente $G=\left\{C_{\mathrm{G}} ; p_{G} ; f_{\mathrm{G}}\right\}$ são obtidos, como demonstrado em [45], por,

$$
\begin{gathered}
p_{G}=p_{1} * p_{2} \\
f=\left[p_{1} * f_{2}\right]+\left[p_{2} * f_{1}\right]
\end{gathered}
$$

Os parâmetros $p$ e $f$ são sequências de impulsos associados com as sequências de capacidades dos estados, $C$. O processo de "convolução discreta" pode ser efetuado utilizando a Transformada Rápida de Fourier (i.e., FFT) para acelerar o processamento computacional [62].

O comportamento da carga total do sistema $L$ pode ser expresso como uma sequência de níveis discretos de carga definidos para o período de análise. É possível construir um modelo de carga descrito pelos mesmos parâmetros utilizados no modelo de geração, i.e., $L=\left\{C_{L} ; p_{L} ; q_{L}\right\}$, onde $p_{L}$ é um vetor (ou sequência) com dimensão $N_{L}$ representando as probabilidades associadas com os estados de carga. Em estudos nos quais o intervalo de tempo considerado é pequeno, a carga pode ser modelada por apenas um nível, i.e., um modelo de carga constante.

O modelo da capacidade da geração, representado pela variável aleatória $G$, pode ser combinado com o modelo da carga descrito pela variável aleatória $L$ para produzir o modelo da reserva de potência $R$, i.e.,

$$
R=G-L
$$

com $R=\left\{C_{R} ; p_{R} ; q_{R}\right\}$, semelhante a $G$ e $L$. Por meio de (2.9) é possível avaliar tanto a reserva estática quanto a reserva operativa, dependendo das considerações utilizadas para gerar o modelo de geração equivalente do sistema. Assim, por exem- 
plo, se $G$ representa a geração equivalente de todas as máquinas sincronizadas, então, $R$ será a reserva girante. Se $G$ é o modelo de todas as máquinas do sistema, incluindo as não sincronizadas e disponíveis no longo prazo, $R$ representa a reserva estática de capacidade de geração.

Os índices de confiabilidade da capacidade de geração, LOLP, EPNS e LOLF, podem ser avaliados a partir dos estados individuais de reserva de geração e carga. Primeiro, as equações (2.7) e (2.8) são utilizadas para se obter as probabilidades e frequências incrementais que descrevem os estados da variável $R$. Considerando que existam $N_{R}$ destes estados, então, para $k=1, N_{R}[45]$ :

$$
\begin{gathered}
\mathrm{LOLP}=\sum_{k} p_{R}\left(r_{k}\right) \\
\mathrm{LOLF}=\sum_{k} q_{R}\left(r_{k}\right) \\
\mathrm{EPNS}=\sum_{k}\left|C_{R}\left(r_{k}\right)\right| p_{R}\left(r_{k}\right)
\end{gathered}
$$

Os outros três principais índices de confiabilidade LOLE, EENS e LOLD podem ser obtidos por meio das equações (2.1), (2.2) e (2.3).

$\mathrm{Na}$ avaliação da confiabilidade de sistemas de médio e grande porte, métodos baseados em simulação estocástica são mais atrativos que métodos baseados em enumeração de estados. O uso do método analítico pode tornar-se proibitivo, pois há uma relação exponencial entre o número de estados e o número de componentes do sistema (fenômeno conhecido "combinatorial curse" ou "maldição da dimensionalidade").

\subsection{2. \\ Avaliação da Confiabilidade via Simulação Monte Carlo}

Técnicas de simulação, ao contrário de métodos analíticos em geral, são robustas mesmo em problemas com elevado número de estados, como em sistemas de grande porte e/ou com múltiplos níveis de carga e geração (e.g., sistemas com elevada penetração de geração eólica) [22]. 
A simulação Monte Carlo, uma técnica de simulação estocástica, obtém os índices de confiabilidade através da condução de sucessivos experimentos computacionais envolvendo o modelo matemático-lógico que descreve o comportamento operativo do sistema [21].

Métodos SMC podem ser classificados, de forma geral, em não sequencial e sequencial ou cronológica. A SMC sequencial efetua amostragens dos estados do sistema cronologicamente, na ordem em que ocorrem, enquanto que a SMC não sequencial amostra os estados do sistema de acordo com sua função distribuição de probabilidade de ocorrência dos estados [2].

Embora a simulação sequencial seja capaz de correlacionar os eventos com seu tempo de ocorrência, o esforço computacional necessário para estimar os índices de confiabilidade é elevado, se comparado com uma simulação não sequencial. Assim, se os eventos em estudo não estão correlacionados com o tempo, utiliza-se, por critérios de eficiência, a SMC não sequencial [63]. É importante ressaltar que é possível avaliar, fazendo algumas alterações no algoritmo padrão, eventos cronológicos por meio da simulação não sequencial. Métodos de simulação derivados da SMC não sequencial com esse intuito são a SMC pseudo-sequencial/cronológica [20], [64] e quase sequencial [6].

Os índices de confiabilidade são estimados através do valor esperado, ou média amostral, da função teste discreta $H\left(\mathbf{X}_{i}\right)$,

$$
\tilde{\mathrm{E}}[H]=\frac{1}{N} \sum_{i=1}^{N} H\left(\mathbf{X}_{i}\right),
$$

$\mathbf{X}_{i}$ é o vetor de estados dos componentes do sistema, na $i$-ésima iteração. Onde $X_{i, j}$ $=1$ para $j$-ésimo componente se este está operando sem falha ( $x_{j}$ está no estado $U p$ ) e $X_{i, j}=0$ para o $j$-ésimo componente falhado (estado operativo de falha - Down). Se $\Omega_{U p}$ é o conjunto de componentes ativos e $\Omega_{D o w n}$ é o conjunto de componentes inativos, cada elemento do vetor $\mathbf{X}_{i}$ pode ser representado como:

$$
X_{i, j}=\left\{\begin{array}{lll}
1 & \text { se } & x_{j} \in \Omega_{U p} \\
0 & \text { se } & x_{j} \in \Omega_{\text {Down }}
\end{array} .\right.
$$

Para o $j$-ésimo componente representado por um modelo Markoviano a dois estados, Up e Down, dadas as taxas de falha, $\lambda_{j}$, e de reparo, $\mu_{j}$, determina-se a 
probabilidade de falha, i.e., a indisponibilidade $\boldsymbol{u}_{j}$. Os estados dos diversos componentes do sistema são determinados comparando-se um vetor de variáveis aleatórias com distribuição uniforme unitária $\mathrm{U}[0,1]$ e o vetor de vetor de probabilidades de falha dos componentes $\mathbf{u}=\left[u_{1}, u_{2}, \ldots, u_{j}, \ldots, u_{n}\right], u_{j} \in \operatorname{Re} 0<u_{j}<1$,

$$
x_{j} \in\left\{\begin{array}{lll}
\Omega_{U p} & \text { se } & x_{j}>u_{j} \\
\Omega_{\text {Down }} & \text { se } & x_{j}<u_{j}
\end{array}\right.
$$

Todos os principais índices GCR podem ser facilmente obtidos pelo estimador não tendencioso definido em (2.15). Para isso, utiliza-se a devida função teste associada aos eventos para os quais o respectivo índice está relacionado. As funções testes $H_{\text {LOLP }}$ e $H_{\text {EPNS }}$ são dadas por [24]:

$$
\begin{aligned}
& H_{\mathrm{LOLP}}\left(\mathbf{Y}_{i}\right)= \begin{cases}0 & \text { se } \mathbf{Y}_{i} \in \Psi_{\text {Success }} \\
1 & \text { se } \mathbf{Y}_{i} \in \Psi_{\text {Failure }}\end{cases} \\
& H_{\mathrm{EPNS}}\left(\mathbf{Y}_{i}\right)= \begin{cases}0 & \text { se } \mathbf{Y}_{i} \in \Psi_{\text {Success }} \\
\Delta P_{i} & \text { se } \mathbf{Y}_{i} \in \Psi_{\text {Failure }}\end{cases}
\end{aligned}
$$

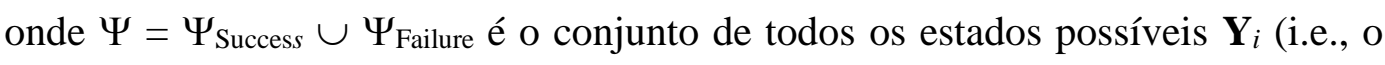
espaço de estados), dividido em dois subespaços $\Psi_{\text {Success }}$ de estados de sucesso e

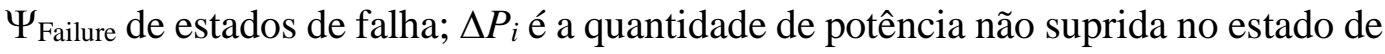
falha $\mathbf{Y}_{i}$. O índice LOLP é o somatório das probabilidades de todos os estados de $\Psi$ onde a capacidade de geração é insuficiente para atender a carga $L$.

A incerteza da estimativa é dada pela variância amostral do estimador, representada por,

$$
V(\widetilde{E}[H])=V(H) / N
$$

A variância, $V[H]$, pode ser calculada através da equação,

$$
V[H]=E\left[H^{2}\right]-E^{2}[H]
$$

A relação entre o desvio padrão amostral, raiz quadrada da variância $\sigma=\sqrt{V(\tilde{E}[H])}$, e o valor esperado da função teste, $\tilde{E}[H]$, representa a incerteza 
em relação à estimação do índice. Essa relação é denominada coeficiente de variação $\beta$, sendo usualmente utilizada como variável de controle da convergência do processo iterativo:

$$
\beta=\frac{\sqrt{V(\tilde{E}[H])}}{\tilde{E}[H]} .
$$

Para o cálculo da variância $V[H]$ e do valor esperado $E[H]$ da função teste em um processo computacional iterativo, é necessário que se tenha os valores de históricos assumidos em cada iteração. Uma das maneiras é armazenar os dados obtidos a cada simulação. No entanto, dependendo do número de simulações e das dimensões do sistema, esse procedimento pode ser dispendioso, ineficiente e até ineficaz. Desta forma, as seguintes equações iterativas podem ser utilizadas,

$$
\begin{gathered}
E_{k}\left[H^{2}\right]=\frac{1}{k} \sum_{i=1}^{k} H_{k}^{2}\left(Y_{i}\right), \\
E_{k}^{2}[H]=\left(\frac{1}{k} \sum_{i=1}^{k} H_{k}\left(Y_{i}\right)\right)^{2} .
\end{gathered}
$$

Substituindo as equações anteriores no cálculo de $V[H]$,

$$
V_{k+1}[H]=E_{k}\left[H^{2}\right]-E_{k}^{2}[H],
$$

onde os somatórios na $k$-ésima iteração são obtidos acumulando os resultados das iterações anteriores. $\mathrm{Na}$ forma iterativa o coeficiente de variação é dado por

$$
\beta_{k+1}=\frac{\sqrt{V_{k+1}[H]}}{\tilde{E_{k+1}}[H]} .
$$

Quando o número de simulações é elevado, $k \rightarrow \infty$, a variância amostral tende a diminuir, enquanto que o valor esperado tende a uma constante. Assim, o coeficiente de variação tende a zero,

$$
\lim _{k \rightarrow \infty} \beta_{k+1}=0
$$


A equação (2.25) confirma a noção intuitiva de que a precisão do experimento é tão melhor quanto maior for o número de experimentos realizados durante a simulação. Especificam-se valores de $\beta \leq \beta_{\max }$; e.g., $5 \%$.

Os passos básicos de um algoritmo de simulação Monte Carlo não sequencial são apresentados a seguir [24], [8]:

Passo 1: $\quad$ Iniciar o número de simulações $k=0$;

Passo 2: $\quad$ Sortear um vetor $\mathbf{X}_{k} \in \Omega$ baseado em sua distribuição de probabilidade $P(x)$; atualize o número de simulações, $k:=k+1$;

Passo 3: Avaliar a função teste $H\left(\mathbf{X}_{k}\right)$ para o vetor de estados dos equipamentos do sistema da amostra $k$;

Passo 4: $\quad$ Estimar o índice por meio de $\tilde{E}[H]$;

Passo 5: Determinar a coeficiente de variação, $\beta_{k}$. Se o critério de parada for satisfeito ( $\beta_{k}$ é menor que o especificado ou máximo número de simulações), parar; senão, retornar ao passo 2.

Uma das principais vantagens do uso de SMC não sequencial é sua capacidade de estimar índices para grandes sistemas de potência com facilidade, pois o número de amostras necessárias para estimar $E[H]$ com uma dada incerteza $\beta$ é relativamente independente do número de estados [8].

Como já mencionado, uma das principais desvantagens da SMC, no entanto, é que quando os estados de falha são raros, tal como em análise envolvendo um curto intervalo de tempo ou em sistemas altamente confiáveis, o tempo para a convergência do processo pode ser excessivamente elevado.

Para contornar o problema da estimação de eventos raros, há estratégias para aumentar a eficiência das ferramentas baseadas em SMC. Em essência, esses métodos alteram a sequência de amostragem dos estados do sistema. No próximo item, descreve-se de forma sucinta a aplicação dos modernos conceitos do método $\mathrm{CE}$ aplicados na estimação de índices por meio de SMC. 


\subsection{3.}

\section{Avaliação da Confiabilidade via Método da Entropia Cruzada}

Com o intuito de melhorar o desempenho de técnicas de SMC vários métodos de redução de variância têm sido propostos na literatura especializada [4]. Algumas dessas VRT são: Variáveis Antitéticas (Antithetic Variates), Variáveis de Controle (Control Variates), Amostragem Estratificada (Stratified Sampling), Amostragem por Importância (Importance Sampling) [6]. Cada um desses métodos apresenta vantagens e desvantagens, bem como particularidades de aplicação [2].

A ideia básica da VRT por IS é intensificar a amostragem dos eventos que causam maior impacto nas falhas do sistema. Uma técnica que apresenta excelentes resultados em termos de ganho de eficiência computacional é a IS via método da Entropia Cruzada, como demonstrado em [5], [6], [22], [61].

Ao aplicar os conceitos de entropia cruzada na otimização dos parâmetros do estimador, o desempenho computacional da SMC pode ser consideravelmente melhorado, tornando a simulação estatisticamente eficiente e possibilitando obter os intervalos de confiança menores [6].

A descrição do método CE na resolução de problemas de otimização combinatória e estimação de probabilidades é atribuída a R.Y. Rubinstein [21]. A aplicação do método na estimação dos índices GCR pode ser encontrada em [22]. Para facilitar o entendimento do trabalho descrito nesta dissertação, alguns conceitos desse método são brevemente descritos neste tópico. Uma demonstração mais detalhada das equações através de uma abordagem matematicamente mais rigorosa pode ser encontrada em [26], [65].

Considere o problema de determinar a probabilidade, $\varsigma$, do evento raro definido como a ocorrência de,

$$
S(\mathbf{X}) \geq \gamma
$$

$S(\mathbf{X})$ é uma função desempenho de uma determinada amostra aleatória $\mathbf{X}, \gamma$ é um número real, $\gamma \in \mathbb{R}$, que representa o limiar da região de interesse do espaço amostral em $f(; \mathbf{u}) . \mathbf{X}=\left(x_{1}, x_{2}, \ldots, x_{N}\right)$ é um vetor de $N$ números aleatórios.

A probabilidade $\&$ pode ser expressa como, 


$$
\wp=P_{u}\{S(\mathbf{X}) \geq \gamma\}
$$

Redefinindo-se a função teste $H(\mathbf{X})$ como

$$
H(\mathbf{X})=I_{\{S(\mathbf{X}) \geq \gamma\}}
$$

onde $I_{\{S(\mathbf{X}) \geq \gamma\}}$, o operador Indicador, é definido como,

$$
I_{\{S(\mathbf{X}) \geq \gamma\}}=\left\{\begin{array}{lll}
1 & \text { se } & \mathbf{S}(\mathbf{X}) \geq \gamma \\
0 & \text { se } & \mathbf{S}(\mathbf{X})<\gamma
\end{array} .\right.
$$

Pode-se definir a probabilidade como,

$$
\wp=P_{u}\{S(\mathbf{X}) \geq \gamma\}=E[H(\mathbf{X})]=E\left[\mathbf{I}_{\{S(\mathbf{X}) \geq \gamma\}}\right]
$$

Utilizando simulação Monte Carlo convencional, $\wp$ pode ser estimada usando $N$ simulações por

$$
\wp=\frac{1}{N} \sum_{i=1}^{N} \mathbf{I}_{\{S(\mathbf{X}) \geq \gamma\}} .
$$

No entanto, como o evento de interesse é raro, será necessário um elevado número de simulações e, consequentemente, alto esforço computacional para obter uma estimativa de $\int$ com um coeficiente de variação dentro de uma tolerância aceitável. À medida que o evento torna-se mais raro, e.g., durante a simulação de um sistema que apresenta uma grande parcela de reserva de geração, esse esforço será ainda maior. Desta forma, para tornar possível a simulação de eventos raros dentro de limites de tempo praticáveis, pode-se utilizar um estimador por meio de amostragem por importância.

Considere a sequência de números pseudoaleatórios gerados pela função massa de probabilidade (pmf) $g$. Nessas condições, $\bigodot$ será estimado através de IS por:

$$
\wp^{\prime}=L R\{\wp\}=\frac{1}{N} \sum_{i=1}^{N} \mathbf{I}_{\{S(\mathbf{X}) \geq \gamma\}} \mathbf{W}(\mathbf{X})
$$

onde

$$
\mathbf{W}(\mathbf{X})=\frac{f(\mathbf{X})}{g(\mathbf{X})}
$$


$L R\{\wp\}$ é o estimador utilizado para obter $\wp^{\prime}$ e o parâmetro $\mathbf{W}(\mathbf{X})$ é denominada razão de verossimilhança.

O problema de estimar $\wp$ torna-se, então, determinar a pmf $g(\mathbf{X})$. Nesse sentido, como $\wp^{\prime}$ deve ser o mais próximo possível de $\wp$, deve-se obter uma função $g$ cuja distância estatística de $f$ seja mínima. Uma medida da distância estatística entre $f$ e $g$ pode ser obtida pela distância de Kullback-Leibler, também conhecida como Entropia Cruzada entre $g$ e $f$,

$$
\mathrm{D}_{K L}(g \| f)=E_{g}\left[\ln \frac{g(\mathbf{X})}{f(\mathbf{X})}\right]=\int g(x) \ln g(x) d x-\int g(x) \ln f(x) d x \text {. }
$$

Pode-se demonstrar que minimizar $D_{K L}(g \| f)$ equivale a

$$
\max _{\mathbf{v}} D(\mathbf{v})=\max _{\mathbf{v}} E_{\boldsymbol{\omega}}\left[I_{\{S(\mathbf{X}) \geq \gamma\}} \mathbf{W}(\mathbf{X} ; \mathbf{u}, \boldsymbol{\omega}) \ln f(\mathbf{X} ; \mathbf{v})\right]
$$

onde $\mathbf{W}(x ; \mathbf{u}, \boldsymbol{\omega})$, para um parâmetro de referência qualquer $\boldsymbol{\omega}$, é definida como:

$$
\mathbf{W}(x ; \mathbf{u}, \boldsymbol{\omega})=\frac{f(x ; \mathbf{u})}{f(x ; \boldsymbol{\omega})}
$$

A solução ótima de (2.35) é obtida quando o parâmetro $v$ maximiza $D(v)$ :

$$
\mathbf{v}^{*}=\underset{\mathbf{v}}{\operatorname{argmax}} E_{\boldsymbol{\omega}}\left[I_{\{S(\mathbf{X}) \geq \gamma\}} \mathbf{W}(\mathbf{X} ; \mathbf{u}, \boldsymbol{\omega}) \ln f(\mathbf{X} ; \boldsymbol{v})\right]
$$

Sendo $D(v)$ uma função convexa e diferenciável em relação à $v$, a solução de (2.37) pode ser estimada resolvendo [66],

$$
\frac{1}{N} \sum_{\mathrm{i}=1}^{\mathrm{N}} I_{\left\{S\left(\mathbf{X}_{i}\right) \geq \gamma\right\}} \mathbf{W}\left(\mathbf{X}_{i} ; \mathbf{u}, \boldsymbol{\omega}\right) \nabla \ln f\left(\mathbf{X}_{i} ; \mathbf{v}\right)=0 .
$$

Sendo $\mathbf{X}$ o vetor de variáveis aleatórias que representam as tentativas em uma experiência na qual são realizadas $n$ tentativas, cada uma com uma probabilidade $u=$ $1-v$ de sucesso. Tem-se que $\mathbf{X}$ segue uma distribuição binomial com parâmetros $n$ e $u, \mathbf{X} \sim B(n, u)$. A probabilidade de $k$ sucessos é dada pela função massa de probabilidade, 


$$
f\left(\mathbf{X}_{i} ; n, v\right)=\frac{n !}{x !(n-x) !}(1-v)^{x}(v)^{n-x}
$$

Substituindo a equação (2.39) na equação (2.38) e resolvendo para $v$, obtém-se:

$$
v_{j}=1-\frac{1}{n}\left[\frac{\sum_{i=1}^{N} I_{\{S(\mathbf{X}) \geq \gamma\}} \mathbf{W}\left(\mathbf{X}_{i} ; \mathbf{u}, \omega\right) \mathbf{X}_{i j}}{\sum_{i=1}^{N} I_{\{S(\mathbf{X}) \geq \gamma\}} \mathbf{W}\left(\mathbf{X}_{i} ; \mathbf{u}, \omega\right)}\right]
$$

Utilizando os conceitos mostrados, pode-se aplicar o método CE na estimação dos índices GCR, como descrito em [5], [6], [22].

Um sistema elétrico de potência em que o sistema de geração é composto por $N_{C}$ estações geradoras, em que a j-ésima estação $\left(G S_{j}\right)$ é composta por $n_{j}$ unidades idênticas e independentes cada uma com capacidade $C_{j}$ e indisponibilidade $u_{j}$, e um nível de carga constante equivalente $L$ pode ser modelado estatisticamente por em termos das funções massa de probabilidade dos seus componentes. Cada unidade de geração pode ser representada por uma variável aleatória $x_{j}$ que segue uma distribuição de Bernoulli com indisponibilidades $f\left(\bullet ; n_{j}, u_{j}\right)$.

Definindo $\mathbf{X}_{k}$ como um possível resultado do vetor aleatório $\mathbf{X}=\left[x_{1}, x_{2}, \ldots, x_{j}, \ldots, x_{N_{C}}\right]$ cujo elemento genérico $x_{j}$ representa o número de unidades disponíveis na estação geradora $G S_{j}, \operatorname{com} x_{j} \in Z$ e $0 \leq x_{j} \leq n_{j}$; onde a função de teste do índice LOLP dada na equação (2.16) é reformulada de acordo com a (2.28):

$$
H_{\mathrm{LOLP}}\left(\mathbf{X}_{k}\right)=I_{\left\{S\left(\mathbf{X}_{k}\right)<L\right\}}= \begin{cases}0 & \text { se } \mathbf{Y}_{i} \in \Psi_{\text {Success }} \\ 1 & \text { se } \mathbf{Y}_{i} \in \Psi_{\text {Failure }}\end{cases}
$$

A pmf $f\left(\mathbf{X}_{k} ; \mathbf{n}, \mathbf{u}\right)$ é a probabilidade ou proporção do tempo que o sistema reside em $\mathbf{X}_{k}$ considerando a pmf associada a $\mathbf{X}, f(\bullet ; \mathbf{n}, \mathbf{u})$. Como todas as variáveis aleatórias envolvidas seguem uma distribuição binomial, o valor da função massa de probabilidade definida em $\mathbf{x}_{k} \operatorname{sob} f(\bullet ; \mathbf{n}, \mathbf{u})$ é dada por: 


$$
f\left(\mathbf{X}_{k} ; \mathbf{n}, \mathbf{u}\right)=\prod_{j=1}^{N_{C}} \frac{n_{j} !}{x_{j} !\left(n_{j}-x_{j}\right) !}\left(1-u_{j}\right)^{x_{j}}\left(u_{j}\right)^{n_{j}-x_{j}}
$$

onde $\mathbf{u}=\left[u_{1}, u_{2}, \ldots, u_{j}, \ldots, u_{N_{C}}\right]$, é um vetor que contêm os parâmetros originais (indisponibilidades) do sistema com $u_{j} \in \mathrm{Re} 0<u_{j}<1$ e $\mathbf{n}=\left[n_{1}, n_{2}, \ldots, n_{j}, \ldots, n_{N_{C}}\right]$ é um vetor constante com o número de unidades existentes em cada estação geradora $G S_{j}, \operatorname{com} n_{j} \in Z$ e $n_{j}>0$.

Define-se a função desempenho da $k$-ésima amostra, $S\left(\mathbf{X}_{k}\right)$, como o somatório de todas as capacidades de geração disponíveis:

$$
S\left(\mathbf{X}_{k}\right)=\mathbf{X}_{k} \mathbf{C}^{\mathrm{T}}=\left[x_{1}, x_{2}, \ldots, x_{j}, \ldots, x_{N_{C}}\right]\left[C_{1}, C_{2}, \ldots, C_{j}, \ldots, C_{N_{C}}\right]^{\mathrm{T}}
$$

Em $f\left(\mathbf{X}_{k} ; \mathbf{n}, \mathbf{u}\right)$, o índice LOLP pode ser obtido por

$$
\mathrm{LOLP}=E_{\mathbf{u}}\left[H_{\mathrm{LOLP}}(\mathbf{X})\right]=\sum H_{\mathrm{LOLP}}\left(\mathbf{X}_{k}\right) f\left(\mathbf{X}_{k} ; \mathbf{n}, \mathbf{u}\right)
$$

ou estimado via SMC utilizando $N$ amostras, $\mathbf{X}_{1}, \mathbf{X}_{2}, \ldots, \mathbf{X}_{N}$ de $\mathbf{x}_{\mathbf{x}} \sim f(; \mathbf{u})$, pelo estimador dado por

$$
\hat{\operatorname{LOLP}}=\frac{1}{N} \sum_{i=1}^{N} I_{\left\{S\left(\mathbf{x}_{i}\right)<L\right\}}
$$

Em avaliações de curto prazo, as probabilidades de falha dos componentes no horizonte de estudo são pequenas. Assim, o evento $\{S(\mathbf{X})<L\}$ será raro. Desta forma, para diminuir o esforço computacional, intensifica-se a amostragem dos eventos de interesse utilizando um estimador por IS não tendencioso:

$$
\hat{\operatorname{LOLP}}=\frac{1}{N} \sum_{i=1}^{N} I_{\left\{S\left(\mathbf{x}_{i}\right)<L\right\}} \mathbf{W}\left(\mathbf{X}_{i} ; \mathbf{n}, \mathbf{u}, \mathbf{v}\right)
$$

onde

$$
\mathbf{W}\left(\mathbf{X}_{i} ; \mathbf{n}, \mathbf{u}, \mathbf{v}\right)=\frac{f\left(\mathbf{X}_{i} ; \mathbf{n}, \mathbf{u}\right)}{f\left(\mathbf{X}_{i} ; \mathbf{n}, \mathbf{v}\right)}=\frac{\prod_{j=1}^{N_{C}}\left(1-u_{j}\right)^{x_{j}}\left(u_{j}\right)^{n_{j}-x_{j}}}{\prod_{j=1}^{N_{C}}\left(1-v_{j}\right)^{x_{j}}\left(v_{j}\right)^{n_{j}-x_{j}}}
$$


A razão de verossimilhança, $\mathbf{W}\left(\mathbf{X}_{i} ; \mathbf{n}, \mathbf{u}, \mathbf{v}\right)$, representa a correção que deve ser realizada no processo de amostragem devido à utilização da $\operatorname{pmf} f(\bullet ; \mathbf{n}, \mathbf{v})$, que é diferente da pmf $f(\bullet ; \mathbf{n}, \mathbf{u})$ original.

O método CE é então aplicado em uma abordagem de múltiplos níveis para determinar iterativamente o vetor de parâmetros ótimos, tal como descrito no algoritmo proposto em [22]. Os passos básicos de um algoritmo para determinação dos índices GCR por SMC via método CE são [5], [22]:

1) Definir $\hat{\mathbf{v}}_{0}:=\mathbf{u}$, ou seja, $\hat{\mathbf{v}}_{0}$ será igual ao vetor de indisponibilidades originais do sistema de geração; $\operatorname{logo}$ fazer $k:=1$ (contador de iterações do processo de otimização do Método CE);

2) Gerar $N$ amostras aleatórias $\mathbf{X}_{1}, \mathbf{X}_{2}, \ldots, \mathbf{X}_{N}$ de estados de geração, de acordo com a função massa de probabilidade $f\left(\bullet ; \mathbf{n}, \hat{\mathbf{v}}_{k-1}\right)$. Avaliar a função desempenho $S\left(\mathbf{X}_{i}\right)$ para todo $\mathbf{X}_{i}$ de acordo com (2.43) e ordenar os resultados em ordem decrescente tal que $\mathbf{S}=\left[S_{[1]}, S_{[2]}, \ldots, S_{[N]}\right]$ e $\mathbf{S}_{[1]} \geq \mathbf{S}_{[2]} \geq \ldots \geq \mathbf{S}_{[N]}$;

3) O próximo passo é encontrar o valor de $\hat{\boldsymbol{L}}_{k}$, ou seja, o nível de carga que será considerado na iteração $k$. O valor de $\hat{L}_{k}$ será uma aproximação do $(\rho)$ quantil amostral tal que $\hat{L}_{k}:=\mathbf{S}_{[(1-\rho) N]}$. Em outras palavras, calcular o valor de $(1-\rho) N$, e utilizar esse valor como um ponteiro $r . \hat{L}_{k}$ será igual ao valor da $r$-ésima posição do vetor $\mathbf{S}$ caso $\mathbf{S}_{[(1-\rho) N]}>L$. Se $\mathbf{S}_{[(1-\rho) N]} \leq L$, fazer $\hat{L}_{k}:=L$. Avaliar a função teste $H\left(\mathbf{X}_{i}\right)=I_{\left\{S\left(\mathbf{x}_{i}\right)<\hat{L}_{k}\right\}}$ para todo $\mathbf{X}_{i}$ e a razão de verossimilhança $\mathbf{W}\left(\mathbf{X}_{i} ; \mathbf{n}, \mathbf{u}, \hat{\mathbf{v}}_{k-1}\right)$ para todo $\mathbf{X}_{i}$, conforme (2.47);

4) Atualizar o vetor de parâmetros de referência $\hat{\mathbf{v}}_{k}$ segundo

$$
\hat{v}_{k, j}:=\hat{v}_{k, j} \alpha+\hat{v}_{k-1, j}(1-\alpha),
$$

onde $\hat{v}_{k, j}$ é calculado usando a equação (2.40),

$$
\hat{v}_{k, j}=1-\frac{1}{n_{j}}\left[\frac{\sum_{i=1}^{N} I_{\left\{S\left(\mathbf{x}_{i}\right)<\hat{L}_{k}\right\}} \mathbf{W}\left(\mathbf{X}_{i} ; \mathbf{n}, \mathbf{u}, \hat{\mathbf{v}}_{k-1}\right) \mathbf{X}_{i j}}{\sum_{i=1}^{N} I_{\left\{S\left(\mathbf{X}_{i}\right)<\hat{L}_{k}\right\}} \mathbf{W}\left(\mathbf{X}_{i} ; \mathbf{n}, \mathbf{u}, \hat{\mathbf{v}}_{k-1}\right)}\right]
$$


com $j=1,2, \ldots, N_{C}$. Onde $\alpha$, um fator de atualização denominado parâmetro de suavização, assume usualmente um valor entre 0,80 e 0,99 ;

5) Se $\hat{\gamma}_{k}=\gamma$, então é o fim do processo de otimização baseado no Método CE, fazer $\mathbf{v}_{\text {opt }}$ igual $\hat{\mathbf{v}}_{K}$ e continuar. Senão, incrementar o contador de iterações $k$ $:=k+1$ e voltar para o passo 2 .

Os próximos passos consistem em executar uma SMC não sequencial estimando os índices de confiabilidade utilizando VRT por IS.

6) Definir $\mathbf{v}_{\text {opt }}$ como $\hat{\mathbf{v}}_{K}$. Fazer o novo contador de iterações $N_{1}:=0$;

7) Gerar uma amostra $\mathbf{X} \operatorname{em} f\left(; \mathbf{u}, \hat{\mathbf{v}}_{K}\right)$, fazer $N_{1}:=N_{1}+1$;

8) Avaliar as funções teste dos índices, a razão de verossimilhança $\mathbf{W}\left(\mathbf{X}_{N_{1}} ; \mathbf{n}, \mathbf{u}, \hat{\mathbf{v}}_{K}\right)$ e o estimador não tendencioso para o índice LOLP na iteração $i$ :

$$
\begin{gathered}
\hat{\operatorname{LOLP}}=\frac{1}{N_{1}} \sum_{i=1}^{N_{1}} H_{\mathrm{LOLP}}\left(\mathbf{X}_{i}\right) \mathbf{W}\left(\mathbf{X}_{i} ; \mathbf{n}, \mathbf{u}, \hat{\mathbf{v}}_{K}\right) \\
\hat{\hat{E P N S}}=\frac{1}{N_{1}} \sum_{i=1}^{N_{1}} H_{\mathrm{EPNS}}\left(\mathbf{X}_{i}\right) \mathbf{W}\left(\mathbf{X}_{i} ; \mathbf{n}, \mathbf{u}, \hat{\mathbf{v}}_{K}\right) \\
\hat{\mathrm{LOLF}}=\frac{1}{N_{1}} \sum_{i=1}^{N_{1}} H_{\mathrm{LOLF}}\left(\mathbf{X}_{i}\right) \mathbf{W}\left(\mathbf{X}_{i} ; \mathbf{n}, \mathbf{u}, \hat{\mathbf{v}}_{K}\right)
\end{gathered}
$$

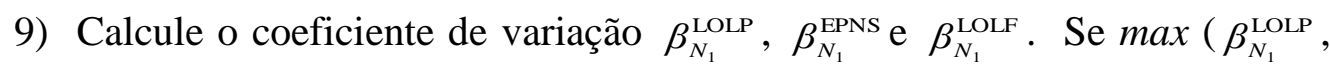
$\left.\beta_{N_{1}}^{\mathrm{EPNS}}, \beta_{N_{1}}^{\mathrm{LOLF}}\right) \leq \beta_{M A X}$ ou $N_{l} \geq N_{M A X}$, pare o algoritmo, caso contrário, volte para 7).

O algoritmo de avaliação dos índices GCR, através de SMC-IS via método CE apresentado neste item, pode ser utilizado para avaliar eficientemente o risco mesmo em sistemas onde os eventos de falha sejam raros. Desta forma, trata-se de uma importante ferramenta de análise que será, ainda neste capítulo, adaptada para ser incorporada à metodologia de dimensionamento probabilístico da reserva girante. 


\section{4. Conclusões}

Neste capítulo discorreu-se sobre conceitos associados à avaliação da confiabilidade de sistemas de energia elétrica. Foram apresentados índices que refletem características dos sistemas de potência, como o índice LOLP, associado à capacidade de suprir adequadamente a demanda.

Por meio de métodos analíticos ou simulação é possível estimar os índices LOLP, LOLE, EPNS, EENS, LOLF e LOLD. Em sistemas de grande porte, métodos de simulação Monte Carlo são recomendados, uma vez que há uma relativa independência do número de estados da representação.

Em problemas com eventos raros (sistemas muito confiáveis ou análises de curto prazo, por exemplo) a SMC pode não ser eficiente para gerar resultados em tempo hábil. Nestes casos, por meio de técnicas de redução de variância é possível melhorar significativamente a eficiência destes métodos.

Neste capítulo foi apresentado um método analítico altamente eficiente, baseado em técnicas de convolução e transformações para o domínio da frequência. Também foram introduzidos os conceitos do método da Entropia Cruzada e a sua aplicação na análise de confiabilidade de sistemas de potência. No próximo capítulo esses conceitos serão estendidos para análises de curto-prazo no problema do dimensionamento da reserva de geração. 


\section{3 Requisitos de Reserva Operativa em Sistemas de Geração}

O dimensionamento do montante da capacidade de geração para assegurar o suprimento da demanda dentro dos níveis adequados de confiabilidade, economicidade e qualidade é um aspecto importante do planejamento e operação de sistemas de potência [4].

Em relação ao horizonte de estudo, este problema geral pode ser divido em dois subproblemas: determinação da capacidade de reserva estática, para o longo e médio prazo (meses a anos); e determinação da reserva operativa, para o curto prazo (algumas horas) [67].

A reserva estática é a capacidade de geração instalada em excesso capaz de garantir o suprimento da carga, mesmo na hipótese da execução da manutenção programada das unidades geradoras, saídas não planejadas de geradores, crescimento da carga além do previsto e indisponibilidade de recursos naturais (hídrico, eólico, etc.) [7].

Enquanto a reserva de capacidade estática está relacionada com a avaliação em longo prazo das necessidades em termos globais, a reserva operativa está relacionada à avaliação em curto prazo da capacidade real necessária para atender um dado nível de carga [2], [5], [6], [7], sendo fornecida por unidades que ficam de prontidão e podem ser rapidamente utilizadas caso sejam solicitadas [3].

O correto dimensionamento da reserva de geração é essencial para que o sistema elétrico seja capaz de desempenhar sua função, mesmo na ocorrência de aumentos inesperados dos níveis de carga ou falhas nos seus geradores [2]. Assim, um dos objetivos do planejamento de sistemas elétricos de potência é determinar os montantes de reserva, tanto estática quanto operativa, necessários para atender os requisitos de confiabilidade do sistema.

Critérios determinísticos têm sido amplamente utilizados no dimensionamento da reserva. Essas abordagens normalmente não consideram explicitamente as incertezas inerentes do sistema nem são capazes de analisar seus efeitos em sis- 
temas de diferentes dimensões e composições. Desta forma, devido às características estocásticas do problema, métodos probabilísticos são uma alternativa mais coerente, uma vez que é possível avaliar, por meio dos índices de risco, o grau de adequação do sistema para diferentes níveis de reserva.

O procedimento geral de dimensionamento sob incertezas da reserva girante ocorre na programação do despacho, ou pré-despacho, e consiste, essencialmente, em comissionar máquinas até que o índice de risco se torne inferior a um valor previamente estabelecido.

Neste capítulo descreve-se o tradicional método PJM e propõe-se o uso de SMC para avaliar o índice de risco. Devido ao pequeno intervalo de tempo considerado (apenas algumas horas para o curto-prazo), a probabilidade de falha dos componentes é baixa e, assim, devido à raridade das falhas do sistema, o uso de técnicas SMC pode tornar-se excessivamente ineficiente (em termos de custo computacional). Descreve-se então uma VRT que utiliza IS para diminuir o esforço computacional. Há também uma breve descrição do método CE para avaliações de curto-prazo e sua aplicação na otimização dos parâmetros da simulação.

\section{1. Serviços Ancilares}

Os serviços ancilares são, em termos gerais, um conjunto de serviços auxiliares providos pelos equipamentos de geração, transmissão e de controle necessários para garantir a transmissão de potência do produtor ao consumidor. São requeridos para operação segura e confiável do sistema [68]. Desta forma, assegurando o suprimento aos mercados de energia elétrica em tempo real [11].

Como mencionado anteriormente, definições específicas e classificações desses serviços auxiliares têm sido realizadas de acordo com as características do sistema elétrico e das diretrizes dos órgãos de regulamentação. Uma descrição das definições e características técnicas dos serviços ancilares associados ao controle da tensão e frequência em diversas partes do mundo pode ser encontrada em [12]. Em [69] alguns aspectos técnicos e econômicos dos mercados de serviços ancilares de diversos países são comparados. 
Os serviços ancilares podem ser classificados, baseando-se na sua contribuição para os requisitos do sistema, em controle de frequência, controle de tensão, controle de estabilidade e reestabelecimento do sistema [68].

A reserva de geração é um dos serviços mais importantes, sendo responsável por uma parcela significativa dos custos relativos aos serviços ancilares [11]. Em [69] os serviços ancilares são classificados em três grupos gerais: Controle de frequência, coordenação e operação, backup e restauração.

\section{2. \\ Reserva Operativa}

O montante de geração programado para o atendimento da demanda deve ser tal que o sistema possua uma margem de reserva suficiente para suportar a perda de capacidade de geração ou aumentos súbitos na demanda, sem haver necessidade de cortar carga. Essa margem de reserva é denominada reserva operativa. O termo reserva operativa é utilizado para designar as quatro classes de reserva: regulação, girante, não girante e reposição [70], ou ainda, primária, secundária, terciária e quaternária [7].

A reserva de potência operativa é insumo fundamental para a manutenção da segurança operacional elétrica, pois mitiga os riscos de não atendimento e garante margem para atuação eficaz do controle automático de geração. Os estudos de planejamento da reserva operativa visam determinar sua correta quantificação e alocação, levando em conta os aspectos inerentes à operação [71].

Através de uma adequada política de planejamento da reserva é possível manter a operação do sistema ao mínimo custo possível, satisfazendo assim um dos principais objetivos do administrador que é a operação econômica e confiável.

Em função das diferentes velocidades de resposta aos distúrbios, em geral, a reserva operativa pode ser dividida em regulação secundária de frequência, regulação terciária de frequência e reservas não sincronizadas [69].

A regulação de frequência secundária requer um período de resposta que oscila, normalmente, entre cerca de 10 s e 15 min. A regulação da frequência terciária deve estar disponível dentro da faixa de 10-30 min, respeitando a otimização do 
despacho econômico entre as unidades geradoras. Para ambos os serviços, as unidades de geração devem estar sincronizadas à rede, e, em geral, é necessário que os serviços sejam mantidos por pelo menos 2 horas [69].

As reservas não sincronizadas são aqueles disponíveis em unidades geradoras que não foram despachados, mas que podem ser acionados estando de prontidão para começar a gerar um dentro período de cerca de $30 \mathrm{~min}$. As tecnologias utilizadas para fornecer esses serviços podem incluir unidades de partida rápida e cargas interruptíveis.

\subsection{1.}

\section{Classificação dos Tipos de Reserva}

A reserva de potência operativa foi sempre um segmento do sistema de geração essencial e importante a ser considerado nos estudos de planejamento da operação dos sistemas elétricos. Devido à "desverticalização" da indústria de energia elétrica, esse tipo de serviço, no âmbito dos serviços ancilares, passou a ser fornecido em alguns países por ofertadores industriais independentes com características próprias [12]. Assim, a reserva de potência é classificada segundo as diretrizes econômicas e/ou as regras dos órgãos regulamentadores de cada país, dependendo basicamente das características estruturais e necessidades específicas de cada sistema [7], [12], [72].

Nos EUA, o NERC (North American Electric Reliability Corporation) classifica a reserva operativa em quatro partes, cujas definiçõos são [70]:

Reserva de regulação: Serviço provido pelas unidades participantes do controle automático de geração (CAG), tanto no sentido de aumentar quanto diminuir o nível de potência gerada, com o intuito de manter o equilíbrio entre a geração e a carga.

Reserva girante: Montante de geração capaz de responder a um distúrbio (e.g., perda de equipamentos, elevação abrupta da carga etc.) em 10 minutos. Essa reserva deve ser proveniente das unidades sincronizadas e/ou interconexões. 
Reserva não girante: Parcela da reserva operativa proveniente de unidades não sincronizadas e que podem ser conectadas ao sistema em até 10 minutos, ou cargas interruptíveis que possam ser desconectadas do sistema em até 10 minutos.

Reserva de reposição: Montante de reserva proveniente de unidades não sincronizadas e interconexões capazes de suprir um déficit de geração dentro do limite de tempo especificado, ou cargas interruptíveis que possam também ser desconectadas dentro do limite de tempo desejado. Esse limite de tempo é da ordem de 60 minutos.

No Brasil, a divisão e classificação da reserva são realizadas segundo as diretrizes do Operador Nacional do Sistema Elétrico (ONS). Segundo o qual os tipos de reserva operativa são [11], [73]:

Reserva primária: É a parcela de reserva deixada nas máquinas sincronizadas com a finalidade de realizar o controle primário de frequência. Esse controle é exercido por meio dos reguladores automáticos de velocidade das unidades geradoras, objetivando limitar a variação de frequência quando da ocorrência de distúrbios que provoquem o desequilíbrio entre a geração e a carga. O ONS estabelece que a reserva primária deva ser igual a $1 \%$ da responsabilidade própria de geração do sistema. Entende-se por responsabilidade própria de geração do sistema, o montante de geração equivalente à carga do próprio sistema mais os contratos de exportação menos os contratos de importação.

Reserva secundária: É a parcela da reserva sincronizada responsável pelo controle secundário de frequência. A reserva secundária é composta pelas unidades participantes do controle automático de geração (CAG), cujos reguladores automáticos de velocidade ficam sob controle dos centros de operação, os quais atuam com o objetivo de restabelecer a frequência do sistema a seu valor nominal e manter ou restabelecer os intercâmbios de potência ativa a valores programados. O ONS determina que cada sistema seja responsável por manter uma reserva secundária igual a 2,5\% da sua responsabilidade própria de geração, acrescida de 1,5\% da carga própria do sistema.

Reserva terciária: É a parcela da reserva sincronizada destinada a cobrir as saídas ou limitações não programadas de unidades geradoras em operação, causadas por defeitos nos equipamentos que as compõem, ou defeitos nos transformadores. Para a reserva terciária, o ONS determina que ela seja igual à diferença entre a reserva sincronizada total recomendada para o sistema, obtida por meio de uma 
análise probabilística, e as parcelas relativas à Reserva Primária e à Reserva Secundária. A reserva terciária deve ser distribuída proporcionalmente entre as empresas com base em suas responsabilidades próprias de geração e suas maiores máquinas,

$$
R_{T_{K}}=\frac{M M_{K} \times R P G_{K}}{\sum M M_{i} \times R P G_{i}} \times R_{T_{S}},
$$

onde $R_{T_{K}}$ é reserva terciária de responsabilidade da empresa, $R_{T_{S}}$ é a reserva terciária total do sistema interligado, $M M_{i}$ é a maior máquina da empresa $i, M M_{k}$ é a maior máquina da empresa $k, R P G_{i}$ é a responsabilidade de geração própria da empresa $i, R P G_{k}$ é a responsabilidade de geração própria da empresa $k$.

Reserva quaternária: $\mathrm{O}$ objetivo dessa parcela da reserva operativa é suprir a perda de blocos de geração e/ou outras emergências não previstas. Fazem parte desse tipo de reserva: carga de bombeamento, cargas interruptíveis, geração hidráulica ou térmica a carvão excedente e geração a óleo.

\subsection{2. Reserva Girante}

Conforme definido em [4], a reserva girante é a parcela da geração que deve estar sincronizada ou que seja possível sincronizar em tempo hábil de forma a repor a perda de unidades de geração ou suprir acréscimos de demanda devido a erros de previsão [WW84].

A reserva girante requerida para prover um determinado nível de confiabilidade é função da capacidade das unidades, do número de unidades, confiabilidade de cada unidade despachada no intervalo de tempo, do nível de carga e dos erros de previsão das variáveis aleatórias envolvidas:

$$
R\left(G^{\text {spin }}, L, t\right)=G^{\text {spin }}(\mathbf{C}, \lambda, t)-L(t, \boldsymbol{\delta})
$$

$G^{\text {spin }}$ é a potência de geração sincronizada/despachada ou que seja possível sincronizar/despachar dentro de um determinado intervalo de processamento; $L$ é a carga equivalente do sistema; $\mathbf{C}$ é vetor de capacidades das unidades de geração; $\lambda$ é a 
taxa de falha dos componentes do sistema de geração e $\boldsymbol{\delta}$ representa os erros de previsão na determinação da carga.

Como é possível observar na equação (3.2), a reserva é uma variável aleatória e, portanto, qualquer inferência a seu respeito deve considerar seu comportamento estocástico. De forma a determinar quantitativamente essa reserva, deve-se mensurar o risco associado aos eventos de perda de carga. Uma vez obtido o risco e seus níveis aceitáveis, a reserva operativa pode ser determinada.

A determinação do nível aceitável de risco depende do grau de confiabilidade desejado, do correspondente custo e dos benefícios obtidos ao mitigar esse risco. Portanto, não há um valor padrão que possa ser aplicado a todos os sistemas [17]. Porém, dado um valor de risco obtido para uma configuração do sistema, sabe-se que é possível diminuí-lo adicionando reserva (considerando que seja possível transmiti-la às áreas do sistema que estejam apresentando insuficiência de geração).

\subsection{3. Método PJM (Pennsylvania - New Jersey - Maryland)}

Um dos primeiros métodos a utilizar técnicas probabilísticas para dimensionar a reserva girante foi desenvolvido em 1963 e ficou conhecido como método PJM, por ter sido aplicado ao sistema interligado Pennsylvania - New Jersey Maryland [7]. Esse método é descrito detalhadamente em [15] e revisitado em [4].

O procedimento básico desenvolvido pelo método PJM consiste em determinar as probabilidades de não suprimento da demanda em um intervalo de tempo no qual não seja possível adicionar geração caso ocorra a saída de uma unidade, essa probabilidade, conhecida como o índice LOLP, é considerada índice de risco do sistema.

Caso a carga não seja modelada por um único nível, isto é, carga variável, o intervalo de tempo total de processamento, denominado "lead time" deve ser discretizado em intervalos de tempo em que a carga possa ser considerada constante.

Cada unidade de geração é representada por um modelo Markoviano de dois estados (Up e Down), como mostrado na Figura 3.1, e durante o lead time considera-se que não é possível efetuar reparo. 


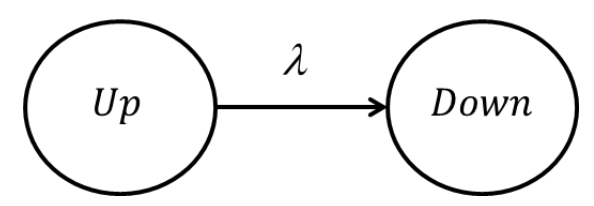

Figura 3.1: Diagrama de espaço de estados

Se as falhas e reparos são exponencialmente distribuídos, a probabilidade de encontrar o sistema no estado Down no tempo $T$, dado que em $t=0$ o sistema encontrava-se no estado $U p$ é dada por:

$$
P_{\text {Down }}(T)=\frac{\lambda}{\lambda+\mu}-\frac{\lambda}{\lambda+\mu} e^{-(\lambda+\mu) T}
$$

onde $\mu=m^{-1}, \lambda=r^{-1}, m$ é o MTTR (Tempo Médio de Reparo) e $r$ é o MTTF (Tempo Médio para a Falha).

Como a possibilidade de reparo durante o tempo de processamento é desconsiderada, isto é, $m \gg T$, tem-se que a taxa de reparo é igual a zero, $\mu=0$. Assim, $P_{D o w n}$ é dada por $P_{D o w n}=1-e^{-\lambda T}$. Como $\lambda T \ll 1$, a essa equação pode ser linearizada através da expansão em série de Taylor, com um único termo, em torno da origem por

$$
P_{\text {Down }}(T) \approx P\left(t_{U p} \leq T\right)=1-e^{-\lambda T} \cong \lambda T
$$

A probabilidade $\lambda T$ é usualmente conhecida como ORR, Outage Replacement Rate, i.e., taxa de reposição (substituição) de saída, que representa a probabilidade da unidade falhar e não ser reparada no intervalo $T$.

Utilizando as ORRs dos componentes do sistema, monta-se uma COPT, por meio da qual é possível avaliar a capacidade de geração dos estados do sistema. O procedimento de construção da COPT é semelhante ao realizado para a capacidade estática utilizando a FOR [2], a única diferença é o uso da ORR como probabilidade de falha. Como a carga é modelada como sendo constante no período de análise, o risco é avaliado diretamente da COPT. Dada uma carga $L$ e a capacidade de geração total equivalente $G$, o risco no tempo $t$ é igual ao valor de probabilidade

$$
\operatorname{Risk}(G)=P\left\{R\left(G^{s p i n}, L, t\right)=G^{\text {spin }}(C, \lambda, t)-L(t, \delta)<0\right\}
$$


ou seja, o risco é avaliado como sendo a probabilidade de o sistema não conseguir assegurar o suprimento da demanda total, ou seja, risco de corte de carga. Assim, como proposto pelo método PJM, o risco pode ser obtido diretamente das linhas da COPT.

O perfil dos requisitos de reserva estática e operativa para o sistema interligado PJM em um período de 52 semanas são apresentados na Figura 3.2 [16], usando o critério de confiabilidade "um dia em dez anos" para a LOLE anual. A área azul representa os níveis de demanda de pico semanais, a área violeta representa a geração despachada. A região amarela corresponde à reserva girante e a área verde representa a reserva de capacidade instalada. A seta vermelha vertical representa o montante de margem de reserva instalada (IRM) sobre o pico de carga anual - necessária para atender o índice de confiabilidade desejado.

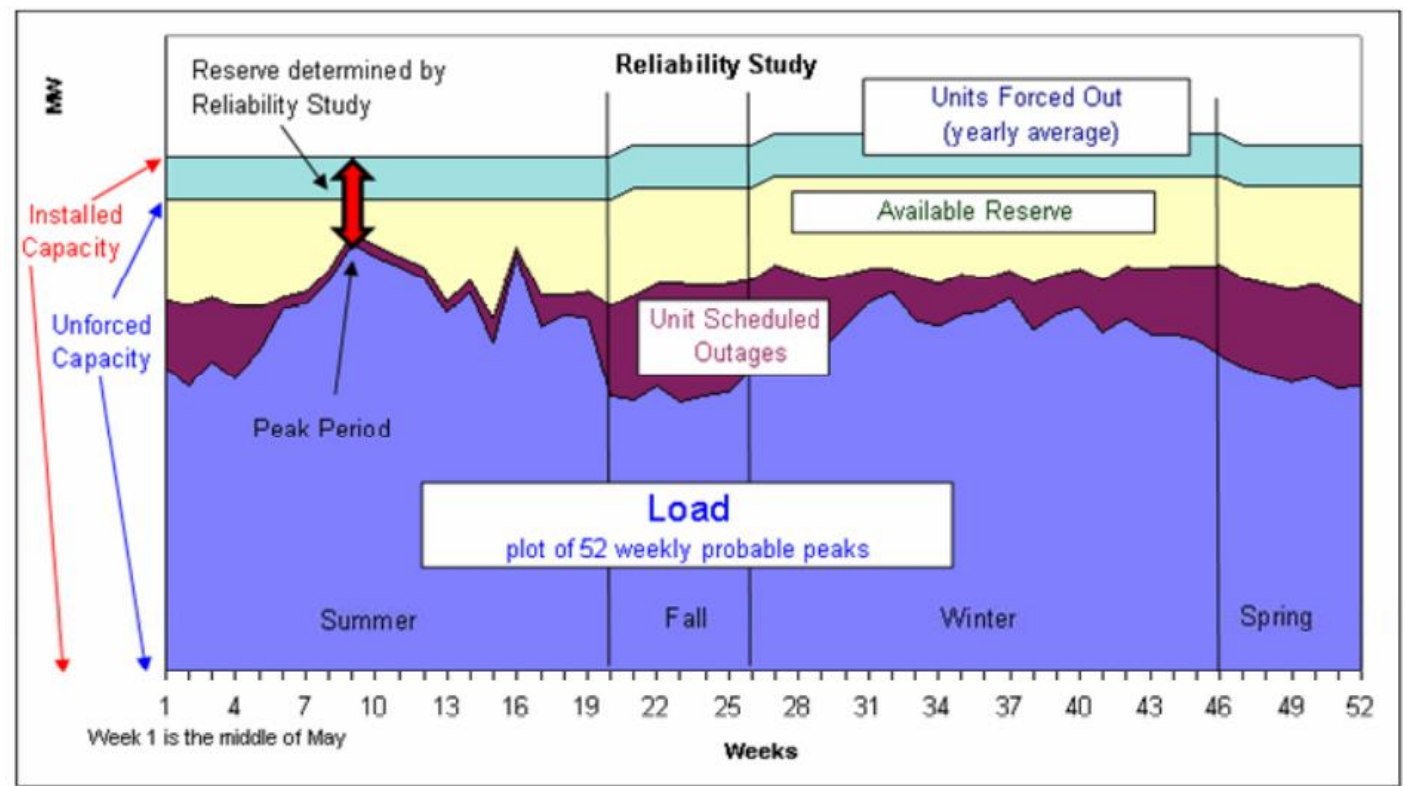

Figura 3.2: Características de capacidade e carga do sistema PJM [16]

O método PJM é usado até hoje, dando subsídio ao planejamento da operação do sistema interligado PJM, com a regra "um dia em dez anos" e com outras funcionalidades e análises adicionais, mas ainda usando um modelo analítico [16].

O operador deve se programar no início do lead time sabendo que não poderá reparar ou substituir qualquer unidade falhada, nem poderá acionar uma nova má- 
quina caso a demanda seja maior que o previsto. O risco deve ser avaliado continuamente no tempo para acompanhar as alterações na carga e no sistema de geração [4]. Assim, é de extrema relevância que a obtenção do risco seja realizada em um tempo hábil.

No método tradicional a carga é considerada constante. No entanto, é possível considerar a demanda com o tempo e as incertezas em relação à sua previsão. Uma das formas a considerar essas incertezas é assumir a carga como sendo normalmente distribuída e discretizada em alguns níveis. A cada nível de cada carga associa-se uma probabilidade de ocorrência desse evento. O risco, naquele intervalo considerado, é obtido ponderando o risco para cada nível de carga com a probabilidade de ocorrência do respectivo nível [4].

O efeito da inclusão de unidades com diferentes "lead times", tais como as unidades de partida rápida (turbinas a gás, turbinas hidráulicas) e as unidades de reserva quente (unidades térmicas que permanecem com a caldeira aquecida), foi analisado em [43]. Embora os modelos sugeridos apresentem uma descrição mais detalhada das plantas de geração, necessita-se de uma quantidade maior de dados, que podem não estar consistentemente disponíveis, para a determinação das taxas de transição entre os estados dos modelos.

Considerações adicionais podem ser feitas, tais como a modelagem de perdas parciais de capacidade das unidades. Isto é possível através da inclusão de mais estados de carga ao modelo inicial de dois estados, como proposto em [42]. Alternativamente ao que havia sido proposto anteriormente pelo método PJM, a modelagem poderia incluir, dentro do intervalo de tempo considerado na avaliação do risco, o efeito da continuidade de fornecimento de potência de unidades parcialmente falhadas.

$\mathrm{Na}$ prática, isso ocorre porque muitas falhas podem ser toleradas e a retirada da máquina pode ser postergada. Assim, a ORR pode ser modificada para incluir o efeito do adiamento da manutenção, dando origem à MORR (Modified Outage Replacement Rate). A MORR é a ORR ponderada pelo fator $1-\theta$, em que $\theta$ é a proporção de $\lambda$ que pode ser postergada [4]:

$$
\mathrm{MORR}=P_{\text {Down }}=(1-\theta) \lambda T=(1-\theta) \times \mathrm{ORR}
$$


Ao se utilizar um nível de detalhamento maior, e mais realístico, o número de estados do modelo do sistema pode aumentar, assim, uma técnica de enumeração pode apresentar dificuldade. Embora em análises de curto prazo muitas das incertezas do problema possam ser desconsideradas sem prejuízo aos resultados, uma modelagem mais detalhada, incluindo essas considerações adicionais, pode ser realizada facilmente por meio de SMC.

Adicionalmente, na avaliação dos requisitos de reserva operativa podem ser consideradas as unidades de partida rápida tais como as unidades a gás e as hidráulicas, cargas interruptíveis, interconexões, etc. [7]. Desta forma, os métodos usados em estudos de dimensionamento de reserva girante devem representar adequadamente todas essas características inerentes aos sistemas de energia elétrica. Todas essas características, que podem estar correlacionadas com o tempo, podem ser avaliadas via técnicas de simulação.

\section{3. Dimensionamento da Reserva usando SMC via Método CE}

Como descrito anteriormente, o operador deve programar unidades de geração considerando que não poderá efetuar alterações no despacho caso algum fator inesperado ocorra. $\mathrm{O}$ risco deve ser analisado previamente e, durante a fase de programação ou pré-despacho, deve-se incluir reserva o suficiente para que o operador do sistema tenha capacidade de manobra para adotar medidas corretivas. O objetivo é evitar interrupção no fornecimento ao consumidor e minimizar os custos operativos totais visando sempre à operação econômica e confiável.

O método PJM, à época de sua publicação, apresentou uma ideia inovadora ao utilizar técnicas probabilísticas de avaliação do risco e dimensionamento da reserva. Através desta técnica analítica, conseguiu-se obter uma ferramenta computacionalmente eficiente na avaliação de sistemas de geração via modelo barra única.

Mesmo quando os eventos de interesse são raros essa eficiência não é prejudicada, pois os métodos analíticos geralmente não são afetados pela raridade da estimação. No entanto, se aplicado a sistemas com elevado número de estados, esse método perde sua eficiência computacional, como, por exemplo, em estudos considerando os sistemas de geração e transmissão. 
Em sistemas com elevada penetração de energia de energia renovável, devido às correlações espaciais e/ou temporais, técnicas analíticas tornam-se praticamente inviáveis. Com o intuito de superar as limitações associadas à estratégia de avaliação do risco em sistemas desse tipo, uma alternativa é usar métodos de simulação associados com técnicas de redução de variância, tal como a SMC via método da Entropia Cruzada.

O passo inicial no planejamento da operação no curto prazo consiste em despachar as unidades até que o nível de capacidade seja superior ao da carga prevista para o período. Este procedimento, denominado Unit Commitment, é, em essência, o processo de determinar o despacho das unidades considerando as características do sistema e suas restrições operativas [74]. O processo de seleção das unidades que serão disponibilizadas é realizado resolvendo um problema de otimização cujo objetivo é minimizar os custos operativos totais.

O pré-despacho pode ser formulado matematicamente como um problema de otimização, cuja solução pode ser obtida através de técnicas de programação linear (PL). Neste caso, a função objetivo representa os custos operativos. Estes devem ser minimizados considerando as diversas restrições do problema. Algumas dessas restrições consideradas na formulação matemática genérica são [74]: atendimento da demanda, limites de capacidade total e capacidades parciais, mínimo tempo de operação e de desligamento das máquinas, quantidade máxima de potência sincronizável, quantidade mínima de reserva, entre outros. As restrições do pré-despacho estão relacionadas também ao processo de ligamento, acionamento e sincronização das unidades [1].

A minimização dos custos de operação do sistema no pré-despacho garante que as máquinas que apresentam os menores custos marginais de operação sejam priorizadas. Desta forma, a seleção unidades de geração segue uma ordem de mérito. As máquinas com baixo custo são programadas para operar durante a maior parte do tempo enquanto que as de maior custo marginal são despachadas apenas quando necessário, por exemplo, durante picos de carga. No Apêndice A, que trata da formulação matemática da Ordem de Mérito para o despacho econômico da geração, é apresentado um modelo matemático que pode ser utilizado para obter a ordem de despacho, considerando a minimização dos custos associados à operação.

Uma vez obtida a configuração do sistema de geração que seja capaz de atender a demanda, o próximo passo do planejamento é dimensionar o montante de 
reserva necessário para satisfazer o critério de risco de perda de carga. Esta fase consiste, basicamente, em efetuar sucessivos incrementos de reserva e, a cada incremento realizado, executar uma nova avaliação do risco. Os incrementos de reserva são efetuados adicionando novas unidades de geração ao sistema.

Como são realizadas várias avaliações de confiabilidade é necessário que a ferramenta de análise seja extremamente eficiente de forma a obter o resultado em tempo hábil para o operador. É necessário também que essa eficiência seja mantida mesmo para cenários do sistema com diferentes quantidades de componentes, pois novos componentes são adicionados ao incrementar o nível de reserva.

Devido ao elevado número de estados necessários para a representação dos sistemas de potência, o uso de métodos de enumeração seria, do ponto de vista do tempo hábil de obtenção da solução do problema, proibitivo. Assim, a princípio, a ferramenta mais adequada para resolver este problema, dada a abrangência dimensional das análises, é a Simulação Monte Carlo. No entanto, devido à raridade dos eventos de falha em avaliações de curto prazo, o desempenho da SMC poderia ser prejudicado. Desta forma, com o intuito de manter a eficiência sem perder a flexibilidade do uso de uma ferramenta de simulação e observando o problema conjunto da elevada dimensionalidade em simultaneidade à raridade das falhas, a ferramenta a ser utilizada deve ser uma SMC-IS via método CE.

O algoritmo proposto para dimensionar a reserva girante é descrito nos passos a seguir.

Passo 1: Dado o sistema de geração composto por $N_{C}$ estações geradoras. Cada estação composta por $n_{j}$ unidades idênticas e independentes com capacidade $C_{j}$, taxa de saída forçada igual a $O R R_{j}$, e um nível de carga constante equivalente $L$, como representado na Figura 3.3, efetuar o pré-despacho para obter uma ordem de prioridades de despacho das unidades segundo o menor custo marginal de operação, conforme apresentado no Anexo A; 


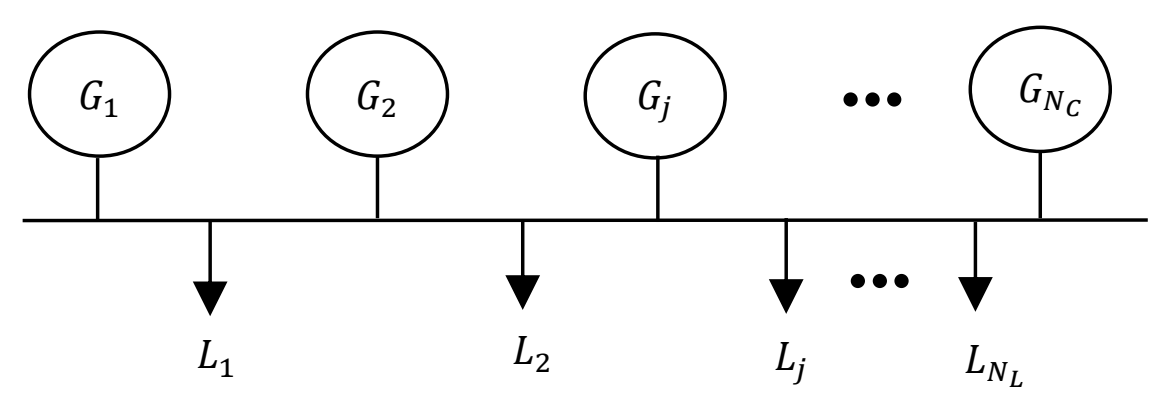

Figura 3.3: Representação do sistema - modelo barra única

Passo 2: $\quad$ Definir o Lead Time T (e.g., 2 horas), usando a taxa de saída forçada de cada unidade definir a probabilidade de falha das unidades como sendo igual à respectiva $\mathrm{ORR}_{j}$, e o vetor de Taxas de Substituição original $\mathbf{u}$,

$$
\begin{gathered}
\mathrm{ORR}_{j}=\lambda_{j} T, \\
\left.\mathbf{u}:=\mathrm{ORR}_{1}, \mathrm{ORR}_{2}, \ldots, \mathrm{ORR}_{N_{C}}\right\rfloor
\end{gathered}
$$

sendo $j=1,2, \ldots, N_{D} ; N_{D}$ é o número de estações de gerações incluídas inicialmente no pré-despacho;

Passo 3: Inicializar o número global de iterações do processo de dimensionamento da reserva girante $N_{R}:=0$;

Passo 4: Definir $\hat{\mathbf{v}}_{0}:=\mathbf{u}$, ou seja, $\hat{\mathbf{v}}_{0}$ será igual ao vetor de ORRs originais do sistema de geração; fazer $k:=1$ e iniciar o processo iterativo de otimização do vetor $\mathbf{v}$ via método CE e atualizar o contador de iterações do processo de dimensionamento da reserva $N_{R}:=N_{R}+1$;

Passo 5: Gerar $N$ amostras aleatórias $\mathbf{X}_{1}, \mathbf{X}_{2}, \ldots, \mathbf{X}_{N}$ de estados de geração, de acordo com a função massa de probabilidade $f\left(; \mathbf{n}, \hat{\mathbf{v}}_{k-1}\right)$. Avaliar a função desempenho $S\left(\mathbf{X}_{i}\right)$ para todo $\mathbf{X}_{i}$ e ordenar os resultados em ordem decrescente tal que $\mathbf{S}=\left[S_{[1]}, S_{[2]}, \ldots, S_{[N]}\right]$ e $\mathbf{S}_{[1]} \geq \mathbf{S}_{[2]} \geq \ldots \geq \mathbf{S}_{[N]}$;

Passo 6: Determinar o nível de carga que será considerado na iteração $k, \hat{L}_{k}$. O valor de $\hat{L}_{k}$ será tal que $\hat{L}_{k}:=\mathbf{S}_{[(1-\rho) N]}$. Em que $(1-\rho) N$ é o valor do 
ponteiro $r . \hat{L}_{k}$ será igual ao valor da $r$-ésima posição do vetor $\mathrm{S}$ caso $\mathbf{S}_{[(1-\rho) N]}>L$. Se $\mathbf{S}_{[(1-\rho) N]} \leq L$, fazer $\hat{L}_{k}:=L ;$

Passo 7: Avaliar a função teste $H\left(\mathbf{X}_{i}\right)=I_{\left\{S\left(\mathbf{X}_{i}\right)<\hat{L}_{k}\right\}}$ e a razão de verossimilhança $\mathbf{W}\left(\mathbf{X}_{i} ; \mathbf{n}, \mathbf{u}, \hat{\mathbf{v}}_{k-1}\right)$ para todo $\mathbf{X}_{i}$ de acordo com

$$
\begin{gathered}
\hat{\operatorname{LOLP}}=\frac{1}{N} \sum_{i=1}^{N} I_{\left\{S\left(\mathbf{X}_{i}\right)<L\right\}} \mathbf{W}\left(\mathbf{X}_{i} ; \mathbf{n}, \mathbf{u}, \mathbf{v}\right), \\
\mathbf{W}\left(\mathbf{X}_{i} ; \mathbf{n}, \mathbf{u}, \mathbf{v}\right)=\frac{f\left(\mathbf{X}_{i} ; \mathbf{n}, \mathbf{u}\right)}{f\left(\mathbf{X}_{i} ; \mathbf{n}, \mathbf{v}\right)}=\frac{\prod_{j=1}^{N_{C}}\left(1-u_{j}\right)^{x_{j}}\left(u_{j}\right)^{n_{j}-x_{j}}}{\prod_{j=1}^{N_{C}}\left(1-v_{j}\right)^{x_{j}}\left(v_{j}\right)^{n_{j}-x_{j}}} ;
\end{gathered}
$$

Passo 8: Atualizar o vetor de parâmetros de referência $\hat{\mathbf{v}}_{k}$ segundo

$$
\begin{gathered}
\hat{v}_{k, j}=\hat{v}_{k, j} \alpha+\hat{v}_{k-1, j}(1-\alpha), \\
\hat{v}_{k, j}=1-\frac{1}{n_{j}}\left[\frac{\sum_{i=1}^{N} I_{\left\{S\left(\mathbf{X}_{i}\right)<\hat{L}_{k}\right\}} \mathbf{W}\left(\mathbf{X}_{i} ; \mathbf{n}, \mathbf{u}, \hat{\mathbf{v}}_{k-1}\right) \mathbf{X}_{i j}}{\sum_{i=1}^{N} I_{\left\{S\left(\mathbf{X}_{i}\right)<\hat{L}_{k}\right\}} \mathbf{W}\left(\mathbf{X}_{i} ; \mathbf{n}, \mathbf{u}, \hat{\mathbf{v}}_{k-1}\right)}\right]
\end{gathered}
$$

$\operatorname{com} j=1,2, \ldots, N_{C}$. Utilizar $\alpha=0,9999$;

Passo 9: Se $\hat{\gamma}_{k}=\gamma$, então é o fim do processo de otimização baseado no Método $\mathrm{CE}$, fazer $\mathbf{v}_{\text {opt }}$ igual $\hat{\mathbf{v}}_{K} \mathrm{e}$ ir para o próximo passo. Senão, incrementar o contador de iterações $k:=k+1$ e voltar para o Passo 5;

Passo 10: Definir $\mathbf{v}_{\text {opt }}$ como $\hat{\mathbf{v}}_{K}$. Fazer o novo contador de iterações $N_{l}:=0$;

Passo 11: Gerar uma amostra $\mathbf{X}$ em $f\left(; \mathbf{n}, \hat{\mathbf{v}}_{k}\right)$ e fazer $N_{1}:=N_{1}+1$;

Passo 12: Avaliar as funções teste dos índices, a razão de verossimilhança $\mathbf{W}\left(\mathbf{X}_{N_{1}} ; \mathbf{n}, \mathbf{u}, \hat{\mathbf{v}}_{K}\right)$ e o estimador não tendencioso para o índice de risco LOLP na iteração $i$ : 


$$
\hat{\operatorname{Risk}}=\frac{1}{N_{1}} \sum_{i=1}^{N_{1}} H_{\mathrm{LOLP}}\left(\mathbf{X}_{i}\right) \mathbf{W}\left(\mathbf{X}_{i} ; \mathbf{n}, \mathbf{u}, \hat{\mathbf{v}}_{K}\right)
$$

Passo 13: Calcular o coeficiente de variação $\beta_{N_{1}}^{\text {LOLP }}$ e ir para o próximo passo se $\beta_{N_{1}}^{\text {LOLP }} \leq \beta_{\mathrm{MAX}}$ ou $N_{l} \geq N_{M A X}$. Caso contrário, volte para 10);

Passo 14: Atualizar montante de reserva da iteração e verificar se o risco obtido é menor que o valor máximo aceitável,

$$
\text { Risk }<\text { Risk }_{\max } \text {. }
$$

Em caso afirmativo, definir o valor dimensionado da reserva girante para o sistema como sendo o valor obtido na iteração atual e parar a execução. Caso contrário, ir para o próximo passo;

Passo 15: Verificar se $N_{D}<N_{\mathrm{C}}$, ou seja, o sistema ainda possui a capacidade estática que pode ser sincronizada para ser adicionada à parcela da reserva girante (se $N_{D}$ é igual a $N_{C}$ significa que toda a capacidade de geração do sistema já está sendo utilizada). Caso seja possível, incluir a próxima unidade, $N_{D}:=N_{D}+1$, e retornar para o passo 4 . Caso contrário, informar que não foi possível atingir o critério de risco e interromper a execução.

A metodologia descrita neste tópico é uma estratégia de dimensionamento da reserva via Simulação Monte Carlo baseada no Método da Entropia Cruzada. Tratase de uma abordagem alternativa e diferente ao tradicional método PJM, uma vez que o risco é estimado via técnicas de simulação. Ao evitar a Enumeração é possível avaliar sistemas de grande porte complexos, dando robustez ao método desenvolvido.

\section{4.}

\section{Conclusões}

O dimensionamento da reserva de potência de geração, seja a estática ou a operativa, é um aspecto importante a ser analisado pelos operadores e planejadores 
de sistemas elétricos de potência. Uma das parcelas importantes da reserva operativa é a girante, ou seja, a parcela que está sincronizada para suprir a demanda caso ocorra a saída inesperada de alguma unidade de geração.

A reserva girante, devido suas características específicas, é mais coerentemente dimensionada ao utilizar técnicas probabilísticas (tal como o método PJM), pois os índices de risco, medidas quantitativas da confiabilidade do sistema, devem ser criteriosamente considerados.

Com o intuito de adequar a metodologia introduzida pelo método PJM à aplicação em sistemas com elevado número de estados, utilizou-se SMC-IS via método CE como ferramenta de avaliação do risco (Probabilidade de Perda de Carga ou LOLP). Com a metodologia proposta é possível chegar aos mesmos resultados obtidos originalmente pelo método PJM. No entanto, devido à utilização de técnicas de SMC, agregou-se flexibilidade e robustez na avaliação.

Ao utilizar SMC, cria-se uma variedade de novas aplicações no âmbito do dimensionamento da reserva. É possível expandir o modelo em barra única para incluir a rede de transmissão. Além disso, pode-se avaliar o risco em sistemas complexos, tal como em sistemas com elevada penetração de energia renovável.

Neste capítulo, foram apresentados os conceitos básicos relacionados ao dimensionamento probabilístico da reserva girante de geração e propôs-se uma metodologia para sua determinação.

No próximo capítulo, as ideias e conceitos apresentados sobre reserva operativa serão revistos e o método proposto será estendido para considerar o sistema de transmissão na determinação do índice de risco. Será realizada uma análise do efeito da inclusão das características reais do sistema de transmissão no dimensionamento da reserva girante necessária para assegurar o grau de confiabilidade indicado no planejamento. 


\section{4 \\ Reserva Girante Considerando Restrições de Transmissão}

No setor elétrico há um interesse crescente em refinar os métodos de alocação de recursos baseados em critérios de confiabilidade. Nesse sentido, os índices de confiabilidade da capacidade de geração fornecem informações importantes para o planejamento e operação dos sistemas. No entanto, esses índices não consideram as falhas no sistema de transmissão. O rápido crescimento dos sistemas e o aumento do número de interconexões levaram ao reconhecimento de que o sistema de transmissão desempenha um papel crítico na determinação da confiabilidade global do sistema [14], [50].

Em sistemas elétricos reais os componentes do sistema de transmissão falham e apresentam restrições devido aos seus limites operativos. Esse fato já é reconhecido em diversos estudos como, por exemplo, planejamento da reserva de capacidade estática [18], análise de segurança [17], [75], entre outras aplicações [54], [8], [14]. Desta forma, a estratégia mais coerente para dimensionar a reserva girante sem desconsiderar os aspectos reais da operação é utilizar índices probabilísticos associados ao risco de perda de carga obtidos através da avaliação da confiabilidade da geração e transmissão, i.e., confiabilidade composta.

A inclusão das restrições de capacidade de transporte da transmissão torna a tarefa de avaliar a confiabilidade do sistema muito mais complexa. Na confiabilidade composta, a avaliação da adequação de um estado do sistema (i.e., o níveis de carga, de geração disponível e de circuitos operando) usualmente requer uma análise de fluxo de potência e a representação de ações corretivas, ao invés de simples comparações entre geração disponível e carga, como é feito no caso da confiabilidade de geração [50], [6], [27].

Devido à representação da rede, a avaliação da confiabilidade composta requer maior custo computacional, uma vez que essa análise depende de fatores como as dimensões da rede e a raridade dos eventos. A avaliação de um elevado número de estados, especialmente em análises de confiabilidade de sistemas de grande 
porte, pode tornar-se extremamente cara (do ponto de vista do esforço computacional), inviável, ou mesmo impraticável [51]. No planejamento da operação a curto prazo, o tempo de execução de um algoritmo pode inclusive impedir a viabilidade de sua utilização, uma vez que os resultados devem ser obtidos em tempo hábil. Assim, é de extrema importância que os métodos desenvolvidos para avaliações nesse campo sejam computacionalmente eficientes.

Vários métodos têm sido propostos com o intuito de diminuir o esforço necessário nesse tipo de avaliação, esses métodos baseiam-se em técnicas que se concentram, essencialmente, em melhorar os algoritmos de análise de rede e diminuir o número de análises de adequação de estados, como em [50], [51], [49]. Redução de Variância, Fluxo de Potência Ótimo via Fuzzy (Fuzzy OPF), Corte do Espaço de Estados (State-space Pruning) e Computação Distribuída são algumas das técnicas utilizadas nesse intuito [51].

Algumas técnicas baseiam-se também em métodos de busca inteligente através de uma população de amostras (Population-Based Intelligence Search - PIS) tais como Algoritmos Genéticos (Genetic Algorithms - GA), Otimização por Enxame de Partículas (Particle Swarm Optimization - PSO), PSO Evolutivo (Evolutionary Particle Swarm Optimization - EPSO), Otimização por Enxame de Partículas (Ant Colony Optimization - ACO) e Sistemas Imunológicos Artificiais (Artificial Immune Systems - AIS) [76].

Há ainda técnicas baseadas em Redes Neurais Artificiais (Artificial Neural Networks - ANR) [51] e várias outras metodologias que combinam essas técnicas com o intuito de aumentar a eficiência computacional. No entanto, apesar de todo o esforço aplicado em pesquisa nesse campo, reconhece-se que há ainda carências por métodos mais eficientes e precisos na avaliação da confiabilidade composta [76].

A eficiência na avaliação da confiabilidade composta através de SMC pode ser substancialmente melhorada ao utilizar-se Amostragem por Importância baseada no método $\mathrm{CE}$, principalmente em análises cujas probabilidades dos eventos de interesse são pequenas, conforme foi demonstrado pelos resultados numéricos em [6] e [27].

Em estudos de curto-prazo, devido ao pequeno intervalo de tempo considerado, algumas configurações do sistema, tais como aquelas com elevado montante 
de reserva, podem apresentar baixa probabilidade de falha, mesmo incluindo as falhas do sistema de transmissão na análise.

Apesar das dificuldades de avaliação que surgem ao considerar a composição geração-transmissão, a ocorrência de falhas no sistema de transmissão pode inviabilizar o atendimento da demanda mesmo em situações de disponibilidade de geração e de reserva, o que resulta em interrupção do suprimento e, consequentemente, impacta nos índices de confiabilidade (i.e., de risco). Portanto, deve-se considerar o efeito do sistema de transmissão em análises de dimensionamento e alocação da reserva operativa.

Como a reserva girante é dimensionada preferivelmente por critérios probabilísticos, considerando índices de risco, as restrições do sistema de transmissão causam impacto em seu dimensionamento. Assim, é de extrema importância que o sistema de transmissão (capacidade e disponibilidade) seja considerado na determinação do risco de perda de carga.

Neste capítulo descreve-se uma ferramenta para avaliação do risco probabilístico de não suprimento da demanda a curto prazo, com base na avaliação da confiabilidade composta, utilizando técnicas de simulação com uso de técnicas de redução de variância via método CE. A partir da qual, uma metodologia para o dimensionamento probabilístico da reserva girante é proposta.

\section{1. \\ Confiabilidade de Sistemas de Geração e Transmissão}

Apesar de sua complexidade e extensão, os sistemas elétricos de potência são compostos, essencialmente, pelos sistemas de geração, transmissão e distribuição. Esses sistemas são considerados as três zonas funcionais e, em avaliações de confiabilidade, podem ser combinados para compor os Níveis Hierárquicos [77], [8].

Em análises de confiabilidade há, essencialmente, quatro principais níveis hierárquicos $(\mathrm{NH})$ [77], [78] como ilustrado na Figura 4.1. O nível NH0 está relacionado às avaliações da disponibilidade de energia na sua forma primária, i.e., as análises consideram os cenários energéticos em termos globais - este nível é também conhecido como Nível Energético [78]. No Nível Hierárquico I (NHI), as avaliações verificam se a capacidade de geração disponível é suficiente para atender a 
demanda. O sistema de transmissão e suas limitações em transportar a energia gerada à carga são desconsiderados. Os métodos de avaliação GCR são baseados na caracterização da distribuição de probabilidade da capacidade de geração disponível, que é então comparada à distribuição da carga a ser suprida.

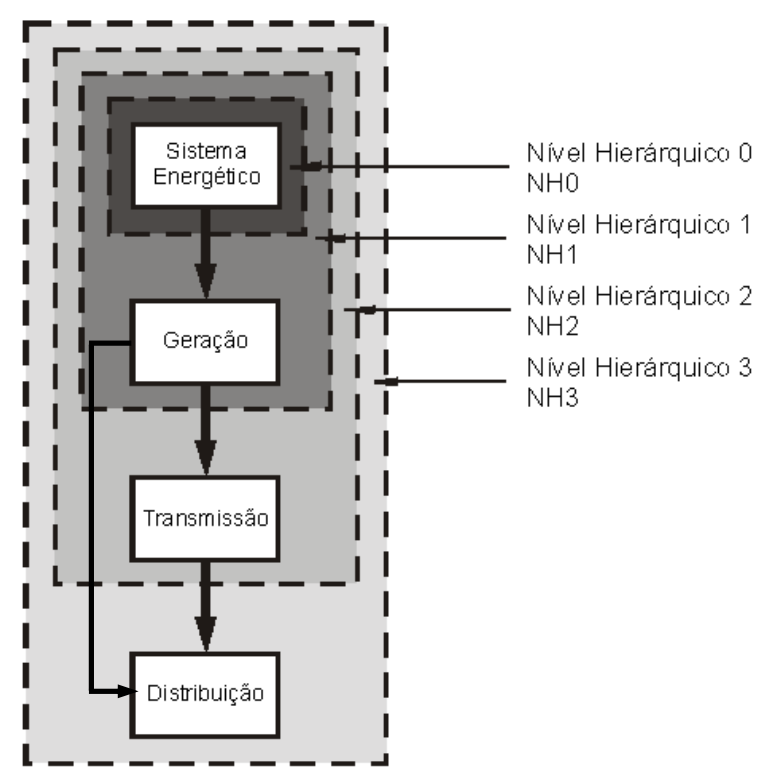

Figura 4.1: Níveis hierárquicos e zonas funcionais

Como citado anteriormente, o rápido crescimento dos sistemas e o aumento do número de interligações levou ao reconhecimento que o sistema de transmissão desempenha um papel crítico na confiabilidade global do sistema.

A confiabilidade de um sistema elétrico depende da configuração da rede, do grau de confiabilidade de cada componente e de suas condições. A garantia do fornecimento em uma determinada área de um sistema elétrico é função da disponibilidade dos diversos componentes da transmissão e da geração, aos quais esta área está conectada, bem como dos equipamentos não diretamente conectados [79].

As falhas de equipamentos de uma área do sistema causam impacto em todo o sistema uma vez que, a princípio, todos os componentes, apesar de estarem em barramentos distintos, estão conectados através do sistema de transmissão. Em avaliações no Nível Hierárquico II, o modelo simples geração/carga é estendido para incluir as limitações da transmissão na análise. Análises de confiabilidade nesse nível são usualmente denominadas de Avaliação da Confiabilidade Composta [8]. 
A inclusão do sistema de transmissão torna a avaliação muito mais complexa, uma vez que a análise de cada configuração do sistema envolve a execução de um algoritmo de análise de fluxo de potência; convencional ou ótimo. Além disso, dependendo das condições da rede, pode ser necessário que medidas corretivas, como redespacho ou corte de carga, sejam executadas. Isto dificulta ainda mais a análise. Apesar desses aspectos, é amplo o reconhecimento da necessidade e relevância desse tipo de análise [8]. Assim, o objetivo da análise da confiabilidade composta é avaliar se o sistema é capaz de atender a carga considerando a possibilidade de falhas na geração e na transmissão.

No Nível Hierárquico III as análises são realizadas considerando a junção das três zonas funcionais. Esse tipo de análise é também denominado de Avaliação da Confiabilidade Global. Trata-se de uma avaliação no nível do consumidor [80]. Devido às dimensões e à complexidade do problema, o sistema de distribuição tem sido usualmente estudado de forma separada da geração e transmissão [8]. Usualmente considera-se o sistema de geração e transmissão representado por pontos de fornecimento com capacidades ilimitadas e totalmente confiáveis [6].

\subsection{1. Modelos de Rede}

O sistema é composto de vários grupos de componentes, tais como geradores, cargas distribuídas nos diversos barramentos, transformadores, linhas de transmissão, etc. Cada um desses componentes pode ser representado por seu modelo em diagrama de estados, por exemplo, um modelo Markoviano. Um estado do sistema é uma combinação dos diversos estados dos componentes.

A avaliação da confiabilidade considerando a rede de transmissão segue os mesmos três passos básicos de um algoritmo de baseado em espaço de estados [8], como citados no capítulo anterior na avaliação da confiabilidade de geração. No entanto, ao considerar o sistema de transmissão, para a avaliação da adequação de um determinado estado do sistema é necessário o uso de uma ferramenta de análise de rede. Essa ferramenta pode ser um fluxo de potência linear ou um fluxo de potência $\mathrm{AC}$, dependendo da representação da rede, se linear ou não linear. 
Basicamente, a análise de adequação consiste em verificar se as restrições operativas são satisfeitas e se necessário executar medidas corretivas para evitar o corte de carga, ou mesmo minimizá-lo [81]. Como, ao utilizar-se SMC, uma análise deve ser efetuada para cada simulação, o número de análises a ser realizado pode ser elevado. Desta forma, é necessário que o algoritmo de análise de rede seja extremamente eficiente, pois parte considerável do tempo total de simulação será dedicada a sua execução.

A rede elétrica pode ser representada através de um modelo AC ou um modelo linearizado, modelo DC. O modelo AC é capaz de representar aspectos relacionados tanto à potência ativa quanto à potência reativa. $\mathrm{O}$ modelo DC considera, essencialmente, aspectos relacionados à potência ativa. Apesar de o modelo AC proporcionar uma representação mais realística e precisa, o modelo DC continua ainda sendo muito utilizado em alguns tipos de estudo em que a relativa perda de exatidão é justificável pelo ganho computacional. A escolha do modelo trata-se, portanto, de um compromisso entre a exatidão requerida e o custo computacional necessário para obtê-la.

Em alguns casos o uso do modelo linear é justificável por não haver alternativa viável como, por exemplo, devido à inexistência ou inexatidão de dados relativos ao sistema de controle de reativos ou em aplicações que envolvem um expressivo volume de computação [82]. Particularmente, este último exemplo é o que ocorre em aplicações de análise de confiabilidade envolvendo SMC, a cada iteração da simulação é necessário a execução de um novo fluxo de potência. $\mathrm{O}$ uso da representação AC pode tornar-se inviável em termos práticos devido à falta de robustez numérica ao se avaliar redes elétricas de grande porte sob contingências de ordens superiores.

O fluxo de potência linear, ou fluxo DC (DC Power Flow), é tanto analiticamente quanto computacionalmente atrativo, principalmente por apresentar características tais como linearidade, simplicidade e bilateralidade (Potência Ativa - Ângulo, $P \theta)$. Algumas das vantagens da representação linearizada da rede são [82]: A solução obtida é não iterativa, confiável e única; Os métodos e softwares relacionados são simples; os modelos são eficientemente otimizáveis, particularmente em análise de contingências; a quantidade de dados da rede necessária para obter a solução é reduzida; os valores dos fluxos, em MW, obtidos na solução apresentam, com algumas ressalvas, precisão razoável. 


\subsection{2.}

\section{Fluxo de Potência Linear}

O fluxo de potência linear é baseado no acoplamento entre a potência ativa injetada nas barras e os ângulos das tensões nodais e permite estimar o valor das grandezas elétricas do sistema a um baixo custo computacional e, para sistemas de transmissão, com uma relativa precisão [83]. Esta ferramenta é particularmente útil na avaliação da confiabilidade via simulação uma vez que neste tipo de análise vários fluxos devem ser executados a cada alteração da rede no decorrer das iterações do processo computacional.

A formulação básica do método é baseada na linearização das equações dos fluxos entre as barras em torno de pequenas variações dos ângulos das tensões nodais. Considere o fluxo de potência entre as barras $k$ e $m, P_{k m}$, como dado pela equação representativa do modelo AC:

$$
P_{k m}=V_{k}^{2} g_{k m}-V_{k} V_{m} g_{k m} \cos \theta_{k m}-V_{k} V_{m} b_{k m} \operatorname{sen} \theta_{k m}
$$

A linearização é realizada desconsiderando as perdas de potência de potência ativa, aproximando as funções trigonométricas através de sua expansão em série de Taylor, adotando as tensões como sendo unitárias, e desprezando a resistência série no cálculo da susceptância série da linha [82], [83]:

$$
\begin{gathered}
P_{k m}=-V_{k} V_{m} b_{k m} \operatorname{sen} \theta_{k m} \\
P_{k m}=-V_{k} V_{m} b_{k m} \theta_{k m} \\
P_{k m}=-b_{k m} \theta_{k m} \\
P_{k m}=\theta_{k m} / x_{k m}
\end{gathered}
$$

Assim, através das aproximações anteriormente descritas, o modelo linear da rede pode ser representado matricialmente por,

$$
\mathbf{P}=\mathbf{B}^{\prime} \boldsymbol{\theta}
$$

onde $\mathbf{P}$ é o vetor de injeções líquidas de potência ativa; $\boldsymbol{\theta}$ é o vetor de ângulos das tensões nodais; B' é uma matriz do tipo admitância nodal com as seguintes leis de 
formação (para evitar a singularidade da matriz $\mathbf{B}$ ' exclui-se a linha e a coluna da matriz relativa à barra de referência):

$$
\begin{gathered}
B_{k m}^{\prime}=-x_{k m}^{-1} \\
B_{k k}^{\prime}=\sum_{m \in \Omega_{k}} x_{k m}^{-1}
\end{gathered}
$$

e $P_{j}=\sum P_{j m}$ é injeção de potência na j-ésima barra.

Com o intuito de aumentar a precisão, ao vetor $\mathbf{P}$ podem ser adicionadas parcelas relacionadas às perdas nos ramos série, $P_{L}$, e em derivação $P_{S}$, calculadas para algum ponto de operação de interesse e distribuídas pelos barramentos [82],

$$
\mathbf{P}-\mathbf{P}_{L}-\mathbf{P}_{S}=\mathbf{B}^{\prime} \boldsymbol{\theta} .
$$

Uma vez obtidos os ângulos nodais através de (4.6), os fluxos podem ser encontrados. Com o resultado é possível verificar se houve alguma sobrecarga em algum circuito testando a seguinte condição

$$
\left|f_{j}\right|=P_{k m}=\left|\theta_{k m} / x_{k m}\right| \leq f_{j_{\max }}
$$

para todos os circuitos $\left(j=1,2, \ldots, N_{L}\right), f_{j_{\max }}$ é a máxima capacidade de transporte de fluxo do $j$-ésimo circuito. Caso alguma restrição tenha sido violada, é necessário adotar uma medida corretiva. Para isso, executa-se um OPF, como será discutido no próximo tópico.

Um dos aspectos importantes do fluxo DC é a inicialização das variáveis. Dadas as injeções de potência ativa nos barramentos, os ângulos nodais são obtidos por (4.6), e vice-versa. Por isso, diferentemente do fluxo AC em que as injeções em alguns tipos de barramento fazem parte do resultado, é importante que as injeções sejam determinadas previamente. Usualmente, as injeções de potência são obtidas de um fluxo AC previamente resolvido, sendo tal abordagem denominada HotStart. Quando uma inicialização AC não estiver disponível, seja devido à ausência de dados de perfis de tensão/Var ou, por exemplo, em alguns problemas de Unit Commitment com restrições de segurança, o modelo DC deve ser construído no modo Cold-Start [82]. 
Pelas razões discutidas, em análises de confiabilidade é comum a utilização de algoritmos de fluxo de potência linear. Neste trabalho utilizou-se a representação linear da rede. $\mathrm{O}$ fluxo DC foi utilizado como uma ferramenta de primeira análise de adequação das diversas configurações simuladas da rede. As injeções de potência da inicialização do modelo são obtidas através da execução de algoritmo de fluxo de potência ótimo linear, executado para o caso base (caso em que não há contingências).

\subsection{3. \\ Fluxo de Potência Ótimo (FPO)}

Em análises de confiabilidade composta, pode-se utilizar o FPO como uma ferramenta de análise da pós-contingência, com o intuito de efetuar medidas corretivas. Basicamente, dado um estado da rede em que houve a saída de um ou mais componentes, o objetivo é encontrar um novo ponto de operação que satisfaça todas as restrições.

No modelo de fluxo de potência linear, as medidas corretivas são essencialmente o redespacho de geração e o corte de carga. Usualmente, para encontrar um novo ponto de operação realiza-se o redespacho da geração. Caso haja insuficiência de geração o corte de carga deve ser minimizado [8].

Uma política de corte de carga é uma regra segundo a qual se determina em quais dos barramentos há necessidade de interromper o suprimento da demanda [6]. Há várias políticas de corte de carga e sabe-se que dependendo da estratégia adotada os índices de confiabilidade por barra são fortemente influenciados. No entanto, grande parte dos índices globais para o sistema tende a não depender da política de corte de carga adotada [84].

Fluxo de Potência Ótimo ou OPF (Optimal Power Flow) é um termo genérico para descrever uma ampla classe de problemas nos quais se procura otimizar uma função objetivo específica, satisfazendo um conjunto de restrições relacionados às particularidades físicas e operativas da rede elétrica [85]. O problema de fluxo de potência ótimo linear tem aplicações em diversos problemas de análise e operação de sistemas de potência, tais como despacho econômico, análise de segurança, pla- 
nejamento da expansão da geração e transmissão, entre outros. Devido à sua simplicidade, à eficiência computacional e ao grau satisfatório de precisão dos resultados, utiliza-se a representação linearizada do fluxo de potência para determinar o estado da rede e o impacto das falhas no sistema de transmissão na avaliação da confiabilidade do sistema.

O objetivo do FPO ou OPF é otimizar o ponto de operação do sistema elétrico. Assim, o algoritmo escolhe entre as infinitas condições operativas possíveis, uma que otimize o critério escolhido. Este critério pode ser, por exemplo, fornecer o ponto de operação mais econômico, minimização do corte de carga, mínima perda de potência ativa nas linhas, mínimo desvio de um ponto de operação específico, etc. No caso da representação linearizada, a ação corretiva através de um OPF é geralmente formulada como um problema de programação linear, PL, na forma padrão que consiste em minimizar uma função objetivo sujeita a restrições de igualdade e de desigualdade:

$\min :$

$$
z=\sum_{j=1}^{N_{B u s}}\left(C_{O \& M}+C_{\text {shed }} \times r_{j}\right)
$$

S. a.:

$$
\begin{gathered}
\mathbf{B}^{\prime} \boldsymbol{\theta}+\mathbf{g}+\mathbf{r}=\mathbf{d} \\
\mathbf{g}_{\min } \leq \mathbf{g} \leq \mathbf{g}_{\max } \\
|\mathbf{f}| \leq \mathbf{f}_{\max } \\
\mathbf{r} \leq \mathbf{d}
\end{gathered}
$$

onde z é a função objetivo que representa a minimização do custo, composto pelo custo de operação e manutenção e do corte de carga; $\mathbf{r}=\left[r_{1}, r_{2}, \ldots, r_{\mathrm{j}}, \ldots, r_{\mathrm{Nbus}}\right]^{T}$ é o vetor de corte de carga por barra; $r_{j}$ é o corte de carga na $j$-ésima barra; $C_{\text {shed }}$ é o custo do corte de carga na $j$-ésima barra; $\mathbf{g}=\left[g_{1}, g_{2}, \ldots, g_{\mathrm{j}}, \ldots, g_{\mathrm{Nbus}}\right]^{T}$ é o vetor de geração por barra; $\mathbf{d}=\left[d_{1}, d_{2}, \ldots, d_{\mathrm{j}}, \ldots, d_{\mathrm{Nbus}}\right]^{T}$ é o vetor de demanda por barra; $\boldsymbol{\theta}$ é o vetor de ângulos das tensões nodais; B' é uma matriz nodal de susceptância, como definido em (4.7); $\mathbf{g}_{\max }$ e $\mathbf{g}_{\min }$ são os vetores de capacidades máxima e mínima de geração por barra; $\mathbf{f}=\left[f_{1}, f_{2}, \ldots, f_{\mathrm{j}}, \ldots, f_{\mathrm{NL}}\right]^{T}$ é o vetor de fluxos nos circuitos, em que $N_{L}$ é o 
número de circuitos do sistema; $\mathbf{f}_{\max }$ é o vetor de máxima capacidade de fluxo por circuito.

O problema representado em (4.10) pode ser resolvido utlizando um algoritmo de programação linear, tal como o método Dual-Simplex, modificado para explorar característcas de esparsidade e com o uso de uma base reduzida [8].

Uma das formas de implementar uma base reduzida, tal como proposto em [84], consiste em resolver o sistema desconsiderando inicialmente parte as restrições representadas em (4.13). Ao desconsiderar parte das restrições, o problema de otimização pode ser resolvido mais rapidamente, pois sua dimensão é menor. Após a obtenção dos resultados, a solução obtida é verificada e caso haja alguma restrição ativa, um fluxo próximo à capacidade máxima, a restrição relativa ao fluxo máximo naquele circuito é adicionada e o problema é resolvido novamente. Os resultados obtidos em [84] mostram que, dependendo do circuito, pode-se obter um melhor desempenho computacional ao adotar tal metodologia.

Um problema adicional que surge ao usar o FPO como medida corretiva é a forma com que é realizado o redespacho quando a contigência é a sobrecarga em uma linhas de transmissão. Neste caso, o corte de carga deve ser feito localmente [6]. Ao resolver o problema proposto em (4.10) com sobrecarga em um circuito, o algoritmo de otimização tenta redespachar tantas máquinas quanto forem necessárias para evitar o corte de carga. No entanto, em sistemas reais, por razões práticas, pode ser impossível ou muito caro para o operador fazer todos esses ajustes nas diversas unidades de geração. Assim, uma das preocupações que surge ao usar FPO como medida corretiva é representar de forma apropriada o redespacho da geração [8].

Nos casos de impraticidade do redespacho, como na operação a curto prazo, a solução pode ser o corte de carga no circuito em sobrecarga. Matematicamente, pode-se fazer o algoritmo convergir para uma solução deste tipo adicionando uma restrição tal que o montante de carga seja no mínimo igual ao fluxo adicional que ultrapassa o máximo suportável pelo circuito,

$$
\sum_{j=1}^{N_{\text {Bus }}} r_{j} \geq \sum_{i \in \Omega_{o}}\left(\left|f_{i}\right|-f_{\max _{j}}\right)
$$


onde $\Omega_{o}$ é o conjunto de circuitos que apresentaram sobrecarga em linhas. A equação (4.15) é então adicionada ao conjunto de restrições do problema original. Essa restrição representa basicamente que, em casos de sobrecarga de linhas de transmissão, o corte de carga total deve ser no mínimo igual ao montante total da sobrecarga.

\section{2. Estimação dos Índices de Risco via Método CE considerando a Rede de Transmissão}

Ao considerar o sistema de transmissão, os conceitos desenvolvidos sobre a aplicação do método CE devem ser estendidos para tratar o problema da confiabilidade composta. Deve-se considerar o comportamento estocástico tanto das unidades de geração quanto do sistema de transmissão, representado pelas linhas de transmissão.

Assim como as unidades de geração foram representadas por um vetor de variáveis aleatórias com distribuição Binomial, as linhas de transmissão podem ser modeladas por um vetor de variáveis aleatórias com distribuição de Bernoulli. Se $\mathbf{X}_{T}=\left[x_{1}, x_{2}, \ldots, x_{j}, \ldots, x_{N_{L}}\right]$ é um vetor de variáveis aleatórias discretas que segue uma distribuição de Bernoulli, ou seja, os valores assumidos pelos seus elementos apresentam, em um dado experimento, probabilidade de sucesso $u$ e probabilidade de falha $v$, então, a função massa de probabilidade para um determinado elemento de $\mathbf{X}_{T}$ será $f(x, v)=(1-v)^{x} v^{1-x}$. Para essa distribuição, que é utilizada para representar o comportamento estocástico de sucesso ou falha de uma única linha de transmissão, o vetor de indisponibilidades distorcidas, $\mathbf{v}$, pode ser obtido, via método CE, para um parâmetro $\omega$ qualquer, por [86]

$$
v_{j}=1-\frac{\sum_{i=1}^{N} I_{\{S(\mathbf{X}) \geq \gamma\}} \mathbf{W}\left(\mathbf{X}_{i}, \mathbf{u}, \omega\right) X_{i j}}{\sum_{i=1}^{N} I_{\{S(\mathbf{X}) \geq \gamma\}} \mathbf{W}\left(\mathbf{X}_{i}, \mathbf{u}, \omega\right)} .
$$


O vetor $\mathbf{X}_{i}=\left[\mathbf{X}_{G}, \mathbf{X}_{T}\right]$, que representa o $i$-ésimo estado do sistema, é composto pelos estados tanto das unidades de geração (agora representada por $\mathbf{X}_{G}$ ) quanto pelos estados das linhas de transmissão, $\mathbf{X}_{T}$. O vetor $\mathbf{u}=\left[\mathbf{u}_{G}, \mathbf{u}_{T}\right]$ é o vetor de indisponibilidades originais, composto pelas indisponibilidades dos componentes da geração, $\quad \mathbf{u}_{G}=\left[u_{G_{1}}, u_{G_{2}}, \ldots, u_{G_{j}}, \ldots, u_{G_{N_{C}}}\right], \quad \mathrm{e} \quad \mathrm{da}$ transmissão, $\mathbf{u}_{T}=\left[u_{T_{1}}, u_{T_{2}}, \ldots, u_{T_{j}}, \ldots, u_{T_{N_{C}}}\right]$.

As razões de verossimilhança da geração, $\mathbf{W}_{G}$, e da transmissão, $\mathbf{W}_{T}$, são:

$$
\begin{gathered}
\mathbf{W}_{G}\left(\mathbf{X}_{G_{i}} ; \mathbf{n}_{G}, \mathbf{u}_{G}, \mathbf{v}_{G}\right)=\frac{f\left(\mathbf{X}_{G_{I}} ; \mathbf{n}_{G}, \mathbf{u}_{G}\right)}{f\left(\mathbf{X}_{G_{I}} ; \mathbf{n}_{G}, \mathbf{v}_{G}\right)}=\frac{\prod_{j=1}^{N_{C}}\left(1-u_{G_{j}}\right)^{x_{G_{j}}}\left(u_{G_{j}}\right)^{n_{G_{j}}-x_{G j}}}{\prod_{j=1}^{N_{C}}\left(1-v_{G_{j}}\right)^{x_{G_{j}}}\left(v_{G_{j}}\right)^{n_{G_{j}}-x_{G j}}} \\
\mathbf{W}_{T}\left(\mathbf{X}_{T_{i}}, \mathbf{u}_{T}, \mathbf{v}_{T}\right)=\frac{f\left(\mathbf{X}_{T_{i}} ; \mathbf{u}_{T}\right)}{f\left(\mathbf{X}_{T_{i}} ; \mathbf{v}_{T}\right)}=\frac{\prod_{j=1}^{N_{L}}\left(1-u_{T_{j}}\right)^{x_{T_{j}}}\left(u_{T_{j}}\right)^{1-x_{T_{j}}}}{\prod_{j=1}^{N_{L}}\left(1-v_{T_{j}}\right)^{x_{T_{j}}}\left(v_{T_{j}}\right)^{1-x_{T j}}}
\end{gathered}
$$

E a razão de verossimilhança composta pode ser obtida por [27],

$$
\mathbf{W}\left(\mathbf{X}_{i} ; \mathbf{n}, \mathbf{u}, \mathbf{v}\right)=\mathbf{W}_{G}\left(\mathbf{X}_{G_{i}} ; \mathbf{n}_{G}, \mathbf{u}_{G}, \mathbf{v}_{G}\right) \mathbf{W}_{T}\left(\mathbf{X}_{T_{i}}, \mathbf{u}_{T}, \mathbf{v}_{T}\right)
$$

Utilizando amostragem por importância, os índices de risco em confiabilidade composta podem ser obtidos por meio do estimador não tendencioso:

$$
\hat{\mathrm{E}_{\mathrm{v}}\left[H_{I}\right]}=\frac{1}{N} \sum_{i=1}^{N} H\left(\mathbf{X}_{i}\right) \mathbf{W}\left(\mathbf{X}_{i} ; \mathbf{n}, \mathbf{u}, \mathbf{v}\right)
$$

O método CE é então utilizado para determinar, através de um algoritmo iterativo adaptativo, o vetor de indisponibilidades ótimo, isto é, aquele cuja distância estatística entre as duas funções massa de probabilidade, $f(; \mathbf{u})$ e $f(; \mathbf{v})$, é mínima [27],

$$
\hat{v}_{T_{k, j}}=\alpha\left(1-\frac{\sum_{i=1}^{N} H\left(\mathbf{X}_{i}\right) \mathbf{W}\left(\mathbf{X}_{i} ; \mathbf{n}, \mathbf{u}, \hat{\mathbf{v}}_{k-1}\right) \mathbf{X}_{\mathrm{T}_{i j}}}{\sum_{i=1}^{N} H\left(\mathbf{X}_{i}\right) \mathbf{W}\left(\mathbf{X}_{i} ; \mathbf{n}, \mathbf{u}, \hat{\mathbf{v}}_{k-1}\right)}\right)+(1-\alpha) \hat{v}_{T_{k-1, j}}
$$


para $j=1,2, \ldots, N_{L}$.

A função desempenho, utilizada para classificar os estados amostrados na $k$ ésima iteração de acordo com sua importância, é também modificada para considerar os cortes de carga. Caso não haja corte carga na amostra, a função desempenho é a própria capacidade de geração disponível, caso contrário, a função desempenho é a diferença entre a carga máxima e o corte de carga total (somatório dos cortes em todos os barramentos):

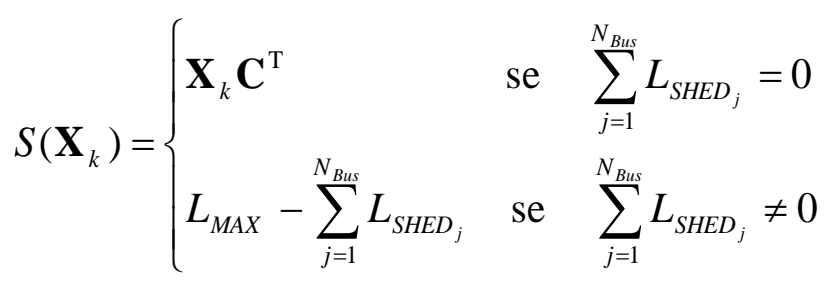

O algoritmo de otimização adaptativa dos parâmetros dos sistemas de geração e transmissão via método CE é obtido alterando o algoritmo proposto anteriormente para distorção das indisponibilidades do sistema de geração. Nesta nova implementação, incluem-se os conceitos generalizados descritos neste tópico, conforme desenvolvidos em [27], [6].

Basicamente, o método CE é utilizado com o intuito de obter uma distorção ótima para as indisponibilidades dos equipamentos. Uma vez obtidas estas distorções, os índices de confiabilidade tradicionais do sistema podem ser determinados utilizando uma SMC não sequencial baseada em amostragem por importância (IS). Ao otimizar a distorção, incentiva-se a amostragem dos eventos mais significativos para a falha do sistema, reduz-se a variância do estimador e, consequentemente, o esforço computacional para avaliação do risco.

Em [27] os conceitos do método CE são aplicados em conjunto com uma técnica de Redução de Variância usando Amostragem por Importância para aumentar a eficiência computacional de uma SMC não sequencial. Neste artigo, avaliouse a confiabilidade composta de alguns sistemas testes. Os resultados obtidos demonstraram que é possível obter ganhos expressivos tanto em termos de redução do tempo de simulação quanto do estreitamento do intervalo de confiança (redução da incerteza da estimação do índice). 


\section{3.}

\section{Avaliação da Reserva Girante considerando a Rede de Transmissão}

No capítulo anterior a reserva girante foi dimensionada desconsiderando as restrições de transmissão, a partir de um modelo "barra única" em que todos os geradores e cargas estavam conectados. Em relação ao tradicional método PJM, uma metodologia mais generalista de avaliação do risco foi descrita ao utilizar técnicas de simulação Monte Carlo. O método CE foi aplicado à SMC-IS para a avaliação do índice probabilístico de risco de perda de carga.

Como tem sido enfatizado, o sistema de transmissão desempenha um papel cada vez mais crítico e fundamental na confiabilidade da operação dos sistemas elétricos de potência [47]. Desta forma, o objetivo deste tópico é adaptar a metodologia já proposta anteriormente para avaliar o índice de risco considerando o sistema de transmissão na análise. Nesse sentido, a definição do risco pode ser reformulada de acordo com,

$$
\operatorname{Risk}(G, T)=P\left\{R\left(G^{\text {spin }}, C^{\text {trans }}, L, t\right)=G^{\text {spin }}\left(C_{G}, \lambda_{G}, C_{T}, \lambda_{T}, t\right)-L(t, \delta)<0\right\},
$$

ou seja, o risco de perda de carga, função da composição entre Geração e Transmissão, é a probabilidade, em um instante $t$, de a reserva girante ser negativa. Além disso, o montante de reserva $R$ é uma variável aleatória relacionada ao nível de geração sincronizada (e que possa ser fornecida pela rede com capacidade, $C^{\text {trans }}$, limitada) e da carga $L$.

Durante o lead time t, não será possível incluir novas máquinas nem reparar aquelas que venham a sair de operação. Também não será possível reparar linhas de transmissão que possam eventualmente falhar durante o intervalo. $\mathrm{O}$ operador deve se programar, no início deste intervalo, considerando essas limitações do sistema. Assim, o nível de reserva deve ser adequadamente dimensionado de forma a prover uma margem de segurança e possibilitar a execução de medidas operativas de controle.

O nível de geração sincronizada e pronta a ser entregue depende das características dos sistemas de geração e transmissão, tais como as respectivas capacidades 
e taxas de falha. Uma vez definido o risco, o problema consiste em, dados os recursos disponíveis ao operador em termos de capacidade de geração, atender ao critério de risco,

$$
\hat{\operatorname{Risk}}(\mathrm{G}, \mathrm{T})<\operatorname{Risk}_{\max }
$$

onde Risk $(\mathrm{G}, \mathrm{T})$ é o risco estimado considerando a confiabilidade composta de uma dada configuração dos sistemas de Geração e Transmissão e da carga momentânea. O algoritmo proposto para avaliar o risco através de SMC-IS via o método CE e dimensionar a reserva girante considerando as restrições do sistema de transmissão é descrito nos passos a seguir:

Passo 1: Dado o sistema com $N_{B u s}$ barramentos, composto por $N_{C}$ estações geradoras e $N_{L}$ linhas de transmissão. O nível de carga em cada barramento, $L_{j}$, pode ser considerado constante, pois apenas um curto prazo é considerado na análise. Cada estação composta por $n_{j}$ unidades idênticas e independentes com capacidade $C_{G_{j}}$ e Taxa de Falha igual a $\lambda_{G_{j}}$. Cada linha de transmissão com capacidade de transmissão igual a $C_{T_{j}}$ e Taxa de Falha igual a $\lambda_{T_{j}}$. Carregar os dados determinísticos e estocásticos do sistema. Definir o tempo de processamento, lead time $t$ (e.g., 2 horas).

Determinar a taxa de substituição de cada unidade dos grupos de estações geradoras:

$$
O R R_{G_{j}}=\lambda_{G_{j}} t \text { para } j=1,2, \ldots, N_{C},
$$

e definir a probabilidade de falha de cada unidade como sendo igual à respectiva $O R R_{G_{j}}$,

$$
\mathbf{u}_{G}=\left[O R R_{G_{1}}, O R R_{G_{2}}, \ldots, O R R_{G_{j}}, \ldots, O R R_{G_{N_{C}}}\right]
$$

Determinar também a taxa de substituição de cada linha de transmissão

$$
O R R_{T_{j}}=\lambda_{T_{j}} t \text { para } j=1,2, \ldots, N_{L},
$$

e definir a probabilidade de falha de cada LT como sendo igual à respectiva $O R R_{T_{j}}$ 


$$
\mathbf{u}_{T}=\left[O R R_{T_{1}}, O R R_{T_{2}}, \ldots, O R R_{T_{j}}, \ldots, O R R_{T_{N_{L}}}\right]
$$

Obter a ordem de prioridades de despacho das unidades de geração segundo o menor custo marginal de operação resolvendo o PPL definido em (9.1);

Passo 2: Atualizar o contador global de iterações do processo de dimensionamento da reserva, $N_{R}:=N_{R}+1$;

Passo 3: Este passo consiste em obter o vetor de parâmetros distorcidos executando o processo de otimização estocástica via o método CE. Fazer $k:=1$, definir $\hat{\mathbf{v}}_{0}:=\mathbf{u}$, ou seja, $\hat{\mathbf{v}}_{0}$ será igual ao vetor de ORRs originais do sistema, onde $\mathbf{u}=\left[\mathbf{u}_{G}, \mathbf{u}_{T}\right]$; e iniciar o processo iterativo de distorção do vetor $\mathbf{v}$ :

3.1) Gerar $N$ amostras aleatórias $\mathbf{X}_{1}, \mathbf{X}_{2}, \ldots, \mathbf{X}_{N}$ de estados de geração, de acordo com a pmf $f\left(; \mathbf{n}, \hat{\mathbf{v}}_{k-1}\right)$;

3.2) Avaliar a adequação das $N$ amostras geradas. Neste passo é necessário verificar a adequação de cada estado gerado, para isso é necessário executar um algoritmo de análise de rede, pois a rede de transmissão, diferente da abordagem tradicional, está sendo considerada. Para cada amostra gerada, executar um fluxo DC linear, obter os ângulos nas barras e verificar se houve sobrecarga. Caso não haja violação ativa, pular o próximo subpasso. Senão, adotar medida corretiva por meio da execução do próximo subpasso;

3.3) Executar o OPF descrito em (4.10). Se a política de corte de carga não permitir a realização do redespacho de geração, incluir as restrições de sobrecarga em situações de contingência, conforme (4.15); 
3.4) Avaliar a função desempenho $S\left(\mathbf{X}_{i}\right)$ para todo $\mathbf{X}_{i}$, como definida em (4.22), e ordenar os resultados em ordem decrescente tal que $\mathbf{S}=\left[S_{[1]}, S_{[2]}, \ldots, S_{[N]}\right]$ e $S_{[1]} \geq S_{[2]} \geq \ldots \geq S_{[N]}$.

3.5) Determinar o nível de carga que será considerado na iteração $k, \hat{L}_{k}$. O valor de $\hat{L}_{k}$ será tal que $\hat{L}_{k}:=\mathbf{S}_{[(1-\rho) N]}$. Em que $(1-\rho) N$ é o valor do ponteiro $r . \hat{L}_{k}$ será igual ao valor na $r$-ésima posição do vetor $\mathbf{S}$ caso $\mathbf{S}_{[(1-\rho) N]}>L$. Se $\mathbf{S}_{[(1-\rho) N]} \leq L$, fazer $\hat{L}_{k}:=L ;$

3.6) Avaliar a razão de verossimilhança, da $k$-ésima iteração, para a geração, $\quad \mathbf{W}_{G, k}\left(\mathbf{X}_{G_{i}} ; \mathbf{n}_{G}, \mathbf{u}_{G}, \mathbf{v}_{G, k-1}\right)$, para a transmissão, $\mathbf{W}_{T, k}\left(\mathbf{X}_{T_{i}}, \mathbf{u}_{T}, \mathbf{v}_{T, k-1}\right)$, e, finalmente, para o sistema, $\mathbf{W}\left(\mathbf{X}_{i} ; \mathbf{n}, \mathbf{u}, \hat{\mathbf{v}}_{k-1}\right)$;

3.7) Avaliar a função teste $H\left(\mathbf{X}_{i}\right)=I_{\left\{S\left(\mathbf{X}_{i}\right)<\hat{L}_{k}\right\}}$ para todo $\mathbf{X}_{i}$ e atualizar o vetor de parâmetros de referência da $k$-ésima iteração para a geração, $\hat{\mathbf{v}}_{G, k}$, conforme definido no capítulo anterior, e para a transmissão, $\hat{\mathbf{v}}_{T, k}$ , conforme (4.21). Obter o vetor para o sistema como $\hat{\mathbf{v}}_{k}=\left[\hat{\mathbf{v}}_{G, k}, \hat{\mathbf{v}}_{T, k}\right]$;

3.8) Se $\hat{\gamma}_{k}=\gamma$, então é o fim do processo de otimização baseado no Método CE, ir para o próximo passo. Senão, incrementar o contador de iterações $k:=k+1$; e voltar para o subpasso 3.1;

Passo 4: Este passo consiste em executar uma SMC-IS para avaliar o risco. O vetor $\hat{\mathbf{v}}_{K}$ é o vetor de parâmetros ótimos, onde $k$ foi a última iteração do processo de otimização baseado no método CE. Iniciar a SMC-IS utilizando o vetor de parâmetros ótimos determinados. Fazer o contador de iterações da SMC-IS igual a zero, $N_{1}:=0$; 
4.1) Fazer $N_{1}=N_{1}+1$. Gerar uma amostra $\mathbf{X}_{i}$ de acordo com a pmf $f\left(; \mathbf{n}, \hat{\mathbf{v}}_{K}\right) ;$

4.2) Avaliar a adequação do estado $\mathbf{X}_{i}$. Para isso, executar um fluxo DC. Verificar se há violações ativas. Se nenhuma restrição operativa foi violada pular o próximo subpasso;

4.3) Executar medida corretiva executando o algoritmo de FPO e classificar o estado do sistema;

4.4) De acordo com o resultado da análise de rede determinar $H_{\mathrm{LOLP}}\left(\mathbf{X}_{i}\right)$ , a razão de verossimilhança $\mathbf{W}\left(\mathbf{X}_{N_{1}} ; \mathbf{n}, \mathbf{u}, \hat{\mathbf{v}}_{K}\right)$ e o estimar o risco através do estimador não tendencioso para o índice LOLP:

$$
\hat{\operatorname{Risk}}=\frac{1}{N_{1}} \sum_{i=1}^{N_{1}} H_{\mathrm{LOLP}}\left(\mathbf{X}_{i}\right) \mathbf{W}\left(\mathbf{X}_{i} ; \mathbf{n}, \mathbf{u}, \hat{\mathbf{v}}_{K}\right) .
$$

4.5) Calcular o coeficiente de variação $\beta_{N_{1}}^{\text {LOLP }}$ e ir para o próximo passo se $\beta_{N_{1}}^{\text {LOLP }} \leq \beta_{\text {LOLP ou }} N_{l} \geq N_{M A X}$. Caso contrário, voltar para o subpasso 4.1;

Passo 5: Atualizar montante de reserva da iteração e verificar se o risco obtido é menor que o valor máximo aceitável

$$
\hat{\operatorname{Risk}}(\mathrm{G}, \mathrm{T})<\operatorname{Risk}_{\max }
$$

Em caso afirmativo, definir o valor dimensionado da reserva girante para o sistema como sendo o valor obtido na iteração atual e parar a execução. Caso contrário, ir para o próximo passo;

Passo 6: Verificar se $N_{D}<N_{C}$, ou seja, o sistema ainda possui a capacidade estática que pode ser sincronizada para ser adicionada à parcela da reserva girante (se $N_{D}$ é igual a $N_{C}$ significa que toda a capacidade de geração do 
sistema já está sendo utilizada). Caso seja possível, incluir a próxima unidade, $N_{D}=N_{D}+1$, e retornar para o passo 2. Caso contrário, informar que não foi possível atingir o critério de risco e interromper a execução.

O algoritmo de seis passos do método apresentado, apesar de utilizar os modernos conceitos de otimização por minimização da entropia cruzada, é simples e direto. O primeiro passo do algoritmo consiste basicamente em carregar os dados do sistema. O terceiro passo é um processo de otimização dos parâmetros. Como resultado desse processo obtém-se um conjunto de parâmetros "distorcidos" que serão utilizados na SMC-IS do quarto passo. O quinto passo verifica se o critério de risco foi satisfeito e o sexto atualiza o número de unidades comissionadas.

\section{4.}

\section{Avaliações Numéricas}

Os resultados da aplicação do método descrito na seção anterior para determinação dos montantes de reserva considerando as restrições de capacidade do sistema de transmissão usando a SMC não sequencial são discutidos nesta seção.

O algoritmo de avaliação da reserva girante foi aplicado ao sistema teste IEEE Reliability Test System [87]. Este sistema possui uma capacidade estática de 3405 MW distribuída em suas 32 unidades de geração, cujas capacidades variam de 12 a 400 MW. O diagrama unifilar desse sistema pode ser visto na Figura 4.2.

No IEEE-RTS, o sistema de transmissão é composto por 38 linhas de transmissão conectando 24 barramentos. A capacidade nominal de transmissão das linhas varia numa faixa de 200 a 625 MW (capacidade emergencial, para o curto prazo).

As unidades de geração estão presentes em 10 dos 24 barramentos do sistema. Para os testes descritos neste tópico, foi utilizado um nível de carga de $2850 \mathrm{MW}$, correspondente ao valor do pico anual do sistema. O lead time considerado é de 2 horas, isto é, o despacho é realizado considerando que não será possível adicionar novas máquinas dentro deste intervalo. 


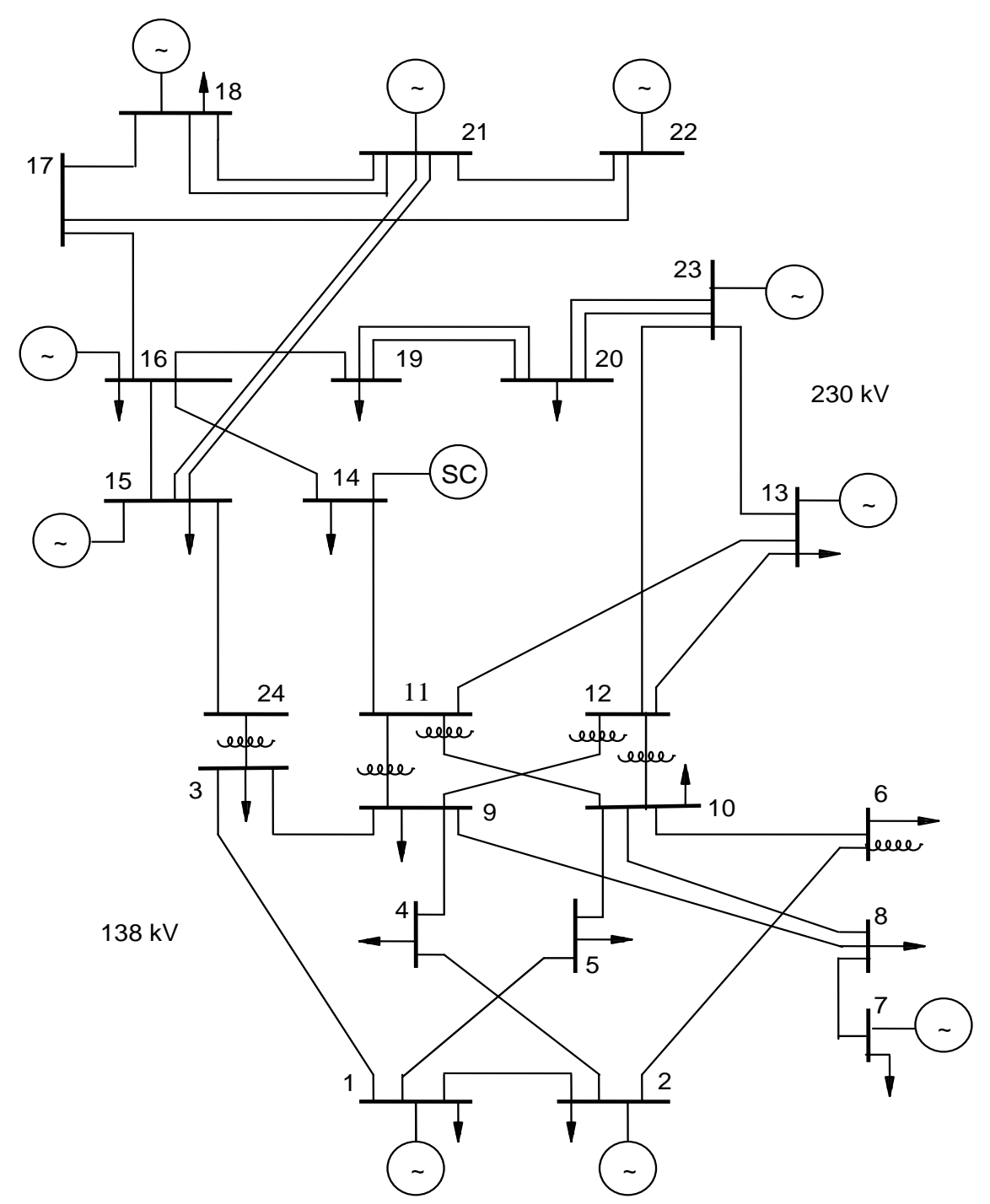

Figura 4.2: IEEE Reliability Test System - RTS [87].

O valor do risco considerado aceitável é de $0,0001\left(10^{-4}\right)$ ou $0,01 \%$. Este é um valor que já foi utilizado na literatura para este sistema teste [17]. Em todos os testes adotou-se como critério de parada o coeficiente de variação $\beta$ inferior a $1 \%$. Em relação aos recursos de computação, as simulações foram realizadas em um PC (computador pessoal - desktop) com um processador Intel Core i5 de $3.10 \mathrm{GHz}$. Para as implementações, usou-se a linguagem de programação FORTRAN 90. Os parâmetros adotados para o método CE foram: $\alpha=0,9999, \rho=0,01$ e N $=8,0 \times 10^{4}$. 


\subsection{1. Comparação dos Métodos de Avaliação do Risco}

Para efeito de comparação, a metodologia proposta foi testada com e sem a utilização de VRT. Em ambas as implementações, isto é, seja por SMC convencional ou por SMC-CE, o risco foi estimado tanto considerando o sistema de transmissão como considerando apenas o sistema de geração (modelo barra única).

Os resultados obtidos, por iteração, podem ser observados na Tabela 4.1. A cada iteração do processo uma unidade de geração é adicionada e o risco é recalculado. O processo é finalizado quando o risco de perda de carga obtido, considerando o sistema de transmissão, é menor que um valor pré-estabelecido ou, caso não seja possível atingi-lo, quando não houver mais reserva estática que possa ser sincronizada.

Como pode ser observado na Tabela 4.1, no início do processo iterativo inclui-se uma quantidade de unidades tal que seja possível suprir a carga. Como a carga é de 2850 MW, inclui-se 20 unidades, uma capacidade total de 2965 MW. Como se pode observar da tabela, o processo continua até que o risco obtido seja inferior ao valor previamente estipulado.

É possível observar, ainda na Tabela 4.1, que o risco obtido ao incluir as restrições e falhas do sistema de transmissão é superior ao risco obtido quando apenas as falhas devido às ocorrências de insuficiência de geração são consideradas. Portanto, é possível perceber que é importante considerar o sistema de transmissão no processo de avaliação dos montantes requeridos de reserva. 
Usando os conceitos do método CE foi possível diminuir significativamente Tabela 4.1: Resultados para o sistema IEEE-RTS 79

\begin{tabular}{|c|c|c|c|c|c|c|c|c|}
\hline \multirow{3}{*}{$N_{D}$} & \multirow{3}{*}{$\begin{array}{l}\text { Cap. } \\
\text { Sinc. } \\
{[\mathrm{MW}]}\end{array}$} & \multirow{3}{*}{$\begin{array}{c}\text { Reserva } \\
\text { Girante } \\
{[\mathrm{MW}]}\end{array}$} & \multicolumn{4}{|c|}{ Índice de Risco } & \multicolumn{2}{|c|}{$\begin{array}{c}\text { Tempo de } \\
\text { Execução [s] }\end{array}$} \\
\hline & & & \multicolumn{2}{|c|}{$\begin{array}{c}\text { SMC } \\
\text { Convencional }\end{array}$} & \multicolumn{2}{|c|}{$\begin{array}{l}\mathrm{SMC} \\
\mathrm{CE}\end{array}$} & \multirow{2}{*}{$\begin{array}{l}\text { SMC } \\
\text { Conv. }\end{array}$} & \multirow{2}{*}{$\begin{array}{l}\text { SMC } \\
\text { CE }\end{array}$} \\
\hline & & & $\mathrm{G}$ & G\&T & G & G\&T & & \\
\hline 20 & 2965 & 115 & 0,020123 & 0,020408 & 0,019652 & 0,020195 & 8,5 & 1,8 \\
\hline 21 & 3065 & 215 & 0,005644 & 0,005904 & 0,005727 & 0,005798 & 29,9 & 6,4 \\
\hline 22 & 3165 & 315 & 0,005383 & 0,005578 & 0,005354 & 0,005595 & 31,4 & 6,4 \\
\hline 23 & 3265 & 415 & 0,000160 & 0,000356 & 0,000159 & 0,000353 & 504,4 & 21,7 \\
\hline 24 & 3277 & 427 & 0,000154 & 0,000351 & 0,000154 & 0,000353 & 504,2 & 26,6 \\
\hline 25 & 3289 & 439 & 0,000149 & 0,000345 & 0,000149 & 0,000346 & 508,3 & 22,4 \\
\hline 26 & 3301 & 451 & 0,000123 & 0,000323 & 0,000119 & 0,000313 & 543,2 & 26,4 \\
\hline 27 & 3313 & 463 & 0,000120 & 0,000317 & 0,000121 & 0,000322 & 561,8 & 23,7 \\
\hline 28 & 3325 & 475 & 0,000119 & 0,000315 & 0,000124 & 0,000322 & 568,3 & 25,3 \\
\hline 29 & 3345 & 495 & 0,000106 & 0,000304 & 0,000108 & 0,000306 & 598,4 & 29,3 \\
\hline 30 & 3365 & 515 & 0,000077 & 0,000277 & 0,000073 & 0,000275 & 655,4 & 35,3 \\
\hline 31 & 3385 & 535 & 0,000075 & 0,000273 & 0,000073 & 0,000272 & 666,1 & 28,5 \\
\hline 32 & 3405 & 555 & 0,000034 & 0,000233 & 0,000035 & 0,000230 & 783,6 & 53,1 \\
\hline
\end{tabular}

o esforço computacional da SMC. O tempo de execução da avaliação do risco para cada configuração pode ser observado na Figura 4.3. Nas duas últimas colunas da Tabela 4.1, pode-se observar os tempos de execução de cada passo do processo iterativo (referentes às colunas G\&T de cada simulação).

O tempo de execução total do algoritmo foi de 5963,5 segundos para a SMC convencional e de 306,7 s para a SMC-CE. O ganho computacional (speed-up) obtido ao usar o método CE foi de 19,44, i.e., o algoritmo que utilizou o método CE foi cerca de vinte vezes mais rápido que o algoritmo da SMC convencional. Como foi demonstrado através dos resultados obtidos, é possível aumentar significativamente a eficiência computacional ao usar a SMC-CE. Nos testes dos próximos itens será utilizado este método para avaliar o risco de perda de carga do sistema. 


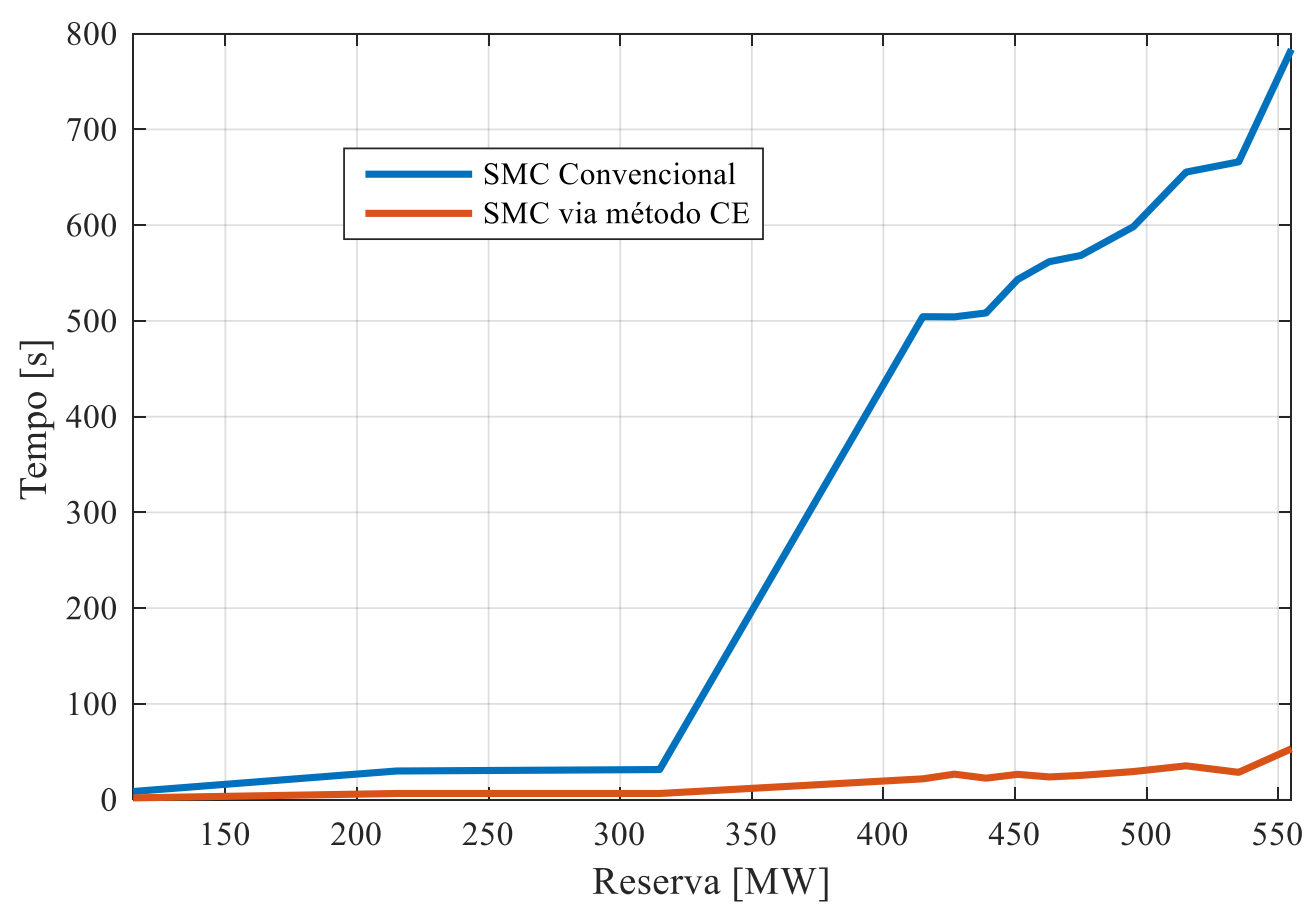

Figura 4.3: Tempo de simulação: SMC convencional $\times$ SMC-CE

\subsection{2. Impacto da Estratégia de Corte de Carga}

A política de corte de carga pode impactar no índice de risco. Usualmente, o corte de carga é a última medida a ser tomada, uma vez que em situações desse tipo o sistema está deixando de desempenhar sua função. No entanto, na operação a curto prazo o operador muitas vezes não dispõe de capacidade de executar o redespacho de geração, caso haja sobrecarga em alguma linha de transmissão.

Não sendo possível evitar o corte de carga, a solução prática viável é efetuar a rejeição de carga na própria região elétrica onde há problemas (sobrecarga, insuficiência de geração, etc.), ou seja, efetuar um corte de carga local (evitando tentativas de redespacho da geração).

A implementação da estratégia de corte da carga locacional foi possível adicionando a restrição representada pela equação (4.15) no algoritmo de análise da adequação do sistema. $\mathrm{O}$ risco obtido para as duas estratégias, i.e., com ou sem redespacho de geração, são mostrados na Tabela 4.2. As simulações dessa tabela 
Tabela 4.2: Efeito da política de corte de carga

\begin{tabular}{|c|c|c|c|c|c|}
\hline \hline & & & \multicolumn{3}{|c|}{ Índice de Risco } \\
\cline { 5 - 6 }$N_{D}$ & $\begin{array}{c}\text { Reserva } \\
\text { Girante } \\
{[\mathrm{MW}]}\end{array}$ & $\begin{array}{c}\text { Cap. } \\
\text { Sinc. } \\
{[\mathrm{MW}]}\end{array}$ & $\mathrm{G}$ & $\begin{array}{c}\text { G\&T } \\
\text { Com } \\
\text { Redespacho }\end{array}$ & $\begin{array}{c}\text { G\&T } \\
\text { Sem } \\
\text { Redespacho }\end{array}$ \\
\hline 20 & 115,0 & 2965,0 & 0,02012154 & 0,02019514 & 0,02019514 \\
\hline 21 & 215,0 & 3065,0 & 0,00550092 & 0,00579725 & 0,00579799 \\
\hline 22 & 315,0 & 3165,0 & 0,00549478 & 0,00541622 & 0,00559522 \\
\hline 23 & 415,0 & 3265,0 & 0,00015655 & 0,00016055 & 0,00035342 \\
\hline 24 & 427,0 & 3277,0 & 0,00015145 & 0,00014989 & 0,00035321 \\
\hline 25 & 439,0 & 3289,0 & 0,00015167 & 0,00015168 & 0,00034655 \\
\hline 26 & 451,0 & 3301,0 & 0,00011981 & 0,00012156 & 0,00031393 \\
\hline 27 & 463,0 & 3313,0 & 0,00012061 & 0,00012162 & 0,00032207 \\
\hline 28 & 475,0 & 3325,0 & 0,00012158 & 0,00011881 & 0,00032168 \\
\hline 29 & 495,0 & 3345,0 & 0,00010552 & 0,00010708 & 0,00030579 \\
\hline 30 & 515,0 & 3365,0 & 0,00007431 & 0,00007318 & 0,00027460 \\
\hline 31 & 535,0 & 3385,0 & --- & -- & 0,00027162 \\
\hline 32 & 555,0 & 3405,0 & --- & -- & 0,00023019 \\
\hline \hline
\end{tabular}

foram realizadas em um tempo de aproximadamente cinco minutos (cada coluna é referente a uma simulação).

Os resultados da Tabela 4.2 são ilustrados no gráfico da Figura 4.4. É possível observar que se fosse possível efetuar o redespacho, as restrições do sistema de transmissão não provocariam impacto significativo no índice de risco de corte de carga. Essa situação reflete um sistema de transmissão operando com uma relativa "distância" dos seus limites, uma vez que pouquíssimos casos da simulação causaram corte de carga devido sobrecarga em linha.

Ao permitir o corte de carga locacional, reflexo da limitação do operador sistema (que é incapaz de alterar em um pequeno intervalo de tempo a geração de várias unidades do sistema), o impacto no índice de risco torna-se evidente.

É possível observar que no início do processo iterativo, como poucas unidades de geração são sincronizadas, as falhas são predominantemente devido à insuficiência de geração. O risco obtido considerando as falhas na transmissão apresenta valores muito próximos do risco calculado considerando apenas falhas na geração. 
À medida que são adicionadas unidades (aumentando assim o montante de

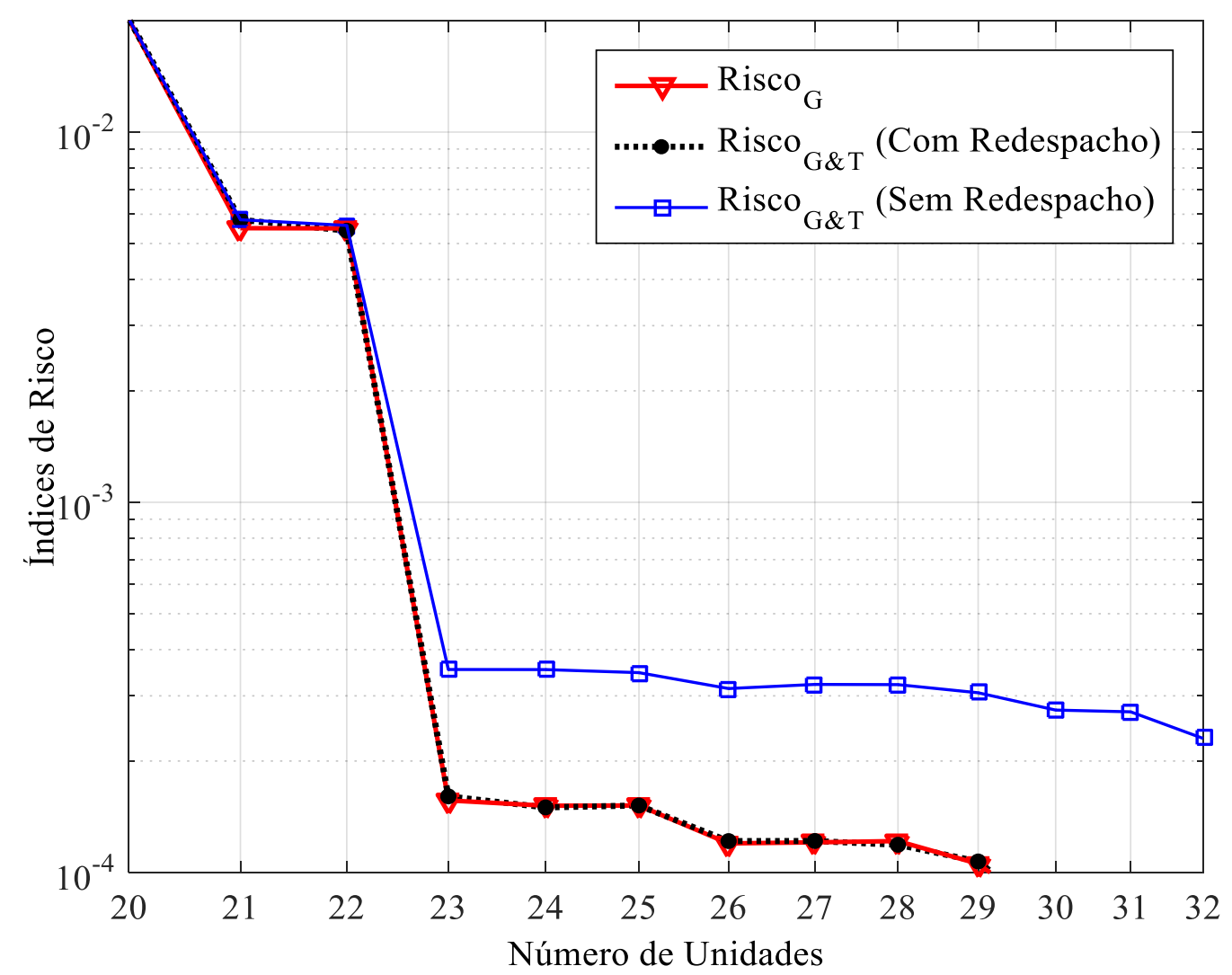

Figura 4.4: Impacto da estratégia de corte de carga no risco.

reserva de geração), diminui-se significativamente o risco associado a falhas na geração (Risco G). No entanto, o mesmo resultado não pode ser observado para o "Risco G\&T sem Redespacho", pois os valores do risco são cada vez maiores que o seu equivalente "Risco G". Isto ocorre porque os problemas do sistema tornamse predominantemente um efeito das falhas e restrições na transmissão e não na geração.

\subsection{3.}

Restrições de Capacidade das Linhas de Transmissão

Na Tabela 4.3 é possível observar o risco para diferentes cenários do sistema de transmissão (sem redespacho de geração). Em cada um dos cenários as capacidades de transmissão das linhas foram reduzidas para um percentual do seu valor nominal em regime de operação normal. 
Tabela 4.3: Índice de risco em função da capacidade de transmissão

\begin{tabular}{|c|c|c|c|c|c|}
\hline \hline$N_{D}$ & $\begin{array}{c}\text { Reserva } \\
\text { Girante } \\
{[\mathrm{MW}]}\end{array}$ & $\Delta C_{T}=-30 \%$ & $\Delta C_{T}=-20 \%$ & $\Delta C_{T}=-10 \%$ & $\Delta C_{T}=0 \%$ \\
\hline \hline 20 & 115 & 1,00000000 & 1,00000000 & 0,02504991 & 0,02019514 \\
\hline 21 & 215 & 0,01458429 & 0,00847957 & 0,00598379 & 0,00579799 \\
\hline 22 & 315 & 0,01317518 & 0,00625006 & 0,00579085 & 0,00559522 \\
\hline 23 & 415 & 0,00521497 & 0,00467359 & 0,00044912 & 0,00035342 \\
\hline 24 & 427 & 0,00523018 & 0,00466290 & 0,00044938 & 0,00035321 \\
\hline 25 & 439 & 0,00514014 & 0,00111660 & 0,00045190 & 0,00034655 \\
\hline 26 & 451 & 0,00522035 & 0,00110824 & 0,00043814 & 0,00031393 \\
\hline 27 & 463 & 0,00507833 & 0,00111814 & 0,00043762 & 0,00032207 \\
\hline 28 & 475 & 0,00169923 & 0,00110629 & 0,00043776 & 0,00032168 \\
\hline 29 & 495 & 0,00275868 & 0,00110431 & 0,00041933 & 0,00030579 \\
\hline 30 & 515 & 0,00152006 & 0,00106692 & 0,00038579 & 0,00027460 \\
\hline 31 & 535 & 0,00149419 & 0,00105667 & 0,00038203 & 0,00027162 \\
\hline 32 & 555 & 0,00149791 & 0,00096336 & 0,00036550 & 0,00023019 \\
\hline \hline \multicolumn{2}{|c|}{ Tempo de } & 1100,76 & 994,43 & 444,13 & 306,78 \\
\hline \multirow{2}{*}{ Execução [s] } & & & &
\end{tabular}

Há um aumento expressivo do risco quando as capacidades de transmissão das LTs do sistema são reduzidas. Em nenhuma das configurações do sistema (isto é, com menos $10 \%, 20 \%$ e $30 \%$ de capacidade de transmissão) foi possível obter um risco menor que $10^{-4}$ (valor especificado), mesmo sincronizando todas as unidades. Trata-se, portanto, de um efeito claro da degradação do sistema de transmissão.

Os tempos de execução total das simulações são apresentados na última linha da Tabela 4.3. É possível observar que quanto maiores as restrições de capacidade de transmissão maior é o tempo computacional das simulações. Isso ocorre porque uma parcela significativa deste tempo é dedicada à análise de adequação da rede que necessita de mais iterações para convergir quando as variáveis estão próximas dos seus limites. 
Tabela 4.4: Impacto da $\mathrm{ORR}_{T}$ no índice de risco

\begin{tabular}{|c|c|c|c|c|c|c|}
\hline \hline$N_{D}$ & $\begin{array}{c}\text { Reserva } \\
\text { Girante } \\
{[\mathrm{MW}]}\end{array}$ & $1 \times \mathrm{ORR}_{T}$ & $2 \times \mathrm{ORR}_{T}$ & $3 \times \mathrm{ORR}_{T}$ & $4 \times \mathrm{ORR}_{T}$ & $5 \times \mathrm{ORR}_{T}$ \\
\hline 20 & 115 & 0,02019514 & 0,02060114 & 0,02088163 & 0,02104390 & 0,02132070 \\
\hline 21 & 215 & 0,00579799 & 0,00599480 & 0,00625598 & 0,00651246 & 0,00687133 \\
\hline 22 & 315 & 0,00559522 & 0,00585344 & 0,00599566 & 0,00613784 & 0,00637128 \\
\hline 23 & 415 & 0,00035342 & 0,00054389 & 0,00074058 & 0,00093119 & 0,00113592 \\
\hline 24 & 427 & 0,00035321 & 0,00054512 & 0,00075551 & 0,00094244 & 0,00113973 \\
\hline 25 & 439 & 0,00034655 & 0,00055339 & 0,00073784 & 0,00092977 & 0,00114581 \\
\hline 26 & 451 & 0,00031393 & 0,00051994 & 0,00070959 & 0,00091948 & 0,00110740 \\
\hline 27 & 463 & 0,00032207 & 0,00051694 & 0,00071079 & 0,00090613 & 0,00112630 \\
\hline 28 & 475 & 0,00032168 & 0,00051825 & 0,00072382 & 0,00090707 & 0,00112127 \\
\hline 29 & 495 & 0,00030579 & 0,00050587 & 0,00070027 & 0,00090729 & 0,00110105 \\
\hline 30 & 515 & 0,00027460 & 0,00047444 & 0,00067266 & 0,00080042 & 0,00098623 \\
\hline 31 & 535 & 0,00027162 & 0,00047502 & 0,00068142 & 0,00085992 & 0,00100071 \\
\hline 32 & 555 & 0,00023019 & 0,00039540 & 0,00059272 & 0,00079035 & 0,00099160 \\
\hline \hline & Tempo de & 306,78 & 377,43 & 514,44 & 474,80 & 797,98 \\
\hline \multirow{5}{*}{ Execução [s] } & & & & &
\end{tabular}

\subsection{4.}

\section{Efeito das Falhas em Linhas de Transmissão}

Falhas no sistema de transmissão podem resultar em corte de carga. Nestes casos, o não suprimento da demanda não ocorre por insuficiência de geração, mas por incapacidade de transporte do fornecimento, ou seja, um efeito das falhas do sistema de transmissão.

A taxa de substituição da $\mathrm{LT}\left(\mathrm{ORR}_{T}\right)$ representa a probabilidade de ocorrências de falhas sem a possibilidade de reparo. $\mathrm{Na}$ Tabela 4.4, apresenta-se o efeito da variação da ORR no índice de risco (o redespacho de geração está desativado neste teste). Como se pode observar, o risco de corte de carga é função também da ORR das linhas de transmissão. Nos testes realizados multiplicou-se a $\mathrm{ORR}_{T}$ por um fator de dois a cinco.

Em [48], propõe-se o dimensionamento e alocação da reserva girante considerando as restrições do sistema de transmissão, mas desprezando a possível saída 


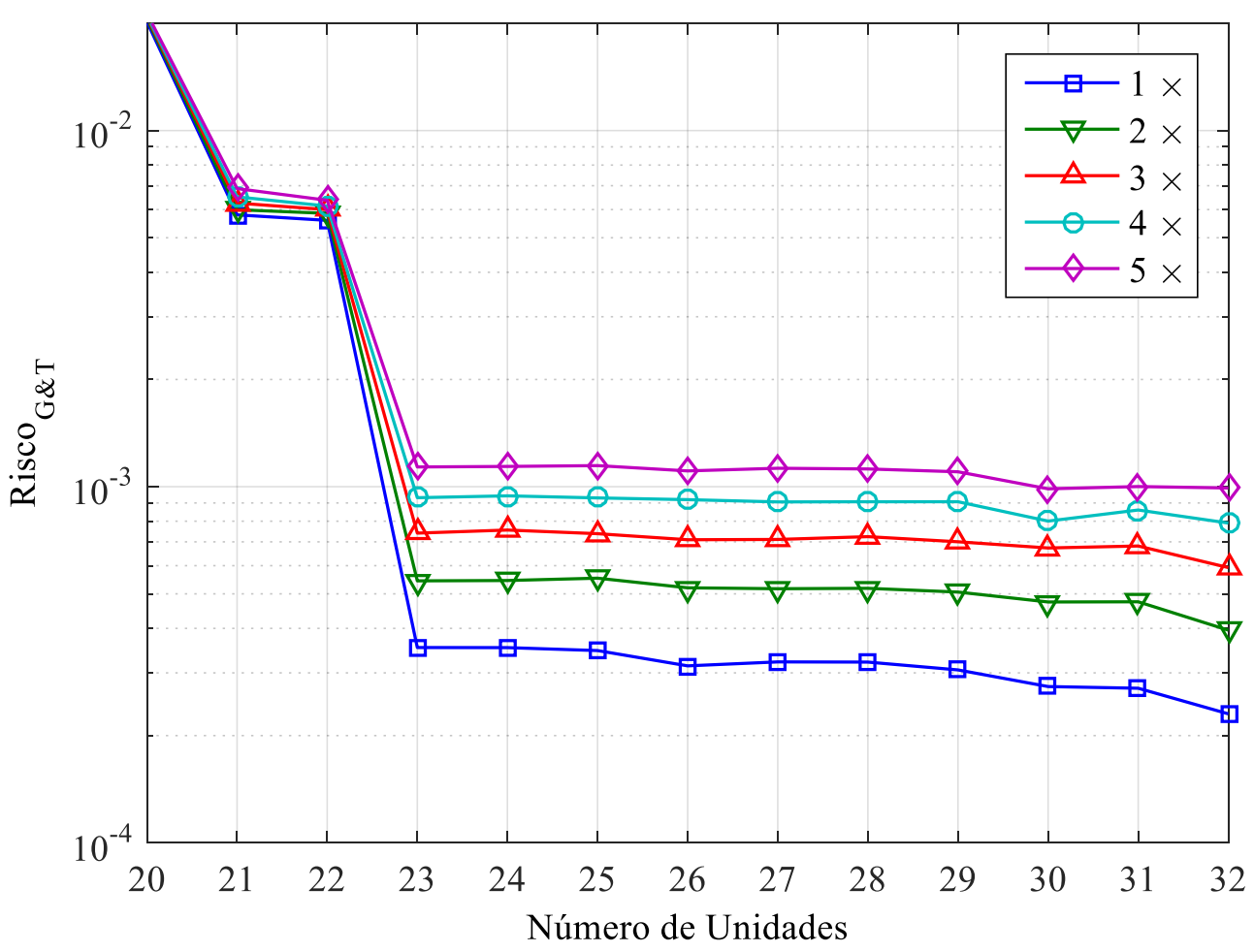

Figura 4.5: Índices de risco em função da ORR da transmissão

de linhas de transmissão. Os valores de risco da Tabela 4.5 foram obtidos desabilitando a possibilidade de falhas em LT na simulação, i.e., a probabilidade de falhas das linhas foi admitida como sendo igual a zero. É possível observar claramente, por meio da Figura 4.5, a degradação do risco em consequência do aumento da ORR das linhas de transmissão.

Comparando-se as Tabela 4.3 e Tabela 4.5, pode-se perceber que para cada configuração simulada (cada linha das tabelas), os riscos obtidos ao se considerar as falhas na LT (Tabela 4.3) apresentam valores superiores aos correspondentes da Tabela 4.5. Esse resultado permite concluir que as falhas na transmissão só podem ser desprezadas em sistemas com linhas de transmissão altamente confiáveis, pois nestes casos a frequência de falhas pode não trazer prejuízo aos resultados. Tratase, portanto, de um caso particular.

Um resultado importante é que uma parcela da reserva girante é alocada com o intuito de minimizar o risco de não suprimento devido às falhas das linhas de transmissão e uma parcela pode ser atribuída às restrições de transporte do sistema de transmissão. 
Tabela 4.5: Índice de risco desconsiderando falhas nas LTs

\begin{tabular}{|c|c|c|c|c|c|}
\hline \hline$N_{D}$ & $\begin{array}{c}\text { Reserva } \\
\text { Girante } \\
{[\mathrm{MW}]}\end{array}$ & $\Delta C_{T}=-30 \%$ & $\Delta C_{T}=-20 \%$ & $\Delta C_{T}=-10 \%$ & $\Delta C_{T}=0 \%$ \\
\hline \hline 20 & 115 & 1,00000000 & 1,00000000 & 0,02399164 & 0,02012154 \\
\hline 21 & 215 & 0,01324662 & 0,00713991 & 0,00549836 & 0,00550092 \\
\hline 22 & 315 & 0,01174270 & 0,00539867 & 0,00549478 & 0,00549478 \\
\hline 23 & 415 & 0,00369084 & 0,00371174 & 0,00015685 & 0,00015655 \\
\hline 24 & 427 & 0,00353184 & 0,00371592 & 0,00015780 & 0,00015145 \\
\hline 25 & 439 & 0,00373575 & 0,00016426 & 0,00015839 & 0,00015167 \\
\hline 26 & 451 & 0,00364073 & 0,00014972 & 0,00014495 & 0,00011981 \\
\hline 27 & 463 & 0,00362857 & 0,00015028 & 0,00014034 & 0,00012061 \\
\hline 28 & 475 & 0,00019483 & 0,00014172 & 0,00014033 & 0,00012158 \\
\hline 29 & 495 & 0,00019756 & 0,00014205 & 0,00012084 & 0,00010552 \\
\hline 30 & 515 & 0,00017092 & 0,00010263 & 0,00008770 & 0,00007431 \\
\hline 31 & 535 & 0,00016649 & 0,00010125 & 0,00008873 & 0,00007443 \\
\hline 32 & 555 & 0,00014704 & 0,00008741 & 0,00007387 & 0,00003443 \\
\hline \hline \multicolumn{2}{|c|}{ Tempo de } & 635,47 & 414,54 & 90,14 & 56,85 \\
\hline Execução [s] & & & & \\
\hline \hline
\end{tabular}

\section{5. \\ Requisitos Mínimos de Reserva Girante em Função do Risco}

Com o aumento da carga o sistema de transmissão, em geral, tende a operar mais carregado, sendo levado a permanecer cada vez mais próximo dos seus limites. Para representar essas condições, nos testes dos próximos itens aumenta-se a carga e a capacidade de geração, mantendo a capacidade de transporte e a taxa de falha das linhas como no sistema original.

Os resultados são apresentados nas Tabela 4.6, Tabela 4.7 e Tabela 4.8. Cada linha dessas tabelas representa um teste realizado com o sistema IEEE-RTS em que a capacidade total de geração e a carga são incrementadas em um fator de $10 \%$ em relação ao sistema original.

Como tem sido enfatizado, dependendo das considerações de representação do sistema, o índice de risco pode refletir ou não o grau de adequação ou a capacidade de suprir adequadamente a demanda de forma contínua. O montante de reserva 
girante dimensionado, considerando as falhas e restrições do sistema de transmissão, deve refletir apropriadamente as limitações operativas.

Através do adequado dimensionamento de reserva de geração é possível aumentar a segurança sistêmica de forma a evitar eventos de corte de carga que seriam causados por contingências no sistema de transmissão.

\subsection{1. \\ Dimensionamento da Reserva via Modelo Barra Única}

Na Tabela 4.6 estão os resultados obtidos, isto é, o montante de reserva, para o modelo barra única. Neste caso, o critério considerado é o risco G, i.e., o algoritmo de determinação da reserva usará o risco de perda de carga considerando apenas o sistema de geração para convergir o processo iterativo.

Para efeito de comparação são dados: o risco obtido devido a falhas apenas no sistema de geração (Risco G), o risco considerando o sistema de transmissão com a possibilidade de efetuar redespacho como medida corretiva (Risco G\&T Com Redespacho) e o risco considerando sistema de transmissão e sem redespacho (Risco G\&T - Sem Redespacho).

Tabela 4.6: Dimensionamento da reserva - Modelo barra única

\begin{tabular}{|c|c|c|c|c|c|c|}
\hline \multirow{2}{*}{$\begin{array}{l}\Delta \mathrm{LG} \\
{[\%]}\end{array}$} & \multirow{2}{*}{$\begin{array}{c}\text { Cap. } \\
\text { Estática } \\
{[\mathrm{MW}]} \\
\end{array}$} & \multirow{2}{*}{$\begin{array}{l}\text { Carga } \\
{[\mathrm{MW}]}\end{array}$} & \multirow{2}{*}{$\begin{array}{c}\text { Reserva } \\
{[\mathrm{MW}]}\end{array}$} & \multicolumn{3}{|c|}{ Índice de Risco } \\
\hline & & & & $\begin{array}{c}\mathrm{G} \\
\text { (Considerado) }\end{array}$ & $\begin{array}{l}\text { G\&T - Com } \\
\text { Redespacho }\end{array}$ & $\begin{array}{l}\text { G\&T - Sem } \\
\text { Redespacho }\end{array}$ \\
\hline 0 & 3405,0 & 2850 & 515,0 & 0,00007431 & 0,00007318 & 0,00027460 \\
\hline 10 & 3745,5 & 3135 & 566,5 & 0,00007370 & 0,00008910 & 0,00038400 \\
\hline 20 & 4086,0 & 3420 & 618,0 & 0,00007370 & 0,00010559 & 0,00079739 \\
\hline 30 & 4426,5 & 3705 & 669,5 & 0,00007370 & 0,00011507 & 0,00107567 \\
\hline 40 & 4767,0 & 3990 & 721,0 & 0,00007370 & 0,00063728 & 0,00150281 \\
\hline 50 & 5107,5 & 4275 & 772,5 & 0,00007431 & 0,00673977 & 0,00787132 \\
\hline 60 & 5448,0 & 4560 & 824,0 & 0,00007431 & 0,00887401 & 0,00962505 \\
\hline 70 & 5788,5 & 4845 & 875,5 & 0,00007431 & 0,02104781 & 0,02313430 \\
\hline 80 & 6129,0 & 5130 & 927,0 & 0,00007431 & 0,02324507 & 0,02351268 \\
\hline 90 & 6469,5 & 5415 & 978,5 & 0,00007431 & 0,03278879 & 0,03211347 \\
\hline 100 & 6810,0 & 5700 & 1030,0 & 0,00007431 & 1,00000000 & 1,00000000 \\
\hline
\end{tabular}


Embora não mostrado na tabela, em todas as configurações testadas, obtevese como resultado um total de 30 unidades comissionadas e foi alcançado praticamente o mesmo valor de risco (i.e., aproximadamente $7,4 \times 10^{-5}$ ). Assim, observa-se que esse índice de risco pouco reflete as características reais do sistema, uma vez que o nível de carregamento das linhas de transmissão foi significativamente alterado e essas modificações não apresentaram impacto no risco de perda de carga do sistema.

Caso as falhas no sistema de transmissão tivessem sido consideradas, o risco seria capaz de refletir a alteração do nível de carregamento, como mostrado nas duas últimas colunas da Tabela 4.6.

\subsection{2. Reserva Considerando o Sistema de Transmissão e Redespacho de Geração}

Neste item são descritos os resultados obtidos ao realizar os mesmos testes anteriores, com a diferença de utilizar o risco obtido considerando o sistema de transmissão e habilitando o redespacho da geração como medida corretiva.

Na Tabela 4.7 estão os resultados do processo ao considerar o "Risco G\&T com Redespacho" como critério de parada. Nos testes com incremento de carga de 10 e 20 por cento, embora o risco tenha sido superior ao risco do modelo barra única, o mesmo número de unidades foi comissionado. Nos testes com $\Delta$ de $30 \mathrm{e}$ 40 por cento foram 32 unidades, duas unidades foram adicionadas como reserva devido a falhas da transmissão. Para $\Delta$ acima de $30 \%$, o risco torna-se superior ao valor máximo aceitável, mesmo com todas as 32 unidades sincronizadas.

A antepenúltima e a última coluna da Tabela 4.7 apresentam os valores do índice de risco calculados para a configuração do sistema obtida após o dimensionamento da reserva. Estes valores foram calculados para que pudessem ser comparados, por motivos didáticos, com o critério de risco adotado. No entanto, estes valores não foram usados no processo de dimensionamento.

É possível observar que o "Risco G” é sensível ao número de unidades, pois foi de $7,4 \times 10^{-5}$ para $3,4 \times 10^{-5}$ quando o número de unidade foi aumentado de 30 para 32. No entanto, é insensível às variações de carga quando há o proporcional incremento de geração. O "Risco G\&T" responde racionalmente aos incrementos de carga, refletindo o aumento das condições de estresse do sistema em geral. 
Tabela 4.7: Reserva - Considerando risco G\&T com redespacho

\begin{tabular}{|c|c|c|c|c|c|c|}
\hline \hline & \multirow{2}{*}{$\begin{array}{c}\text { Cap. } \\
{[\%]}\end{array}$} & \multirow{2}{*}{$\begin{array}{c}\text { Estática } \\
{[\mathrm{MW}]}\end{array}$} & \multirow{2}{*}{$\begin{array}{c}\text { Carga } \\
{[\mathrm{MW}]}\end{array}$} & $\begin{array}{c}\text { Reserva } \\
\left(N_{D}\right) \\
{[\mathrm{MW}]}\end{array}$ & \multicolumn{4}{|c|}{ Índice de Risco } \\
\cline { 6 - 8 } & & $\mathrm{G}$ & $\begin{array}{c}\text { G\&T - Com } \\
\text { Redespacho }\end{array}$ & $\begin{array}{c}\text { G\&T - Sem } \\
\text { Redespacho }\end{array}$ \\
\hline 0 & 3405,0 & 2850 & $515,0(30)$ & 0,00007431 & 0,00007318 & 0,00027460 \\
\hline 10 & 3745,5 & 3135 & $566,5(30)$ & 0,00007370 & 0,00008910 & 0,00038400 \\
\hline 20 & 4086,0 & 3420 & $642,0(30)$ & 0,00007442 & 0,00008847 & 0,00080045 \\
\hline 30 & 4426,5 & 3705 & $721,5(32)$ & 0,00003448 & 0,00009220 & 0,00097223 \\
\hline 40 & 4767,0 & 3990 & $777,0(32)$ & 0,00003433 & 0,00042335 & 0,00149357 \\
\hline \hline
\end{tabular}

\subsection{3. \\ Reserva Considerando o Sistema de Transmissão e sem Redespa- cho}

Por fim, neste item utiliza-se o risco G\&T com redespacho como critério de dimensionamento. Os resultados caso o critério de risco considerado não permita redespacho da geração como medida corretiva são apresentados na Tabela 4.8 e na Figura 4.6. Em todos esses testes não foi possível satisfazer a condição de risco mesmo com as 32 unidades do sistema sendo comissionadas.

Como dito anteriormente, ao aumentar o nível de carregamento o sistema de transmissão é levado a operar próximo dos seus limites de capacidade. Isso faz com que situações de sobrecarga em linhas de transmissão tornem-se frequentes. É natural que o índice de risco deva refletir esse tipo de ocorrência, no entanto, isso não ocorre com o risco obtido via modelo barra única (como pode ser observado na Tabela 4.8 - coluna relativa ao Risco G). Ao incluir a rede de transmissão na avaliação do risco foi possível sensibilizar o índice para refletir esse tipo de ocorrência.

Ao aumentar o nível de carregamento pode-se observar que o risco obtido considerando o redespacho de geração torna-se cada vez mais próximo do índice de risco obtido sem permitir o redespacho. Isso ocorre porque quanto mais carregadas estiverem as linhas, mais difícil será efetuar o redespacho. Ao observar as duas últimas colunas da Tabela 4.8 pode-se observar esse fenômeno tornando-se cada vez mais evidente à medida que a geração e a carga crescem. 
Tabela 4.8: Reserva - Considerando risco G\&T sem redespacho

\begin{tabular}{|c|c|c|c|c|c|c|}
\hline \multirow[b]{2}{*}{$\begin{array}{c}\Delta \mathrm{LG} \\
{[\%]}\end{array}$} & \multirow{2}{*}{$\begin{array}{l}\text { Cap. } \\
\text { Estática } \\
{[\mathrm{MW}]}\end{array}$} & \multirow{2}{*}{$\begin{array}{l}\text { Carga } \\
{[\mathrm{MW}]}\end{array}$} & \multirow{2}{*}{$\begin{array}{l}\text { Reserva } \\
{[\mathrm{MW}]}\end{array}$} & \multicolumn{3}{|c|}{ Índice de Risco } \\
\hline & & & & G & $\begin{array}{l}\text { G\&T - Com } \\
\text { Redespacho }\end{array}$ & $\begin{array}{l}\text { G\&T - Sem Re- } \\
\text { despacho }\end{array}$ \\
\hline 0 & 3405,0 & 2850 & 555,00 & 0.00003448 & 0.00003399 & 0,00023019 \\
\hline 10 & 3745,5 & 3135 & 610,50 & 0,00003433 & 0,00007317 & 0,00036762 \\
\hline 20 & 4086,0 & 3420 & 666,00 & 0,00003433 & 0,00008794 & 0,00069171 \\
\hline 30 & 4426,5 & 3705 & 721,50 & 0,00003448 & 0,00009220 & 0,00097223 \\
\hline 40 & 4767,0 & 3990 & 777,00 & 0,00003433 & 0,00042335 & 0,00149357 \\
\hline 50 & 5107,5 & 4275 & 832,50 & 0,00003448 & 0,00672175 & 0,00790112 \\
\hline 60 & 5448,0 & 4560 & 888,00 & 0,00003443 & 0,00849318 & 0,00963426 \\
\hline 70 & 5788,5 & 4845 & 943,50 & 0,00003447 & 0,01483129 & 0,02309457 \\
\hline 80 & 6129,0 & 5130 & 999,00 & 0,00003443 & 0,02240266 & 0,02341572 \\
\hline 90 & 6469,5 & 5415 & 1054,50 & 0,00003447 & 0,02395244 & 0,02352749 \\
\hline 100 & 6810,0 & 5700 & 1110,00 & 0,00003441 & 0,03313174 & 0,03301049 \\
\hline
\end{tabular}

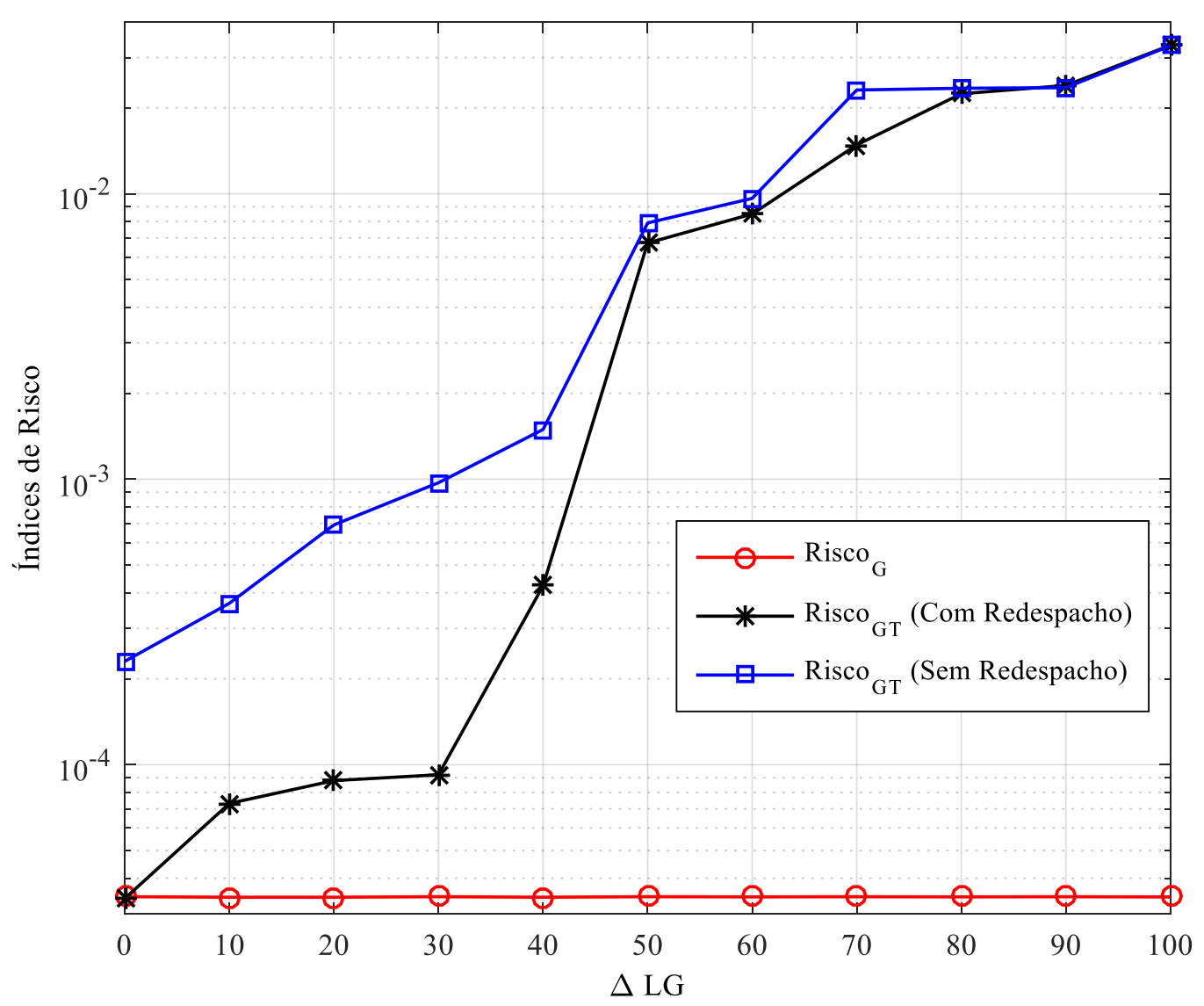

Figura 4.6: Impacto das medidas corretivas nos índices de risco 
Nos cenários com $\Delta$ igual $90 \%$ e $100 \%$, o risco torna-se praticamente igual para ambas as situações (i.e., com ou sem redespacho). Isso significa que para carregamentos maiores que $90 \%$ não é possível adequar o sistema, mesmo tentando efetuar o redespacho.

Ao observar a primeira linha das tabelas Tabela 4.6 e Tabela 4.8 ( $\Delta$ igual a $10 \%$ ) conclui-se que, para o critério de risco aceitável de $1,0 \times 10^{-4}$, o montante de reserva girante dimensionado foi de 566,50 MW para o modelo barra única e de 610,50 MW para o modelo com sistema de transmissão (sem adotar redespacho como medida corretiva). Trata-se, portanto, de um adicional de 44,00 MW de reserva que está sendo comissionada para habilitar o operador a ter capacidade de manobra de forma a evitar eventos de corte de carga que seriam causados por contingências no sistema de transmissão.

\section{6.}

\section{Impacto das Perdas no Sistema de Transmissão}

Com o intuito de tornar claras as comparações com ou sem a representação das linhas de transmissão, o montante de perdas foi desconsiderado. No entanto, a inclusão das perdas nas linhas de transmissão é um aspecto importante, principalmente ao lidar com sistemas de transmissão de grande porte, onde a geração pode estar distante dos centros de consumo e consequentemente as perdas durante o transporte da energia podem ser significativas.

Neste tópico será analisado o impacto das perdas de transmissão nos índices de risco. Uma breve descrição da modelagem utilizada na representação das perdas é dada a seguir.

\subsection{1.}

\section{Perdas de Transmissão no Modelo Linearizado}

O fluxo de potência entre as barras k e m pode ser obtido pela expressão,

$$
\begin{gathered}
P_{k m}=V_{k}^{2} g_{k m}-V_{k} V_{m} g_{k m} \cos \theta_{k m}-V_{k} V_{m} b_{k m} \operatorname{sen} \theta_{k m}, \\
P_{m k}=V_{m}^{2} g_{k m}-V_{k} V_{m} g_{k m} \cos \theta_{k m}+V_{k} V_{m} b_{k m} \operatorname{sen} \theta_{k m} .
\end{gathered}
$$


Considerando as tensões nas barras como sendo unitárias, e para pequenas excursões de ângulo entre barras adjacentes, tem-se $\operatorname{sen} \theta_{k m} \cong \theta_{k m} \mathrm{e}$ $\cos \theta_{k m} \cong 1-\theta_{k m}^{2} / 2$. Considerando $r_{k m}<<x_{k m}$ pode-se chegar nas equações $g_{k m}=\frac{r_{k m}}{r_{k m}^{2}+x_{k m}^{2}}$ e $b_{k m}=-1 / x_{k m}$. Logo, os fluxos entre as barras podem ser estimados por

$$
\begin{aligned}
& P_{k m}=g_{k m} \theta_{k m}^{2} / 2+\theta_{k m} / x_{k m}, \\
& P_{m k}=g_{k m} \theta_{k m}^{2} / 2-\theta_{k m} / x_{k m} .
\end{aligned}
$$

Pode-se interpretar as expressões $P_{k m}$ e $P_{m k}$ como o somatório do fluxo transmitido no ramo com uma componente de perdas de valor igual a $g_{k m} \theta_{k m}^{2} / 2$. Desta forma, $P_{k m}$ e $P_{m k}$ carregam, cada uma, a metade das perdas do ramo. As perdas totais no ramo de transmissão $\mathrm{km}$ são, portanto,

$$
P_{\text {loss }}=P_{k m}+P_{m k}=g_{k m} \theta_{k m}^{2}
$$

Uma das formas de representar as perdas no modelo linearizado é adicionar cargas ao sistema. $\mathrm{O}$ montante de carga a ser incrementado em cada barra é igual à metade das perdas nos ramos diretamente ligados em cada barra. Considerando as perdas nos ramos, a injeção na barra $k$ pode ser obtida por

$$
\begin{gathered}
P_{k}=\sum_{m \in \Omega_{k}} P_{m k}=\frac{1}{2} \sum_{m \in \Omega_{k}} g_{k m} \theta_{k m}^{2}+\sum_{m \in \Omega_{k}} \theta_{k m} x^{-1} \\
P_{k}=P_{l o s s-k}+\sum_{m \in \Omega_{k}} \theta_{k m} x^{-1} .
\end{gathered}
$$

Onde $P_{k}$ é a nova injeção líquida no sistema considerando as perdas e $P_{l o s s-k}$ é carga adicional na barra k; a metade do somatório das perdas nos ramos diretamente conectados na barra. 
O cálculo das perdas pode ser estimado também usando a resistência e o fluxo passante na linha, $P_{l o s s}=g_{k m} \theta_{k m}^{2}$. Sendo a condutância definida em função da resistência e reatância, tem-se,

$$
P_{l o s s}=\frac{r_{k m}}{r_{k m}^{2}+x_{k m}^{2}} \theta_{k m}^{2}
$$

Sendo $r_{k m} \ll x_{k m}$, tem-se que $r_{k m}^{2}+x_{k m}^{2} \cong x_{k m}^{2}$. Logo, $P_{l o s s}=r_{k m}\left(\frac{\theta_{k m}}{x_{k m}}\right)^{2}$. Portanto,

$$
P_{l o s s}=r_{k m} f_{k m}^{2} \text {. }
$$

Nesta expressão as perdas são obtidas diretamente em função da resistência da linha de transmissão e do fluxo passante no ramo.

As perdas de transmissão devem ser descontadas do montante disponível de reserva,

$$
R\left(G^{\text {spin }}, L, t\right)=G^{\text {spin }}\left(\mathbf{C}_{\mathrm{G}}, \lambda_{\mathrm{G}}, t\right)-L(t, \boldsymbol{\delta})-P_{\text {loss }} .
$$

Assim, ao representar a transmissão é possível analisar o impacto das perdas ôhmicas ao longo dos circuitos na adequabilidade dos níveis de reserva.

\subsection{2.}

\section{Montante de Perdas - Sistema IEEE RTS}

No teste realizado neste tópico, avalia-se o efeito da inclusão das perdas de transmissão no montante de reserva e sua influência no risco de corte de carga. Nas tabelas a seguir são apresentados os montantes de reserva e os índices de risco associados a cada cenário de geração, com o número de unidades despachadas variando de 20 a 32 unidades. Na Tabela 4.10 são também apresentadas as perdas nas linhas de transmissão usando as equações $P_{l o s s}=g_{k m} \theta_{k m}^{2}$ e $P_{l o s s}=r_{k m} f_{k m}^{2}$. 
Tabela 4.9: Risco no sistema IEEE RTS sem perdas na transmissão

\begin{tabular}{|c|c|c|c|}
\hline \hline$N_{D}$ & $\begin{array}{c}\text { Geração } \\
{[\mathrm{MW}]}\end{array}$ & $\begin{array}{c}\text { Reserva Girante } \\
{[\mathrm{MW}]}\end{array}$ & Índice de Risco \\
\hline 20 & 2965 & 115 & 0.02019388 \\
\hline 21 & 3065 & 215 & 0.00586910 \\
\hline 22 & 3165 & 315 & 0.00571051 \\
\hline 23 & 3265 & 415 & 0.00035328 \\
\hline 24 & 3277 & 427 & 0.00034887 \\
\hline 25 & 3289 & 439 & 0.00035147 \\
\hline 26 & 3301 & 451 & 0.00032086 \\
\hline 27 & 3313 & 463 & 0.00031788 \\
\hline 28 & 3325 & 475 & 0.00031756 \\
\hline 29 & 3345 & 495 & 0.00030459 \\
\hline 30 & 3365 & 515 & 0.00027016 \\
\hline 31 & 3385 & 535 & 0.00027730 \\
\hline 32 & 3405 & 555 & 0.00023218 \\
\hline
\end{tabular}

Tabela 4.10: Impacto das perdas $\left(P_{\text {loss }}=g \times \theta^{2}\right)$

\begin{tabular}{|c|c|c|c|c|c|c|c|}
\hline \hline & & \multicolumn{3}{|c|}{$P_{\text {loss }}=g \times \theta^{2}$} & \multicolumn{3}{|c|}{$P_{\text {loss }}=r \times f^{2}$} \\
\cline { 3 - 8 }$N_{D}$ & $\begin{array}{c}\text { Geração } \\
{[\mathrm{MW}]}\end{array}$ & $\begin{array}{c}\text { Reserva } \\
\text { Girante } \\
{[\mathrm{MW}]}\end{array}$ & $\begin{array}{c}\text { Perdas } \\
{[\mathrm{MW}]}\end{array}$ & $\begin{array}{c}\text { Índice de } \\
\text { Risco }\end{array}$ & $\begin{array}{c}\text { Reserva } \\
\text { Girante } \\
{[\mathrm{MW}]}\end{array}$ & $\begin{array}{c}\text { Perdas } \\
{[\mathrm{MW}]}\end{array}$ & $\begin{array}{c}\text { Índice de } \\
\text { Risco }\end{array}$ \\
\hline \hline 20 & 2965 & 38.57 & 76.43 & 0.03004334 & 40.98 & 74.02 & 0.03004334 \\
\hline 21 & 3065 & 144.50 & 70.50 & 0.02045900 & 146.59 & 68.41 & 0.02045900 \\
\hline 22 & 3165 & 249.66 & 65.34 & 0.00572377 & 251.47 & 63.53 & 0.00572377 \\
\hline 23 & 3265 & 354.04 & 60.96 & 0.00400948 & 355.62 & 59.38 & 0.00400948 \\
\hline 24 & 3277 & 365.93 & 61.07 & 0.00385206 & 367.51 & 59.49 & 0.00385206 \\
\hline 25 & 3289 & 377.82 & 61.18 & 0.00392486 & 379.39 & 59.61 & 0.00392486 \\
\hline 26 & 3301 & 389.70 & 61.30 & 0.00394365 & 391.28 & 59.72 & 0.00394365 \\
\hline 27 & 3313 & 401.58 & 61.42 & 0.00044230 & 403.17 & 59.83 & 0.00044230 \\
\hline 28 & 3325 & 413.47 & 61.53 & 0.00042607 & 415.05 & 59.95 & 0.00042607 \\
\hline 29 & 3345 & 433.57 & 61.43 & 0.00042142 & 435.15 & 59.85 & 0.00042142 \\
\hline 30 & 3365 & 453.66 & 61.34 & 0.00038789 & 455.25 & 59.75 & 0.00038789 \\
\hline 31 & 3385 & 473.75 & 61.25 & 0.00039079 & 475.33 & 59.67 & 0.00037853 \\
\hline 32 & 3405 & 493.83 & 61.17 & 0.00037353 & 495.42 & 59.58 & 0.00037437 \\
\hline \hline
\end{tabular}

Na Figura 4.7 é apresentado o resultado comparativo em termos de risco e de montante de reserva girante (em função do número de unidades despachadas), para as avaliações com e sem perdas de transmissão. É possível perceber que o impacto 
das perdas é diminuir o montante de reserva girante e consequentemente deteriorar os índices de risco de corte de carga.

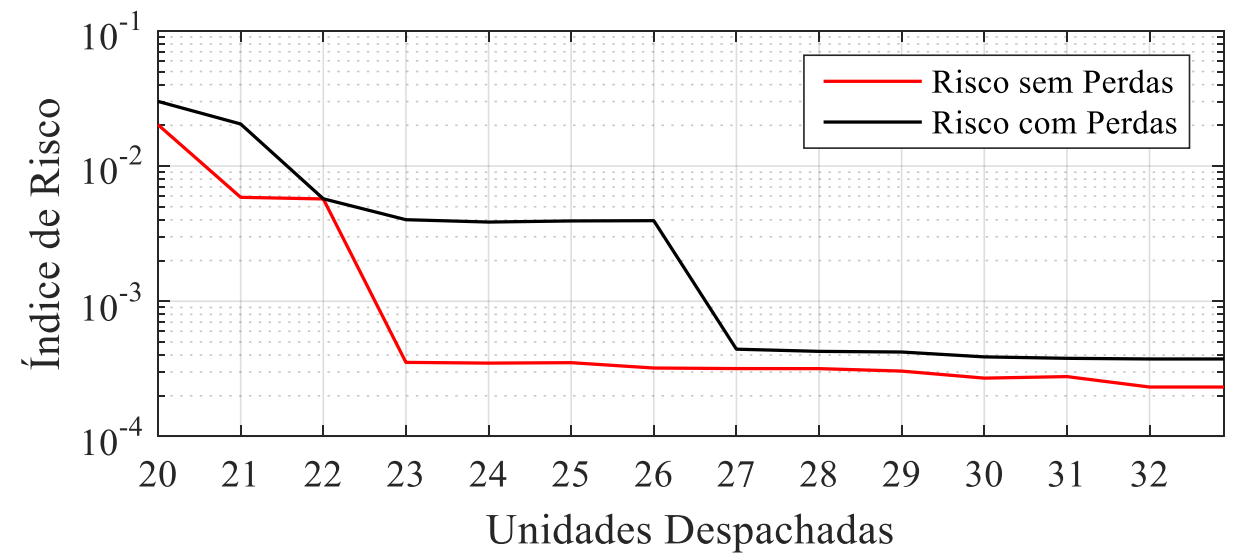

Figura 4.7: Impacto das perdas de transmissão no índice de risco

É possível perceber que as perdas diminuem ao incluir mais máquinas, isso pode ocorrer, por exemplo, devido ao melhor perfil de despacho com unidades de geração mais próximas às cargas.

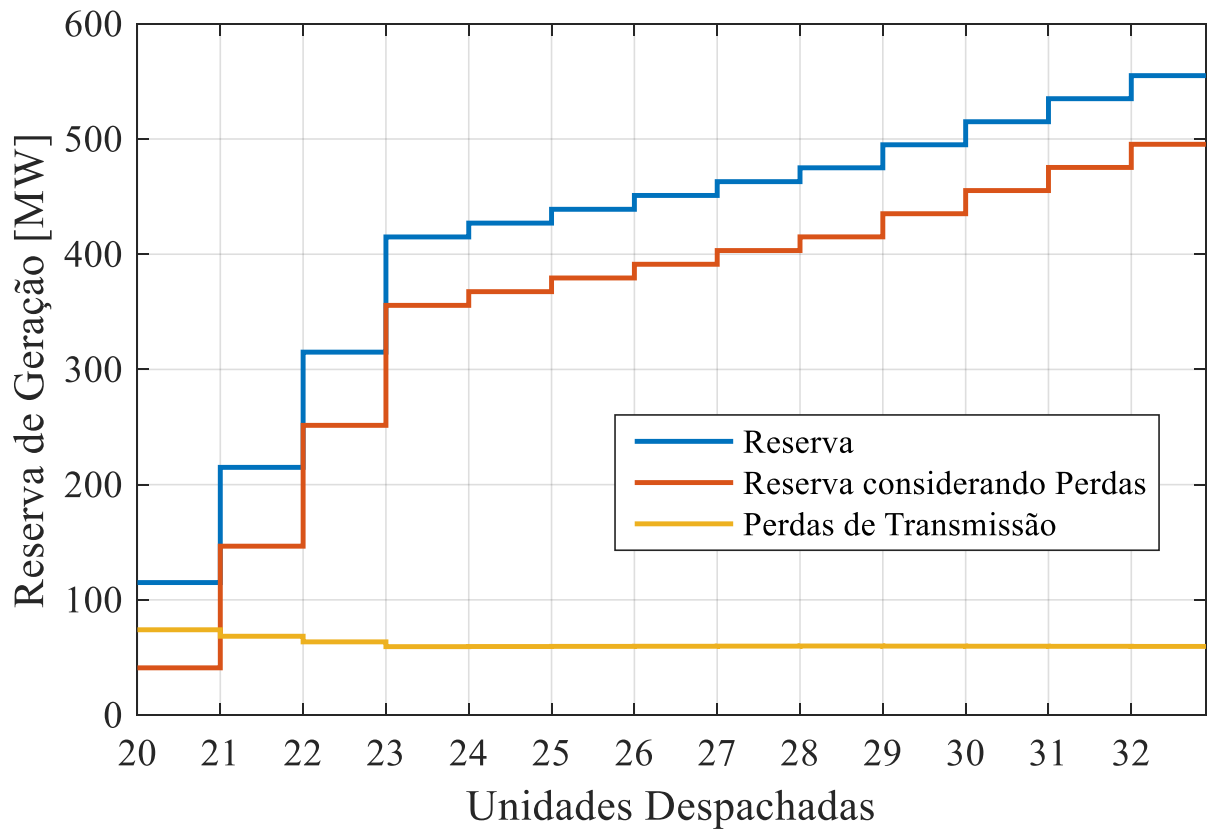

Figura 4.8: Impacto das perdas de transmissão no montante de reserva 


\section{7. \\ Aplicação do Método CE para identificação de Equipamentos Críti- cos}

Ao minimizar a distância estatística entre as distribuições de probabilidade usando técnicas de redução de variância, o método da entropia cruzada modifica os parâmetros dos equipamentos do sistema de forma a aumentar a frequência de ocorrência dos eventos considerados importantes. Nas análises de adequação dos níveis de reserva, as modificações nos parâmetros são mais significativas naqueles elementos que são responsáveis pelos eventos de insuficiência de reserva (ou corte de carga). Desta forma, por meio das distorções nos parâmetros é possível identificar os equipamentos mais importantes para o problema, isto é, aqueles em que o operador deve atuar com maior cautela, do ponto de vista do planejador, aqueles elementos que podem necessitar de reforços estruturais.

Pode-se definir o Fator de Distorção Relativa (FDR) como a diferença entre as taxas de substituição originais e as modificadas (normalizada pelo parâmetro original),

$$
\mathrm{FDR}=\frac{\mathrm{ORR}_{\text {orig }}-\mathrm{ORR}_{\text {dist }}}{1-\mathrm{ORR}_{\text {orig }}}
$$

Os elementos com maior fator de distorção são os que mais impactam para o corte de carga. Usando o FDR, pode-se classificar quais são esses componentes. Essa informação pode ser utilizada para priorizar a alocação de reforços no sistema elétrico.

Na Tabela 4.11 o Fator de Distorção Relativa (FDR) é calculado para os componentes do sistema IEEE RTS, isto é, as 32 unidades de geração despachadas com os 38 circuitos do sistema de transmissão em operação normal. Para obter as distorções são também consideradas as perdas de transmissão e nas análises de rede considera-se a impossibilidade de redespachar geração (restrição da dinâmica de operação no curto-prazo). São usadas 80000 amostras para obtenção das ORRs distorcidas via método da Entropia Cruzada.

Ainda na Tabela 4.11, o FDR é apresentado também para as linhas de transmissão. As linhas com maior FDR são as mais críticas, i.e., onde é possível observar 
com maior frequência os gargalos de transmissão. Pode-se perceber que os equipamentos que mais contribuem para ocorrências de corte de carga são as três LTs conectadas à barra 8 , que é uma região frágil do sistema (barra 7 tem geração elevada e é facilmente ilhada na saída da LT que conectam as barras 7 e 8). Em seguida, em grau de importância, estão os geradores, cuja FDR é maior para as unidades de maior capacidade.

Os equipamentos que mais contribuem para as ocorrências de corte carga e, com os maiores montantes de corte, são os que apresentam as maiores distorções no parâmetro. Desta forma, os conceitos do método da Entropia Cruzada podem ser empregados para obter parâmetros que podem ser aplicados como critério para analisar a possibilidade de alterar a ordem de mérito no despacho de unidades para compor a reserva. Além disso, é possível obter a classificação dos equipamentos com base em sua importância (em termos de confiabilidade) para o sistema. Os ativos mais importantes podem ser priorizados para a alocação de reforços por parte do planejador/operador.

Tabela 4.11: Classificação dos equipamentos - IEEE RTS

\begin{tabular}{|c|c|c|c|c|c|c|}
\hline \hline Equipamento* & $\begin{array}{c}\text { Cap. } \\
{[\mathrm{MW}]}\end{array}$ & $\begin{array}{c}\text { Barra i } \\
\text { ou } \\
\text { Barras i-j }\end{array}$ & $\begin{array}{c}\text { 1-ORR } \\
\text { Original }\end{array}$ & $\begin{array}{c}\text { 1-ORR } \\
\text { Distorcido }\end{array}$ & $\begin{array}{c}\text { FDR } \\
{[\%]}\end{array}$ & Ranking \\
\hline \hline LT & 175 & $8-10$ & 0,9999 & 0,7394 & 26,05 & 1 \\
\hline LT & 175 & $8-9$ & 0,9999 & 0,7449 & 25,50 & 2 \\
\hline LT & 175 & $7-8$ & 0,9999 & 0,7963 & 20,36 & 3 \\
\hline GS & 400 & 21 & 0,9982 & 0,8883 & 11,01 & 4 \\
\hline GS & 400 & 18 & 0,9982 & 0,8884 & 11,00 & 5 \\
\hline GS & 350 & 28 & 0,9983 & 0,9157 & 8,267 & 6 \\
\hline GS & 197 & 13 & 0,9979 & 0,9687 & 2,930 & 7 \\
\hline GS & 155 & 23 & 0,9979 & 0,9689 & 2,908 & 8 \\
\hline GS & 155 & 16 & 0,9979 & 0,9702 & 2,782 & 9 \\
\hline GS & 155 & 27 & 0,9979 & 0,9709 & 2,711 & 10 \\
\hline GS & 100 & 7 & 0,9983 & 0,9820 & 1,638 & 11 \\
\hline \hline
\end{tabular}

*GS: Generation Station / LT: Transmission Line 


\section{8. \\ Conclusões}

Neste capítulo foi apresentada uma metodologia para o dimensionamento da reserva de geração de curto-prazo. Em uma abordagem que usa métodos de simulação e técnicas de redução de variância via método da Entropia Cruzada.

A metodologia compartilha todas as vantagens do uso de técnicas de avaliação baseadas em SMC, tais como flexibilidade de representação e habilidade de avaliação de sistemas de médio e grande porte. Além disso, por meio de IS via método CE, evita-se uma das principais desvantagens do uso de simulação, i.e., o alto custo computacional para avaliação da probabilidade de eventos raros.

Uma das questões que têm sido levantadas, principalmente em sistemas com fontes intermitentes (eólicas), é a flexibilização da capacidade de linhas de transmissão [19], uma vez que a capacidade de transmissão não é constante, mas depende de diversos fatores, tais como temperatura ambiente, velocidade dos ventos, etc. Por meio do método proposto análises envolvendo linhas de transmissão de diferentes capacidades (podendo até ser variáveis) podem ser realizadas considerando o efeito na habilidade do sistema de suprir adequadamente a demanda no curto prazo.

Tratando-se de análises de curto-prazo, os eventos de perda de carga tornamse raros e assim o tempo de simulação aumenta significativamente. No entanto, os resultados devem ser gerados rapidamente para o operador. Desta forma, o uso de técnicas de amostragem por importância é indispensável. O esforço computacional ao aplicá-las, quando comparado com uma SMC convencional, é expressivo.

Ao incluir o sistema de transmissão, percebe-se que há um impacto significativo no índice de risco de perda de carga do sistema. Com o intuito de mitigar esse risco é necessário que uma quantidade maior de reserva seja adicionada. Trata-se de uma reserva cujo intuito é possibilitar o suprimento da demanda mesmo em situações de falha no sistema de transmissão e não apenas devido à insuficiência de geração.

O aumento da taxa de falha ou a diminuição da capacidade de transmissão de linhas tem como consequência o aumento dos níveis de risco. Assim, se o sistema 
opera próximo de seus limites, uma quantidade maior de reserva deve estar sincronizada para evitar o corte de carga.

A probabilidade de que eventos de corte possam acontecer aumenta se as restrições de transporte forem acentuadas. O mesmo efeito é observado se as taxas de falha são aumentadas. Se, devido às limitações práticas do operador, não for possível efetuar redespacho como medida corretiva, o efeito das restrições da transmissão no índice de risco é ainda mais significativo.

O efeito das perdas em linhas de transmissão foi também analisado. Ficou demonstrado que as perdas elevam o risco de corte de carga. Foi proposto ainda um método para classificar os equipamentos do sistema em função de sua contribuição para as falhas no sistema.

Neste capítulo o foco foi em discutir sobre o dimensionamento considerando índices de confiabilidade composta, mas em sistemas com predominância de unidades térmicas, cuja geração não é intermitente. No próximo capítulo serão discutidos aspectos relativos ao planejamento da reserva em sistemas com fontes renováveis. 


\section{5 \\ Planejamento da Reserva via Simulação Monte Carlo Quase Sequencial com Fontes Renováveis}

O planejamento do setor elétrico é fundamental para assegurar a continuidade do abastecimento e o suprimento de energia ao menor custo, com o menor risco e com os menores impactos socioambientais para a sociedade [88].

O planejamento da operação de um sistema com alta penetração de fontes renováveis é mais complexo devido ao grande número de variáveis aleatórias envolvidas, às fortes correlações com variáveis climáticas e às flutuações na capacidade destas fontes. Assim, os modelos matemáticos utilizados na representação destes sistemas apresentam maior grau de complexidade e, usualmente, envolvem um elevado número de estados.

Este capítulo apresenta uma metodologia de avaliação dos montantes de reserva girante em sistemas com elevada penetração de energias renováveis. Os índices de risco associados são estimados considerando a sequência temporal de ocorrência dos eventos. São utilizadas séries históricas de capacidade de fontes eólicas e os valores previstos de variação horária da demanda. Por meio da simulação Monte Carlo Quase Sequencial é possível representar cronologicamente as variações de geração e suas correlações temporais.

Devido à raridade dos eventos em questão e ao elevado custo computacional das avaliações de risco e para permitir a análise em tempo hábil, os parâmetros da simulação são otimamente distorcidos com base nos conceitos de entropia cruzada e das técnicas de redução de variância via amostragem por importância, como descrito nos capítulos anteriores.

Ao inserir fontes eólicas no sistema, a volatilidade da geração aumenta significativamente, as análises devem considerar intervalos de tempo da ordem de horas a minutos, uma vez que a disponibilidade dos recursos energéticos de fontes renováveis eólica e solar pode variar nessa escala de tempo.

Em sistemas com elevada penetração de energia eólica a capacidade de suprir a demanda adequadamente varia em função tanto da saída forçada de equipamentos 
(geradores, linhas de transmissão, transformadores, etc.) quanto da capacidade disponível de vento/sol aos geradores. As incertezas associadas à geração são potencializadas, demandando ainda mais métodos com a capacidade de avaliar os riscos envolvidos na operação de sistemas com fontes variáveis no curto-prazo.

Neste capítulo é proposto também um critério de segurança associado à distribuição de probabilidade dos níveis de reserva. Trata-se de uma ferramenta para subsidiar o planejador da operação na tomada de decisões envolvendo cenários energeticamente desfavoráveis e/ou pouco prováveis.

O método desenvolvido é aplicado ao sistema IEEE RTS [87], devidamente modificado com a substituição de geração térmica por eólica, possibilitando a análise do comportamento das fontes renováveis. Os resultados demonstram que com a ferramenta proposta é possível avaliar cronologicamente, de forma computacionalmente eficiente e considerando os critérios de risco e de segurança, a reserva em vários cenários de um sistema com fontes de geração intermitentes/variáveis.

\section{1. Introdução}

Como definido nos capítulos anteriores, a reserva girante é a parcela da reserva operativa proveniente de geradores sincronizados $1 /$ despachados, e interligados à rede de transmissão, aptos a suprir a demanda na ocorrência de falhas de unidades de geração, erros na previsão de carga e variações de capacidade de geração de fontes renováveis [21], [67].

A flutuação de capacidade de geração decorrente da elevada penetração de fontes renováveis, principalmente eólica e solar/fotovoltaica, tem tornado o planejamento da operação dos sistemas cada vez mais complexo, em função do aumento do número de variáveis aleatórias [89], [90].

\footnotetext{
${ }^{1}$ Os geradores eólicos usualmente não giram mecanicamente na mesma rotação/frequência síncrona da rede, empregam retificadores e inversores para injetar sua potência no sistema interligado (a depender da tecnologia construtiva).
} 
Em [32] o ONS descreve a revisão de sua metodologia de dimensionamento para lidar com o crescimento da geração eólica no Brasil. Como descrito no relatório, a penetração da geração eólica na matriz energética do SIN introduz mudança no cálculo da Reserva de Potência Operativa.

Uma das alterações refere-se ao método de cálculo a Reserva de Potência Operativa convencional (dimensionada para fazer face à perda de unidades geradoras e desvios de previsão de carga), que, segundo [32], deve ser revista em função da variabilidade da participação da geração eólica na composição do parque gerador para o atendimento à carga. Além disso, considerando-se que a programação da geração no SIN é efetuada para cada 30 minutos, uma parcela adicional de reserva de potência deve ser estabelecida para fazer face à variabilidade da geração eólica neste intervalo de tempo. Por fim, os desvios da geração eólica verificada em relação àquela prevista devem ser considerados, pois são significativamente maiores que os desvios de previsão da carga.

Na Figura 5.3 é possível observar a variação do fator de capacidade médio mensal da geração eólica do SIN. Os registros históricos mostram que, em média, o fator de capacidade pode variar de aproximadamente 30 para mais $50 \%$ (curva verde) no mesmo ano. A variação diária da geração para o período de um mês é dada na Figura 5.2.

Na Figura 5.2 é possível observar as curvas de variação da geração ao longo do dia (em cada hora) para todos os dias de um mês, conforme informado pelo ONS no Boletim mensal de geração eólica [30]. Em destaque, é mostrada a geração mínima, máxima e média (as duas curvas externas de maior espessura representam as envoltórias, com o máximo e mínimo que foi verificado para cada hora ao longo dos dias do mês). É possível observar que mesmo para o curto-prazo, no horizonte de horas, pode haver significativa variação da capacidade de geração.

As incertezas associadas ao problema do dimensionamento da reserva girante têm sido acentuadas, justificando ainda mais o uso de métodos com a capacidade de avaliar as incertezas inerentes à operação e planejamento de sistemas com participação significativa de fontes renováveis. 


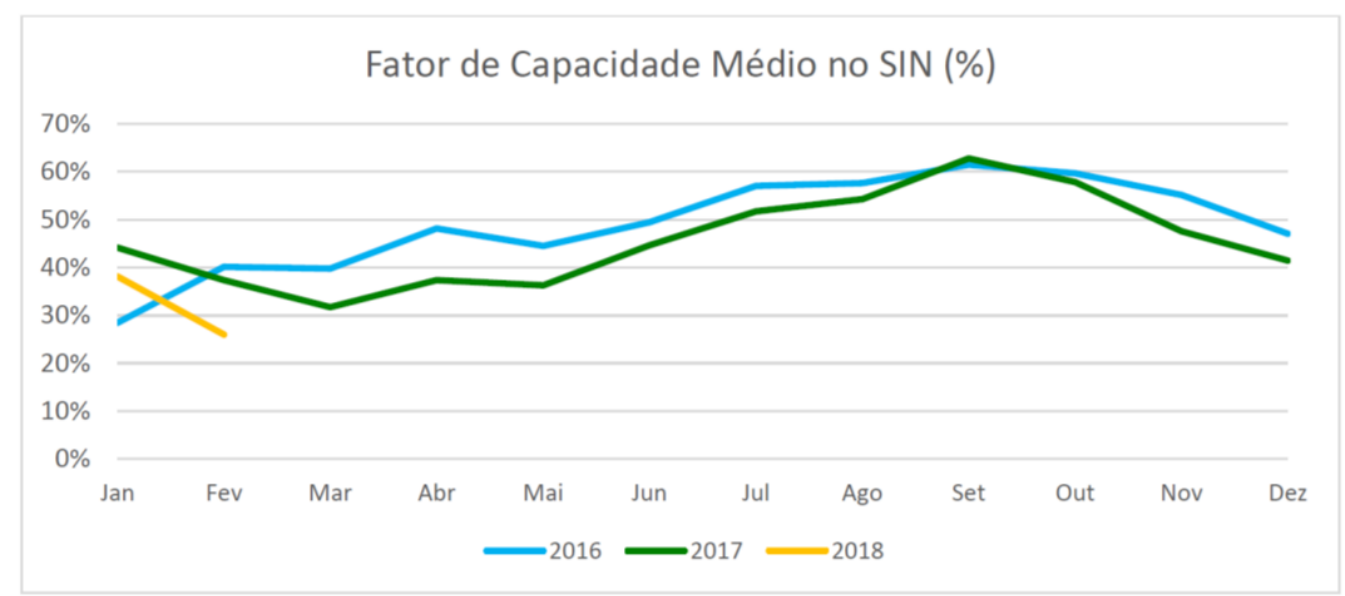

Figura 5.3: Fator de capacidade médio mensal

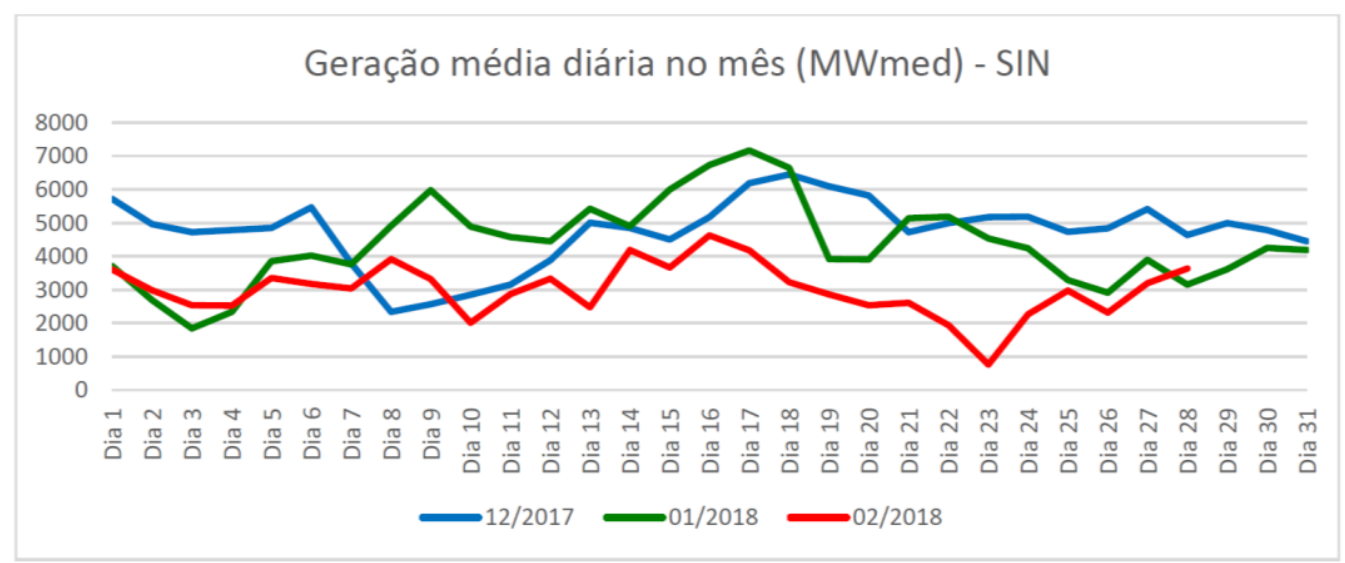

Figura 5.1: Geração eólica no SIN (média diária) [30]

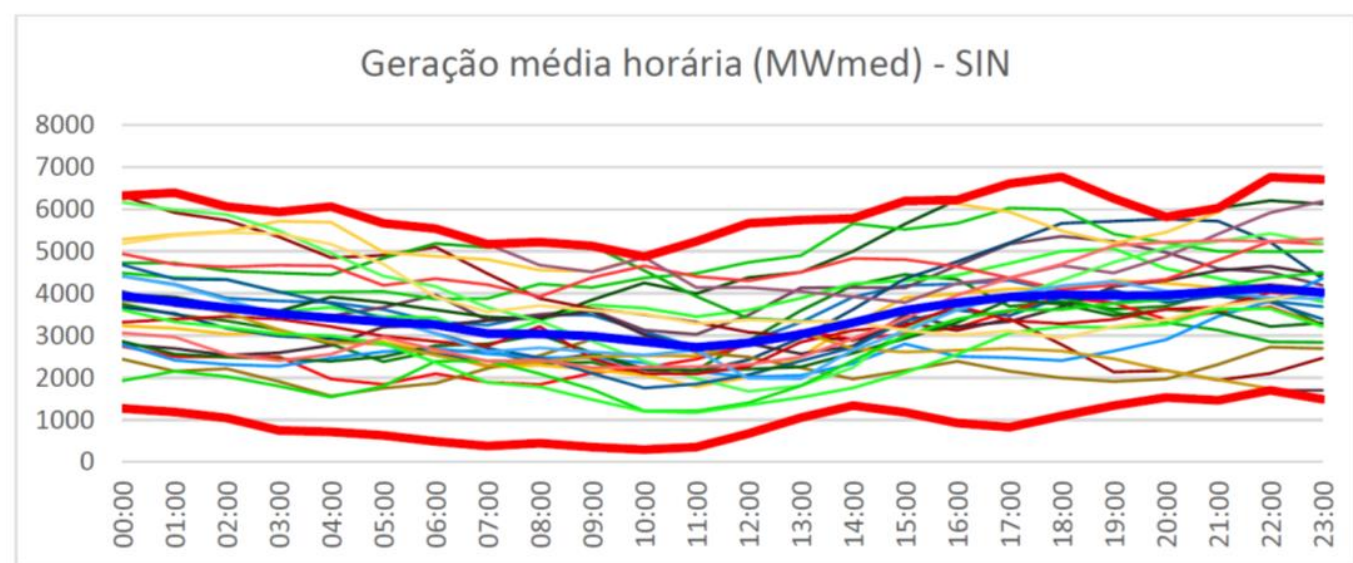

Figura 5.2: Geração eólica no SIN (média horária) [30] 


\section{2.}

\section{Avaliação do Risco via Simulação Monte Carlo}

O risco de não suprimento da demanda pode ser estimado por meio de duas representações distintas: espaço de estados e modelos cronológicos. Enumeração e simulação Monte Carlo (SMC) não sequencial são exemplos de métodos baseados em representação por espaço de estados [4], onde modelos Markovianos são usados para reproduzir o comportamento estocástico dos equipamentos do sistema. Os estados são selecionados e avaliados de acordo com a sua probabilidade de ocorrência, sem considerar a sequência histórica dos eventos [67]. Devido ao elevado número de estados necessários para representar realisticamente sistemas complexos, o uso da SMC, nestes casos, é preferível em relação às técnicas de enumeração [22], [91].

A avaliação de eventos com correlação temporal (e.g., variação da capacidade de geração de fontes eólicas em função da disponibilidade do vento) requer o emprego de algoritmos baseados em modelos cronológicos, tal como a SMC sequencial ou cronológica. Métodos baseados na SMC cronológica são mais robustos para avaliar sistemas com forte dependência da sequência de ocorrência dos eventos, comparados aos métodos de SMC não sequencial. No entanto, o esforço computacional é significativamente maior, podendo ser impraticável, como em análises envolvendo eventos raros (probabilidades da ordem de $10^{-5}$ ). Para superar a barreira associada ao elevado custo computacional das simulações sequenciais, métodos híbridos de SMC, tais como a SMC pseudocronológica e pseudossequencial têm sido propostos [64], [20].

A simulação pseudossequencial [64] retêm a flexibilidade e eficácia dos métodos de SMC sequenciais, além de apresentar maior eficiência. No entanto, o ganho computacional obtido ao se aplicar tais conceitos não é suficiente para que apresentem o mesmo nível de eficiência computacional dos algoritmos não sequenciais. Por meio de uma modelagem apropriada do sistema de potência, a simulação pseudocronológica [20] é capaz de representar cargas variantes, durações de interrupções, entre outros aspectos tempo-dependentes, além de reter a eficiência computacional característica dos métodos de SMC não sequencial. 
Baseando-se nos aspectos necessários para manter a eficiência computacional da simulação não sequencial e da SMC pseudocronológica, e também observando os conceitos de entropia cruzada da teoria da informação [21], o método quase sequencial CE (cross-entropy) utiliza um modelo Markoviano multinível não agregado [20] para representar o comportamento cronológico da carga e das incertezas associadas à flutuação da capacidade de geração das fontes renováveis, principalmente as eólicas por apresentarem maior volatilidade [22].

A simulação Monte Carlo quase sequencial [22] foi recentemente aplicada na análise dos requisitos de reserva estática. A avaliação de índices de confiabilidade da capacidade de geração foi realizada, mantendo os mesmos níveis de eficiência computacional da SMC não sequencial. As incertezas associadas às variações de carga, ao comportamento estocástico das unidades de geração e a flutuação da capacidade das fontes renováveis foram representadas cronologicamente por meio de um modelo Markoviano multiníveis de estados não agregados [20].

Considerando ainda o problema da reserva estática, o método quase sequencial foi estendido para incluir os conceitos de entropia cruzada [21], [22], mantendo a capacidade de avaliar os índices de confiabilidade, i.e., LOLP, LOLF, EENS, etc., considerando aspectos cronológicos e espaciais, tais como: cargas variantes, flutuação de capacidade de geração (e.g., fontes eólicas, hidráulicas, fotovoltaicas), e rotinas de manutenção.

O método CE [21], [22], [26] foi aplicado na estimação dos parâmetros ótimos ou quase ótimos do estimador via amostragem por importância. O método $\mathrm{CE}$ foi também aplicado na análise da operação no curto prazo (algumas horas), considerando falhas no sistema de transmissão [29].

Neste capítulo, introduz-se uma nova metodologia que estende os conceitos propostos em [22] para o problema de avaliação dos requisitos de reserva girante, em sistemas com elevada penetração de fontes renováveis. O risco de curto prazo do não suprimento da demanda é avaliado a partir da cronologia das séries estocásticas envolvidas, sendo proposto também um critério de segurança associado à distribuição de probabilidade dos cenários de reserva de geração. Os índices de risco são estimados através da SMC quase sequencial via método da entropia cruzada. O algoritmo proposto é aplicado ao sistema IEEE RTS 79 [87], devidamente modificado pela inserção de geração eólica. 


\section{3. \\ Reserva Girante Considerando Fontes Renováveis}

O montante de geração programado, para o atendimento da demanda, deve ser tal que o sistema possua uma margem de reserva suficiente para suportar a perda de capacidade de geração ou aumentos súbitos na demanda, sem haver necessidade de cortar carga [4]. Em sistemas com elevada penetração de energia renovável, a reserva de geração também desempenha a importante função de habilitar o sistema para suportar as variações de capacidade de geração devido à volatilidade da velocidade dos ventos, da irradiação solar e das vazões hidráulicas.

A reserva girante $R$, requerida para prover um determinado nível de confiabilidade no intervalo de tempo $t$, é função da capacidade de geração sincronizada $G^{\text {spin }}$, que é composta de $N U$ unidades cuja fonte pode ser, por exemplo, hidráulica, térmica, solar, eólica, entre outras. Assim,

$$
G^{\text {spin }}(t, N U)=G_{\text {hydro }}(t)+G_{\text {thermal }}(t)+G_{\text {wind }}(t) .
$$

A variável $R$ é função também da taxa de falha de cada uma das unidades sincronizadas durante o intervalo $t$, da carga $L$ equivalente do sistema e dos erros de previsão das variáveis envolvidas no problema [29], i.e.,

$$
R\left(G^{\text {spin }}, L, t\right)=G^{\text {spin }}\left(\mathbf{C}_{G}, \lambda_{G}, t\right)-L(t, \boldsymbol{\delta}),
$$

onde $\boldsymbol{C}$ representa o vetor de capacidade dos geradores, $\lambda$ as taxas de falha e $\delta$ os erros de previsão de carga observados no período de tempo considerado. O número de unidades sincronizadas em um dado período de tempo $N U$ é também função das capacidades e taxas de falha dos geradores, i.e., $N U=N U\left(\mathbf{C}_{G}, \lambda_{\mathrm{G}}\right)$, pois uma vez estabelecido um montante requerido de reserva, a geração a ser sincronizada é computada somando as capacidades das máquinas em operação que podem ser despachadas (não indisponíveis por ocorrência de falha). Para as unidades térmicas $C_{G}$ é a própria capacidade nominal, para os geradores eólicos, no entanto, esse valor de capacidade varia em função da disponibilidade e velocidade dos ventos.

Devidos às incertezas inerentes à avaliação da reserva de geração, a aplicação de métodos probabilísticos torna-se necessário [4], [67]. O risco, de acordo com o 
método PJM [15], é definido como a probabilidade da reserva ser negativa durante o lead time $t$, ou seja,

$$
\operatorname{Risk}\left(R, G^{\text {spin }}, L, t\right)=P\left\{R\left(G^{\text {spin }}, L, t\right)<0\right\} .
$$

Dados os recursos energéticos disponíveis, em termos de capacidade de geração térmica e renovável, o operador deve sincronizar uma quantidade apropriada de unidades para atender ao critério de risco estabelecido,

$$
\text { Risk }\left(R, G^{s p i n}, L, t\right)<\text { Risco }_{\text {max }},
$$

i.e., o risco de corte de carga deve ser, sempre que possível, inferior ao risco máximo admissível, i.e., Riscomax, para os cenários considerados.

Variações em relação ao método PJM foram propostas com o intuito de considerar unidades de partida rápida, perdas parciais de geração das unidades, cargas interruptíveis, limites na capacidade de assistência em sistemas interligados, falhas e restrições de transmissão, entre outros aspectos [4], [29] e [41].

\section{4 . \\ Critério de Segurança}

Em sistemas de energia elétrica com fontes renováveis (intermitentes e voláteis), como as fazendas eólicas, pode não ser possível garantir que o sistema atenda ao critério de risco em alguns cenários altamente desfavoráveis. Isto pode ocorrer, por exemplo, quando em simultaneidade ao aumento da carga houver diminuição da velocidade dos ventos (menor geração eólica). Dependendo da probabilidade de ocorrência destes casos, em decorrência das restrições de capacidade de geração instalada, pode não ser economicamente viável ou mesmo impraticável, programar reserva suficiente para garantir um valor de risco menor que o máximo permissível. Para contornar esse problema, pode-se adotar uma estratégia de segurança baseada em um índice de risco admissível $\mathrm{I}_{\text {safety }}$ que pode ser definido como,

$$
P\left\{\operatorname{Risk}\left(R, G^{\text {spin }}, L, t\right)<\operatorname{Risk}_{\text {max }}\right\}>\mathrm{I}_{\text {safety }},
$$

onde $P\{$.$\} indica a probabilidade de atendimento do critério de risco. Tal critério$ pode ser entendido como uma estratégia para regular a suscetibilidade do operador à violação do risco. 
No planejamento da operação são programadas unidades garantindo que o critério de risco seja atendido com uma determinada probabilidade (e.g., $\mathrm{I}_{\text {safety }}=$ 0,95). A probabilidade de não satisfazer o critério de risco é no máximo igual a 1 (um) menos o índice de segurança admissível, i.e., "1 - I Isafety" (e.g., 1 - I Isafety $_{\text {}}=0,05$ ou $5 \%)$.

A carga definida na avaliação do índice de risco pode ser maior ou menor que a verificada pelo operador, devido aos erros de previsão da carga futura $( \pm \delta)$. A adoção do critério de segurança pode também evitar que uma quantidade adicional de reserva seja indevidamente recomendada.

No Brasil, o operador do sistema prevê a violação do critério de segurança "N-1" em situações excepcionais da operação/planejamento, tais como em cenários energéticos desfavoráveis, restrições do sistema de transmissão, atendimento a cargas através de sistemas radiais singelos ou de um único transformador, e em casos de situações conjunturais [57]. Como o critério (N-1) não avalia os riscos associados, não há parâmetros numéricos específicos para definir as situações em que a violação é permitida, a decisão segue recomendações colegiadas dos agentes setoriais envolvidos.

Considerando o efeito das falhas na transmissão nos índices de risco, o critério de segurança pode ser avaliado considerando o risco composto

$$
P\left\{\operatorname{Risk}_{\mathrm{GT}}\left(R, G^{\text {spin }}, L, t\right)<\text { Risk }_{\text {max }}\right\}>\mathrm{I}_{\text {GTsafety }},
$$

Assim, o operador pode programar as unidades geradoras para atender ao critério de risco composto, sendo que esse critério pode ser violado dentro de níveis de segurança aceitáveis. O índice de segurança composto I $\mathrm{I}_{\mathrm{GTsafety}}$ pode ser maior ou igual ao $\mathrm{I}_{\text {safety }}$ relacionado, dependendo da aversão ao risco dos operadores e planejadores.

\section{5 .}

\section{Representação da Geração Eólica no Curto Prazo}

Em avaliações de reserva estática, o comportamento estocástico das unidades de geração pode ser aferido via um modelo Markoviano de dois estados (up e down), especificado pelas taxas de falha $(\lambda)$ e reparo $(\mu)$. No caso de avaliações de curto prazo, como no caso da reserva operativa, o diagrama de estados pode ser 
modificado para incorporar os conceitos do método PJM. Durante o lead-time não é possível reparar unidades que saíram de operação de forma não programada (saída forçada/falha), portanto, $\mu=0$. A probabilidade de falha de uma unidade de geração (térmica, hidráulica, eólica, etc.), no intervalo $[0, t]$, i.e., $P_{\text {falha }}(t)$, pode ser obtida por

$$
P_{\text {falha }}(t) \approx P\left(t_{U p} \leq t\right)=1-e^{-\lambda t}
$$

Para intervalos de até umas poucas horas, a equação (6) pode ser aproximada por $P_{\text {falha }}(t) \approx \lambda t$, como havia sido proposto nos capítulos anteriores para geradores convencionais e linhas de transmissão.

Unidades convencionais (térmicas e hidráulicas) podem ser representadas pelo modelo de dois estados, com probabilidades dadas por: $P_{U p}=1-\mathrm{ORR}$ e $P_{\text {falh }}=$ ORR. As fazendas eólicas, por outro lado, supondo $N_{W}$ aerogeradores idênticos, podem ser representadas nos estudos considerando o curto prazo via modelos de estados agregados [67], como mostrado na Figura 5.4. A probabilidade de encontrar $n$ unidades falhadas no intervalo $[0, t], P_{n}(t)$, é dada por,

$$
P_{n}(t)=\left(\begin{array}{c}
N_{W} \\
n
\end{array}\right) \times(1-\mathrm{ORR})^{N_{W}-n} \times(\mathrm{ORR})^{n},
$$

onde $\left(\begin{array}{c}N_{W} \\ n\end{array}\right)$ é o coeficiente binomial.

Dado o estado inicial do modelo agregado da fazenda eólica, a transição ocorre para estados de menor potência em consequência da saída/falha de unidades e da ausência de reparo. Na Figura 5.4, $\mathrm{C}_{0}$ representa o estado de maior capacidade de geração, $\mathrm{C}_{1}$ o segundo maior e assim sucessivamente. Pode-se empregar SMC e/ou técnicas de enumeração para avaliação dos estados do modelo.

Supondo $N_{A W}$ unidades eólicas operando, é possível estimar o montante de geração eólica no instante $t$, i.e., $G C_{\text {wind }}$, para cada caso da série histórica correspondente, 


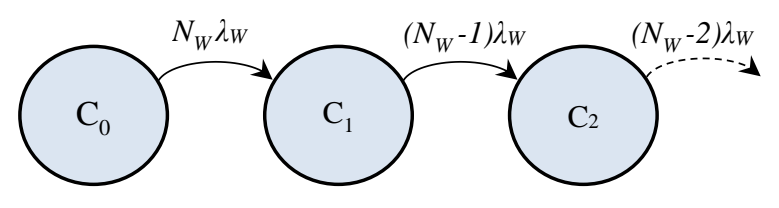

Figura 5.4: Modelo multiestados de curto-prazo - Geração eólica

$$
G C_{\text {wind }}\left(N_{A W}, t\right)=C F_{\text {wind }}(t) \times \sum_{i=1}^{N_{A W}} G_{\text {wind }_{i}} .
$$

A equação (5.9) expressa o comportamento estocástico dos geradores de uma fazenda eólica. A variação desse tipo de fonte é resultado da combinação da flutuação da capacidade de geração disponível (capturado pelo fator de capacidade, $C F_{\text {wind }}$ ), consequência da intermitência dos recursos energéticos na sua forma primária (e.g., ausência de ventos) e do número de unidades operativas do grupo, que pode variar em função de falhas e manutenções.

\section{6. \\ Simulação Monte Carlo Quase Sequencial via Método da Entropia Cruzada}

Métodos baseados em SMC [21], [23], não sequenciais ou sequenciais, são considerados ferramentas robustas na avaliação de risco de sistemas complexos. A simulação não sequencial é capaz de avaliar os índices de confiabilidade de grandes sistemas de potência com elevada eficiência, como ficou demonstrado nos capítulos anteriores.

Para capturar a correlação temporal dos eventos, no entanto sem perder a eficiência computacional característica dos métodos baseados na SMC não sequencial, a SMC quase sequencial (SMC-QS) [22] representa o comportamento cronológico do sistema de potência por meio de um modelo Markoviano não agregado de níveis múltiplos [20].

Um modelo tempo-sequencial geração-carga, utilizado nas avaliações via SMC-QS, pode ser observado na Figura 5.5. Os diferentes níveis de capacidade de geração e de carga são representados por estados sequencialmente conectados na mesma ordem cronológica, que aparecem nas séries históricas (ou previstas) de geração eólica, hidráulica, etc., e pelos níveis de carga correspondentes. Dado um cenário "s", um intervalo de tempo $[0, t]$ pode ser discretizado em $k$ subintervalos de 
duração $h$ (e.g., em horas). Cada período, representado por um grupo de estados no modelo, é amostrado seguindo a taxa de transição temporal $\lambda_{h}$.

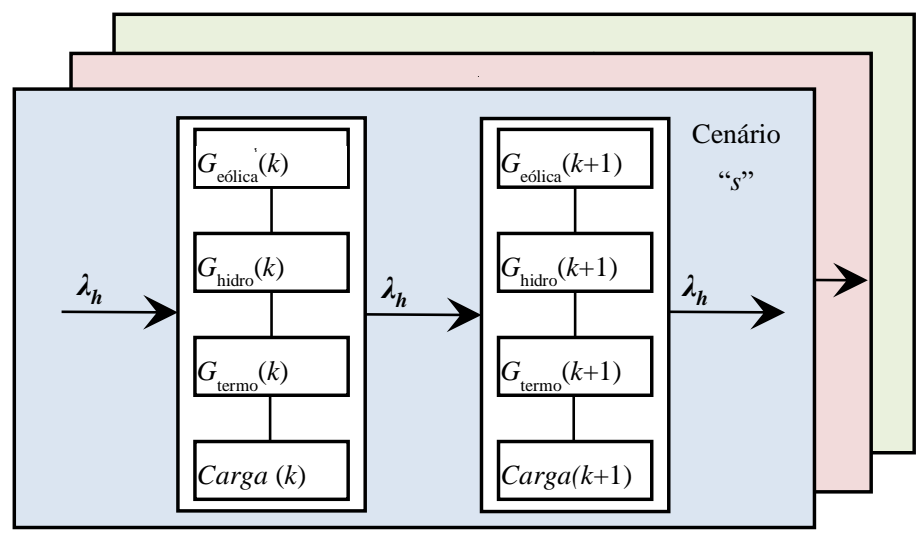

Figura 5.5: Modelo multinível geração-carga tempo-sequencial

A ideia central da SMC-QS [22] é rastrear a variação de carga para capturar a dependência temporal da capacidade de geração das fontes renováveis (geradores eólicos). Baseado no modelo de simulação proposto é possível capturar qualquer evento com correlação temporal. No entanto, o esforço computacional pode ser elevado, consequência da baixa probabilidade dos eventos de corte de carga nas análises de curto prazo [22]. O custo computacional pode ser significativamente diminuído otimizando os parâmetros da SMC, distorcendo as taxas de reposição (ORR) dos equipamentos, por meio da aplicação dos conceitos de entropia cruzada [21].

O índice de risco pode ser estimado, em cada cenário de geração e carga, usando técnicas de amostragem por importância (IS) [22], [29], como foi realizado na SMC convencional. Assim,

$$
\hat{\text { Risk }}=\frac{1}{N} \sum_{i=1}^{N} I_{\left\{S\left(\mathbf{X}_{i}\right)<L\right\}} \mathbf{W}\left(\mathbf{X}_{i}, \mathbf{p}, \mathbf{q}\right),
$$

onde $\mathbf{W}\left(\mathbf{X}_{i}, \mathbf{p}, \mathbf{q}\right)$ é a razão de verossimilhança, q é o vetor de ORRs distorcidas, i.e., os elementos de q são obtidos modificando os elementos de $\mathbf{p}$, com o intuito de amostrar aqueles mais importantes durante a SMC-CE quase sequencial. Os vetores p e q contêm as probabilidades de falha dos geradores convencionais e também dos geradores eólicos. 
Em essência, a avaliação do índice de risco via SMC Quase Sequencial segue os seguintes passos principais:

(i) Selecionar um cenário e escolher sequencialmente um ponto da série histórica com os níveis de carga e de geração térmica, hidráulica e renovável, conforme modelo Markoviano tempo-sequencial não agregado da Figura 5.5. Os cenários e pontos de operação podem ser sorteados com base na probabilidade histórica de ocorrência;

(ii) Usando os conceitos do método da entropia cruzada, gerar aleatoriamente $N_{C E}$ amostras do tipo de $\mathbf{X}_{i}$ com base nas taxas de falha das unidades de geração e dos níveis de carga prevista para obter $\mathbf{q}$, o conjunto de parâmetros otimamente distorcidos a ser utilizado na simulação via Amostragem por importância;

(iii) Gerar $N$ amostras de $\mathbf{X}_{i}$, avaliar a adequação de cada uma das amostras e estimar o risco de curto prazo por meio da equação (5.10). Voltar para o passo inicial e repetir o processo para os cenários e pontos de operação de interesse.

\section{7. \\ Estratégia de Inicialização}

Um método empírico determinístico historicamente utilizado para determinar o montante de reserva é o método da maior máquina, pelo qual se deve sincronizar um montante de reserva girante no mínimo igual ao valor da potência da maior máquina existente no sistema [4]. Devido ao elevado esforço computacional necessário para avaliar o índice de risco, propõe-se uma estratégia de inicialização do número de unidades baseado neste método.

Durante o processo de dimensionamento da reserva, adicionam-se unidades sincronizadas uma de cada vez e reavalia-se o índice de risco até que o critério de risco pré-estabelecido seja satisfeito. Este processo pode ser acelerado filtrando a quantidade de cenários a serem analisados. Usando os conceitos do método da maior máquina para estimar o número inicial de máquinas que serão despachadas na primeira iteração do processo de avaliação das alternativas, pode-se adotar a seguinte heurística para determinar o número inicial de unidades $\left(N U_{i n i}\right)$,

$$
N U_{i n i}=n \in\left\{1, N_{G U} \mid G^{\operatorname{sinc}}(n)-L \geq \operatorname{Max}_{i}\left(G C_{i}\right)\right\},
$$


i.e., $n$ é um valor entre 1 e o número total de geradores disponíveis, $N_{G U}$, escolhido de forma que a reserva será no mínimo igual à capacidade de geração da maior máquina do sistema. Outra regra ou heurística poderá ser utilizada para determinar o montante de geração inicial.

\section{8.}

\section{Algoritmo da SMC Quase Sequencial}

O algoritmo para avaliação da reserva girante baseado na SMC-QS via método CE é resumidamente descrito nos oito passos a seguir:

Passo 1: Ler os parâmetros gerais, i.e.: $N_{\mathrm{GU}}, \mathbf{C}$ (vetor de capacidade dos geradores convencionais e eólicos), $\lambda_{h}, \lambda_{W}$ (taxas de transição), $k$ (número de intervalos da sequência cronológica), $N_{\mathrm{WS}}$ (número de séries eólicas), I $\mathrm{I}_{\text {safety }}$, dados históricos de geração eólica das séries e valores previstos para a carga em cada intervalo da sequência $L=\left\{L_{1}, \ldots, L_{k}\right\}$. Definir a ordem de mérito das unidades de geração pelo menor custo, ou por alguma outra estratégia. Definir os parâmetros do método CE: $\rho$ (parâmetro de múltiplos níveis), $\alpha$ (coeficiente de amortecimento) e $N_{\mathrm{CE}}$ (número de amostras da iteração de distorção via $\mathrm{CE}$ ). Iniciar o processo iterativo para avaliar a reserva girante para a sequência da série; Repetir os passos de 2 a 7 , para todos os períodos $(h=1, \ldots$, k) pelo número de séries eólicas $N_{\mathrm{WS}}$;

Passo 2: Calcular o número inicial de unidades com base no método da maior máquina e despachar $N U_{i n i}$ unidades de geração;

Passo 3: Definir as taxas de reposição forçada - ORRs das unidades de geração do sistema; Executar o método CE para definir o vetor de parâmetros distorcidos, q. Iniciar o contador de iterações da SMC, $N:=0$;

Passo 4: Atualizar $N:=N+1$; Avaliar $I_{\left\{S\left(\mathbf{X}_{N}\right)<L\right\}}$ para verificar se houve corte de carga na amostra simulada, a razão de verossimilhança $\mathbf{W}$, e o estimador do índice de risco;

Passo 5: Avaliar o coeficiente de variação associado ao índice de risco. Se a incerteza da estimação é aceitável ou $N \geq N_{\operatorname{MAX}}$ (máximo número de iterações 
do MCS-IS), ir para o próximo passo; caso contrário, retornar ao passo anterior;

Passo 6: Atualizar o montante de reserva e verificar se o risco estimado na iteração é inferior ao valor máximo aceitável. Em caso afirmativo, o montante de reserva da iteração atende ao requisito estabelecido e o processo de dimensionamento está concluído. Caso contrário, ir para a próxima iteração;

Passo 7: Verificar se $n<N_{\mathrm{GU}}$, indicando que o sistema ainda possui reserva estática para ser convertida em reserva girante. Neste caso, adicionar a próxima unidade, $n:=n+1$, e retornar para o Passo 4. Caso contrário $\left(n=N_{\mathrm{GU}}\right.$, i.e., toda capacidade de geração já está sendo utilizada), notificar que não foi possível atender ao critério de risco e finalizar o processo;

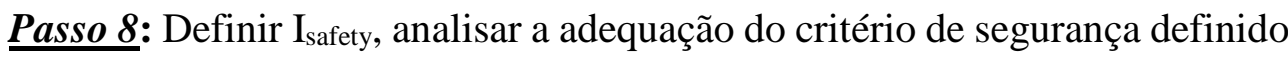
e imprimir os resultados para todas as séries simuladas.

\section{9.}

\section{Resultados Numéricos - PARTE I}

O método proposto foi aplicado ao sistema IEEE RTS com modificações. O tempo de processamento (lead time) é de duas horas. O coeficiente de variação $\beta$, associado às incertezas na estimação do índice de risco, é no máximo igual a um por cento, i.e., $\beta \leq 1 \%$. Os valores definidos para os parâmetros do método CE são: $\alpha=0,999, \rho=0,01$, e $N_{\mathrm{CE}}=5 \times 10^{4}$. 


\subsection{1.}

\section{IEEE RTS - Geração Eólica e Cenários de Carga}

Como dito anteriormente, o sistema IEEE-RTS é composto de 32 unidades de geração, com capacidade instalada total de 3405 MW e carga máxima de 2850 MW. A reserva estática (capacidade instalada subtraída da carga) é, portanto, de 555MW no pico de carga. O Sistema RTS-IEEE Eólico (ou IEEE Wind) foi obtido pela substituição de uma unidade térmica a carvão de $350 \mathrm{MW}$, por uma fazenda eólica formada por 763 unidades de 2 MW (capacidade nominal), para possibilitar

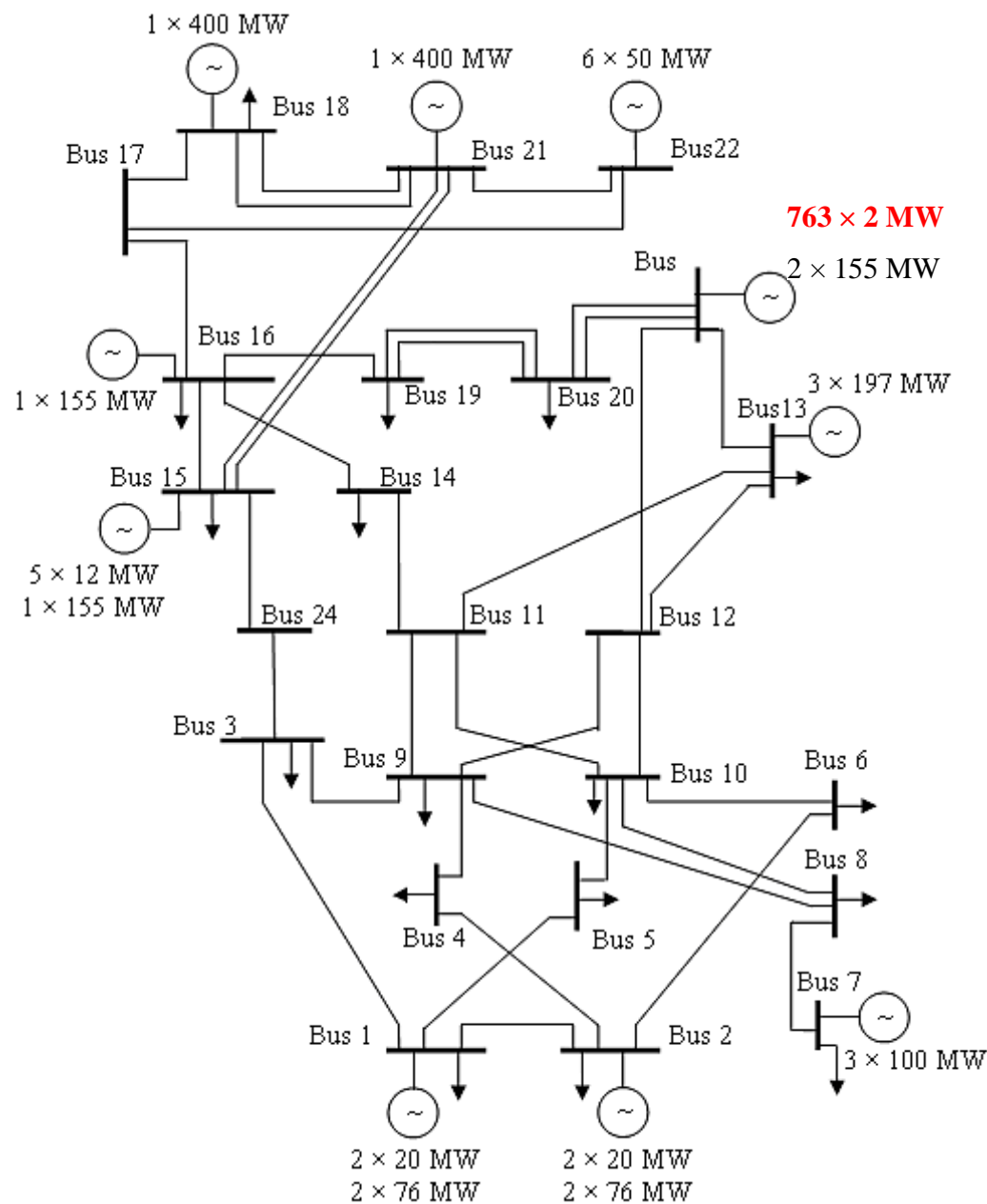

Figura 5.6: IEEE RTS-79 com geração eólica 
Tabela 5.1: Dados cronológicos: Geração eólica e carga

\begin{tabular}{|c|c|c|c|c|c|c|}
\hline \hline \multirow{2}{*}{$\begin{array}{c}\text { Tempo } \\
\text { Seq. }\end{array}$} & $\begin{array}{c}\text { Nível de } \\
\text { Carga } \\
\end{array}$ & \multicolumn{5}{|c|}{ Cenários de Capacidade de Geração Eólica (pu) } \\
\cline { 3 - 7 } & Favorável & Normal & Desfavorável & Decrescente & Crescente \\
\hline \hline 1 & 0,90 & 0,333 & 0,238 & 0,131 & 0,505 & 0,159 \\
\hline 2 & 0,90 & 0,363 & 0,209 & 0,142 & 0,473 & 0,236 \\
\hline 3 & 0,90 & 0,272 & 0,229 & 0,154 & 0,418 & 0,291 \\
\hline 4 & 0,90 & 0,355 & 0,195 & 0,170 & 0,377 & 0,329 \\
\hline 5 & 1,00 & 0,258 & 0,207 & 0,151 & 0,329 & 0,377 \\
\hline 6 & 1,00 & 0,347 & 0,181 & 0,160 & 0,291 & 0,418 \\
\hline 7 & 1,00 & 0,319 & 0,216 & 0,165 & 0,236 & 0,473 \\
\hline 8 & 1,00 & 0,330 & 0,215 & 0,167 & 0,159 & 0,505 \\
\hline \hline & Média: & 0,322 & 0,211 & 0,155 & 0,349 & 0,349 \\
\cline { 2 - 7 } & Desvio: & 0,038 & 0,018 & 0,013 & 0,118 & 0,118 \\
\cline { 3 - 7 }
\end{tabular}

a análise de casos envolvendo fontes renováveis (eólicas) [67], o ponto de inserção de geração no sistema é ilustrado na Figura 5.6. Com esta modificação, considerando um fator de capacidade de 0,23 para a geração eólica, o montante de geração do sistema original é, em média, mantido.

O número total de unidades de geração é de 794 (32 geradores do sistema original menos uma unidade térmica a carvão mais 763 aerogeradores). A capacidade instalada total é de $4581 \mathrm{MW}$ (3405MW - $350 \mathrm{MW}+1526 \mathrm{MW})$. Foram considerados dois níveis de carga, 90\% da carga pico na primeira hora e $100 \%$ na segunda hora.

Na Tabela 5.1 o fator de capacidade da fazenda eólica é apresentado considerando cinco cenários: favorável, normal, desfavorável, decrescente e crescente. Os três primeiros cenários representam condições climáticas/energéticas que se diferenciam, em essência, pelo valor médio da energia disponível. O cenário desfavorável apresenta o menor valor médio para os fatores de capacidade. Os cenários normal e favorável apresentam maior média que o cenário desfavorável (pior caso). No entanto, há também maior variação (maior volatilidade). Os cenários crescente/decrescente representam condições em que há rápido aumento/decréscimo da capacidade de geração, consequência de variação da velocidade do vento. A variação da geração eólica, bem como a curva de carga prevista, pode ser observada na Figura 5.7. 
Devido à elevada volatilidade das fontes eólicas, em que a potência disponível pode variar significativamente em curtos intervalos de tempo (minutos), a sequência cronológica de duas horas foi discretizada em oito intervalos de 15 (quinze) minutos, para cada um destes intervalos foi atribuído um índice numérico de 1 a 8 , conforme é possível observar na primeira coluna da Tabela 5.1. O primeiro intervalo, cujo índice é 1, representa o período de 00:00 até 00:15, e assim sucessivamente. Em cada ponto da sequência, avalia-se a adequação do montante de reserva para as próximas duas horas, dadas as previsões de carga e de energia disponível para geração eólica (e suas incertezas associadas), hidráulica e térmica.

\subsection{2.}

\section{Avaliações de Risco de Não Suprimento e Segurança Sistêmica}

Na Tabela 5.2 são apresentados os valores estimados do risco de não suprimento da demanda do sistema. Na Figura 5.8 é possível observar o comportamento

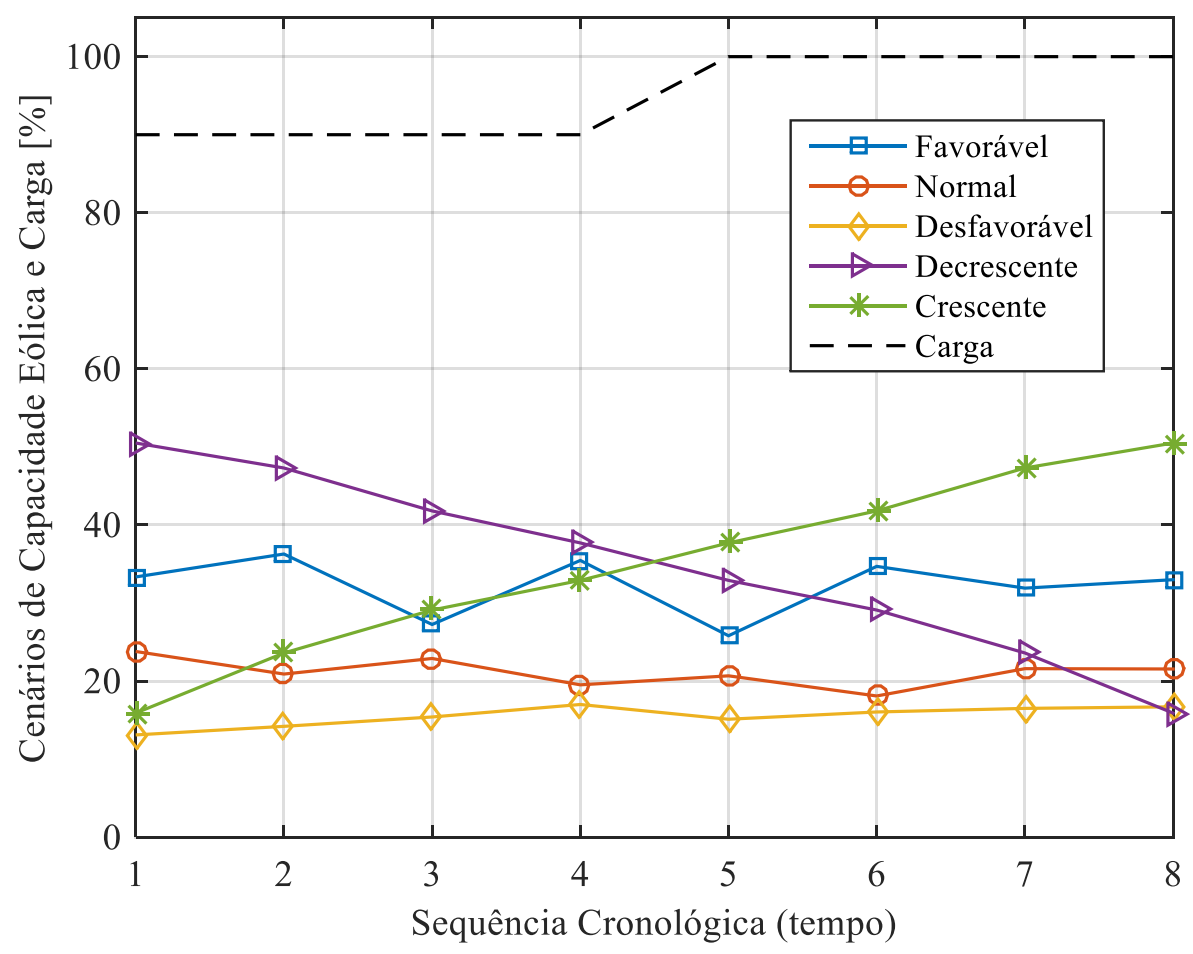

Figura 5.7: Sequência de cenários de vento e níveis de carga 
do índice de risco, em função do tempo na sequência cronológica, com as 794 unidades sincronizadas. Mesmo no curto intervalo de tempo de duas horas, há ampla variação do índice de risco. No cenário Decrescente o risco varia de aproximadamente $10^{-12}$ para $10^{-4}$, trata-se de uma resposta à volatilidade e intermitência da geração eólica do sistema, que tem como consequência a elevação do nível de incertezas do sistema na operação de curto prazo.

É importante ressaltar que nem todas as fontes renováveis são intermitentes, as fontes hidráulicas com grandes reservatórios, por exemplo, apresentam menor volatilidade e não contribuem significativamente para o aumento das incertezas no curto-prazo.

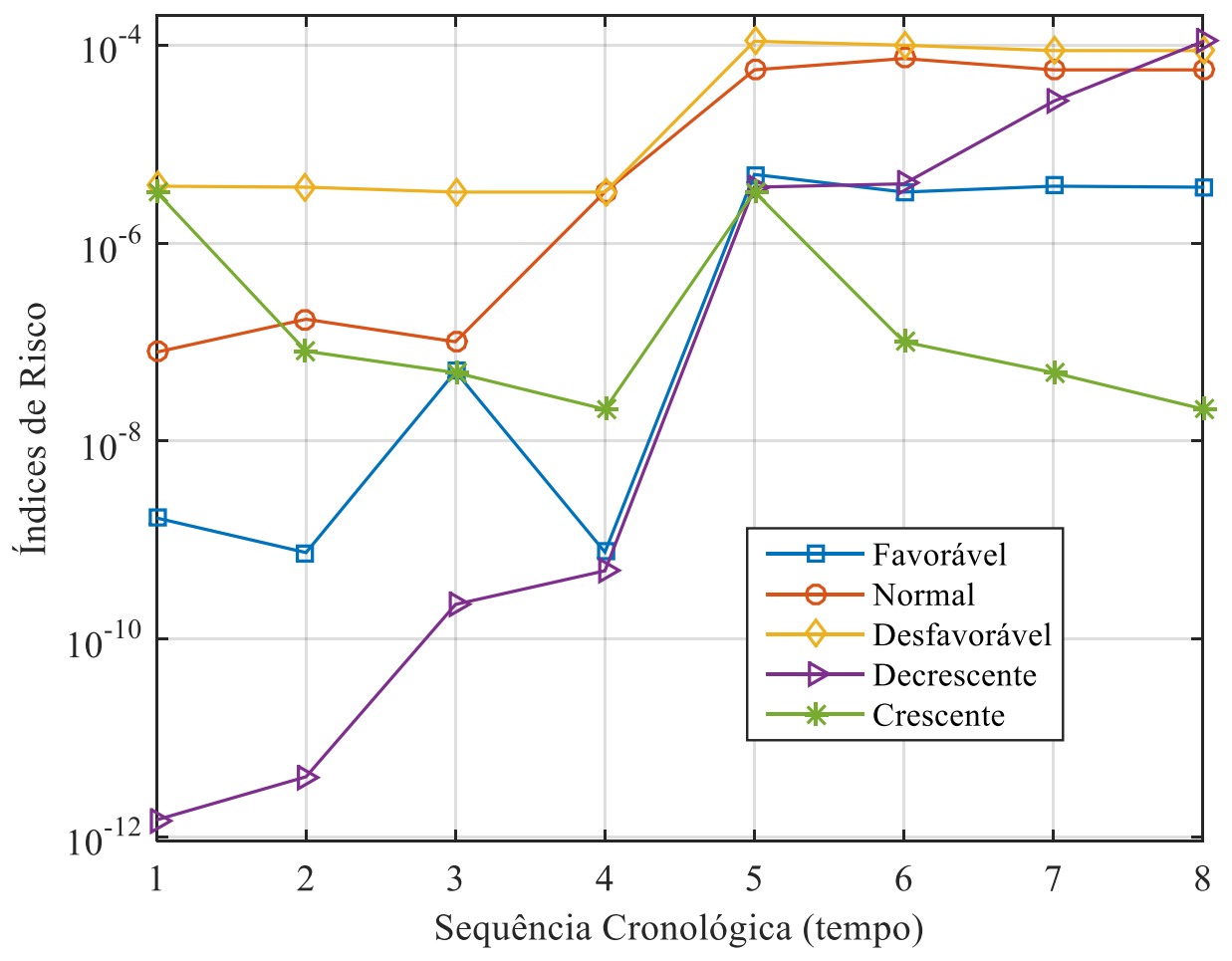

Figura 5.8: Variações do índice de risco nas séries eólicas 
Tabela 5.2: Avaliação do risco das séries eólicas

\begin{tabular}{|c|c|c|c|c|c|c|}
\hline \hline \multirow{2}{*}{$\begin{array}{c}\text { Tempo } \\
\text { Seq. }\end{array}$} & $\begin{array}{c}\text { Nível de } \\
\text { Carga } \\
(\mathrm{pu})\end{array}$ & \multicolumn{5}{|c|}{ Índices de Risco } \\
\cline { 3 - 7 } & & Favorável & Normal & Desfavorável & Decrescente & Crescente \\
\hline \hline 1 & 0,90 & $1,67 \times 10^{-9}$ & $7,89 \times 10^{-8}$ & $3,75 \times 10^{-6}$ & $1,48 \times 10^{-12}$ & $3,27 \times 10^{-6}$ \\
\hline 2 & 0,90 & $7,45 \times 10^{-10}$ & $1,70 \times 10^{-7}$ & $3,67 \times 10^{-6}$ & $4,04 \times 10^{-12}$ & $8,08 \times 10^{-8}$ \\
\hline 3 & 0,90 & $5,04 \times 10^{-8}$ & $1,00 \times 10^{-7}$ & $3,27 \times 10^{-6}$ & $2,23 \times 10^{-10}$ & $4,90 \times 10^{-8}$ \\
\hline 4 & 0,90 & $7,53 \times 10^{-10}$ & $3,28 \times 10^{-6}$ & $3,27 \times 10^{-6}$ & $4,88 \times 10^{-10}$ & $2,09 \times 10^{-8}$ \\
\hline 5 & 1,00 & $4,93 \times 10^{-6}$ & $5,62 \times 10^{-5}$ & $1,09 \times 10^{-4}$ & $3,67 \times 10^{-6}$ & $3,29 \times 10^{-6}$ \\
\hline 6 & 1,00 & $3,27 \times 10^{-6}$ & $7,32 \times 10^{-5}$ & $9,97 \times 10^{-5}$ & $3,96 \times 10^{-6}$ & $1,00 \times 10^{-7}$ \\
\hline 7 & 1,00 & $3,75 \times 10^{-6}$ & $5,62 \times 10^{-5}$ & $8,79 \times 10^{-5}$ & $2,70 \times 10^{-5}$ & $4,90 \times 10^{-8}$ \\
\hline 8 & 1,00 & $3,67 \times 10^{-6}$ & $5,62 \times 10^{-5}$ & $8,79 \times 10^{-5}$ & $1,08 \times 10^{-4}$ & $2,10 \times 10^{-8}$ \\
\hline \hline
\end{tabular}

O índice de risco reflete apropriadamente o grau de adequação do montante de reserva em cada um dos cenários. Como pode ser observado na Figura 5.8, há um aumento geral do risco quando o nível da carga é elevado de 90 para $100 \%$. Os casos mais severos, com valores de risco na região próxima de $10^{-4}$, ocorrem quando simultaneamente há elevação da carga e queda da capacidade eólica. Observando a curva do risco para o cenário "desfavorável” é possível perceber que mesmo quando o sistema está operando com carga leve (90\%), pode ser necessária uma maior quantidade de reserva para compensar a baixa capacidade de geração eólica.

O valor dimensionado de reserva e o risco, em cada um dos cinco cenários equiprováveis das séries avaliadas, podem ser observados nas Figura 5.9(a) e (b), respectivamente (foram considerados dois valores de risco admissível: $10^{-2}$ e $10^{-4}$ ). Assumindo Risk $\max$ igual a $10^{-2}$, foi possível garantir o critério de risco em todos os casos analisados, isto é, com 100\% de segurança. Entretanto, para o critério de risco de $10^{-4}$, ocorrem dois casos de violação do limite máximo aceitável, o primeiro ocorre no cenário de condições de vento Desfavorável e o segundo quando a capacidade eólica é reduzida (cenário Decrescente). 


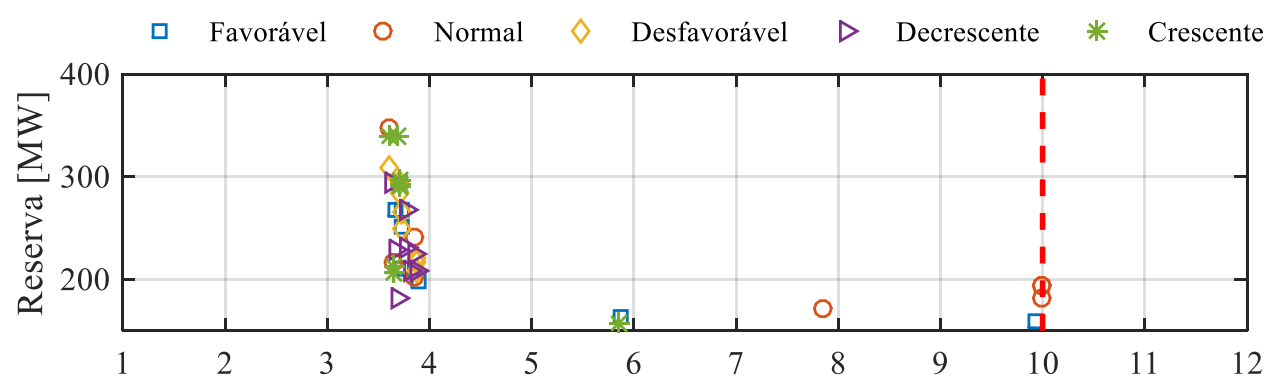

(a) Probabilidade de Corte de Carga $\left(\right.$ Risco $\left._{\text {max }}=10^{-2}\right) \times 10^{-3}$

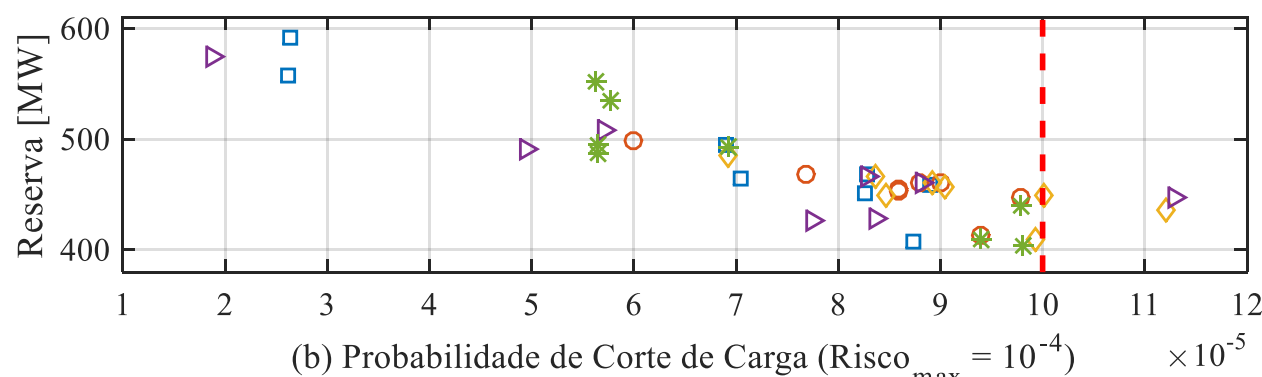

Figura 5.9: Variações do índice de risco nos cenários de geração eólica

A probabilidade de não atendimento do índice de risco considerando o critério de $10^{-4}$ foi $2 / 40=0,05$. Em outras palavras, é possível afirmar que o critério de risco é atendido com fator de segurança de $0,95\left(I_{\text {safety }}=0,95\right)$. Apesar da violação do critério de risco especificado, pelo critério de segurança, os cenários simulados podem ser considerados adequados com $95 \%$ de margem de segurança.

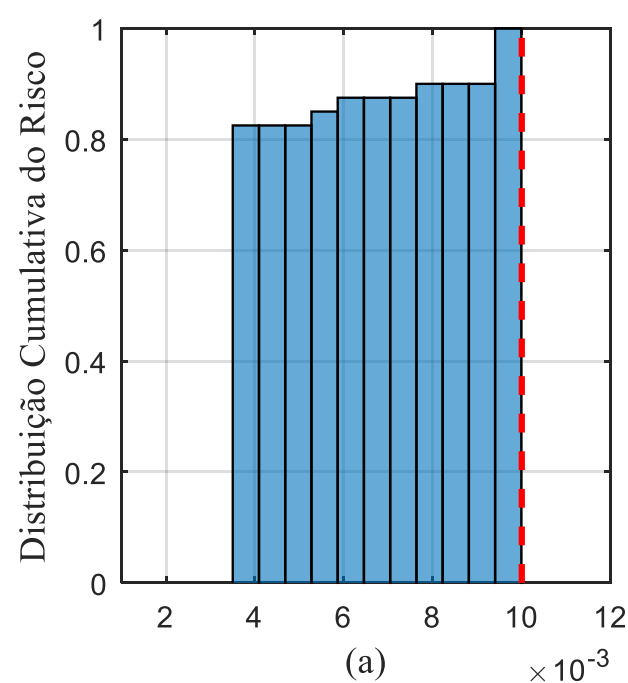

(a)

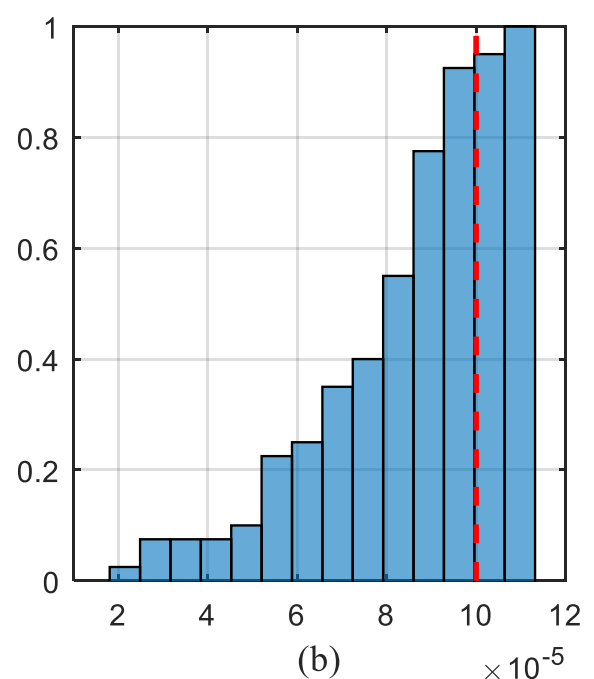

(b) $\quad \times 10^{-5}$

Figura 5.10: Histograma do risco para os critérios: $10^{-2}$ (a) e $10^{-4}$ (b) 

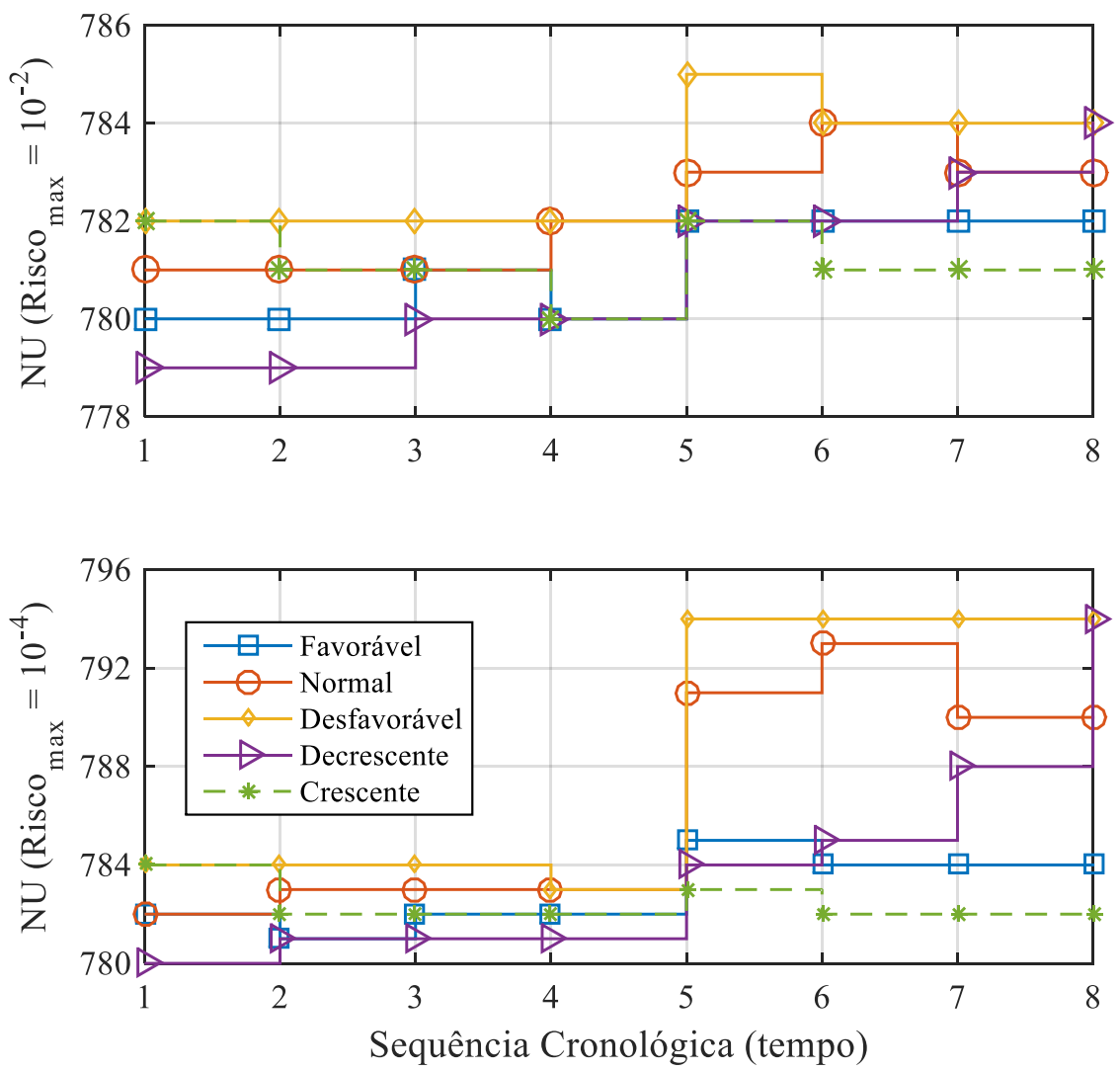

Figura 5.11: Número de unidades geradoras

Nas Figura 5.10 (a) e (b) são apresentadas as distribuições cumulativas dos riscos estimados considerando os critérios $10^{-2}$ e $10^{-4}$. Como mencionado anteriormente, só é possível garantir plenamente a não violação do critério $10^{-2}$. No caso do critério $10^{-4}$, mostrado na Figura 5.10(b), há uma probabilidade de cinco por cento de superar o limite aceitável de risco.

O número de unidades $(N U)$ para satisfazer os critérios de $10^{-2}$ e $10^{-4}$ em cada um dos pontos de operação dos cinco cenários avaliados pode ser observado na Figura 5.11. É possível observar que no cenário Desfavorável, devido à baixa capacidade de geração, um maior número de máquinas é requerido.

Para o critério $10^{-2}$, no cenário Favorável o número de unidades varia de 780 a 782, variando o nível de carga de 90 a $100 \%$, respectivamente. Analisando o cenário Crescente, é interessante observar que no início do intervalo foram necessárias 782 unidades e no final 781. É possível concluir que mesmo quando o nível de carga é baixo, pode ser necessário sincronizar mais máquinas devido à baixa capacidade das fontes eólicas. 
É possível observar que para satisfazer o critério de risco máximo de $10^{-4}$, mais restritivo que o critério $10^{-2}$, é requerido um maior (ou igual) número de máquinas sincronizadas, para um mesmo ponto de operação (ou intervalo da sequência). No cenário Desfavorável, quando a carga varia de 90 para $100 \%$, o número de unidades varia de 784 para 794. Neste caso, foram requeridas dez máquinas adicionais para garantir o atendimento confiável do pico de carga.

O algoritmo integrado QS-SMC-CE proposto gastou, em média, menos de quatro segundos de tempo de CPU por avaliação. Para todos os cinco cenários, 97 e 225 avaliações foram necessárias para a análise dos 2 critérios de risco considerados, i.e., $10^{-2}$ e $10^{-4}$, respectivamente.

\subsection{0.}

\section{Resultados Numéricos - PARTE II: Efeito das Restrições de Trans- missão}

Nos testes a seguir as linhas de transmissão do sistema IEEE RTS WIND são representadas, as perdas de transmissão também foram consideradas. Na Tabela 5.3 e na Figura 5.12 são apresentados os montantes de geração disponível em cada cenário. Foram mantidos os mesmos níveis de geração da Parte I.

Tabela 5.3: Geração Despachada (794 U) [MW]

\begin{tabular}{|c|c|c|c|c|c|c|}
\hline \hline Seq. & Carga [MW] & Favorável & Normal & Desfavorável & Decrescente & Crescente \\
\hline \hline 1 & 2565 & 3563.77 & 3418.04 & 3254.91 & 3825.63 & 3297.63 \\
\hline 2 & 2565 & 3608.63 & 3373.93 & 3271.69 & 3776.80 & 3415.14 \\
\hline 3 & 2565 & 3470.84 & 3404.45 & 3290.00 & 3692.87 & 3499.07 \\
\hline 4 & 2565 & 3596.12 & 3352.88 & 3314.42 & 3630.30 & 3557.05 \\
\hline 5 & 2850 & 3448.86 & 3370.42 & 3303.74 & 3557.05 & 3630.30 \\
\hline 6 & 2850 & 3584.52 & 3331.05 & 3299.77 & 3499.07 & 3692.87 \\
\hline 7 & 2850 & 3541.95 & 3384.46 & 3306.79 & 3415.14 & 3776.80 \\
\hline 8 & 2850 & 3558.43 & 3383.85 & 3251.85 & 3297.63 & 3825.63 \\
\hline \hline
\end{tabular}




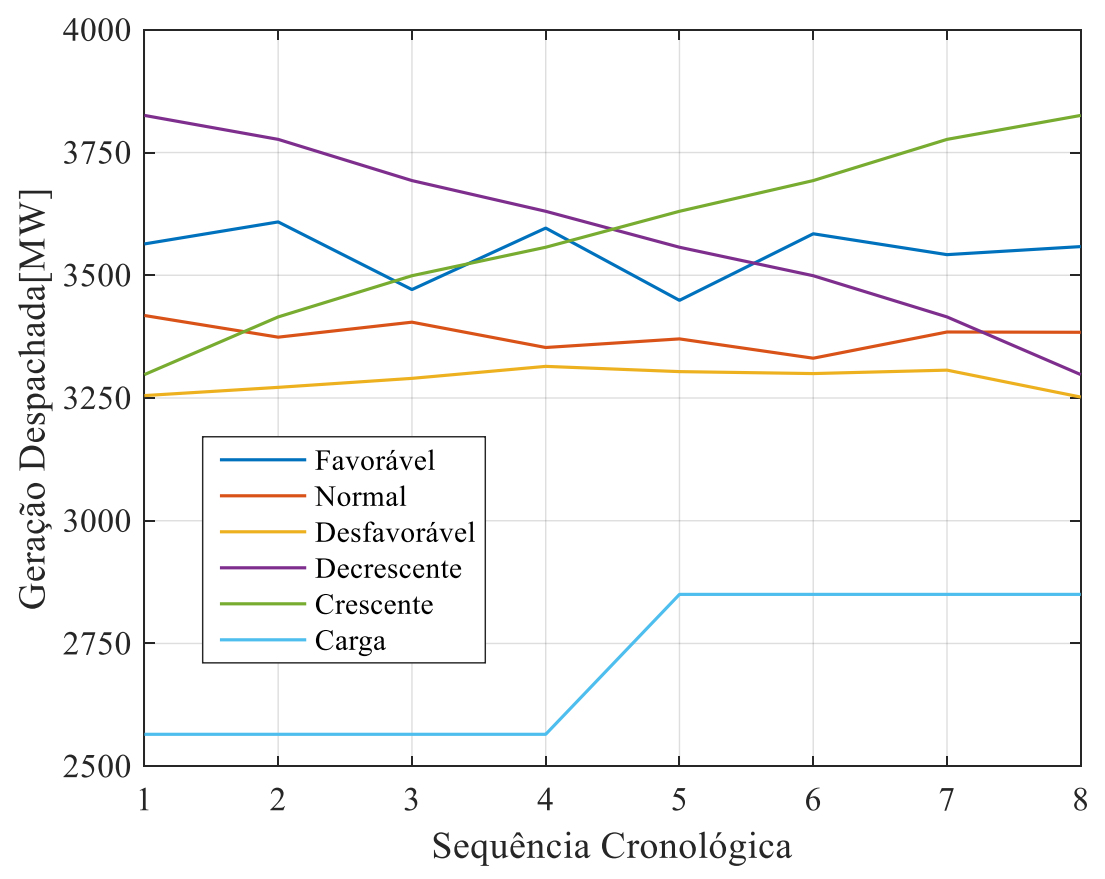

Figura 5.12: Cenários de geração

É possível perceber que o montante de geração despachada está fortemente relacionado aos fatores de capacidade da usina eólica.

Na Tabela 5.4 e na Figura 5.13 são apresentados os montantes de reserva disponível para cada cenário, caso todas as unidades do sistema sejam despachadas. Na Tabela 5.5 a reserva é apresentada com percentual da carga do período. Em todos os casos as perdas nas linhas de transmissão foram consideradas.

Tabela 5.4: Reserva Disponível [MW] com as 794 unidades despachadas*

\begin{tabular}{|c|c|c|c|c|c|c|}
\hline \hline Seq. & Carga [MW] & Favorável & Normal & Desfavorável & Decrescente & Crescente \\
\hline \hline 1 & 2565 & 922,84 & 791,07 & 636,20 & 1176,11 & 677,06 \\
\hline 2 & 2565 & 963,57 & 749,65 & 652,28 & 1130,27 & 788,31 \\
\hline 3 & 2565 & 839,69 & 778,35 & 669,78 & 1046,68 & 865,18 \\
\hline 4 & 2565 & 951,15 & 729,61 & 693,06 & 985,04 & 916,94 \\
\hline 5 & 2850 & 537,28 & 462,27 & 398,00 & 639,68 & 708,32 \\
\hline 6 & 2850 & 665,49 & 424,38 & 394,16 & 584,95 & 765,75 \\
\hline 7 & 2850 & 625,46 & 475,75 & 400,95 & 505,11 & 840,45 \\
\hline 8 & 2850 & 640,97 & 475,16 & 347,67 & 392,09 & 882,74 \\
\hline \hline
\end{tabular}

*Considerando as perdas nas linhas de transmissão 
Tabela 5.5: Reserva Disponível [\% Carga] com as 794 unidades despachadas

\begin{tabular}{|c|c|c|c|c|c|c|}
\hline \hline Seq. & Carga [MW] & Favorável & Normal & Desfavorável & Decrescente & Crescente \\
\hline \hline 1 & 2565 & 35,98 & 30,84 & 24,80 & 45,85 & 26,40 \\
\hline 2 & 2565 & 37,57 & 29,23 & 25,43 & 44,07 & 30,73 \\
\hline 3 & 2565 & 32,74 & 30,35 & 26,11 & 40,81 & 33,73 \\
\hline 4 & 2565 & 37,08 & 28,44 & 27,02 & 38,40 & 35,75 \\
\hline 5 & 2850 & 18,85 & 16,22 & 13,96 & 22,44 & 24,85 \\
\hline 6 & 2850 & 23,35 & 14,89 & 13,83 & 20,52 & 26,87 \\
\hline 7 & 2850 & 21,95 & 16,69 & 14,07 & 17,72 & 29,49 \\
\hline 8 & 2850 & 22,49 & 16,67 & 12,20 & 13,76 & 30,97 \\
\hline \hline
\end{tabular}

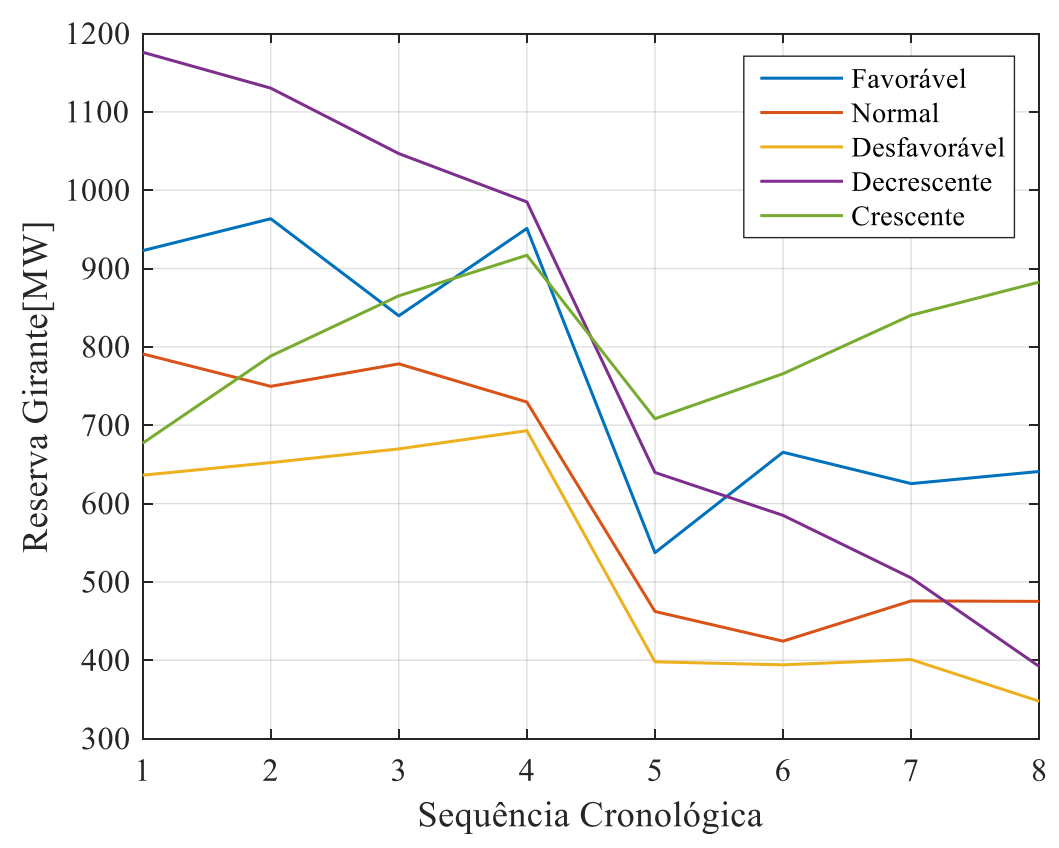

Figura 5.13: Reserva disponível em cada cenário de geração

Na Figura 5.14 são apresentados os valores dos índices de risco para cada cenário. É possível observar que o risco de corte é maior para o período de maior demanda. 


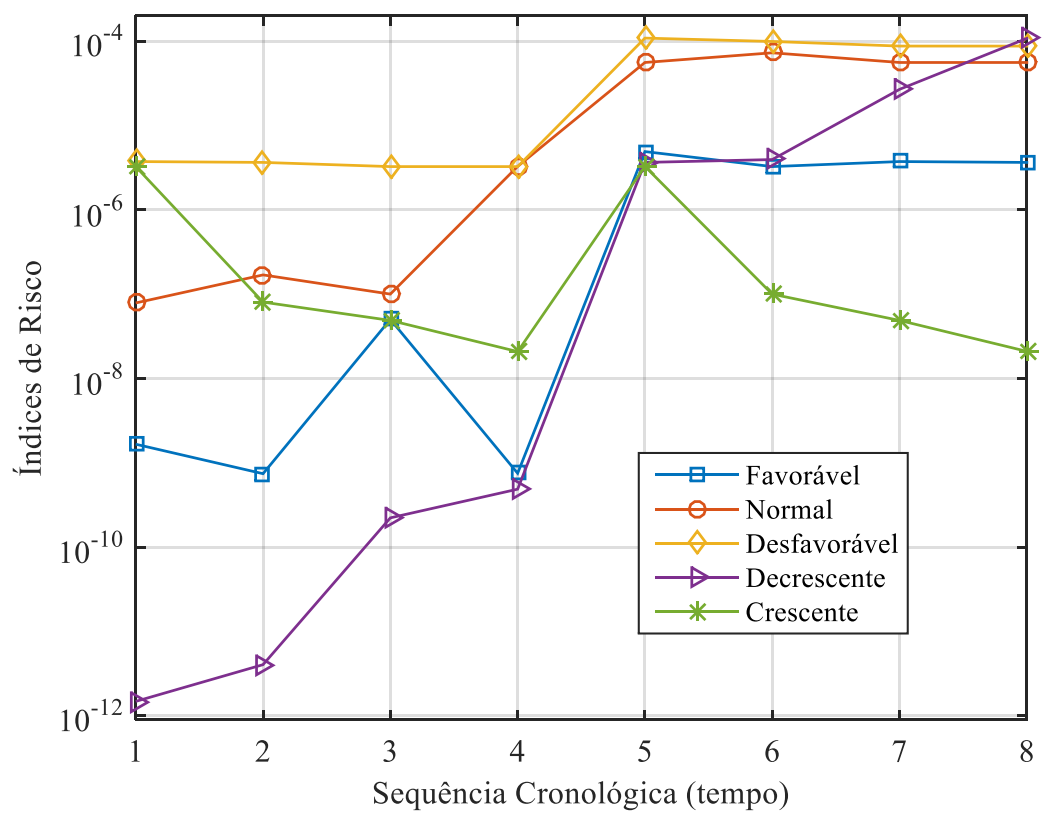

Figura 5.14: Índices de risco para cada cenário de geração

\subsection{1. Resultados Numéricos - Parte III: Classificação dos Equipamentos}

Neste tópico será apresentada a comparação entre os índices de risco desprezando e considerando as restrições de transmissão. Também serão apresentados alguns resultados envolvendo o fator de distorção FDR e o critério de segurança.

Para diminuir o número de variáveis e possibilitar melhor interpretação dos resultados, em todos os testes a partir desse ponto será mantido um único patamar de carga (carga pico, $2850 \mathrm{MW}$ ).

\subsection{1.}

\section{Comparação dos Índices de Risco}

Para cada intervalo de 15 minutos, no período de duas horas, a Tabela 5.6 mostra a geração disponível do sistema (considerando a intermitência das fontes de vento), a “Reserva G” com o Riscog correspondente, sem restrições de transmissão, e a "Reserva GT" com o respectivo RiscoGT, considerando restrições de transmis- 
são. A Figura 5.15 ilustra estes dois riscos, ou seja, Riscog e Riscogt. Como esperado, se a capacidade de transmissão for ilimitada e totalmente confiável, o risco de perda de carga dentro do período de duas horas é muito menor.

Tabela 5.6: Índices de Risco - IEEE RTS Wind: Cenário Normal

\begin{tabular}{|c|c|c|c|c|c|}
\hline \hline $\mathrm{T}_{\mathrm{SEQ}}$ & $\begin{array}{c}\text { Geração } \\
{[\mathrm{MW}]}\end{array}$ & $\begin{array}{c}\text { Reserva G } \\
{[\mathrm{MW}]}\end{array}$ & Risco & $\begin{array}{c}\text { Reserva GT } \\
{[\mathrm{MW}]}\end{array}$ & Risco $_{\text {GT }}$ \\
\hline \hline 1 & 3418,19 & 568,19 & $2,71 \times 10^{-5}$ & 508,02 & $3,25 \times 10^{-4}$ \\
\hline 2 & 3373,93 & 523,93 & $5,63 \times 10^{-5}$ & 465,64 & $3,61 \times 10^{-4}$ \\
\hline 3 & 3404,45 & 554,45 & $4,30 \times 10^{-5}$ & 494,89 & $3,50 \times 10^{-4}$ \\
\hline 4 & 3352,57 & 502,57 & $5,67 \times 10^{-5}$ & 445,11 & $3,79 \times 10^{-4}$ \\
\hline 5 & 3370,88 & 520,88 & $5,56 \times 10^{-5}$ & 462,71 & $3,55 \times 10^{-4}$ \\
\hline 6 & 3331,21 & 481,21 & $7,49 \times 10^{-5}$ & 424,53 & $3,74 \times 10^{-4}$ \\
\hline 7 & 3384,62 & 534,62 & $5,60 \times 10^{-5}$ & 475,89 & $3,53 \times 10^{-4}$ \\
\hline 8 & 3383,09 & 533,09 & $5,71 \times 10^{-5}$ & 474,43 & $3,60 \times 10^{-4}$ \\
\hline \hline
\end{tabular}

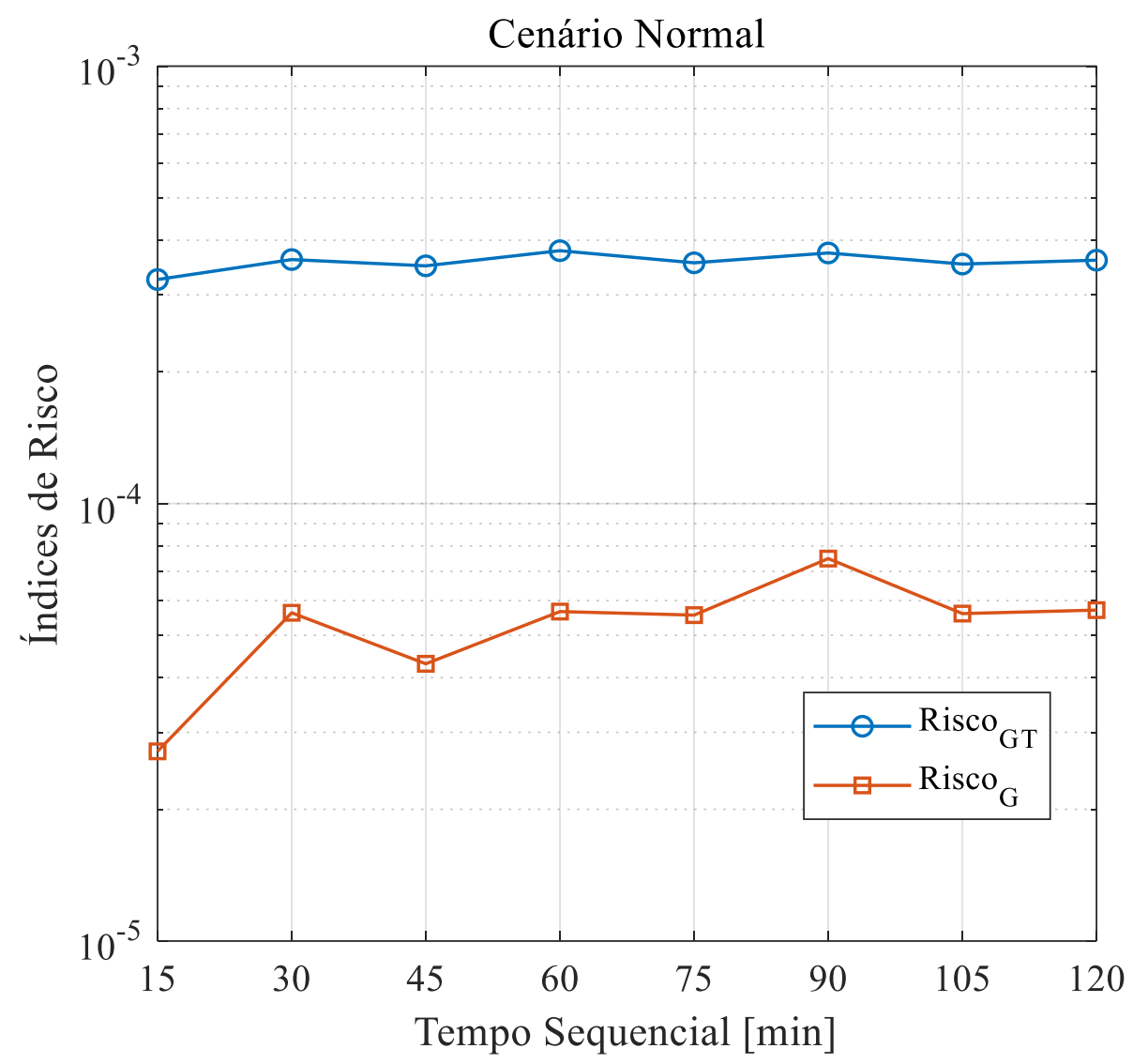

Figura 5.15: Índices de risco para o cenário "Normal" 
Na Figura 5.16 é possível observar a variação do risco de corte para os demais cenários (favorável, desfavorável, crescente e decrescente). É interessante observar que no cenário Desfavorável, devido ao baixo fator de capacidade de geração, o Riscogt torna-se mais sensível, respondendo de forma mais agressiva às pequenas variações de geração. Por outro lado, no cenário Favorável, como há maior disponibilidade de geração, o Risco ${ }_{G T}$ torna-se menos sensível às variações da geração eólica, refletindo que os problemas do sistema não estão associados à insuficiência de geração.

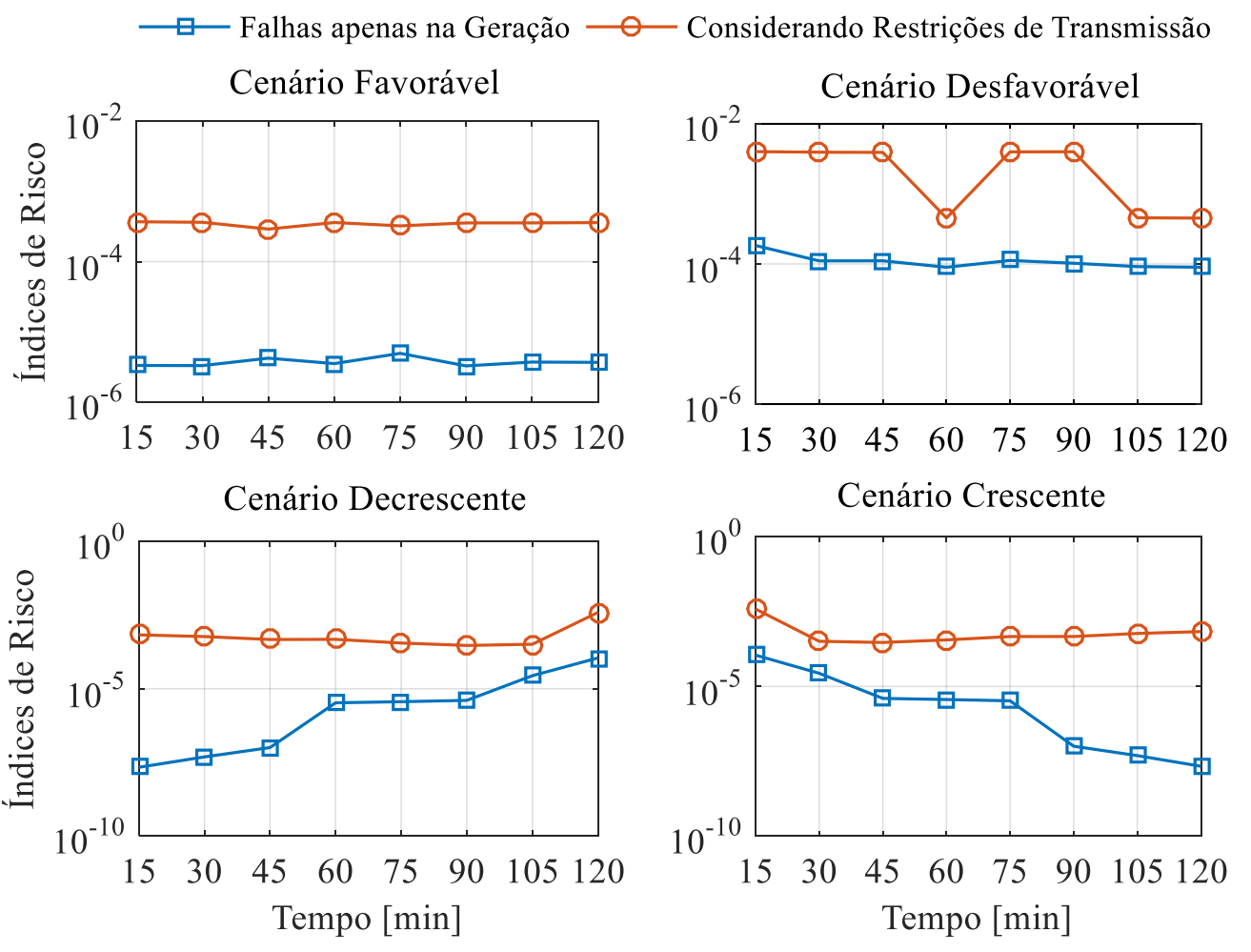

Figura 5.16: Risco nos cenários Favorável, Desfavorável, Crescente e Decrescente

Ainda na Figura 5.16 é possível observar que para os cenários Decrescente e Crescente, nem sempre despachar mais geração pode ser benéfico ao sistema. No cenário Crescente, a capacidade de geração é aumentada pela maior disponibilidade de vento, ao tentar despachar mais geração da fazenda eólica houve impacto no risco de corte de carga em função da limitação das capacidades das linhas de transmissão. No Apêndice C estão os valores numéricos dos índices de risco utilizados para gerar esta figura. 


\subsection{2.}

\section{Classificação dos Equipamentos via Amostragem por Importância}

Na Tabela 5.7 e na Tabela 5.8 são apresentados os cálculos do índice FDR para a classificação (ranking) dos equipamentos no Cenário Crescente (Sistema RTS Wind). No início do intervalo $\left(T_{\text {seq }}=1\right)$, os eventos de corte de carga ocorrem em função, principalmente, da insuficiência de geração. No final do período, como há elevada disponibilidade de vento, as linhas tornam-se mais importantes, pois o sistema requer capacidade de transmissão para escoar a geração eólica. Além disso, há um deslocamento da geração para uma região que já possui bastante reserva, o que diminui a geração despachada na região mais deficitária de geração. No curtoprazo, há uma diminuição da "flexibilidade" do sistema (maior risco de corte de carga).

Tabela 5.7: FDR para classificação dos equipamentos - IEEE RTS Wind:

Cenário Crescente; $T_{\text {seq }}=1$; Fator de Capacidade Eólico $=0,159 \mathrm{pu}$

\begin{tabular}{|c|c|c|c|c|c|c|}
\hline \hline Equipamento & $\begin{array}{c}\text { Cap. } \\
{[\mathrm{MW}]}\end{array}$ & $\begin{array}{c}\text { Barra i } \\
\text { ou } \\
\text { Barras i-j }\end{array}$ & $\begin{array}{c}\text { ORR } \\
\text { Original }\end{array}$ & $\begin{array}{c}\text { ORR } \\
\text { Distorcida }\end{array}$ & $\begin{array}{c}\text { FDR } \\
{[\%]}\end{array}$ & Ranking \\
\hline \hline GS & 400 & 18 & 0,9982 & 0,5342 & 46,48 & 1 \\
\hline GS & 400 & 21 & 0,9982 & 0,5400 & 45,90 & 2 \\
\hline LT & 175 & $8-10$ & 0,9999 & 0,9743 & 2,56 & 3 \\
\hline LT & 175 & $8-9$ & 0,9999 & 0,9747 & 2,52 & 4 \\
\hline LT & 175 & $7-8$ & 0,9999 & 0,9790 & 2,09 & 5 \\
\hline \hline
\end{tabular}


Tabela 5.8: FDR para classificação dos equipamentos - IEEE RTS Wind:

Cenário Crescente; $T_{\text {seq }}=8$; Fator de Capacidade Eólico $=0,505$ pu

\begin{tabular}{|c|c|c|c|c|c|c|}
\hline \hline Equipamento & $\begin{array}{c}\text { Cap. } \\
{[\mathrm{MW}]}\end{array}$ & $\begin{array}{c}\text { Barra i } \\
\text { ou } \\
\text { Barras i-j }\end{array}$ & $\begin{array}{c}\text { ORR } \\
\text { Original }\end{array}$ & $\begin{array}{c}\text { ORR } \\
\text { Distorcida }\end{array}$ & $\begin{array}{c}\text { FDR } \\
{[\%]}\end{array}$ & Ranking \\
\hline \hline LT & 500 & $23-12$ & 0,9999 & 0,8043 & 19,56 & 1 \\
\hline LT & 500 & $13-23$ & 0,9999 & 0,8355 & 16,44 & 2 \\
\hline LT & 175 & $8-9$ & 0,9999 & 0,8482 & 15,18 & 3 \\
\hline LT & 175 & $8-10$ & 0,9999 & 0,8650 & 13,50 & 4 \\
\hline LT & 500 & $15-24$ & 0,9999 & 0,8686 & 13,14 & 5 \\
\hline LT & 500 & $14-16$ & 0,9999 & 0,8823 & 11,76 & 6 \\
\hline LT & 175 & $7-8$ & 0,9999 & 0,9118 & 8,81 & 7 \\
\hline LT & 400 & $3-24$ & 0,9999 & 0,9837 & 1,63 & 8 \\
\hline \hline
\end{tabular}

\subsection{3.}

\section{Avaliação do Critério de Segurança Considerando o Sistema de Transmissão}

Na Figura 5.17 é possível observar o histograma com distribuição cumulativa do índice de risco de não suprimento da carga considerando a probabilidade de falha das unidades de geração e das linhas de transmissão. Neste caso, foram analisados três critérios de risco máximo, $10^{-4}, 10^{-3}$ e $10^{-2}$. Percebe-se que não foi possível satisfazer com segurança o critério de risco máximo igual a $10^{-4}$, uma vez que em todos os cenários analisados o risco foi superior ao valor máximo. O risco de $10^{-3}$ foi atendido parcialmente. Por outro lado, garante-se com $100 \%$ de segurança que há reserva de geração e capacidade de transporte para assegurar um risco máximo de $10^{-2}$, independentemente do cenário de geração eólica.

Em resumo, dependendo das características do sistema (tanto do ponto de vista de disponibilidade de reserva de geração quanto do ponto vista de topologia da rede de transmissão), caso seja requerido um valor de risco mais restritivo, pode não ser possível garantir a operação dentro dos critérios de segurança. 

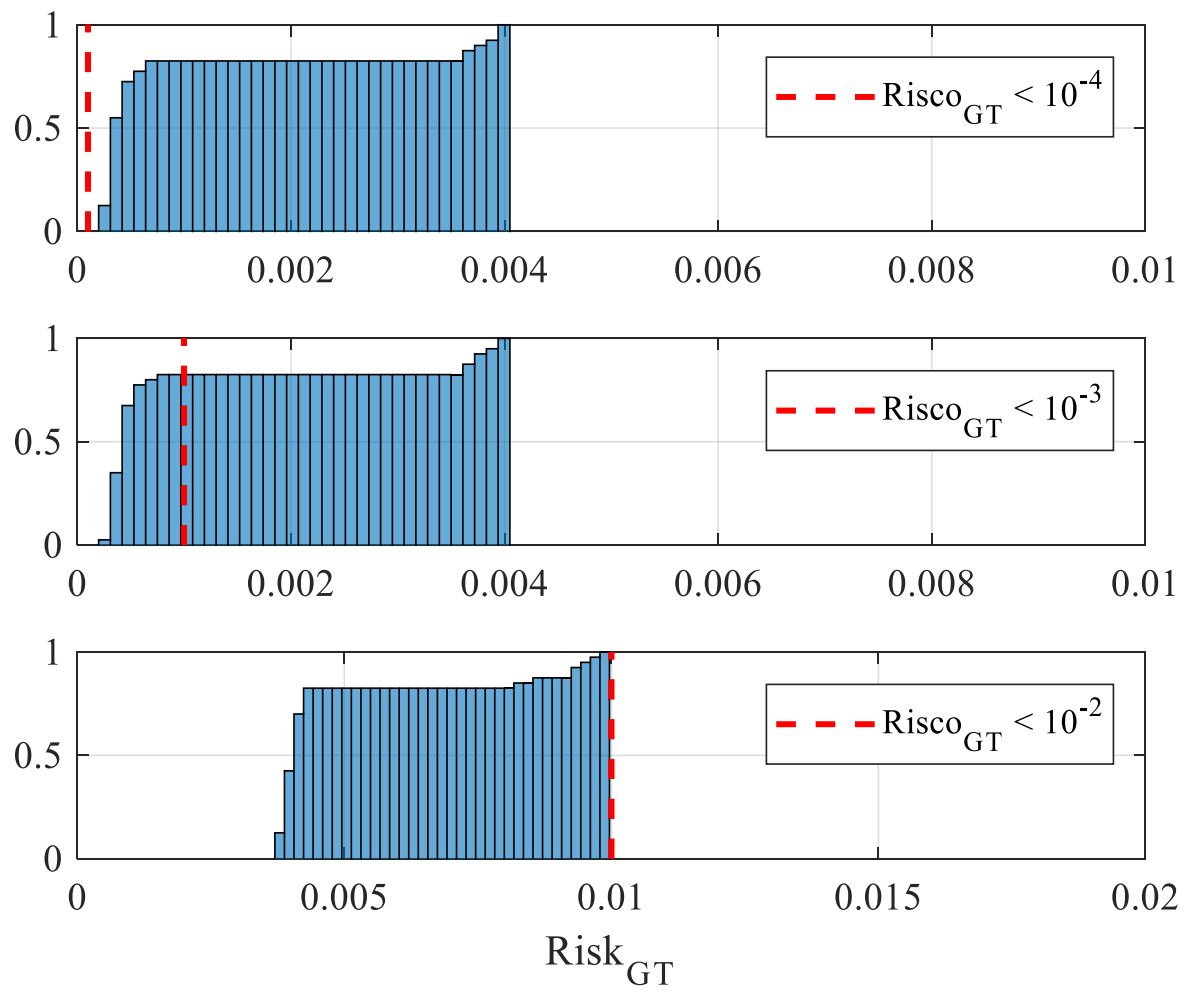

Figura 5.17: Histograma do risco composto

Na Figura 5.18 está ilustrado o montante de reserva em função do percentual da carga que seria necessário para tentar assegurar que o risco de corte, dada a ocorrência de cada cenário, seja inferior ao máximo permissível estabelecido. O risco (neste caso dado em segundos [s]) reflete o valor esperado do corte de carga, em cada cenário, no intervalo de simulação ( $T=7200 \mathrm{~s}$ ou 2 horas) e pode ser interpretado como um índice LOLE de curto-prazo,

$$
\operatorname{Risk}[s]=T[s] \times \operatorname{Risk} \text {. }
$$




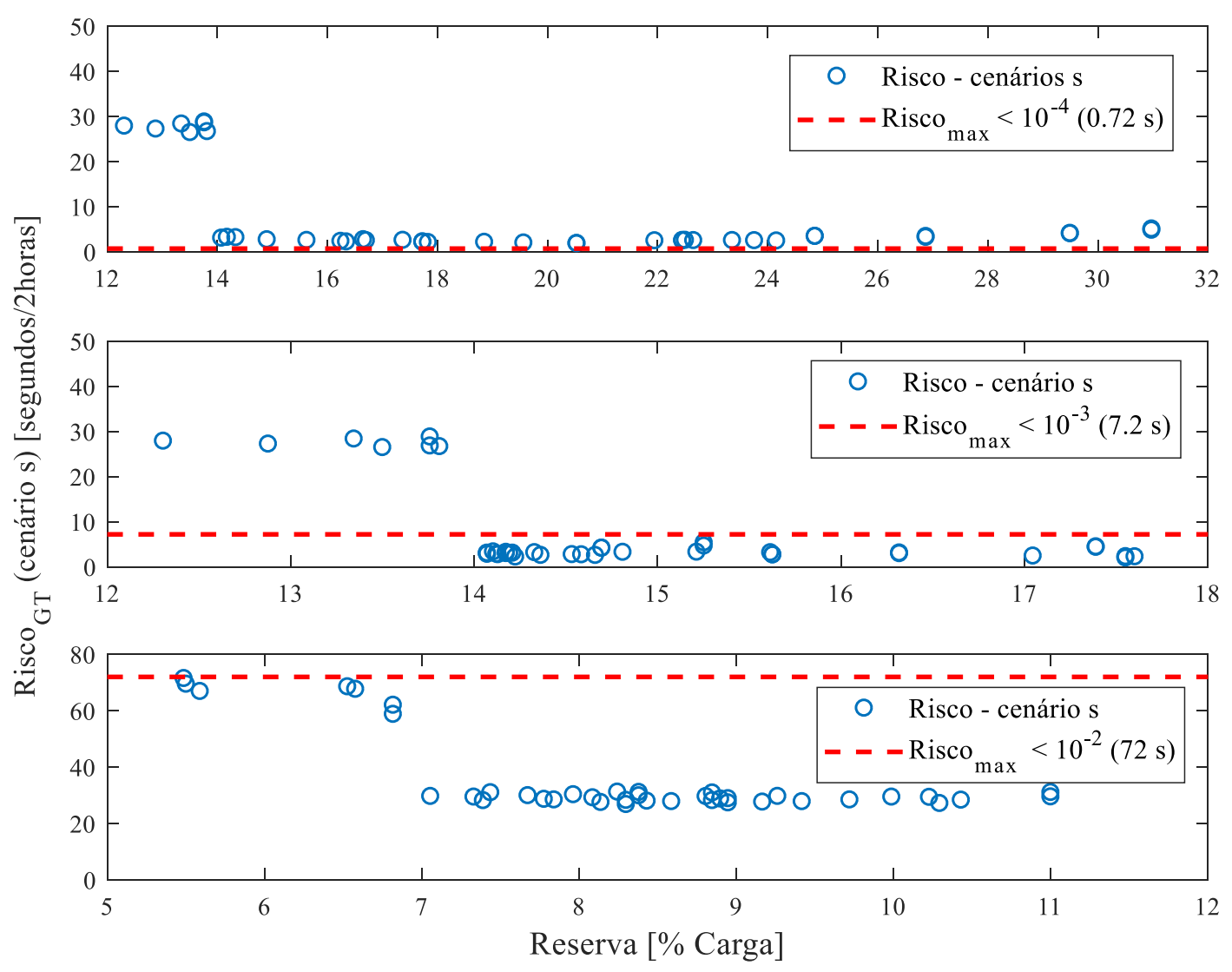

Figura 5.18: Risco e reserva como percentual da carga

No sistema IEEE Wind foram avaliados cinco cenários de vento, todos considerados equiprováveis. Para o critério de risco máximo de $10^{-2}$, programando um montante de reserva de até $11 \%$ da carga é possível garantir com segurança que o risco de corte de carga é inferior a 72 segundos (em cada cenário). Para Risk max $_{<}$ $10^{-3}$, seria necessário até $18 \%$ de reserva e para Risk $k_{\max }<10^{-4}$ até $32 \%$ (neste caso seriam empregadas todas as unidades disponíveis). Em outras palavras, quanto maior a aversão ao risco, maior será a quantidade de reserva girante. Nestes testes, considera-se que seria possível programar adequadamente a quantidade de máquinas a serem incluídas no despacho a cada intervalo de 15 minutos.

O risco de corte global do sistema (em segundos), embora não tenha sido mostrado nas figuras anteriores, pode ser estimado em função do risco no cenário e da probabilidade de ocorrência de cada cenário $\left(\mathrm{p}_{\mathrm{C}}\right)$,

$$
\operatorname{Risk}_{\text {system }}[s]=T[s] \sum_{\forall C} \operatorname{Risk}_{\mathrm{GT}} \times p_{C}
$$


Na Figura 5.19 é possível observar o histograma do risco supondo um número fixo de geradores durante o intervalo de duas horas simulado, para quatro possibilidades de programação: 783, 784, 785 e 786 unidades despachadas. Em cada um dos gráficos está mostrada a probabilidade acumulada do índice de risco (dada a ocorrência do cenário), que varia em função das diferentes disponibilidades de reserva (dependente do vento). Tendo como referência o critério de risco de $10^{-1}$, caso fossem programadas apenas 783 unidades haveria violação do risco em praticamente metade dos casos simulados (50\% de probabilidade de violação). Despachando 784 unidades, seria possível incrementar o nível de segurança, mas ainda haveria uma chance de cerca de $20 \%$ de não atender o risco estabelecido. Sincronizando mais uma unidade $(\mathrm{NU}=785)$ seria possível assegurar o atendimento ao limite de risco em qualquer cenário. A partir deste ponto, aumentar o número de unidade para 786 já não traria ganhos significativos de confiabilidade, refletindo a existência de reserva suficiente para lidar com os eventos de insuficiência de geração.
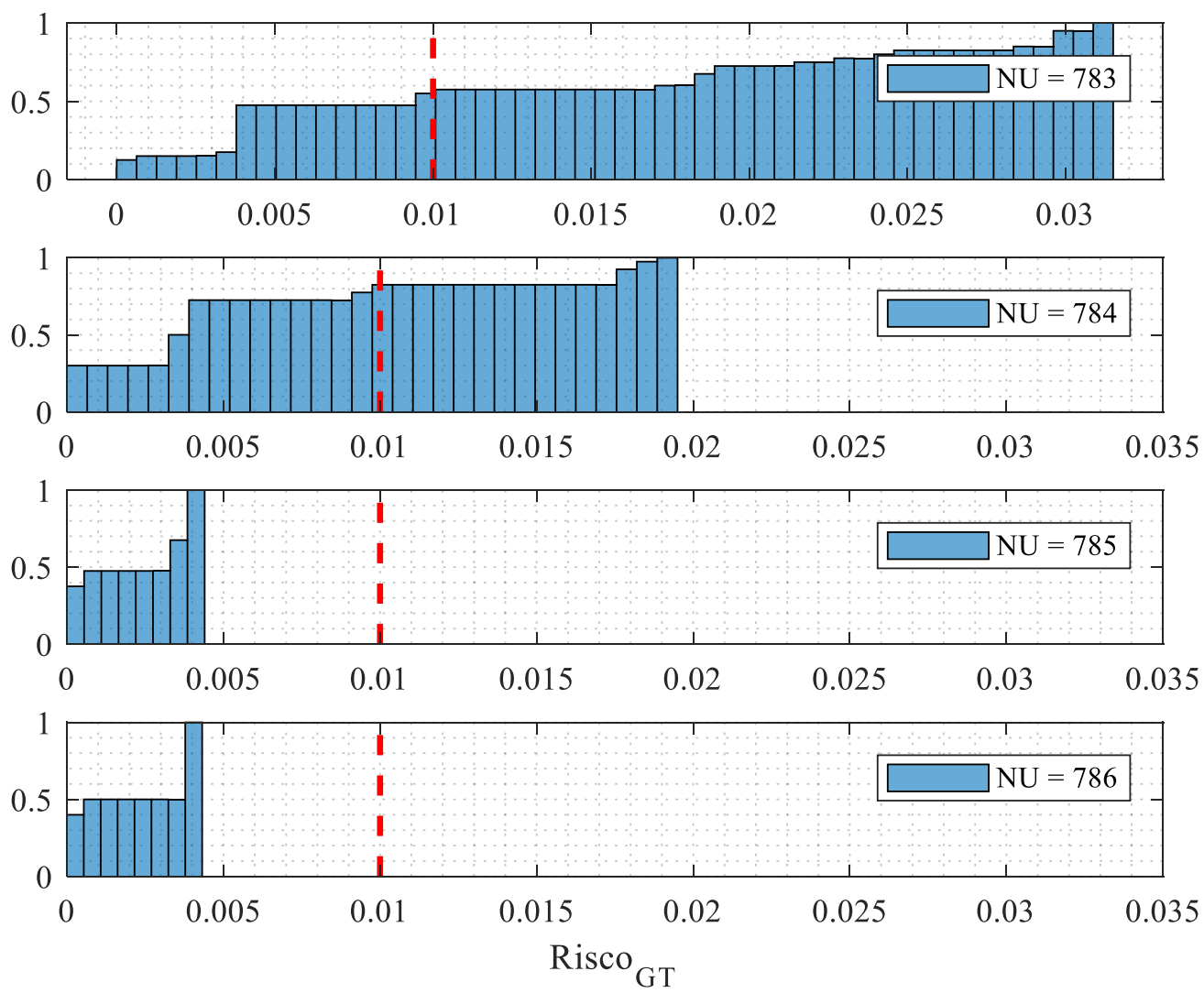

Figura 5.19: Risco em função do número de unidades 

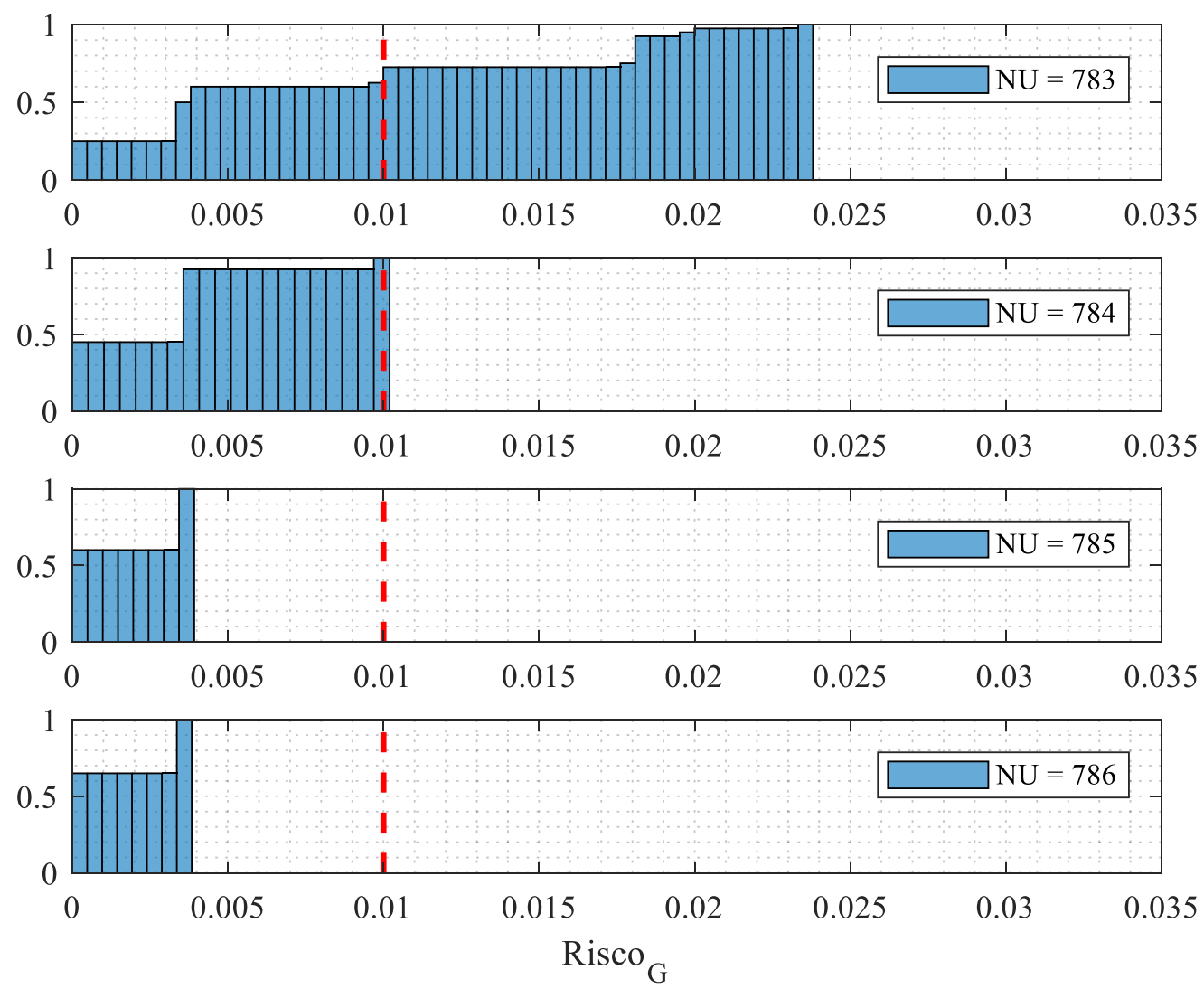

Figura 5.20: Risco desconsiderando as falhas e restrições de transmissão

Para continuar aumentando a segurança do sistema, o operador deverá adotar medidas que possam administrar os gargalos de transmissão ou incrementar a reserva de geração. Portanto, do ponto de vista de uma análise probabilística, poderia ser recomendada a programação de 785 unidades para compor a reserva girante. Desta forma, seria possível mitigar o risco de não suprimento de curto-prazo e garantir a segurança sistêmica frente às incertezas analisadas (falhas, volatilidade de eólicas, indisponibilidade de transmissão).

Na Figura 5.20 é possível observar o comportamento do risco para o mesmo teste da Figura 5.19, mas desconsiderando as falhas e limitações de capacidade das linhas de transmissão e transformadores. É possível observar que, neste caso, com apenas 784 unidades seria possível satisfazer com segurança o risco de $10^{-2}$. Desta forma, ao não observar as limitações do sistema de transmissão, o administrador do sistema poderia subdimensionar a reserva. 
No Apêndice A é possível observar os dados das unidades de geração, ordenadas segundo o custo de despacho. Das unidades de número 783 a 785 são adicionadas máquinas de $100 \mathrm{MW}$ de capacidade, a 786ª unidade é de $12 \mathrm{MW}$. Assim, é natural observar significativa redução do risco ao adicionar as três primeiras máquinas e uma redução marginal ao adicionar a $786^{\mathrm{a}}$ unidade (que tem capacidade relativamente menor).

\subsection{2.}

\section{Conclusões}

Uma nova metodologia para a avaliação da reserva girante em sistemas com elevada penetração de energia renovável foi proposta. A intermitência das fontes renováveis, em particular a variação da capacidade dos geradores eólicos, é representada por um modelo tempo-sequencial combinado de geração e carga, que foi desenvolvido especificamente para estudos com horizonte de tempo de planejamento de curto-prazo.

Em virtude do aumento significativo das incertezas associadas às fontes renováveis, um novo critério de segurança é também discutido, como complemento às técnicas tradicionais de avaliação de reserva baseadas no método PJM.

O índice de risco é estimado por meio do algoritmo SMC-QS-CE (simulação Monte Carlo quase sequencial via método da entropia cruzada), onde os parâmetros do estimador são apropriadamente distorcidos com base nos conceitos de entropia cruzada. Além disso, os resultados do processo de otimização estocástica empregados para obter as distorções dos parâmetros, foram também empregados para identificar e classificar os elementos que mais contribuem para a ocorrência de falhas no sistema.

O método SMC-QS-CE proposto é inicializado por meio de uma heurística baseada no critério da maior máquina. A integração de todas essas ferramentas demonstrou ser uma abordagem altamente eficiente do ponto de vista do esforço computacional, tendo em mente a complexidade inerente aos sistemas de grande porte com geração intermitente.

Os resultados numéricos obtidos com o sistema teste demonstraram a eficácia e robustez do método proposto. Embora apenas geração eólica tenha sido incluída 
nas análises, é possível incluir outros tipos de fontes variáveis, tais como solar/fotovoltaica, entre outras.

O método proposto foi estendido para analisar o efeito da presença do sistema de transmissão na estimação do índice de risco no problema do planejamento da operação de sistemas com elevada penetração de fontes renováveis, bem como outras incertezas inerentes ao problema do planejamento da reserva operativa.

Ao incluir a representação da rede de transmissão foi possível capturar o efeito da inserção de fontes voláteis. Demonstrou-se que nem sempre é globalmente benéfico aumentar a margem de reserva do sistema, uma vez que pode haver restrições de capacidade. Usando as avaliações de risco e conhecendo os elementos críticos do sistema, o planejador pode administrar a penetração de fontes voláteis, garantindo a operação sustentável e confiável mesmo com elevada margem de fontes renováveis.

No próximo capítulo será apresentada a abordagem de análise em sistemas multiárea e alguns exemplos de aplicação em um sistema real de maior porte. 


\section{6 Requisitos de Reserva em Sistemas Multiárea}

Em busca da eficiência econômica e da necessidade de transportar o excedente de geração aos centros de consumo, os sistemas elétricos têm evoluído na direção de se tornarem cada vez mais interligados, mais malhados e mais extensos.

Além do benefício econômico da operação interligada, com a introdução da competição nos sistemas de geração, as interligações buscam possibilitar o livre acesso ao sistema de transmissão aos consumidores, geradores e demais agentes setoriais envolvidos. Buscam ainda dar capacidade ao transporte de geração entre as diferentes regiões geoelétricas do sistema, em função da complementaridade dos recursos energéticos nas diferentes áreas dos sistemas de energia elétrica.

Neste capítulo analisa-se o impacto da alocação de reserva girante nas áreas do sistema, considerando a capacidade de intercambio por meio das linhas de interligação e as falhas das linhas de transmissão. Analisa-se também o impacto da inserção de fontes renováveis no perfil de risco das áreas e do sistema. Por fim, com o emprego da SMC Quase-sequencial e o modelo de geração e carga tempo-sequenciais, avalia-se a variação do perfil de risco de corte de carga com o tempo, para as áreas e para o sistema com a inserção de fontes renováveis (eólicas).

Entre os objetivos deste capítulo está a inclusão do sistema de transmissão em sistemas de grande porte considerando a abordagem multiárea, sendo observados os seguintes pontos:

- Estimação dos índices de risco por área elétrica;

- Análise do efeito das restrições de transmissão na provisão de reserva local e via intercâmbios;

- Análise dos índices de risco como subsídio para o planejamento da reserva de geração e alocação dos montantes em função das características do sistema.

- Aplicação da metodologia em um sistema real. 


\section{1.}

\section{Reserva Operativa no Sistema Multiárea}

Neste tópico será apresentado o desenvolvimento e fundamentação teórica da metodologia proposta, com a extensão do Método da Entropia Cruzada para o problema Multiárea. Na figura 6.1 ilustra-se a representação do sistema destacando as diferentes áreas e suas interligações via linhas de transmissão/interligação.

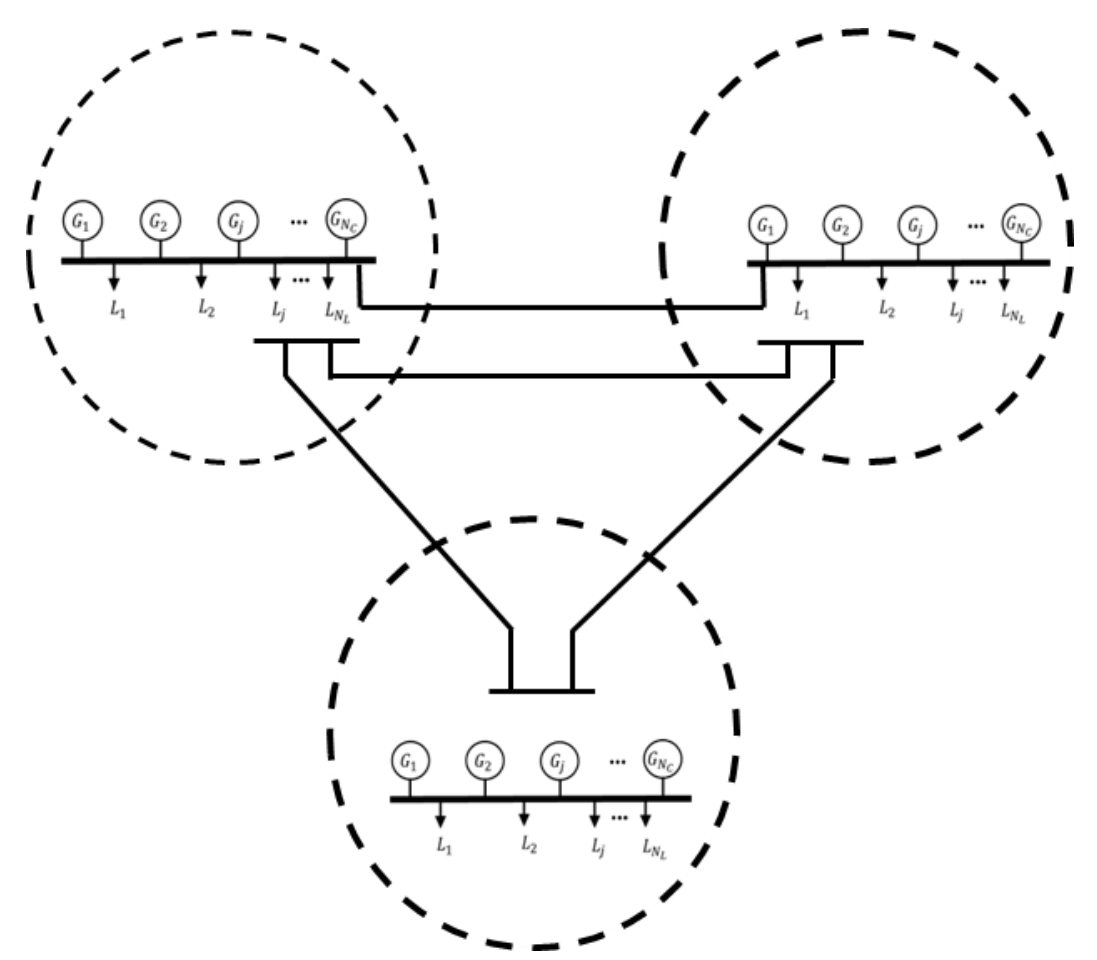

Figura 6.1: Sistema com interligações entre áreas elétricas

A reserva girante deve ser dimensionada e alocada em cada área considerando as flutuações de geração e as variações locais de carga, observando as previsões de demanda e de geração eólica nos diversos períodos do intervalo de planejamento.

De forma análoga ao exposto nos capítulos anteriores, a geração requerida para prover um determinado nível de confiabilidade no intervalo de tempo $t$, é função da capacidade das máquinas da área $\mathrm{A}_{i}$, que dispõe de $N U$ unidades locais, cuja fonte pode ser, por exemplo, hidráulica, térmica, solar, eólica, entre outras: 


$$
G^{\text {spin }}\left(t, N U, A_{i}\right)=G_{\text {hydro }}\left(t, A_{i}\right)+G_{\text {thermal }}\left(t, A_{i}\right)+G_{\text {wind }}\left(t, A_{i}\right) .
$$

A reserva girante em cada área é a diferença entre a geração e a carga,

$$
R\left(G^{\text {spin }}, L, t, A_{i}\right)=G^{\text {spin }}\left(\mathbf{C}_{G}, \lambda_{G}, t, A_{i}\right)-L\left(t, \boldsymbol{\delta}, A_{i}\right),
$$

Considerando a possibilidade de intercâmbio entre as áreas, a reserva da área pode ser incrementada importando geração por meio das linhas de interligação,

$$
R\left(G^{\text {spin }}, L, t, A_{i}\right)=G^{s p i n}\left(\mathbf{C}_{G}, \lambda_{G}, t, A_{i}\right)-L\left(t, \boldsymbol{\delta}, A_{i}\right)+\sum_{j \neq i} \Delta P_{j},
$$

onde $\Delta P_{j}$ é o balanço de potência de intercâmbio, considerando as importações e exportações, da interligação entre as áreas $A_{i}$ e $A_{j}$.

A geração do sistema é a soma das gerações de todas as áreas,

$$
G^{s p i n}(t, N U)=\sum_{\forall A_{i}} G^{s p i n}\left(t, N U, A_{i}\right)
$$

Da mesma forma, a reserva do sistema é a soma das reservas de cada área,

$$
R\left(G^{\text {spin }}, L, t\right)=\sum_{\forall A_{i}} R\left(G^{\text {spin }}, L, t, A_{i}\right)
$$

\section{2. \\ Método da Entropia Cruzada Aplicado ao Problema Multiárea}

O método da Entropia Cruzada pode ser aplicado ao problema da estimação dos riscos de corte de carga no problema multiárea com o objetivo de diminuir a quantidade de amostras a serem avaliadas e, consequentemente, o esforço computacional.

Os eventos de corte de carga devem ser avaliados para cada área. A função de desempenho $S(\mathrm{X})$ pode ser adaptada para capturar o corte de carga em cada área. Supõe-se que o risco pode ser estimado para cada área individualmente em um processo sequencial, em cada iteração apenas uma área é monitorada e convergida. O 
processo é repetido para todas as áreas de interesse. Alternativamente, é possível monitorar todas as áreas simultaneamente.

Empregando os conceitos do método CE em conjuntos com técnicas de Amostragem por Importância, os parâmetros da simulação podem ser distorcidos e as estimativas do índice de risco podem ser avaliadas para as áreas do sistema,

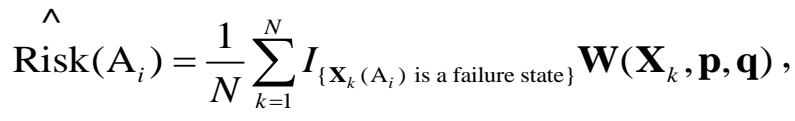

onde $\mathbf{W}\left(\mathbf{X}_{k}, \mathbf{p}, \mathbf{q}\right)$ é a razão de verossimilhança, $\mathbf{X}_{k}\left(\mathrm{~A}_{i}\right)$ é o vetor de estado da área, e q é o vetor de indisponibilidades de curto-prazo distorcidas, obtido a partir de $\mathbf{p}$.

No tópico a seguir são apresentados os resultados obtidos ao aplicar o método proposto ao sistema IEEE RTS e ao Sistema Norte e Nordeste Brasileiro (NNB Rede Básica).

\section{3. \\ Resultados - Sistema IEEE RTS}

O sistema IEEE RTS foi dividido em duas áreas, por grupos de níveis de tensão. Uma área corresponde a todas as barras no nível de $138 \mathrm{kV}$ e a outra área às barras com tensão base de $230 \mathrm{kV}$, conforme Fig. 6.2. As barras 3, 9 e 10 são barras de fronteira da Área $138 \mathrm{kV}$, interligam-se à Área $230 \mathrm{kV}$ com as barras $11,12 \mathrm{e}$ 24 por meio dos transformadores $138 / 230 \mathrm{kV}$.

Na obtenção dos resultados com o sistema IEEE RTS, foi considerado o valor de 0,01 MW como o montante mínimo de carga não suprida em uma barra qualquer para efeito de avaliação do risco. Assim, os cortes de carga maiores que 0,01 MW são os eventos de interesse usados na estimação dos índices de risco. Outros valores podem ser usados, quando definido em procedimentos dos órgãos reguladores setoriais. 


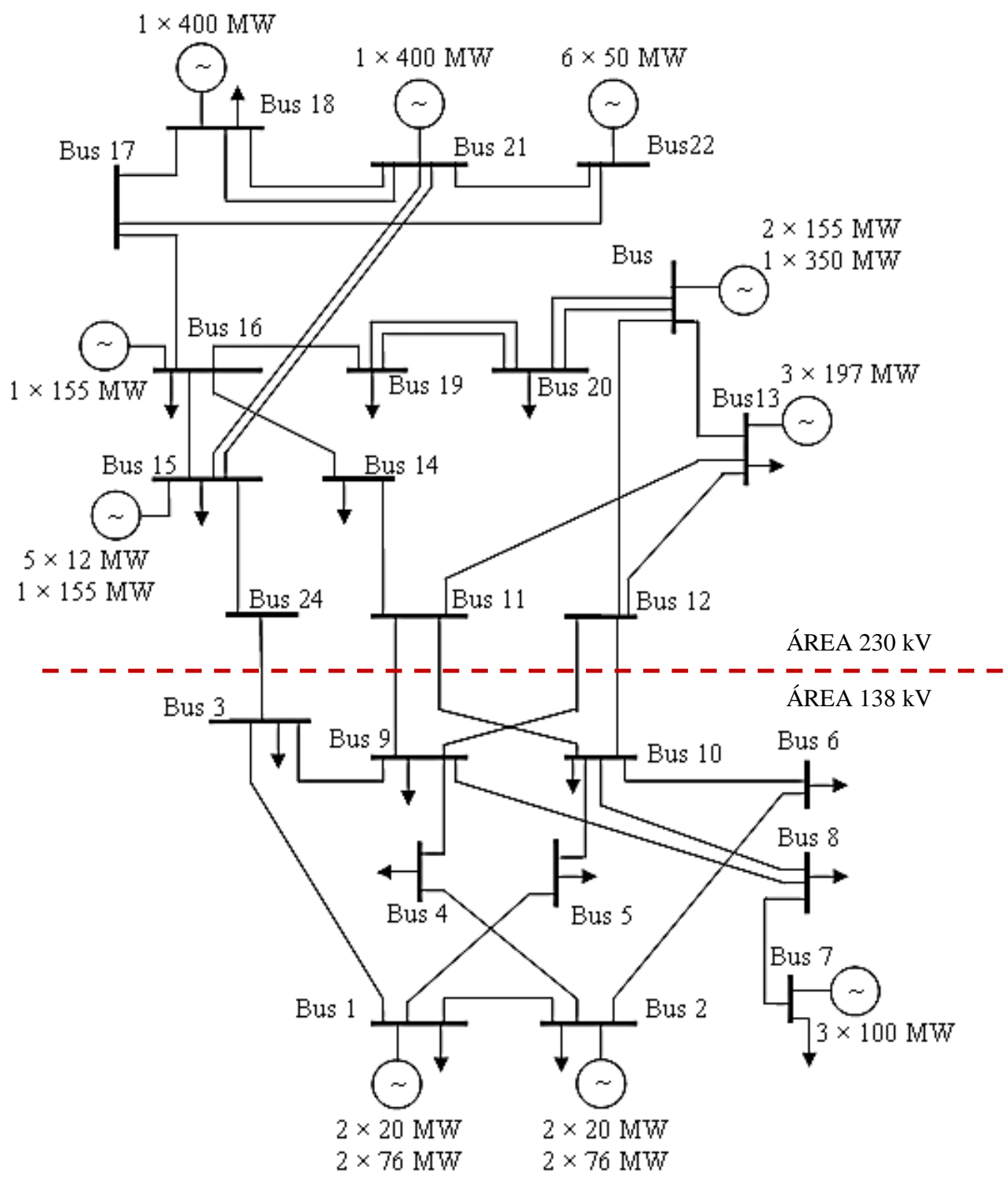

Figura 6.2: Áreas do sistema IEEE RTS-79

O despacho das estações geradoras será realizado seguindo a ordem de mérito de acordo com os custos de operação. Desta forma, as unidades com menor custo de operação são primeiramente despachadas. Na Tabela 6.1 estão listados os custos de referência utilizados para a formação da ordem de despacho para o sistema IEEE RTS original. 
Na Tabela 6.2 é apresentado o balanço geração-carga de cada área. Como pode ser observado, a área de $138 \mathrm{kV}$ é deficitária e a de $230 \mathrm{kV}$ é superavitária em 1203 MW de reserva, compensando para que o sistema tenha 555 MW de reserva global.

Tabela 6.1: Características do sistema de geração - IEEE RTS

\begin{tabular}{|c|c|c|c|c|c|c|c|}
\hline $\begin{array}{l}\text { Estação } \\
\text { Geradora }\end{array}$ & $\begin{array}{l}\text { Barramento } \\
\text { de Conexão }\end{array}$ & Área & $\mathrm{NU}$ & $\begin{array}{l}\text { Classe } \\
\text { (Tipo) }\end{array}$ & $\begin{array}{c}\text { Potência } \\
\text { Mínima } \\
{[\mathrm{MW}]}\end{array}$ & $\begin{array}{c}\text { Capacidade } \\
{[\mathrm{MW}]}\end{array}$ & $\begin{array}{l}\text { Custo de } \\
\text { Operação } \\
\text { [\$/MWh] }\end{array}$ \\
\hline 1 & 1 & 138 & 2 & 2 & 5 & 20 & 48,50 \\
\hline 2 & 1 & 138 & 2 & 4 & 15 & 76 & 15,30 \\
\hline 3 & 2 & 138 & 2 & 2 & 5 & 20 & 48,50 \\
\hline 4 & 2 & 138 & 2 & 4 & 15 & 76 & 15,30 \\
\hline 5 & 7 & 138 & 3 & 5 & 30 & 100 & 23,80 \\
\hline 6 & 13 & 230 & 3 & 7 & 40 & 197 & 22,80 \\
\hline 7 & 15 & 230 & 5 & 1 & 3 & 12 & 28,50 \\
\hline 8 & 15 & 230 & 1 & 6 & 40 & 155 & 12,44 \\
\hline 9 & 16 & 230 & 1 & 6 & 40 & 155 & 12,44 \\
\hline 10 & 18 & 230 & 1 & 9 & 100 & 400 & 6,30 \\
\hline 11 & 21 & 230 & 1 & 9 & 100 & 400 & 6,30 \\
\hline 12 & 22 & 230 & 6 & 3 & 8 & 50 & 10,00 \\
\hline 13 & 23 & 230 & 2 & 6 & 40 & 155 & 12,44 \\
\hline 14 & 23 & 230 & 1 & 8 & 75 & 350 & 12,10 \\
\hline
\end{tabular}

Tabela 6.2: Geração, carga e reserva de cada área

\begin{tabular}{|c|c|c|c|c|}
\hline Área & NU & $\begin{array}{c}\text { Capacidade de Geração } \\
{[\mathrm{MW}]}\end{array}$ & $\begin{array}{c}\text { Carga } \\
{[\mathrm{MW}]}\end{array}$ & $\begin{array}{c}\text { Reserva Estática } \\
{[\mathrm{MW}]}\end{array}$ \\
\hline $138 \mathrm{kV}$ & 11 & 684 & 1332 & -648 \\
\hline $230 \mathrm{kV}$ & 21 & 2721 & 1518 & 1203 \\
\hline Sistema & 32 & 3405 & 2850 & 555 \\
\hline
\end{tabular}


Nas tabelas 6.3 e 6.4 estão os montantes de reserva, por área, de acordo com o número de unidades, despachando de 20 a 32 unidades seguindo a ordem de mérito baseada no custo da operação do sistema completo.

Tabela 6.3: Área $1(138 \mathrm{kV})$ com $\mathrm{L}_{\text {pico }}\left(\mathrm{A}_{1}\right)=1332 \mathrm{MW}$

\begin{tabular}{|c|c|c|c|c|c|}
\hline \multirow{2}{*}{$\begin{array}{c}\text { Iteração } \\
1\end{array}$} & \multirow{2}{*}{\begin{tabular}{|c|}
$\begin{array}{c}\mathrm{NU} \\
\text { Área } 138 \mathrm{kV}\end{array}$ \\
4 \\
\end{tabular}} & \multirow{2}{*}{$\begin{array}{c}\begin{array}{c}\text { Geração } \\
\text { [MW] }\end{array} \\
304 \\
\end{array}$} & \multicolumn{3}{|c|}{$\begin{array}{c}\text { Reserva Local } \\
{[\mathrm{MW}]\left[\% \text { de } \mathrm{L}_{\text {pico }}\left(\mathrm{A}_{1}\right)\right]\left[\% \text { de } \mathrm{G}\left(A_{1}\right)\right]}\end{array}$} \\
\hline & & & -1028 & $-77,2$ & $-338,2$ \\
\hline 2 & 5 & 404 & -928 & $-69,7$ & $-229,7$ \\
\hline 3 & 6 & 504 & -828 & $-62,2$ & $-164,3$ \\
\hline 4 & 7 & 604 & -728 & $-54,7$ & $-120,5$ \\
\hline 5 & 7 & 604 & -728 & $-54,7$ & $-120,5$ \\
\hline 6 & 7 & 604 & -728 & $-54,7$ & $-120,5$ \\
\hline 7 & 7 & 604 & -728 & $-54,7$ & $-120,5$ \\
\hline 8 & 7 & 604 & -728 & $-54,7$ & $-120,5$ \\
\hline 9 & 7 & 604 & -728 & $-54,7$ & $-120,5$ \\
\hline 10 & 8 & 624 & -708 & $-53,2$ & $-113,5$ \\
\hline 11 & 9 & 644 & -688 & $-51,7$ & $-106,8$ \\
\hline 12 & 10 & 664 & -668 & $-50,2$ & $-100,6$ \\
\hline 13 & 11 & 684 & -648 & $-48,6$ & $-94,7$ \\
\hline
\end{tabular}

Tabela 6.4: Área $230 \mathrm{kV}$ com $\mathrm{L}_{\text {pico }}\left(\mathrm{A}_{2}\right)=1518 \mathrm{MW}$

\begin{tabular}{|c|c|c|c|c|c|}
\hline Iteração & $\begin{array}{c}\text { NU } \\
\text { Área } 230 \mathrm{kV}\end{array}$ & $\begin{array}{c}\text { Geração } \\
{[\mathrm{MW}]}\end{array}$ & \multicolumn{4}{|c|}{$\begin{array}{c}\text { Reserva } \\
{[\mathrm{MW}]\left[\% \text { de } \mathrm{L}_{\text {pico }}\left(\mathrm{A}_{2}\right)\right]\left[\% \mathrm{de} \mathrm{G}\left(A_{2}\right)\right]}\end{array}$} \\
\hline 1 & 16 & 2661 & 1143 & 75,3 & 43,0 \\
\hline 2 & 16 & 2661 & 1143 & 75,3 & 43,0 \\
\hline 3 & 16 & 2661 & 1143 & 75,3 & 43,0 \\
\hline 4 & 16 & 2661 & 1143 & 75,3 & 43,0 \\
\hline 5 & 17 & 2673 & 1155 & 76,1 & 43,2 \\
\hline 6 & 18 & 2685 & 1167 & 76,9 & 43,5 \\
\hline 7 & 19 & 2697 & 1179 & 77,7 & 43,7 \\
\hline 8 & 20 & 2709 & 1191 & 78,5 & 44,0 \\
\hline 9 & 21 & 2721 & 1203 & 79,2 & 44,2 \\
\hline 10 & 21 & 2721 & 1203 & 79,2 & 44,2 \\
\hline 11 & 21 & 2721 & 1203 & 79,2 & 44,2 \\
\hline 12 & 21 & 2721 & 1203 & 79,2 & 44,2 \\
\hline 13 & 21 & 2721 & 1203 & 79,2 & 44,2 \\
\hline
\end{tabular}

Nos tópicos a seguir são apresentados os valores dos índices de risco estimados considerando os aspectos associados aos efeitos da representação do sistema de transmissão. 


\subsection{1.}

\section{Cenário 1: Sem Restrições de Capacidade e sem Falha em Linhas de Transmissão}

Considerando o sistema de transmissão com capacidade ilimitada e sem falhas, o índice de risco é equivalente em todas as áreas e é igual ao risco de corte de carga do sistema completo. De fato, neste modelo simplificado todas as unidades de geração estão eletricamente conectadas à mesma barra, portanto todas as barras e áreas do sistema contribuem igualmente no esquema de corte de carga. O coeficiente de variação $\beta$ é observado para todas as áreas.

Tabela 6.5: Risco por área - Modelo Barra Única $\left(\beta_{\max }=1 \%, \forall \mathrm{A}_{\mathrm{i}}\right)$

\begin{tabular}{|c|c|c|c|c|c|c|}
\hline NU & $\begin{array}{c}\mathrm{T}_{\mathrm{CPU}} \\
{[\mathrm{s}]}\end{array}$ & $\begin{array}{c}\text { Geração } \\
\text { [MW] }\end{array}$ & $\begin{array}{l}\text { Reserva } \\
{[\mathrm{MW}]}\end{array}$ & $\begin{array}{c}\text { Risco } \\
\text { Sistema }\end{array}$ & $\begin{array}{c}\text { Risco } \\
\text { Área } 230 \mathrm{kV}\end{array}$ & $\begin{array}{c}\text { Risco } \\
\text { Área } 138 \mathrm{kV}\end{array}$ \\
\hline 20 & 1.02 & 2965 & 115 & 0,01972940 & 0,01972940 & 0,01972940 \\
\hline 21 & 2.31 & 3065 & 215 & 0,00562894 & 0,00562894 & 0,00562894 \\
\hline 22 & 1.84 & 3165 & 315 & 0,00539985 & 0,00539985 & 0,00539985 \\
\hline 23 & 2.17 & 3265 & 415 & 0,00015848 & 0,00015848 & 0,00015848 \\
\hline 24 & 5.00 & 3277 & 427 & 0,00015170 & 0,00015170 & 0,00015170 \\
\hline 25 & 3.59 & 3289 & 439 & 0,00015410 & 0,00015410 & 0,00015410 \\
\hline 26 & 3.27 & 3301 & 451 & 0,00012200 & 0,00012200 & 0,00012200 \\
\hline 27 & 2.98 & 3313 & 463 & 0,00011874 & 0,00011874 & 0,00011874 \\
\hline 28 & 2.61 & 3325 & 475 & 0,00012194 & 0,00012194 & 0,00012194 \\
\hline 29 & 2.61 & 3345 & 495 & 0,00010610 & 0,00010610 & 0,00010610 \\
\hline 30 & 3.39 & 3365 & 515 & 0,00007486 & 0,00007486 & 0,00007486 \\
\hline 31 & 2.28 & 3385 & 535 & 0,00007492 & 0,00007492 & 0,00007492 \\
\hline 32 & 3.30 & 3405 & 555 & 0,00003431 & 0,00003431 & 0,00003431 \\
\hline
\end{tabular}

Nas tabelas 6.5 e 6.6 foram utilizados os seguintes parâmetros de simulação $N_{\mathrm{CE}}=40.000$ e $\mathrm{L}_{\min }=0,01 \mathrm{MW}$. É possível observar que, como não há restrições de transmissão entre as áreas no sistema elétrico, o risco é o mesmo para qualquer região, uma vez que qualquer evento de insuficiência de geração é compartilhado 
para todas as barras. Nos próximos testes o sistema de transmissão será representado, sendo então possível analisar a confiabilidade de cada área por meio do risco de corte de carga nas barras da área.

Tabela 6.6: Risco por área - Modelo Barra Única $\left(\beta_{\max }=5 \%, \forall \mathrm{A}_{\mathrm{i}}\right)$

\begin{tabular}{|c|c|c|c|c|c|c|}
\hline $\mathrm{NU}$ & $\begin{array}{c}\mathrm{T}_{\mathrm{CPU}} \\
{[\mathrm{s}]}\end{array}$ & $\begin{array}{c}\text { Geração } \\
\text { [MW] }\end{array}$ & $\begin{array}{c}\text { Reserva } \\
{[\mathrm{MW}]}\end{array}$ & $\begin{array}{c}\text { Risco } \\
\text { Sistema }\end{array}$ & $\begin{array}{c}\text { Risco } \\
\text { Área } 230 \mathrm{kV}\end{array}$ & $\begin{array}{c}\text { Risco } \\
\text { Área } 138 \mathrm{kV}\end{array}$ \\
\hline 20 & 0.81 & 2965 & 115 & 0,01945561 & 0,01945561 & 0,01945561 \\
\hline 21 & 1.61 & 3065 & 215 & 0,00541898 & 0,00541898 & 0,00541898 \\
\hline 22 & 1.47 & 3165 & 315 & 0,00533762 & 0,00533762 & 0,00533762 \\
\hline 23 & 1.62 & 3265 & 415 & 0,00015964 & 0,00015964 & 0,00015964 \\
\hline 24 & 2.94 & 3277 & 427 & 0,00015464 & 0,00015464 & 0,00015440 \\
\hline 25 & 2.64 & 3289 & 439 & 0,00014836 & 0,00014836 & 0,00014836 \\
\hline 26 & 2.41 & 3301 & 451 & 0,00012446 & 0,00012446 & 0,00012426 \\
\hline 27 & 2.02 & 3313 & 463 & 0,00012204 & 0,00012204 & 0,00012204 \\
\hline 28 & 1.97 & 3325 & 475 & 0,00012591 & 0,00012591 & 0,00011598 \\
\hline 29 & 1.91 & 3345 & 495 & 0,00010278 & 0,00010278 & 0,00010278 \\
\hline 30 & 2.25 & 3365 & 515 & 0,00007561 & 0,00007561 & 0,00007561 \\
\hline 31 & 1.73 & 3385 & 535 & 0,00007212 & 0,00007212 & 0,00007212 \\
\hline 32 & 1.62 & 3405 & 555 & 0,00003453 & 0,00003453 & 0,00003453 \\
\hline
\end{tabular}

$\mathrm{O}$ teste $\operatorname{com} \beta_{\max }$ de $1 \%$ foi realizado para verificar se seria justificável empregar um menor coeficiente de variação para obter valores mais confiáveis. No modelo barra única, pode-se empregar $\beta_{\max }=5 \%$ sem perda de precisão (comparando as tabelas, os valores são relativamente próximos).

\subsection{2. Cenário 2: Sistema de Transmissão com Falhas, mas com Capaci- dade llimitada}

Na tabela a seguir é possível observar o índice de risco caso apenas as falhas do sistema de transmissão sejam representadas, desconsiderando as restrições de capacidade. Como no cenário de carga em análise as linhas operam com relativa folga, as falhas no sistema não apresentam efeito significativo. Neste teste foi admitido o redespacho de geração como medida corretiva.

Na Tabela 6.7 foram utilizados os seguintes parâmetros de simulação $N_{\mathrm{CE}}=$ 60.000 amostras, $\beta_{\max }=5 \%, \mathrm{~L}_{\min }=0,01 \mathrm{MW}$. 
Na Tabela 6.8 o teste anterior é repetido, mas desconsiderando a possibilidade de redespacho de geração. Como é possível observar analisando os resultados numéricos, não há impactos significativos nos índices de risco.

Tabela 6.7: Sistema de transmissão sem restrições - com redespacho $\left(\beta_{\max }=5 \%\right)$

\begin{tabular}{|c|c|c|c|c|c|c|}
\hline \hline $\mathrm{NU}$ & $\begin{array}{c}\mathrm{T}_{\text {CPU }} \\
{[\mathrm{s}]}\end{array}$ & $\begin{array}{c}\text { Geração } \\
{[\mathrm{MW}]}\end{array}$ & $\begin{array}{c}\text { Reserva } \\
{[\mathrm{MW}]}\end{array}$ & $\begin{array}{c}\text { Risco G\&T } \\
\text { Sistema }\end{array}$ & $\begin{array}{c}\text { Risco } \\
\text { Área } 230 \mathrm{kV}\end{array}$ & $\begin{array}{c}\text { Risco } \\
\text { Área } 138 \mathrm{kV}\end{array}$ \\
\hline \hline 20 & 1.28 & 2965 & 115 & 0,01966630 & 0,01966630 & 0,01966630 \\
\hline 21 & 2.36 & 3065 & 215 & 0,00539158 & 0,00534061 & 0,00539158 \\
\hline 22 & 2.11 & 3165 & 315 & 0,00574528 & 0,00574528 & 0,00574528 \\
\hline 23 & 2.52 & 3265 & 415 & 0,00015963 & 0,00015963 & 0,00015963 \\
\hline 24 & 4.45 & 3277 & 427 & 0,00014925 & 0,00014925 & 0,00014925 \\
\hline 25 & 3.27 & 3289 & 439 & 0,00014978 & 0,00014978 & 0,00014978 \\
\hline 26 & 3.02 & 3301 & 451 & 0,00012464 & 0,00012464 & 0,00012464 \\
\hline 27 & 2.84 & 3313 & 463 & 0,00011634 & 0,00011634 & 0,00011634 \\
\hline 28 & 2.86 & 3325 & 475 & 0,00012422 & 0,00012422 & 0,00012422 \\
\hline 29 & 2.67 & 3345 & 495 & 0,00010332 & 0,00010332 & 0,00010332 \\
\hline 30 & 2.67 & 3365 & 515 & 0,00007674 & 0,00007674 & 0,00007674 \\
\hline 31 & 2.52 & 3385 & 535 & 0,00007310 & 0,00007310 & 0,00007310 \\
\hline 32 & 2.48 & 3405 & 555 & 0,00003291 & 0,00003291 & 0,00003291 \\
\hline \hline
\end{tabular}

Tabela 6.8: Sistema de transmissão sem restrições $-\operatorname{sem}$ redespacho $\left(\beta_{\max }=5 \%\right)$

\begin{tabular}{|c|c|c|c|c|c|c|}
\hline \hline $\mathrm{NU}$ & $\begin{array}{c}\mathrm{T}_{\mathrm{CPU}} \\
{[\mathrm{s}]}\end{array}$ & $\begin{array}{c}\text { Geração } \\
{[\mathrm{MW}]}\end{array}$ & $\begin{array}{c}\text { Reserva } \\
{[\mathrm{MW}]}\end{array}$ & $\begin{array}{c}\text { Risco G\&T } \\
\text { Sistema }\end{array}$ & $\begin{array}{c}\text { Risco } \\
\text { Área } 230 \mathrm{kV}\end{array}$ & $\begin{array}{c}\text { Risco } \\
\text { Área } 138 \mathrm{kV}\end{array}$ \\
\hline \hline 20 & 1.20 & 2965 & 115 & 0,01966630 & 0,01966630 & 0,01966630 \\
\hline 21 & 2.22 & 3065 & 215 & 0,00539158 & 0,00534061 & 0,00539158 \\
\hline 22 & 1.98 & 3165 & 315 & 0,00574528 & 0,00574528 & 0,00574528 \\
\hline 23 & 2.17 & 3265 & 415 & 0,00015963 & 0,00015963 & 0,00015963 \\
\hline 24 & 3.67 & 3277 & 427 & 0,00014925 & 0,00014925 & 0,00014925 \\
\hline 25 & 2.91 & 3289 & 439 & 0,00014978 & 0,00014978 & 0,00014978 \\
\hline 26 & 2.72 & 3301 & 451 & 0,00012464 & 0,00012464 & 0,00012464 \\
\hline 27 & 2.64 & 3313 & 463 & 0,00011634 & 0,00011634 & 0,00011634 \\
\hline 28 & 2.56 & 3325 & 475 & 0,00012422 & 0,00012422 & 0,00012422 \\
\hline 29 & 2.42 & 3345 & 495 & 0,00010332 & 0,00010332 & 0,00010332 \\
\hline 30 & 2.47 & 3365 & 515 & 0,00007674 & 0,00007674 & 0,00007674 \\
\hline 31 & 2.41 & 3385 & 535 & 0,00007310 & 0,00007310 & 0,00007310 \\
\hline 32 & 2.38 & 3405 & 555 & 0,00003291 & 0,00003291 & 0,00003291 \\
\hline \hline
\end{tabular}




\subsection{3. \\ Cenário 3: Sistema de Transmissão com Falhas e considerando as Capacidades Nominais das Linhas de Transmissão}

Na Tabela 6.9 a seguir estão os resultados considerando o sistema de transmissão: suas restrições e falhas. Neste caso, para efeito de análise, foi admitido o redespacho de geração como medida corretiva. O índice de risco do sistema é levemente superior ao estimado anteriormente supondo o sistema de transmissão ilimitado e totalmente confiável.

O risco nas duas áreas é equivalente e, como nos cenários anteriores, é aproximadamente igual ao risco do sistema.

Tabela 6.9: Representação das restrições e falhas $-\operatorname{com}$ redespacho $\left(\beta_{\max }=5 \%\right)$

\begin{tabular}{|c|c|c|c|c|c|c|}
\hline \hline NU & $\begin{array}{c}\mathrm{T}_{\mathrm{CPU}} \\
{[\mathrm{s}]}\end{array}$ & $\begin{array}{c}\text { Geração } \\
{[\mathrm{MW}]}\end{array}$ & $\begin{array}{c}\text { Reserva } \\
{[\mathrm{MW}]}\end{array}$ & $\begin{array}{c}\text { Risco G\&T } \\
\text { Sistema }\end{array}$ & $\begin{array}{c}\text { Risco } \\
\text { Área } 230 \mathrm{kV}\end{array}$ & $\begin{array}{c}\text { Risco } \\
\text { Área } 138 \mathrm{kV}\end{array}$ \\
\hline \hline 20 & 1.91 & 2695 & 115 & 0,02019514 & 0,02010961 & 0,02019514 \\
\hline 21 & 6.80 & 3065 & 215 & 0,00579237 & 0,00552163 & 0,00579237 \\
\hline 22 & 3.05 & 3165 & 315 & 0,00535556 & 0,00535556 & 0,00535556 \\
\hline 23 & 3.97 & 3265 & 415 & 0,00015763 & 0,00015763 & 0,00015763 \\
\hline 24 & 7.72 & 3277 & 427 & 0,00014972 & 0,00014972 & 0,00014972 \\
\hline 25 & 5.80 & 3289 & 439 & 0,00015057 & 0,00015057 & 0,00015057 \\
\hline 26 & 5.38 & 3301 & 451 & 0,00012180 & 0,00012180 & 0,00012180 \\
\hline 27 & 5.56 & 3313 & 463 & 0,00012408 & 0,00012408 & 0,00012408 \\
\hline 28 & 4.45 & 3325 & 475 & 0,00012025 & 0,00012025 & 0,00012025 \\
\hline 29 & 4.55 & 3345 & 495 & 0,00010551 & 0,00010551 & 0,00010551 \\
\hline 30 & 4.36 & 3365 & 515 & 0,00007396 & 0,00007396 & 0,00007396 \\
\hline 31 & 4.45 & 3385 & 535 & 0,00007391 & 0,00007391 & 0,00007391 \\
\hline 32 & 4.72 & 3405 & 555 & 0,00003477 & 0,00003477 & 0,00003477 \\
\hline \hline
\end{tabular}

Nas tabelas acima foram utilizados os seguintes parâmetros de simulação $N_{\mathrm{CE}}$ $=80.000$ amostras, $\beta_{\max }=1 \%, L_{\min }=0,01 \mathrm{MW}$.

No sistema IEEE RTS, adotando a medida corretiva de redespacho de geração, os riscos são equitativos nas áreas, mesmo considerando as falhas e as limitações de capacidade de linhas de transmissão. O RTS apresenta um sistema de transmissão reconhecidamente robusto, fato já descrito em diversos trabalhos. 


\subsection{4.}

\section{Cenário 4: Sistema de Transmissão - Sem redespacho de Geração}

$\mathrm{Na}$ operação dos sistemas elétricos no curto prazo pode não ser possível efetuar o redespacho como medida corretiva. Em alguns cenários opta-se pelos esquemas de alívio de carga, que podem ser implementados por rejeição/corte de carga ou por ajuste do perfil de tensão. Os valores de risco dados na Tabela 6.10 foram estimados admitindo a impossibilidade (i.e., impraticidade) de efetuar o redespacho de geração.

Com a representação do sistema de transmissão e do esquema de corte de carga locacional o índice de risco estimado reflete apropriadamente o desempenho das áreas do sistema, em termos de grau de adequação do fornecimento. Ao restringir o redespacho, o índice pode inclusive refletir o grau de segurança estática do sistema.

Da Tabela 6.10 é possível observar que os índices de risco são distintos em cada área; reflexo dos níveis de geração, capacidade de transmissão e falhas dos componentes de cada área. Também é possível observar que a Área de $230 \mathrm{kV}$ é mais confiável (apresenta menores valores de risco) e que as ocorrências de corte de carga do sistema estão predominantemente localizadas na Área de $138 \mathrm{kV}$.

Tabela 6.10: Transmissão representada e geração sem redespacho $\left(\beta_{\max }=5 \%\right)$

\begin{tabular}{|c|c|c|c|c|c|c|}
\hline \hline NU & $\begin{array}{c}\mathrm{T}_{\text {CPU }} \\
{[\mathrm{s}]}\end{array}$ & $\begin{array}{c}\text { Geração } \\
{[\mathrm{MW}]}\end{array}$ & $\begin{array}{c}\text { Reserva } \\
{[\mathrm{MW}]}\end{array}$ & $\begin{array}{c}\text { Risco G\&T } \\
\text { Sistema }\end{array}$ & $\begin{array}{c}\text { Risco } \\
\text { Área 230 kV }\end{array}$ & $\begin{array}{c}\text { Risco } \\
\text { Área 138 kV }\end{array}$ \\
\hline \hline 20 & 1.75 & 2695 & 115 & 0,02109175 & 0,02099038 & 0,02109175 \\
\hline 21 & 5.06 & 3065 & 215 & 0,00560686 & 0,00546981 & 0,00560686 \\
\hline 22 & 4.84 & 3165 & 315 & 0,00534709 & 0,00523600 & 0,00534709 \\
\hline 23 & 7.50 & 3265 & 415 & 0,00035044 & 0,00015599 & 0,00035044 \\
\hline 24 & 10.95 & 3277 & 427 & 0,00035567 & 0,00015249 & 0,00035567 \\
\hline 25 & 8.95 & 3289 & 439 & 0,00035918 & 0,00015344 & 0,00035901 \\
\hline 26 & 10.02 & 3301 & 451 & 0,00031957 & 0,00012662 & 0,00031957 \\
\hline 27 & 9.44 & 3313 & 463 & 0,00031337 & 0,00011660 & 0,00031327 \\
\hline 28 & 9.86 & 3325 & 475 & 0,00031464 & 0,00011145 & 0,00031464 \\
\hline 29 & 10.78 & 3345 & 495 & 0,00029718 & 0,00009712 & 0,00029718 \\
\hline 30 & 15.69 & 3365 & 515 & 0,00027079 & 0,00006952 & 0,00027075 \\
\hline 31 & 14.95 & 3385 & 535 & 0,00026761 & 0,00006970 & 0,00026757 \\
\hline 32 & 52.34 & 3405 & 555 & 0,00023087 & 0,00003253 & 0,00023086 \\
\hline \hline
\end{tabular}


$\mathrm{Na}$ Tabela 6.10 acima as estimações foram obtidas observando o coeficiente de variação máximo de cinco por cento $\left(\beta_{\max }=5 \%\right)$, considerando o coeficiente de variação dos índices por área. No entanto, para uma maior precisão das estimações em cada área de interesse, na Tabela 6.11 exibe-se como o índice de risco considerando um coeficiente de variação máximo de $1 \%$. Por meio deste teste é possível concluir que com a tolerância $\beta_{\max }$ de $5 \%$ os resultados são confiáveis e evita-se o maior esforço computacional caso fosse empregado menor valor para o coeficiente de variação (e.g., $\beta_{\max }=1 \%$ ).

Tabela 6.11: Transmissão representada e geração sem redespacho $\left(\beta_{\max }=1 \%\right)$

\begin{tabular}{|c|c|c|c|c|c|c|}
\hline $\mathrm{NU}$ & $\begin{array}{c}\mathrm{T}_{\mathrm{CPU}} \\
{[\mathrm{s}]}\end{array}$ & $\begin{array}{c}\text { Geração } \\
{[\mathrm{MW}]}\end{array}$ & $\begin{array}{c}\text { Reserva } \\
{[\mathrm{MW}]}\end{array}$ & $\begin{array}{c}\text { Risco G\&T } \\
\text { Sistema }\end{array}$ & $\begin{array}{c}\text { Risco } \\
\text { Área } 230 \mathrm{kV}\end{array}$ & $\begin{array}{c}\text { Risco } \\
\text { Área } 138 \mathrm{kV}\end{array}$ \\
\hline 20 & 2.11 & 2695 & 115 & 0,02019514 & 0,02010961 & 0,02019514 \\
\hline 21 & 7.92 & 3065 & 215 & 0,00579402 & 0,00552295 & 0,00579402 \\
\hline 22 & 6.50 & 3165 & 315 & 0,00556373 & 0,00537317 & 0,00556373 \\
\hline 23 & 85.11 & 3265 & 415 & 0,00035880 & 0,00016051 & 0,00035875 \\
\hline 24 & 86.22 & 3277 & 427 & 0,00034756 & 0,00015107 & 0,00034755 \\
\hline 25 & 94.78 & 3289 & 439 & 0,00034951 & 0,00015108 & 0,00034949 \\
\hline 26 & 116.06 & 3301 & 451 & 0,00031935 & 0,00012054 & 0,00031932 \\
\hline 27 & 124.56 & 3313 & 463 & 0,00031849 & 0,00012026 & 0,00031848 \\
\hline 28 & 129.89 & 3325 & 475 & 0,00031879 & 0,00012003 & 0,00031876 \\
\hline 29 & 150.97 & 3345 & 495 & 0,00030372 & 0,00010659 & 0,00030370 \\
\hline 30 & 321.08 & 3365 & 515 & 0,00027317 & 0,00007462 & 0,00027315 \\
\hline 31 & 295.69 & 3385 & 535 & 0,00027311 & 0,00007538 & 0,00027309 \\
\hline 32 & 4235.77 & 3405 & 555 & 0,00023343 & 0,00003529 & 0,00023260 \\
\hline
\end{tabular}

Na Figura 6.3 são reproduzidos os resultados da Tabela 6.11, sendo possível observar claramente que o risco é diferente entre as áreas.

Em função da raridade dos eventos (o risco é menor ao ser segmentado por áreas), o tempo de simulação sofre aumento significativo. Isto ocorre porque as distorções são obtidas para minimizar a variância dos índices do sistema e não da área. Para superar esse efeito indesejado, a função de desempenho deve ser modificada. Uma possibilidade é usar o corte de carga da área cujo índice de risco é mais raro como classificador da importância dos eventos. 


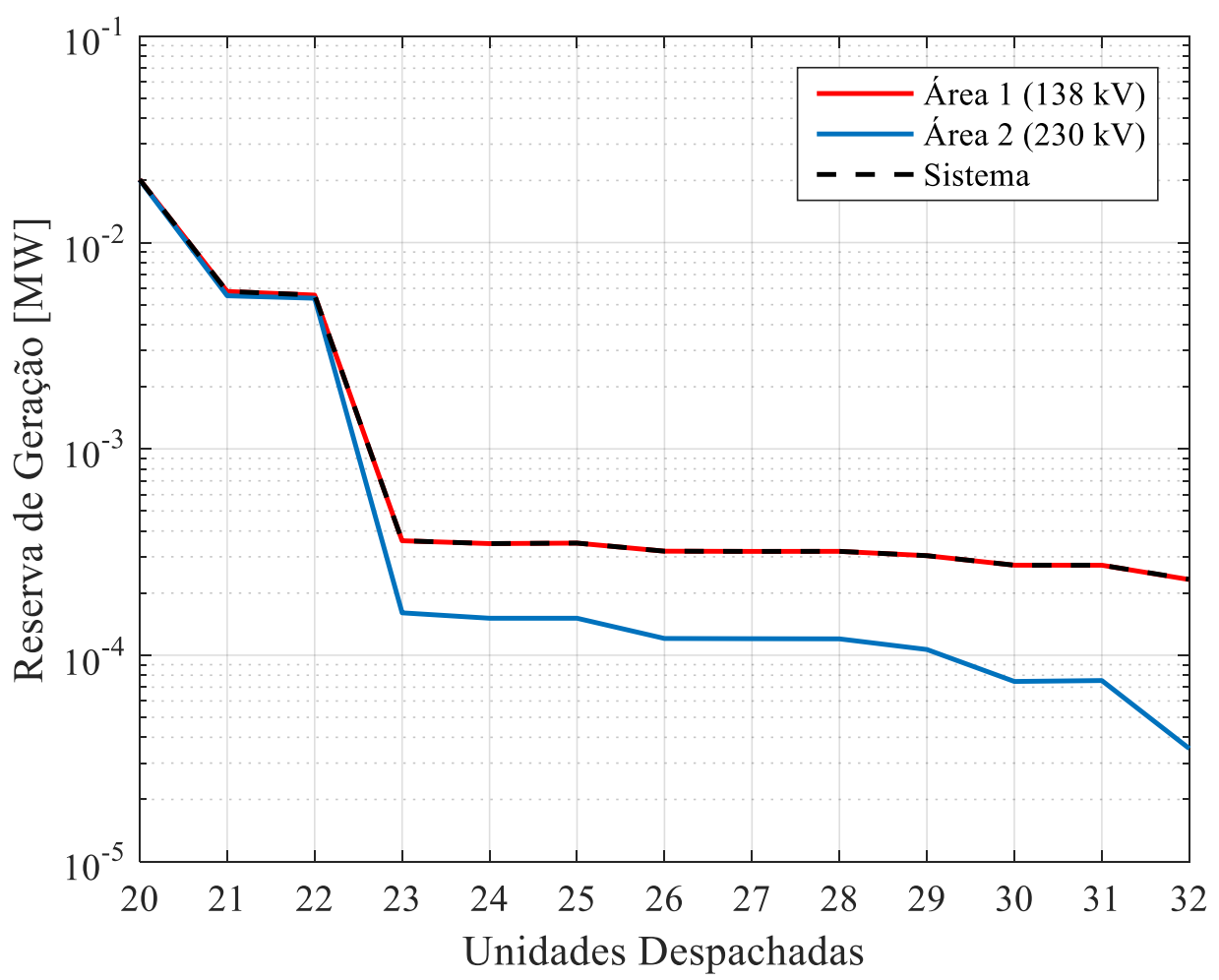

Figura 6.3: Índices de Risco do sistema e das áreas

\subsection{5.}

\section{Cenário 5: Efeito das Restrições de Transporte entre as Áreas}

As linhas de transmissão que transportam a geração entre as áreas do sistema de potência são usualmente denominadas linhas de interligação (LI). No sistema IEEE RTS, por tratar-se de um sistema altamente malhado, a interligação é realizada exclusivamente por meio de transformadores de 138/230 kV de $400 \mathrm{MW}$. Neste teste, a capacidade das interligações será gradativamente decrescida. Representado, por exemplo, a ocorrência de restrições operativas de fluxo de geração ou de restrições de balanço de mercado entre áreas. Assim, nos próximos testes a capacidade dos transformadores da interligação entre as áreas será restringida para 90, 80 e $70 \%$ da capacidade emergencial de curto-prazo.

É possível observar que restringindo o intercâmbio de geração entre as áreas os índices de risco tendem a se distanciar. De fato, devido às restrições de intercâmbio, cada área poderá responder às ocorrências de contingências usando os montan- 
tes de reserva alocados na própria área. Apenas por meio da representação das restrições do sistema de transmissão é possível observar o impacto nos índices de risco do grau de adequação da alocação espacial da reserva.

Tabela 6.12: Região de fronteira com $90 \%$ de capacidade

\begin{tabular}{|c|c|c|c|c|c|c|}
\hline \hline NU & $\begin{array}{c}\mathrm{T}_{\mathrm{CPU}} \\
{[\mathrm{s}]}\end{array}$ & $\begin{array}{c}\text { Geração } \\
{[\mathrm{MW}]}\end{array}$ & $\begin{array}{c}\text { Reserva } \\
{[\mathrm{MW}]}\end{array}$ & $\begin{array}{c}\text { Risco G\&T } \\
\text { Sistema }\end{array}$ & $\begin{array}{c}\text { Risco } \\
\text { Área } 230 \mathrm{kV}\end{array}$ & $\begin{array}{c}\text { Risco } \\
\text { Área } 138 \mathrm{kV}\end{array}$ \\
\hline \hline 20 & 1.73 & 2965 & 115 & 0,02109175 & 0,02099038 & 0,02109175 \\
\hline 21 & 5.09 & 3065 & 215 & 0,00560686 & 0,00546981 & 0,00560686 \\
\hline 22 & 4.83 & 3165 & 315 & 0,00534709 & 0,00523600 & 0,00534709 \\
\hline 23 & 7.53 & 3265 & 415 & 0,00035044 & 0,00015599 & 0,00035044 \\
\hline 24 & 10.47 & 3277 & 427 & 0,00035567 & 0,00015249 & 0,00035567 \\
\hline 25 & 9.31 & 3289 & 439 & 0,00035918 & 0,00015344 & 0,00035901 \\
\hline 26 & 10.95 & 3301 & 451 & 0,00031957 & 0,00012662 & 0,00031957 \\
\hline 27 & 10.91 & 3313 & 463 & 0,00031337 & 0,00011660 & 0,00031327 \\
\hline 28 & 10.36 & 3325 & 475 & 0,00031464 & 0,00011145 & 0,00031464 \\
\hline 29 & 11.17 & 3345 & 495 & 0,00029718 & 0,00009712 & 0,00029718 \\
\hline 30 & 15.73 & 3365 & 515 & 0,00027079 & 0,00006952 & 0,00027075 \\
\hline 31 & 15.08 & 3385 & 535 & 0,00026761 & 0,00006970 & 0,00026757 \\
\hline 32 & 52.06 & 3405 & 555 & 0,00023087 & 0,00003253 & 0,00023086 \\
\hline \hline
\end{tabular}

Tabela 6.13: Região de fronteira com $80 \%$ de capacidade

\begin{tabular}{|c|c|c|c|c|c|c|}
\hline \hline $\mathrm{NU}$ & $\begin{array}{c}\mathrm{T}_{\mathrm{CPU}} \\
{[\mathrm{s}]}\end{array}$ & $\begin{array}{c}\text { Geração } \\
{[\mathrm{MW}]}\end{array}$ & $\begin{array}{c}\text { Reserva } \\
{[\mathrm{MW}]}\end{array}$ & $\begin{array}{c}\text { Risco G\&T } \\
\text { Sistema }\end{array}$ & $\begin{array}{c}\text { Risco } \\
\text { Área } 230 \mathrm{kV}\end{array}$ & $\begin{array}{c}\text { Risco } \\
\text { Área } 138 \mathrm{kV}\end{array}$ \\
\hline \hline 20 & 1.77 & 2965 & 115 & 0,02094490 & 0,02089423 & 0,02094490 \\
\hline 21 & 6.75 & 3065 & 215 & 0,00562898 & 0,00539891 & 0,00562898 \\
\hline 22 & 6.67 & 3165 & 315 & 0,00532980 & 0,00522141 & 0,00532980 \\
\hline 23 & 11.88 & 3265 & 415 & 0,00044017 & 0,00016131 & 0,00044017 \\
\hline 24 & 13.75 & 3277 & 427 & 0,00044558 & 0,00015430 & 0,00044558 \\
\hline 25 & 13.36 & 3289 & 439 & 0,00042885 & 0,00013711 & 0,00042885 \\
\hline 26 & 13.70 & 3301 & 451 & 0,00041156 & 0,00012942 & 0,00041156 \\
\hline 27 & 13.83 & 3313 & 463 & 0,00040855 & 0,00012316 & 0,00040846 \\
\hline 28 & 14.06 & 3325 & 475 & 0,00040116 & 0,00011827 & 0,00040116 \\
\hline 29 & 16.52 & 3345 & 495 & 0,00039113 & 0,00010604 & 0,00039113 \\
\hline 30 & 26.89 & 3365 & 515 & 0,00035943 & 0,00007650 & 0,00035940 \\
\hline 31 & 24.64 & 3385 & 535 & 0,00035111 & 0,00006970 & 0,00035111 \\
\hline 32 & 194.45 & 3405 & 555 & 0,00031836 & 0,00003494 & 0,00031832 \\
\hline \hline
\end{tabular}


Tabela 6.14: Região de fronteira com $70 \%$ de capacidade

\begin{tabular}{|c|c|c|c|c|c|c|}
\hline \hline $\mathrm{NU}$ & $\begin{array}{c}\mathrm{T}_{\mathrm{CPU}} \\
{[\mathrm{s}]}\end{array}$ & $\begin{array}{c}\text { Geração } \\
{[\mathrm{MW}]}\end{array}$ & $\begin{array}{c}\text { Reserva } \\
{[\mathrm{MW}]}\end{array}$ & $\begin{array}{c}\text { Risco G\&T } \\
\text { Sistema }\end{array}$ & $\begin{array}{c}\text { Risco } \\
\text { Área } 230 \mathrm{kV}\end{array}$ & $\begin{array}{c}\text { Risco } \\
\text { Área } 138 \mathrm{kV}\end{array}$ \\
\hline 20 & 1.78 & 2965 & 115 & 0,02094800 & 0,02089737 & 0,02094800 \\
\hline 21 & 6.53 & 3065 & 215 & 0,00584287 & 0,00553067 & 0,00584287 \\
\hline 22 & 6.19 & 3165 & 315 & 0,00533043 & 0,00522222 & 0,00533043 \\
\hline 23 & 13.38 & 3265 & 415 & 0,00044688 & 0,00016170 & 0,00044688 \\
\hline 24 & 14.78 & 3277 & 427 & 0,00045156 & 0,00015400 & 0,00045156 \\
\hline 25 & 15.69 & 3289 & 439 & 0,00043963 & 0,00013749 & 0,00043963 \\
\hline 26 & 15.58 & 3301 & 451 & 0,00042578 & 0,00013057 & 0,00042569 \\
\hline 27 & 16.12 & 3313 & 463 & 0,00043029 & 0,00012980 & 0,00043019 \\
\hline 28 & 15.62 & 3325 & 475 & 0,00040994 & 0,00012596 & 0,00040994 \\
\hline 29 & 18.33 & 3345 & 495 & 0,00039741 & 0,00010248 & 0,00039734 \\
\hline 30 & 28.69 & 3365 & 515 & 0,00037369 & 0,00007576 & 0,00037361 \\
\hline 31 & 30.00 & 3385 & 535 & 0,00037271 & 0,00007421 & 0,00037271 \\
\hline 32 & 172.09 & 3405 & 555 & 0,00032796 & 0,00003455 & 0,00032794 \\
\hline \hline
\end{tabular}

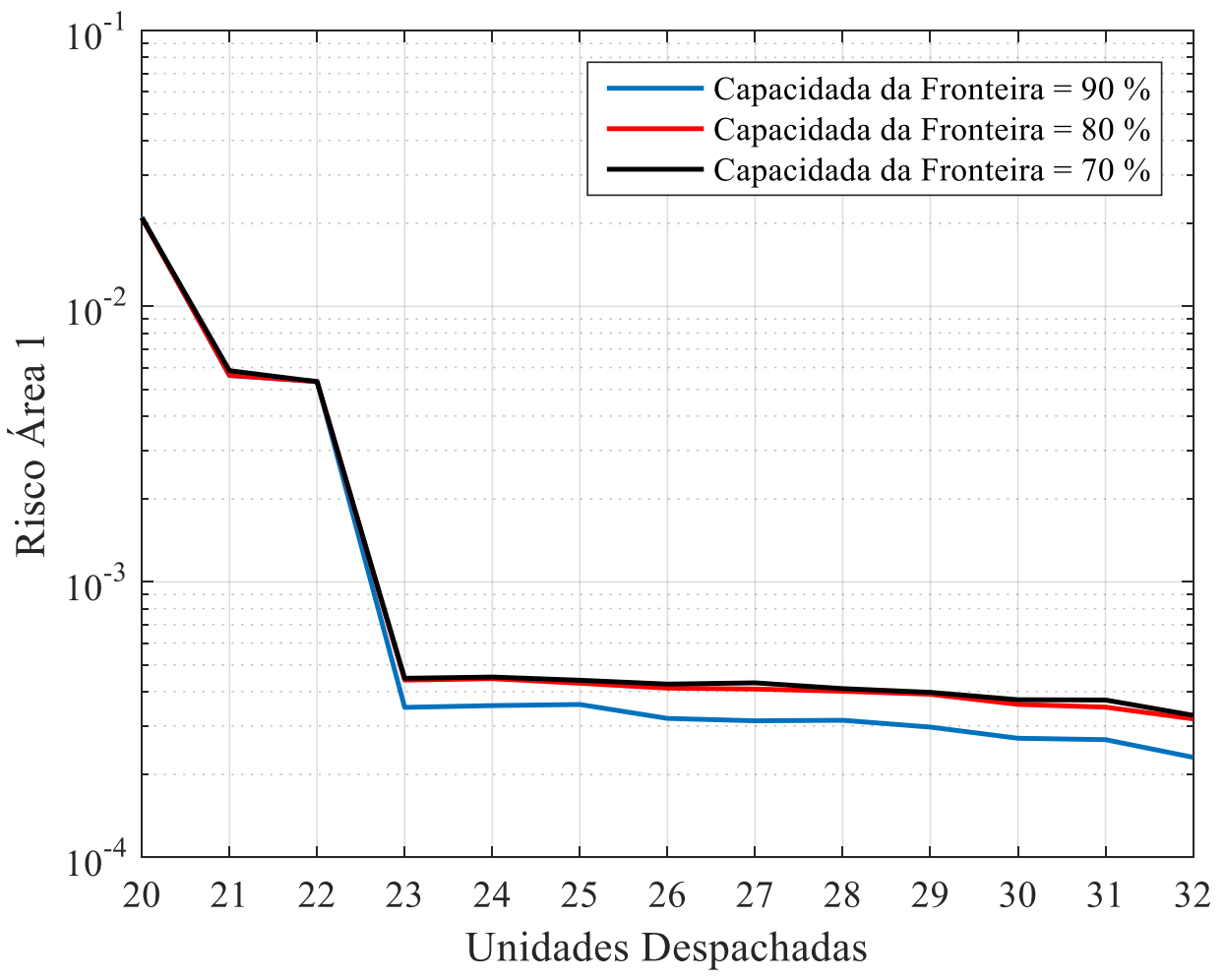

Figura 6.4: Índice de risco da área 2 em função da capacidade dos equipamentos de fronteira entre as áreas 
É interessante observar que mesmo com o aumento das restrições, a Área 230 $\mathrm{kV}$ se torna mais confiável. Isso ocorre porque o montante de reserva tende a concentrar-se na própria área, dando maior liberdade para a adoção de medidas operativas e, como consequência, obtém-se um aumento da confiabilidade da Área de $230 \mathrm{kV}$ (que tem maior montante de reserva) e deterioração da Área de $138 \mathrm{kV}$ (deficitária em reserva de geração).

Por meio da figura 6.4 é possível observar que, com a intensificação das restrições de capacidade dos equipamentos de fronteira, há aumento do risco de corte de carga na área de $138 \mathrm{kV}$.

Como os níveis de reserva em cada área não são iguais, o índice de risco reflete apropriadamente a distinção do grau de adequação de cada área. Quanto maiores são as restrições de fluxo nas interligações, mais os índices de risco de cada área se distanciam. No caso do sistema IEEE RTS, pode-se inferir que a reserva de geração está mais adequadamente alocada na Área de $230 \mathrm{kV}$, pois essa área apresenta os menores índices de risco de corte de carga. No Apêndice D é apresentada uma aplicação do Índice de Gini na avaliação da distribuição do risco nas áreas do sistema IEEE RTS.

\section{4 . Resultados - Sistema Norte-Nordeste Brasileiro}

Para validar a aplicação das ferramentas desenvolvidas neste trabalho, usouse um sistema baseado numa configuração do sistema brasileiro, o sistema NorteNordeste Brasileiro (NNB). Os dados usados foram adaptados da Base de Dados da Empresa de Pesquisa Energética - EPE, mais especificamente do Plano Decenal de Expansão de Energia - PDE 2026 [92], tendo como base o cenário Norte Úmido, Carga Média, Ano 2017. Na Figura 6.5 é possível observar o diagrama simplificado do sistema elétrico brasileiro, com a representação das principais linhas de transmissão em operação, disponibilizado pelo ONS [93].

O plano decenal representa a Rede Básica e algumas regiões da rede de distribuição. Como a rede de distribuição tradicionalmente não é utilizada na alocação da reserva operativa, fez-se um equivalente para conter apenas a rede básica das regiões Norte e Nordeste 


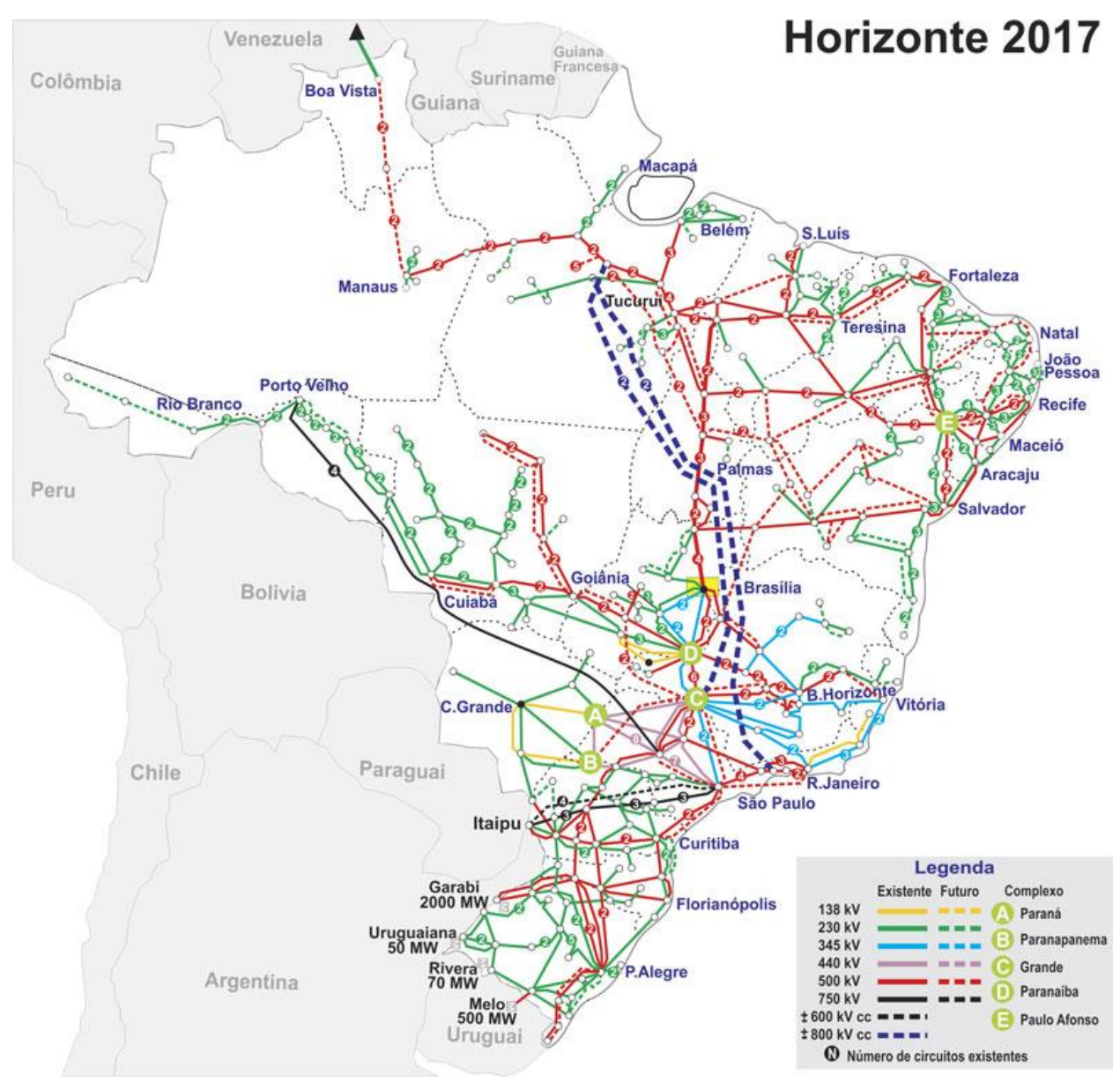

Figura 6.5: Diagrama do Sistema Elétrico Brasileiro - ONS [93]

Esse sistema equivalente é composto de 471 barras, sendo: 187 barras de geração, 752 ramos de transmissão, 146 estações geradoras. Subdivido em áreas, apresenta 22 áreas de transmissão e duas áreas de controle de geração, que são compostas por diversos agentes de geração e transmissão, incluindo distribuidoras de energia elétrica e consumidores livres. Estão representadas todas as barras da Rede Básica (tensão base maior ou igual a $230 \mathrm{kV}$ ) e algumas barras com tensão menor, mas que estão na fronteira e representam subestações importantes (escoamento de geração, grandes consumidores, etc.). 
Tabela 6.15: Áreas Elétricas do PDE2026 - Sistema NNB

\begin{tabular}{|c|c|}
\hline Número & Área \\
\hline 1 & CHESF - Sistema Sul \\
\hline 2 & CHESF - Sistema Leste \\
\hline 3 & CHESF - Sistema Norte \\
\hline 4 & CHESF - Sistema Oeste \\
\hline 5 & CHESF - Sistema Centro \\
\hline 6 & CHESF - Sistema Sudoeste \\
\hline 7 & Eletronorte \\
\hline 8 & Norte-Sul \\
\hline 10 & Tucuruí-Macapá-Manaus \\
\hline 76 & Belo Monte \\
\hline 105 & Celpe \\
\hline 106 & Ceal \\
\hline 107 & Energipe \\
\hline 108 & Coelba \\
\hline 109 & Cemar \\
\hline 110 & Celpa \\
\hline 112 & Consumidores Livres (RB) - Norte \\
\hline 113 & Manaus \\
\hline 114 & Amapá \\
\hline 117 & Consumidores Livres (RB) - Nordeste \\
\hline 118 & Eólicas Nordeste \\
\hline 119 & Solares N/NE \\
\hline
\end{tabular}

Os resultados com o sistema NNB demonstram que é praticável, em tempo hábil de simulação, obter os índices de risco de curto prazo. Nas simulações realizadas, testou-se um cenário sem as linhas de transmissão e um cenário considerando as restrições do sistema de transmissão. No primeiro caso (sistema barra única), o tempo computacional para avaliar o risco foi de cerca de 9 minutos $(9 \mathrm{~min}$ e 36 segundos), já no segundo (com sistema de transmissão), o tempo computacional foi da ordem de 100 minutos. 


\subsection{1.}

\section{Áreas do Sistema Elétrico}

Uma das discussões que surge ao avaliar a reserva em sistemas de grande porte é a definição da área de interesse. É preciso estabelecer os critérios para delimitação das áreas do sistema, uma vez que a definição da área está relacionada com o estudo que está sendo realizado.

Há diversas definições de área no Sistema Elétrico Brasileiro, do ponto de vista do planejamento da operação as duas principais são as áreas de controle da geração e as áreas de controle da transmissão, cujos critérios de classificação são definidos pelo operador do sistema. Nos tópicos a seguir são descritas as diretrizes para delimitação dessas áreas.

\subsection{2. Áreas de Controle da Geração}

A área de controle da geração, segundo a definição do ONS para o SEB, é a área do sistema sob responsabilidade de um centro de operação em que atua um mecanismo de CAG para controlar a frequência e o intercâmbio com as demais áreas [94].

Cada área de controle da geração é subordinada a apenas um centro de operação e possui capacidade de geração que permite o equilíbrio entre carga e geração em qualquer período de carga. As fronteiras entre as áreas são delimitadas por pontos de intercâmbio, que são locais dotados de telemedidores. Basicamente, cada área é composta por usinas (controladas automaticamente ou não controladas automaticamente), carga e transmissão da área.

No diagrama da Figura 6.6 a seguir, são ilustradas as áreas de controle de geração do SIN (com seus respectivos centros de controle) e os pontos de medição de intercâmbio de potência em suas fronteiras. 


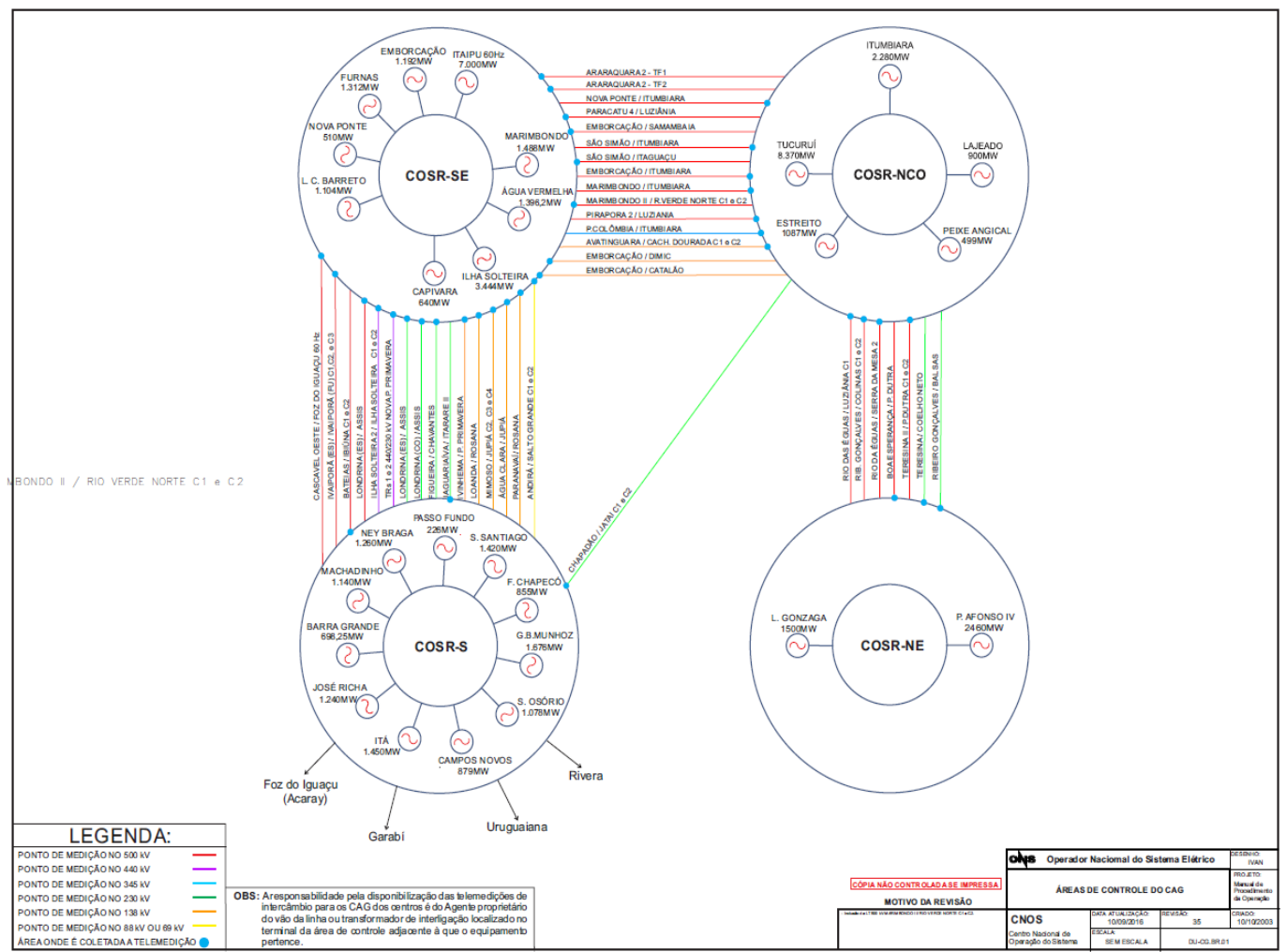

Figura 6.6: Áreas de controle da geração - Centros Regionais de Operação do sistema Brasileiro ONS - [94]

\subsection{3.}

\section{Áreas de Controle da Transmissão}

A filosofia, a estratégia e as diretrizes para a realização do controle da transmissão em operação normal são definidas nos Procedimento de Rede do ONS [95].

Basicamente, as áreas de controle da transmissão são regiões do sistema elétrico com relativa autonomia para realização do controle de tensão e de carregamento dos equipamentos. Essas áreas são definidas com o intuito de delimitar a hierarquização das ações de controle, uma vez que a estratégia de atuação consiste em manobrar primeiro os equipamentos com influência local e, apenas se necessário, utilizar os equipamentos com influência regional e sistêmica.

Os principais recursos de controle da transmissão, utilizados também para viabilizar os intercâmbios programados para as diversas áreas, são: reatores de barra manobráveis, bancos de capacitores, excitação de unidades geradoras, compensadores síncronos e estáticos, reatores de linha manobráveis, comutadores sob carga 
de transformadores e de reguladores série e manobras de linhas de transmissão. Esgotados todos esses recursos, podem ser adotados, como último recurso para mitigar violações de tensão e/ou carregamento, ações para gerenciamento de carga [96].

No diagrama da Figura 6.7 a seguir podem ser observadas as áreas de controle da transmissão do SEB:

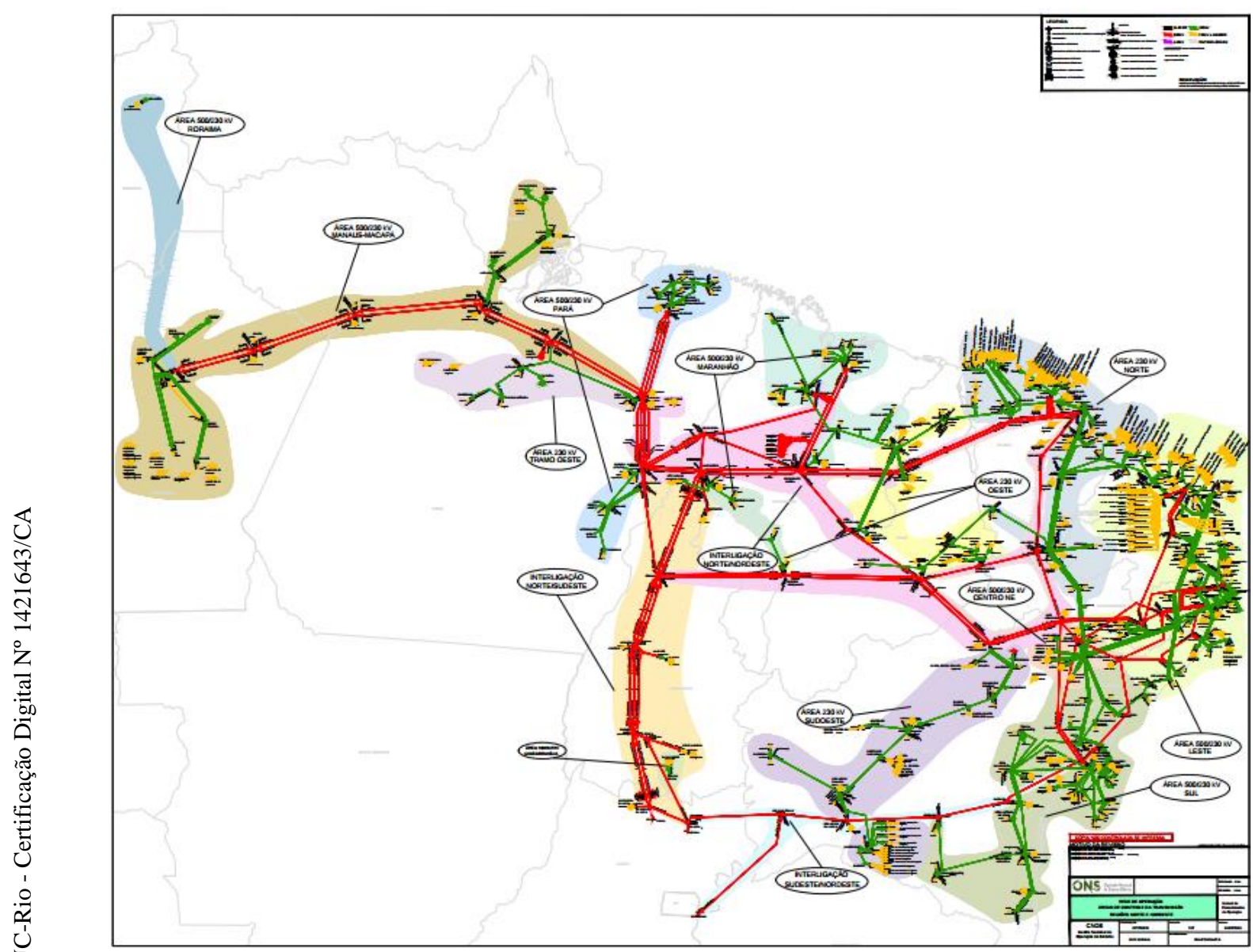

Figura 6.7: Áreas de controle da transmissão ONS- [95]

Com a tendência de maior detalhamento da representação do sistema, podese definir uma área de controle composta: região com geração e margem adequada para suprir de forma confiável a demanda considerando as restrições de transmissão da área e os limites de intercâmbio. Trata-se de uma subdivisão dos submercados com o intuito de representar conjuntamente os mecanismos de controle da geração e os limites de carregamento da transmissão, para efeitos de estudos de planejamento da adequação da operação. A área de controle composta é uma ideia que pode vir a ser explorada em trabalhos futuros. 
Considerando a delimitação de área do PDE26, foram estimados os valores de risco para as áreas do Sistema NNB, os resultados são apresentados nos próximos tópicos. O coeficiente de variação máximo global para o sistema foi de $5 \%$. Para as áreas foi adotado como aceitável o dobro deste valor.

- Risco de cada área - Representação via barra única:

Tabela 6.16: Risco sistema NNB - Modelo Barrra Única

\begin{tabular}{|c|c|c|c|}
\hline \hline $\begin{array}{c}\text { Área } \\
\text { PDE26 }\end{array}$ & Nome da Área & Risco & $\beta$ Área \\
\hline 1 & CHESF - Sistema Sul & $.68822 \mathrm{E}-16$ & 0,04672 \\
\hline 2 & CHESF - Sistema Leste & $.68822 \mathrm{E}-16$ & 0,04672 \\
\hline 3 & CHESF - Sistema Norte & $.68822 \mathrm{E}-16$ & 0,04672 \\
\hline 4 & CHESF - Sistema Oeste & $.68822 \mathrm{E}-16$ & 0,04672 \\
\hline 5 & CHESF - Sistema Centro & $.68822 \mathrm{E}-16$ & 0,04672 \\
\hline 6 & CHESF - Sistema Sudoeste & $.68822 \mathrm{E}-16$ & 0,04672 \\
\hline 7 & ELETRONORTE & $.68822 \mathrm{E}-16$ & 0,04672 \\
\hline 8 & NORTE-SUL & $.68822 \mathrm{E}-16$ & 0,04672 \\
\hline 10 & Tucuruí-Macapa-Manaus & $.68822 \mathrm{E}-16$ & 0,04672 \\
\hline 76 & Belo Monte & $.68822 \mathrm{E}-16$ & 0,04672 \\
\hline 105 & CELPE & $.68822 \mathrm{E}-16$ & 0,04672 \\
\hline 106 & CEAL & $.68822 \mathrm{E}-16$ & 0,04672 \\
\hline 107 & ENERGIPE & $.68822 \mathrm{E}-16$ & 0,04672 \\
\hline 108 & COELBA & $.68822 \mathrm{E}-16$ & 0,04672 \\
\hline 109 & CEMAR & $.68822 \mathrm{E}-16$ & 0,04672 \\
\hline 110 & CELPA & $.68822 \mathrm{E}-16$ & 0,04672 \\
\hline 112 & Consumidores Livres (RB) - Norte & $.68822 \mathrm{E}-16$ & 0,04672 \\
\hline 113 & MANAUS & $.68822 \mathrm{E}-16$ & 0,04672 \\
\hline 114 & AMAPA & $.68822 \mathrm{E}-16$ & 0,04672 \\
\hline 117 & Consumidores Livres (RB) - Nordeste & $.68822 \mathrm{E}-16$ & 0,04672 \\
\hline 118 & ÉOLICAS NORDESTE & $.68822 \mathrm{E}-16$ & 0,04672 \\
\hline 119 & SOLARES N/NE & $.68822 \mathrm{E}-16$ & 0,04672 \\
\hline \hline & & & \\
\hline \hline
\end{tabular}

No sistema equivalente usado na simulação, a capacidade instalada (geração máxima com as estações geradores reais e virtuais despachadas foi de $41628 \mathrm{MW}$. A geração mínima, devido à inflexibilidade de algumas máquinas, foi de 4337 MW. A carga equivalente foi de 25449 MW. No ponto de operação simulado, que não 
observou possíveis correlações das séries hidrológicas entre as regiões Norte e Nordeste, o risco apresentou valor considerado baixo. Na operação do sistema real, esse valor poderá ser consideravelmente maior, a depender da disponibilidade dos recursos energéticos, da política de acionamento das máquinas, bem como dos despachos das usinas geradoras, entre outros fatores.

Nos próximos tópicos são apresentados os índices de risco com a devida representação das capacidades das linhas de transmissão do SIN, para cada área.

- Risco de cada área (sem redespacho), sem falha nas linhas de transmissão e com restrições de capacidade de transmissão:

Tabela 6.17: Risco por área - com restrições de capacidade

\begin{tabular}{|c|c|c|c|}
\hline $\begin{array}{c}\text { Área } \\
\text { PDE26 }\end{array}$ & Nome da Área & Risco & $\beta$ Área \\
\hline 1 & CHESF - Sistema Sul & $.92736 \mathrm{E}-02$ & 0,05254 \\
\hline 2 & CHESF - Sistema Leste & $.87504 \mathrm{E}-02$ & 0,05416 \\
\hline 3 & CHESF - Sistema Norte & $.11035 \mathrm{E}-01$ & 0,05012 \\
\hline 4 & CHESF - Sistema Oeste & $.11035 \mathrm{E}-01$ & 0,05012 \\
\hline 5 & CHESF - Sistema Centro & $.11010 \mathrm{E}-01$ & 0,05018 \\
\hline 6 & CHESF - Sistema Sudoeste & $.11085 \mathrm{E}-01$ & 0,04999 \\
\hline 7 & ELETRONORTE & $.11060 \mathrm{E}-01$ & 0,05005 \\
\hline 8 & NORTE-SUL & $.11085 \mathrm{E}-01$ & 0,04999 \\
\hline 10 & Tucuruí-Macapá-Manaus & $.10885 \mathrm{E}-01$ & 0,05050 \\
\hline 76 & Belo Monte & $.10188 \mathrm{E}-01$ & 0,05242 \\
\hline 105 & CELPE & $.11060 \mathrm{E}-01$ & 0,05005 \\
\hline 106 & CEAL & $.10587 \mathrm{E}-01$ & 0,05130 \\
\hline 107 & ENERGIPE & $.10188 \mathrm{E}-01$ & 0,05242 \\
\hline 108 & COELBA & $.11085 \mathrm{E}-01$ & 0,04999 \\
\hline 109 & CEMAR & $.10038 \mathrm{E}-01$ & 0,05286 \\
\hline 110 & CELPA & $.10188 \mathrm{E}-01$ & 0,05242 \\
\hline 112 & Consumidores Livres (RB) - Norte & $.11085 \mathrm{E}-01$ & 0,04999 \\
\hline 113 & MANAUS & $.10885 \mathrm{E}-01$ & 0,05050 \\
\hline 114 & AMAPA & $.10188 \mathrm{E}-01$ & 0,05242 \\
\hline 117 & Consumidores Livres (RB) - Nordeste & $.11010 \mathrm{E}-01$ & 0,05018 \\
\hline 118 & ÉOLICAS NORDESTE & $.10188 \mathrm{E}-01$ & 0,05242 \\
\hline 119 & SOLARES N/NE & $.10188 \mathrm{E}-01$ & 0,05242 \\
\hline
\end{tabular}


Por meio da Tabela 6.17, comparando com a Tabela 6.16, é possível observar que a representação das capacidades das linhas impacta significativamente nas estimativas dos índices de risco. Uma das possíveis justificativas, é a forte dependência das linhas de transmissão para escoar a geração entre áreas. Devido as dimensões continentais do sistema elétrico em questão, é natural que a transmissão impacte no risco de suprir adequadamente a demanda, mesmo no curto-prazo.

- Risco de cada área (sem redespacho) com falha nas linhas de transmissão

Tabela 6.18: Risco por área - com restrições de capacidade e falhas nas LTs

\begin{tabular}{|c|c|c|c|}
\hline \hline $\begin{array}{c}\text { Área } \\
\text { PDE26 }\end{array}$ & Nome da Área & Risco & $\beta$ Área \\
\hline \hline 1 & CHESF - Sistema Sul & $.11069 \mathrm{E}-01$ & 0,05781 \\
\hline 2 & CHESF - Sistema Leste & $.10386 \mathrm{E}-01$ & 0,06122 \\
\hline 3 & CHESF - Sistema Norte & $.13562 \mathrm{E}-01$ & 0,04996 \\
\hline 4 & CHESF - Sistema Oeste & $.13562 \mathrm{E}-01$ & 0,04996 \\
\hline 5 & CHESF - Sistema Centro & $.13562 \mathrm{E}-01$ & 0,04996 \\
\hline 6 & CHESF - Sistema Sudoeste & $.13562 \mathrm{E}-01$ & 0,04996 \\
\hline 7 & ELETRONORTE & $.13576 \mathrm{E}-01$ & 0,04992 \\
\hline 8 & NORTE-SUL & $.13562 \mathrm{E}-01$ & 0,04996 \\
\hline 10 & Tucuruí-Macapá-Manaus & $.13562 \mathrm{E}-01$ & 0,04996 \\
\hline 76 & Belo Monte & $.13562 \mathrm{E}-01$ & 0,04996 \\
\hline 105 & CELPE & $.13576 \mathrm{E}-01$ & 0,04992 \\
\hline 106 & CEAL & $.13562 \mathrm{E}-01$ & 0,04996 \\
\hline 107 & ENERGIPE & $.13562 \mathrm{E}-01$ & 0,04996 \\
\hline 108 & COELBA & $.13562 \mathrm{E}-01$ & 0,04996 \\
\hline 109 & CEMAR & $.13562 \mathrm{E}-01$ & 0,04996 \\
\hline 110 & CELPA & $.13562 \mathrm{E}-01$ & 0,04996 \\
\hline 112 & Consumidores Livres (RB) - Norte & $.13576 \mathrm{E}-01$ & 0,04992 \\
\hline 113 & MANAUS & $.13562 \mathrm{E}-01$ & 0,04996 \\
\hline 114 & AMAPA & $.13562 \mathrm{E}-01$ & 0,04996 \\
\hline 117 & Consumidores Livres (RB) - Nordeste & $.13562 \mathrm{E}-01$ & 0,04996 \\
\hline 118 & ÉOLICAS NORDESTE & $.13494 \mathrm{E}-01$ & 0,05016 \\
\hline 119 & SOLARES N/NE & $.13494 \mathrm{E}-01$ & 0,05016 \\
\hline & & & \\
\hline
\end{tabular}


Os índices apresentados na Tabela 6.18 foram estimados considerando a possibilidade de falhas nas linhas. Como é possível observar, houve impacto no valor do risco. Entretanto, devido à elevada confiabilidade da transmissão, pode-se observar que a deterioração dos índices foi marginal. Desta forma, pelo menos nesses pontos de operação simulados, a capacidade dos equipamentos foi o fator mais preponderante para o grau de adequação de curto-prazo do sistema.

\section{5 . \\ Conclusões}

No âmbito do planejamento da reserva de geração, quando não há restrições de transmissão e sendo possível a aplicação de medidas corretivas (tal como o redespacho de geração), a incapacidade de prover reserva operativa frente aos eventos de insuficiência de geração são compartilhadas por todas as regiões do sistema.

Cada área de um sistema elétrico apresenta características específicas referentes ao desempenho e confiabilidade. Portanto, os índices de risco devem refletir o grau de confiabilidade do suprimento, indicando o grau de adequação dos montantes de reserva planejados. De fato, quando as restrições de transmissão estão presentes e as falhas e limitações de capacidade são devidamente representadas, é possível capturar os diferentes graus de risco em cada uma das áreas, como mostrado por meio dos resultados com o sistema IEEE RTS e com o Norte-Nordeste Brasileiro. A representação das restrições de capacidade das LTs do sistema NNB mostrou uma degradação generalizada dos índices de risco, refletindo a importância da transmissão para a operação de curto-prazo desse sistema.

Nos resultados mostrados, os índices são estimados observando o coeficiente de variação das áreas e do sistema. Ao comparar os riscos do sistema e de suas diversas áreas, observa-se que o risco de corte de carga é maior para o sistema e mais raro para as áreas. De fato, a ocorrência de corte em qualquer área é computada no cálculo dos índices para o sistema, mas ocorrências de corte de carga isoladas em regiões específicas não contribuem para deteriorar os índices de outras áreas que não sofreram o impacto da contingência. 


\section{7 \\ Conclusões e Propostas}

Em sistemas com fontes renováveis, devido à intermitência da capacidade de geração e da variabilidade dos recursos energéticos, as incertezas associadas ao suprimento da demanda são substancialmente maiores. A aplicação de metodologias com a habilidade de avaliar apropriadamente as incertezas associadas ao planejamento da reserva de geração torna-se ainda mais necessária.

Os operadores de sistemas elétricos estão continuamente submetidos a situações em que devem tomar decisões complexas em curtos intervalos de tempo. Um elevado esforço técnico é dedicado ao planejamento e operação do sistema de forma econômica e confiável, visando sempre mitigar o risco de corte de carga. O método proposto neste trabalho foi desenhado para auxiliar os agentes do setor na tomada de decisões no tocante ao planejamento e dimensionamento da reserva operativa.

Dada uma configuração do sistema elétrico, a avaliação do risco de perda de carga permite o comissionamento de um adequado número de unidades geradoras, observando a não violação dos critérios estabelecidos e dentro dos corretos níveis quantificados de segurança.

As avaliações de risco de curto-prazo, mesmo quando esse risco é raro, são possíveis ao usar técnicas de amostragem por importância, com os parâmetros sendo distorcidos usando os conceitos de entropia cruzada. Como mostrado nos resultados apresentados, foi possível estimar o risco com significativa redução do esforço computacional.

As restrições de linhas de transmissão podem ser apropriadamente consideradas, possibilitando a identificação dos problemas sistêmicos associados ao transporte de energia. Como foi demonstrado por meio dos resultados, uma parcela da reserva de geração é função das restrições e limitações de capacidade da transmissão, ou seja, a reserva pode ser alocada em função de falhas tanto devido a problemas associados à insuficiência de geração quanto à incapacidade de transporte da rede. 
Uma quantidade maior de reserva é requerida em sistemas com rede de transmissão cujas linhas apresentem maior taxa de falha ou maior nível de carregamento. O efeito da taxa de falha e do grau de carregamento só pode ser capturado devido à representação do modelo da rede na análise.

Ao segmentar o sistema em áreas, é possível obter índices por região. Desta forma, é possível caracterizar adequadamente as diversas regiões em função dos montantes alocados para cada área. Essa análise é possível ao incluir as restrições de interligação/transmissão.

Manter o sistema operando dentro dos padrões de confiabilidade consiste em adotar medidas de forma que a demanda possa ser suprida mesmo na eventual ocorrência de falhas de equipamentos. O correto dimensionamento da quantidade de reserva girante é crucial para mitigar o risco de perda de carga.

Este trabalho propôs uma metodologia de subsídio ao planejamento do montante de reserva girante em sistemas complexos, considerando a penetração de fontes renováveis e ainda observando as restrições de transmissão em sistemas multiárea.

No primeiro capítulo foram introduzidos alguns dos conceitos utilizados e foi apresentada uma revisão das principais referências.

No segundo capítulo, os conceitos básicos relacionados ao dimensionamento da reserva girante, no tocante aos índices de confiabilidade e aos métodos utilizados para sua avaliação foram apresentados. A aplicação do método da Entropia Cruzada na avaliação de sistemas elétricos foi revisitada.

Usando uma representação via modelo simplificado tipo "barra única", foi proposto no terceiro capítulo um método para avaliação dos requisitos de reserva operativa considerando o valor de risco especificado.

No Capítulo 4, foi analisado o efeito das restrições e falhas do sistema de transmissão e incluindo as perdas de transmissão, demonstrando a aplicação da metodologia em sistemas com elevado número de estados. O uso de técnicas de redução de variância tornou possível a obtenção de resultados em tempo hábil no âmbito da operação a curto prazo.

No Capítulo 5 foi proposta uma metodologia para o planejamento da reserva de geração em sistema com fontes renováveis. Por meio da SMC Quase sequencial e dos conceitos do método CE foi possível avaliar a adequação dos níveis de reserva 
considerando as flutuações de capacidade das fontes eólicas e as correlações temporais entre a geração e a carga. Por fim, no Capítulo 6 foram apresentados os riscos segmentados por área elétrica para o sistema IEEE RTS e para o sistema NorteNordeste Brasileiro.

Pode-se destacar as seguintes contribuições apresentadas nesta tese para literatura técnica atual:

- Representação do sistema de transmissão, com modelagem e avaliação do impacto das perdas elétricas das linhas de transmissão nos índices de risco de curto-prazo;

- Avaliação do efeito das correlações temporais da geração das fontes renováveis usando SMC Quase-sequencial, considerando o efeito da representação completa do sistema de transmissão na análise;

- Proposta de Índice de Segurança, que pode ser empregado em conjunto com os conceitos do método PJM para dar flexibilidade operativa em sistemas com elevada participação de fontes renováveis;

- Proposta de metodologia de classificação de equipamentos conforme sua importância sistêmica em função de sua contribuição para os eventos de falha e,

- Aplicação do método CE na avaliação de sistemas com múltiplas áreas, possibilitando a análise do risco de cada área, que pode ser empregado para subsidiar decisões de planejamento, auxiliando na alocação dos montantes de reserva operativa.

A aplicação do método CE possibilita elevados ganhos computacionais, tornando possível estimar a probabilidade de ocorrência de eventos raros em sistemas de grande porte ou com elevado número de variáveis de estado ou de incertezas. Entretanto, uma de suas desvantagens é a distorção das curvas de distribuição dos índices. Trata-se de um trade-off a ser avaliado em cada aplicação. Neste trabalho essa característica foi superada empregando a SMC Quase-sequencial, montando as curvas a posteriore. 


\section{1. Proposta de Trabalhos Futuros}

Este trabalho não contempla o assunto tratado em toda sua plenitude científica. Foram abordados métodos para a aplicação do método CE na avaliação do risco, foi avaliado o impacto das restrições de transmissão no dimensionamento da reserva e foi mostrada uma aplicação considerando fontes renováveis.

Ao incluir o sistema de transmissão, considerar suas falhas e limites de transporte, abre-se um amplo campo de possibilidades de análises que podem ser realizadas. O fator locacional pode ser explorado, isto é, a indicação dos locais mais adequados para acionamento da reserva.

Uma possibilidade importante é, no âmbito da mitigação dos riscos sistêmicos, a possibilidade de alocação dos riscos em função de seu agente impactante. Parte da responsabilidade por eventos de corte de carga está associada a problemas devido à insuficiência de geração, em função da inadequação dos níveis de reserva. A outra parte está associada aos gargalos de transmissão. Com a mensuração desses riscos é possível particionar a atenção necessária a cada segmento envolvido.

A ordem de mérito baseada no menor custo de operação foi utilizada por tratar-se de uma abordagem tradicionalmente utilizada. No entanto, ao segui-la, pode ser que máquinas adicionadas sejam incluídas em regiões em que o sistema de transmissão esteja operando próximo de seus limites e, portanto, a geração adicionada na região pode não maximizar o ganho em termos de confiabilidade. Assim, um dos aspectos que surge ao incluir o sistema de transmissão é a possibilidade de analisar se a reserva adicionada está sendo alocada de forma ótima (i.e., custo versus risco) nas diversas regiões do sistema.

Em trabalhos futuros, outras técnicas de redução de variância podem ser exploradas. Os métodos em potencial podem envolver Amostragem por Importância Sequencial, Amostragem Estratificada, entre outros. Métodos de implementação que possam aumentar a eficiência computacional das simulações também estão em análise.

O método da Entropia Cruzada pode ser utilizado para identificar elementos críticos do sistema em função de seu desempenho e contribuição para os eventos de 
interesse, podendo ser usado para apontar os equipamentos mais importantes e que, portanto, merecem mais atenção dos operadores e planejadores.

Há a possibilidade de aprofundar a discussão sobre os tipos de geradores que estão habilitados para participar dos processos de alocação de reserva girante, principalmente em função de avanços construtivos dos mecanismos e algoritmos de controle da potência dos geradores eólicos e das tecnologias de armazenamento (i.e., storage devices).

Mesmo no curto-prazo, as incertezas na demanda e na previsão de geração podem vir a impactar no montante necessário de reserva de geração. Uma das propostas de trabalho futuro é aprofundar os aspectos associados aos erros de previsão da demanda e aos modelos de carga de acordo com sua localização nas áreas do sistema elétrico.

\section{2.}

\section{Publicações Técnicas}

Ao longo do desenvolvimento desta tese foram desenvolvidos os seguintes trabalhos técnicos:

- A.M. Leite da Silva, J.F. Costa Castro, and R.A. Gonzalez Fernandez, "Spinning reserve assessment under transmission constraints based on cross-entropy method," IEEE Trans. on Power Syst., vol. 31, no. 21, pp. 1624-1632, Mar. 2016.

- A.M. Leite da Silva, J.F. Costa Castro, R.A. González-Fernández, “Spinning reserve assessment via quasi-sequential Monte Carlo simulation with renewable sources", 14th International Conference on Probabilistic Methods Applied to Power Systems - PMAPS 2016, Beijing, 16-20 Oct., 2016.

- J.F. Costa Castro, A.M. Leite da Silva, “Avaliação da reserva operativa em sistemas com elevada penetração de fontes renováveis via simulação Monte Carlo quase sequencial", Simpósio Brasileiro de Sistemas Elétricos - SBSE 2016, Natal, 22-25 Maio, 2016. 
- A.M. Leite da Silva, J.F. Costa Castro e R. Billinton, "Probabilistic Assessment of Spinning Reserve via Cross-Entropy Method Considering Renewable Sources and Transmission Restrictions," IEEE Trans. on Power Syst., (aceito para publicação), 2018. 


\section{8}

\section{Referências bibliográficas}

1. WOOD, A. J.; WOLLENBERG, B. F.. Power Generation, Operation, and Control. $2^{\text {a }}$ ed. Wiley Interscience, 1996.

2. BILLINTON, R.; ALLAN, R.N.. Reliability Evaluation of Engineering Systems: Concepts and Techniques. Plenum Press, 1992.

3. PRADA, J. F. The Value Of Reliability In Power Systems - Pricing Operating Reserves. Cambridge. July 1999.

4. BILLINTON, R.; ALLAN, R.N. Reliability Evaluation of Power Systems. $2^{a}$ ed. London: Plenum Press, 1996.

5. GONZÁleZ-FERnÁNDEZ, R. A. Avaliação da Confiabilidade da Capacidade de Geração via o Método da Entropia Cruzada. Itajubá. 2009.

6. GONZÁLEZ-FERnÁNDEZ, R. A. Aplicações do Método da Entropia Cruzada na Confiabilidade de Sistemas Elétricos de Potência. Itajubá. 2012.

7. SALES, W. S. Planejamento da Reserva Operativa de Sistemas de Geração com Elevada Penetração de Energia Eólica. Itajubá. 2009.

8. PEREIRA, M. V. F.; BALU, N. J. Composite Generation/Transmission Reliability Evaluation. IEEE Proceedings, 80, April 1992. 470-491.

9. PEREZ AlvareZ, G.. Dimensionamento e Valoração da Capacidade de Reserva Operativa em Ambientes Competitivos Utilizando Técnicas Probabilísticas. Itajubá. 2003.

10. LEITE DA SILVA, A. M.; ALVAREZ, G. P.. Operating Reserve Capacity Requirements and Pricing in Deregulated Markets Using Probabilistic Techniques. IET Gener. Transm. Distrib., 1, May 2007. 439-446.

11. PRADA, R. B. et al. Provision of Generation Reserves as an Ancillary Service in the Brazilian System. 14th PSCC. Sevilha, 24-28 June 2002. 
12. REBOURS, Y. G. et al. A Survey of Frequency and Voltage Control Ancillary Services — Part I: Technical Features. IEEE Transactions On Power Systems, 22, February 2007. 350-357.

13. GOOI, H. B. et al. Optimal Scheduling of Spinning Reserve. IEEE Transactions on Power Systems, v. 14, November 1999. p. 1485-1492.

14. SCHILlinG, M. TH.; MELLO, J. C. O.; GOMES, P. Introdução da Confiabilidade Composta no Planejamento da Operação Elétrica. SBA Controle \& Automação, v. 6, Janeiro-Fevereiro 1995. p. 38-47.

15. ANSTINE, L.T. et al. Application of Probabilistic Methods to the Determination of Spinning Reserve Requirements for the PennsylvaniaNew Jersey-Maryland Interconnection. IEEE Winter General Meeting. October 1963.

16. CAPACITY ADEQUACY PLANNING DEPARTMENT - PJM INTERCONNECTION. PJM Generation Adequacy Analysis: Technical Methods. October 2003.

17. KHAN, M. E.; BILlintON, R.. Composite System Spinning Reserve Assessment in Interconnected Systems. IEE Proc. Gener. Transm. Distrib. May 1995.

18. PESSANHA, J. F. M.; MELO, A. C. G.; FALCÃO, D. M. Allocation of Generation Capacity Reserve Considering the Transmission Network. IEEE Power Tech '99 Conference. Budapest, Hungary. Aug 29 Sept 2, 1999.

19. LEITE DA SILVA, A. M. et al. Long term evaluation of operating reserve with high penetration of renewable energy sources. 2011 IEEE Power and Energy Society General Meeting. San Diego, 24-29 July 2011. p. 1-7.

20. LEITE DA SILVA, A. M. et al. Pseudo-Chronological Simulation for Composite Reliability Analysis with Time Varying Loads. IEEE Transactions on Power Systems, v. 15, February 2000. 73-80.

21. RUBISNTEIN, R. Y.; KROESE, D. P.. Simulation and the Monte Carlo Method. 2nd. ed. New York, NY, USA: Wiley, 2007.

22. LEITE DA SILVA, A. M.; GONZÁLEZ-FERNÁNDEZ, R. A.; SINGH, C. Generating Capacity Reliability Evaluation Based on Monte Carlo 
Simulation and Cross-Entropy Methods. IEEE Transactions on Power Systems, v. 25, February 2010. p. 129-137.

23. BILlintON, R.; LI, W. Reliability Assessment of Electrical Power Systems Using Monte Carlo Methods. NY: Plenum, 1994.

24. MELO, A. C. G.; PEREIRA, M. V. F.; LEITE DA SILVA, A. M. Frequency and Duration Calculations in Composite Generation and Transmission Reliability Evaluation. IEEE Transactions on Power Systems, v. 7, May 1992. p. 469-476.

25. SCHILLING, M. TH.; REI, A. M.. Reliability Assessment of the Brazilian Power System Using Enumeration and Monte Carlo. IEEE Transactions on Power Systems, v. 23, August 2008.

26. Rubinstein, R. Y.; KROESE, D. P.. The Cross-Entropy Method. A Unified Approach to Combinatorial Optimization, Monte-Carlo Simulation, and Machine Learning. New York: Springer, 2004.

27. GONZÁLEZ-FERNÁNDEZ, R. A. et al. Composite Systems Reliability Evaluation Based on Monte Carlo Simulation and Cross-Entropy Methods. IEEE Transactions on Power Systems, v. 28, 25 June 2013. p. 4598 - 4606.

28. CARVALHO, L. M. et al. Simplified Cross-Entropy Based Approach for Generating Capacity Reliability Assesment. IEEE Transactions on Power Systems, v. 28, May 2013. p. 1609-1616.

29. LEITE DA SILVA, A. M.; COSTA CASTRO, J. F.; GONZALEZ FERNANDEZ, R. A. Spinning reserve assessment under transmission constraints based on cross-entropy method. IEEE Trans. on Power Syst., v. 31, March 2016. p. 1624-1632.

30. OPERADOR NACIONAL DO SISTEMA ELÉTRICO - ONS. Boletim Mensal de Geração Eólica Fevereiro/2018. Rio de Janeiro. 2018.

31. STRBAC, G. et al. Impact of wind generation on the operation and development of the UK electricity systems. Electric Power Systems Research, v. 77, 2007. p. 1214-1227.

32. ONS - OPERADOR NACIONAL DO SISTEMA. Metodologia para o Dimensionamnto da Reserva Operativa do SIN Face ao Crescimento da Geração Eólica. Rio de Janeiro. 2016. 
33. BILLINTON, R. Bibliography on Application of Probability Methods in the Evaluation of Generating Capacity Requirements. IEEE Winter Power Meeting, 1966. p. 66-62.

34. BILLINTON, R. Bibliography on the Application of Probability Methods in Power System Evaluation. IEEE Transactions on Power Apparatus and Systems, v. 91, 1972. p. 649-660.

35. IEEE SUBCOMMITTEE ON THE APPLICATION OF PROBABILITY METHODS. Bibliography on the Application of Probability Methods in Power System Reliability Evaluation, 1971 - 1977. IEEE Transactions on Power Apparatus and Systems, v. 97, November/December 1978.

36. ALLAN, R.N.; BILlINTON, R.; LEE, S.H.. Bibliography on the Application of Probability Methods in Power System Evaluation, 1977 1982. IEEE Transactions on Power Apparatus and Systems, PAS-103, February 1984.

37. ALLAN, R. N. et al. Bibliography on the Application of Probability Methods in Power System Reliability Evaluation, 1982-1987”. IEEE Transactions on Power Systems, v. 3, November 1988. p. 1555-1564.

38. SCHILLING, M. TH. et al. Bibliography on Power System Probabilistic Analysis (1962-1988). IEEE Transactions on Power Systems, 5, February 1990.

39. ALLAN, R. N. et al. Bibliography on the Application of Probability Methods in Power System Reliability Evaluation, 1987-1991. IEEE Transactions on Power Systems, v. 9, 1994. p. 41-49.

40. BILLINTON, R.; FOTUHI-FIRUZABAD, M.; BERTLING, L. Bibliography on the Application of Probability Methods in Power System Reliability Evaluation, 1996-1999. IEEE Transactions on Power Systems, v. 16, November 2001. p. 595-602.

41. BILLINTON, R.; CHOWDHURY, N.A. Operating Reserve Assessment in Interconnected Generating Systems. IEEE Transactions on Power Systems, v. 3, November 1988. p. 1479-1487. 
42. BILlitON, R.; JAIN, A.V. Unit Derating Levels in Spinning Reserve Studies. IEEE Winter Power Meeting. New York, N.Y. January 31-February 5 1971. p. 1677-1687.

43. BILLITON, R.; JAIN, A.V. The Effect of Rapid Start and Hot Reserve Units in Spinning Reserve Studies. IEEE Transactions on Power Apparatus and Systems, 1972. p. 511-516.

44. REI, A. M. Metodologias para o Estabelecimento da Reserva Operativa de Geração em Sistemas de Potência. Rio de Janeiro. 1992.

45. LEITE DA SILVA, A. M.; MELLO, A. C. G.; CUNHA, S. H. F. Frequency and Duration Method for Reliability Evaluation of Large-scale Hydrothermal Generating Systems. IEE Proceedings, v. 138, January 1991. p. 94-102.

46. SCHILLING, M. TH. et al. Bibliography on Composite System Reliability (1964-1988). IEEE Transactions on Power Systems, v. 4, August 1989. p. $1122-1132$.

47. IEA - INTERNATIONAL ENERGY AGENCY. Learning from the blackouts: Transmission System Security in Competitive Electricity Markets. Paris - France. 2005.

48. JAEFARI-NOKANDI, M.; MONSEF, H. Scheduling of Spinning Reserve Considering Customer Choice on Reliability. IEEE Transactions on Power Systems, v. 24, November 2009. p. 1555-1564.

49. OLIVEIRA, G. C.; PEREIRA, M. V. F.; CUNHA, S. H. F. A Technique for Reducing Computational Effort in Monte-Carlo Based Composite Reliability Evaluation. IEEE Transactions on Power Systems, 4, October 1989.

50. PEREIRA, M. V. F.; PINTO, L. M. V. G. A New Computational Tool for Composite Reliability Evaluation. IEEE Transactions on Power Systems, v. 7, February 1992. p. 258-264.

51. LEITE DA SILVA, A. M. et al. Composite Reliability Assessment Based on Monte Carlo Simulation and Artificial Neural Networks. IEEE Transactions on Power Systems, v. 22, August 2007. p. 1202-1209. 
52. ZHAOHONG, B.; XIFAN, W. Studies on Variance Reduction Technique of Monte Carlo Simulation in Composite System Reliability Evaluation. Electric Power Systems Research, v. 63, August 2002. p. 59-64.

53. MATTOS, R. S.; VEIGA, A. Otimização de Entropia: Implementação Computacional dos Princípios Maxente Minxent. Pesquisa Operacional, v. 22, p. 37-59, Janeiro a Junho de 2002.

54. EPRI. Workshop Proceedings: Power System Planning and Engineering — Research Needs and Priorities, Report EL-6503. [S.1.]. 1990.

55. EPE - EMPRESA DE PESQUISA ENERGÉTICA. EPE-DEE-RE077/2007-r0: Análise dos Índices de Confiabilidade do SIN. Rio de Janeiro. 2007.

56. NETO, F. C. Fatores de Influência na Avaliação de Indicadores Probabilísticos da Adequação de Sistemas de Potência. Itajubá. 2011.

57. OPERADOR NACIONAL DO SISTEMA ELÉTRICO. Diretrizes e critérios para estudos elétricos - Procedimentos de Rede: Submódulo 23.3. Rio de Janeiro. 2011.

58. SOARES, N. H. M. Risco Probabilístico de Referência do Sistema Elétrico Brasileiro. Dissertação de Metrado - UNIFEI. Itajubá. 2002.

59. BILlintON, R.; ALlAN, R.N.. Probabilistic Assessment of Power Systems. Proceedings Of The IEEE, 88, February 2000. 140-162.

60. OU, Y.; GOEL, L. Using Monte Carlo Simulation For Overall Distribution System Reliability Worth Assessment. IEE Proc. Gener. Transm. Distrib, v. 146, September 1999. p. 535-540.

61. GONZÁLEZ-FERNÁNDEZ, R. A.; LEITE DA SILVA, A. M. Reliability Assessment of Time Dependent Systems via Sequential Cross-Entropy Monte Carlo Simulation. IEEE Transactions on Power Systems, v. 26, November 2011. p. 2381-2389.

62. ALLAN, R. N.; LEITE DA SILVA, A. M.; BURCHETT, R. C. Evaluation Methods and Accuracy in Probabilistic Load Flow Solutions. IEEE Transactions on Power Apparatus and Systems, v. 100, May 1981. p. 2539 - 2546. 
63. GREEN, R. C. et al. Intelligent State Space Pruning for Monte Carlo Simulation with Applications in Composite Power System Reliability. Elsevier-Engineering Applications of Artificial Intelligence, v. 26, 2013. p. $1707-1724$.

64. MELO, J. C. O.; PEREIRA, M. V. F.; LEITE DA SILVA, A. M. Evaluation of Reliability Worth in Composite Systems Based on Pseudo-Sequential Monte Carlo Simulation. IEEE Transactions on Power Apparatus and Systems, v. 9, August 1994. p. 1318-1326.

65. HOMEM-DE-MELlO, T.; RUBINSTEIN, R. Y.. Estimation of Rare Event Probabilities Using Cross-Entropy. Proc. Winter Simulation Conference. San Diego, CAv. Dec. 2002. p. 310-319.

66. BOER, P.-T. D. et al. A Tutorial on the Cross-Entropy Method. Annals of Operations Research, Springer Science + Business Media, v. 134, January 2005. p. 19-67.

67. LEITE DA SILVA, A. M. et al. Long-Term Probabilistic Evaluation of Operating Reserve Requirements with Renewable Sources. IEEE Transactions on Power Systems, v. 25, February 2010.

68. EURELECTRIC - UNION OF THE ELECTRICITY INDUSTRY. Connection rules for generation and management of ancillary services. Brussels, Belgium. 2000.

69. RAINERI, R.; RÍOS, S.; SCHIELE, D. Technical and economic aspects of ancillary services markets in the electric power industry: an international comparison. Energy Policy, v. 34, p. 1540-1555, 2006.

70. NORTH AMERICAN ELECTRIC RELIABILITY CORPORATION. NERC Operating Manual. [S.1.]. March 2008.

71. OPERADOR NACIONAL DO SISTEMA ELÉTRICO. Disponivel em: <http://www.ons.org.br/>. Acesso em: 01 Agosto 2013.

72. GALVIS MANSO, J. C.; FELTRIN, A. P.; LOYO, J. M. Y. Valorização da Reserva Operativa em um Ambiente Competitivo para Geradores Hidrelétricos. Revista Controle \& Automação, v. 21, p. 439-453, Outubro 2010. 
73. OPERADOR NACIONAL DO SISTEMA ELÉTRICO. Controle da Geração em Operação Normal - Procedimentos de Rede: Submódulo 10.6. Rio de Janeiro. Outubro de 2007.

74. SHEBLE, G. B.; FAHD, G. N. Unit Commitment Literature Synopsis. IEEE Transactions on Power Systems, v. 9, February 1994. p. 128-135.

75. BILlinTON, R.; KHAN, E. A Security Based Approach of Composite Power System Reliability Evaluation. IEEE Transactions on Power Systems, v. 7, February 1992. p. 65-71.

76. PINDORIYA, N. M.; JIRUTITIJAROEN, P.; SRINIVASAN, D. Composite Reliability Evaluation Using Monte Carlo Simulation and Least Squares Support Vector Classifier. IEEE Transactions on Power Systems, v. 26, November 2011. p. 2483- 2490.

77. BILLINTON, R. Evaluation of Reliability Worth in an Electric Power System. Reliability Engineering and System Safety, v. 46, 1994. p. 15-23.

78. LEITE DA SILVA, A. M.; PEREIRA, M. V. F.; SCHILling, M. TH. Power System Analysis under Uncertainties - Concepts and Techniques. II Simpósio de Especialistas em Planejamento da Operação e Expansão Elétrica - II SEPOPE. São Paulo, Brasil: [s.n.]. Agosto 1989.

79. MALLARD, S. A.; THOMAS, V. C. A Method for Calculating Transmission System Reliability. IEEE Transactions on Power Apparatus and Systems, v. 81, March 1968. p. 824-834.

80. BILLINTON, R.; JONNAVITHULA, S. Test System for Teaching Overall Power System Reliability Assessment. IEEE Transactions on Power Systems, v. 11, November 1996. p. 1670-1676.

81. DIAS, J.A.S.; BORGES, C.L.T.. Object Oriented Model for Composite Reliability Evaluation Including Time Varying Load and Wind Generation. Proceedings of the 11th International Conference on Probabilistic Methods Applied to Power Systems - PMAPS 2010. Singapore. 14-17 June 2010. p. 767- 772.

82. STOTT, B.; JARDIM, J.; ALSAÇ. O. DC Power Flow Revisited. IEEE Transactions on Power Systems, August 2009. 1290-1300. 
83. MONTICELLI, A. J. Fluxo de Carga em Redes de Energia Elétrica. São Paulo: Edgard Blitcher, 1983.

84. RESENDE, L. C. Avaliação da Confiabilidade Preventiva de Sistemas Életricos de Grande Porte Utilizando Redes Neurais. Itajubá. 2006.

85. MOMOH, J. A.; EL-HAWARY, M. E.; ADAPA, R. A Review of Selected Optimal Power Flow Literature to 1993 - Part I: NonLinear and Quadratic Programming Approaches. IEEE Transactions on Power Systems, v. 14, February 1999. p. 96-104.

86. HUI, K.-P. et al. The Cross-Entropy Method for Network Reliability Estimation. Annals of Operations Research, Springer Science + Business Media, v. 134, November 2005. p. 101-118.

87. RELIABILITY TEST SYSTEM TASK FORCE OF THE IEEE SUBCOMMITTEE ON THE APPLICATION OF PROBABILITY METHODS. IEEE Reliability Test System. IEEE Transactions on Power Apparatus and Systems, v. 98, November/December 1979. p. 2047-2054.

88. FORTUNATO, L.A.M.; NETO, T.A.A.; ALBUQUERQUE, J.C.R. Introdução ao Planejamento da Expansão e Operação de Sistemas de Produção de Energia Elétrica. Niteroi: Universidade Federal Fluminense EDUFF, 1990.

89. MATOS, M. et al. Probabilistic evaluation of reserve requirements of generating systems with renewable power sources: The Portuguese and Spanish cases. Int. Journal of Electrical Power \& Energy Systems, v. 31, October 2009. p. 562-569.

90. GONZÁLEZ-FERNÁNDEZ, R. A.; LEITE DA SILVA, A. M.; OVIEDOSANABRIA, R. E. Generating capacity reliability assessment of the Itaipu hydroelectric plant via sequential Monte Carlo simulation. 18th PSCC. Wroclaw Poland. 18-22 Aug. 2014.

91. LI, W. Risk Assessment of Power Systems - Models, Methods, and Applications. New York: IEEE Press, 2005.

92. EPE - EMPRESA DE PESQUISA ENERGÉTICA. PDE 2026, 25 Agosto 2017. Disponivel em: <www.epe.gov.br>. Acesso em: 25 Agosto 2017. 
93. ONS - OPERADOR NACIONAL DO SISTEMA. Information about the Brazilian Interconected Power System - ONS. Disponivel em: $<$ http://ons.org.br/PublishingImages/paginas/sobre_sin/mapas/>. Acesso em: Janeiro 2018.

94. ONS - OPERADOR NACIONAL DO SISTEMA. Glossário de Termos Técnicos, Submódulo 20.1, revisão 1.0. [S.1.]. 2009.

95. ONS - OPERADOR NACIONAL DO SISTEMA. Controle da transmissão em Operação Normal, Submódulo 10.7, rev. 1.1. [S.1.]. 2010.

96. ONS - OPERADOR NACIONAL DO SISTEMA. Planejamento e programação da operação elétrica, Módulo 6, revisão 2.0. 2011.

97. FGV - FUNDAÇÃO GETÚLIO VARGAS, Curso: Bem estar social e Desigualdade. Disponível em http://www.cps.fgv.br/cps/Pesquisas/Politicas_soiais_alunos/2012/Site/. Acesso em: 01 Jan. 2018. 


\section{9}

\section{Apêndice A:}

Ordem de Mérito para Despacho Econômico da Geração

É possível obter a ordem de mérito, de forma simplificada para uma análise de curto prazo, resolvendo o problema de programação linear (PPL) representado por:

$$
\begin{gathered}
\min C(\boldsymbol{X}, \boldsymbol{G}, L)=\sum_{j=1}^{N_{C}}\left[n_{j} \times C_{O \& M_{j}}+n_{k} \times C_{R_{j}}\right]+C_{\text {int }} \\
C_{O \& M_{j}}=x_{j} \times C_{j}^{\text {Prod }} \times P_{j} \\
C_{R_{j}}=x_{j} \times C_{j}^{R} \times R_{j} \\
C_{\text {int }}=U C \times L^{\text {shed }} \\
L^{\text {shed }}=\sum_{j=1}^{N_{\text {Bus }}} L_{j}^{\text {shed }}
\end{gathered}
$$

sujeito a:

$$
\begin{aligned}
& \sum_{j=1}^{N_{c}}\left(x_{j} \times P_{j}-x_{j} \times R_{j}\right)=L^{t} \\
& \sum_{j=1}^{N_{c}} x_{j} \times P_{j}^{\text {max }}=L^{t}+R^{\text {static }} \\
& x_{j} \times P_{j}^{\text {min }} \leq P_{i}^{t} \leq x_{j} \times P_{j}^{\text {max }}
\end{aligned}
$$

sendo $t$ o tempo; $L^{t}$ é Demanda no tempo t; $R_{j}^{t}$ é a reserva da $j$-ésima unidade no tempo t; $P_{i}^{t}$ é a potência da $i$-ésima unidade no tempo $t ; x_{j}$ representa o estado da $j$-ésima unidade; $L^{\text {shed }}$ é o montante de corte de carga; $C_{j}^{\text {Prod }}$ é o custo de geração da $j$-ésima unidade; $C_{o \& m_{i}}$ é o custo de operação e manutenção da $i$-ésima unidade; $C_{R_{j}}$ é o custo da oferta de reserva girante da j-ésima unidade; $C_{i n t_{i}}$ é custo associado às interrupções. A três restrições do problema representado em (9.1) representam, respectivamente, a restrição de atendimento da demanda do curto prazo, restrição 
de máxima reserva de capacidade estática e restrição associadas aos limites máximos e mínimos de geração das unidades.

\section{1.}

\section{Ordem de mérito Sistema IEEE RTS Wind}

Na tabela a seguir é apresentada a ordem de mérito para as estações geradoras do sistema IEEE RTS Wind.

Tabela 9.1: Lista de unidades de geração segundo ordem de mérito.

\begin{tabular}{|c|c|c|c|c|}
\hline$N U$ & $N_{G}$ & $\begin{array}{c}\text { Cap. } \\
{[\mathrm{MW}]}\end{array}$ & $\begin{array}{c}\text { Custo } \\
{[\$ / \mathrm{MW}]}\end{array}$ & $\begin{array}{c}\text { ORR } \\
{\left[\times 10^{-3}\right]}\end{array}$ \\
\hline $0-763$ & 763 & 2 & 0.00 & 1.042 \\
\hline $764-765$ & 2 & 400 & 6.30 & 1.818 \\
\hline $766-771$ & 6 & 50 & 10.00 & 1.010 \\
\hline $772-775$ & 2 & 155 & 12.44 & 2.083 \\
\hline $776-779$ & 4 & 76 & 15.30 & 1.020 \\
\hline $780-782$ & 3 & 197 & 22.80 & 2.105 \\
\hline $783-785$ & 3 & 100 & 23.80 & 1.667 \\
\hline $786-790$ & 5 & 12 & 28.50 & 0.680 \\
\hline $791-794$ & 4 & 20 & 48.50 & 4.444 \\
\hline \hline
\end{tabular}


10

Apêndice B:

Índices de risco - Sistema IEEE RTS Wind

Nas tabelas a seguir são apresentados os valores do índice risco para os cinco cenários do sistema IEEE RTS Wind considerando a carga constante (carga pico) e todas as 794 unidades despachadas.

Tabela 10.1: Índices de Risco - Cenário Favorável

\begin{tabular}{|c|c|c|c|c|c|}
\hline Seq. & $\begin{array}{c}\text { Geração } \\
\text { Disponível } \\
{[\mathrm{MW}]}\end{array}$ & Reserva G & Risk G & $\begin{array}{c}\text { Reserva G- } \\
\text { Trans. Losses }\end{array}$ & Risk GT \\
\hline 1 & 3563,16 & 713,16 & $3,32 \mathrm{E}-06$ & 645,42 & $3,70 \mathrm{E}-04$ \\
\hline 2 & 3608,94 & 758,94 & $3,31 \mathrm{E}-06$ & 688,36 & $3,63 \mathrm{E}-04$ \\
\hline 3 & 3470,07 & 620,07 & $4,22 \mathrm{E}-06$ & 557,45 & $2,91 \mathrm{E}-04$ \\
\hline 4 & 3596,73 & 746,73 & $3,53 \mathrm{E}-06$ & 676,93 & $3,61 \mathrm{E}-04$ \\
\hline 5 & 3448,71 & 598,71 & $4,95 \mathrm{E}-06$ & 537,13 & $3,23 \mathrm{E}-04$ \\
\hline 6 & 3584,52 & 734,52 & $3,28 \mathrm{E}-06$ & 665,49 & $3,56 \mathrm{E}-04$ \\
\hline 7 & 3541,79 & 691,79 & $3,71 \mathrm{E}-06$ & 625,31 & $3,56 \mathrm{E}-04$ \\
\hline 8 & 3558,58 & 708,58 & $3,68 \mathrm{E}-06$ & 641,12 & $3,60 \mathrm{E}-04$ \\
\hline \hline
\end{tabular}

Tabela 10.2: Índices de Risco - Cenário Normal

\begin{tabular}{|c|c|c|c|c|c|}
\hline Seq. & $\begin{array}{c}\text { Geração } \\
\text { Disponível } \\
{[\text { MW] }}\end{array}$ & Reserva G & Risk G & $\begin{array}{c}\text { Reserva G- } \\
\text { Trans. Losses }\end{array}$ & Risk GT \\
\hline 1 & 3418.19 & 568.19 & $2.71 \times 10^{-5}$ & 508.02 & $3.25 \times 10^{-4}$ \\
\hline 2 & 3373.93 & 523.93 & $5.63 \times 10^{-5}$ & 465.64 & $3.61 \times 10^{-4}$ \\
\hline 3 & 3404.45 & 554.45 & $4.30 \times 10^{-5}$ & 494.89 & $3.50 \times 10^{-4}$ \\
\hline 4 & 3352.57 & 502.57 & $5.67 \times 10^{-5}$ & 445.11 & $3.79 \times 10^{-4}$ \\
\hline 5 & 3370.88 & 520.88 & $5.56 \times 10^{-5}$ & 462.71 & $3.55 \times 10^{-4}$ \\
\hline 6 & 3331.21 & 481.21 & $7.49 \times 10^{-5}$ & 424.53 & $3.74 \times 10^{-4}$ \\
\hline 7 & 3384.62 & 534.62 & $5.60 \times 10^{-5}$ & 475.89 & $3.53 \times 10^{-4}$ \\
\hline 8 & 3383.09 & 533.09 & $5.71 \times 10^{-5}$ & 474.43 & $3.60 \times 10^{-4}$ \\
\hline
\end{tabular}


Tabela 10.3: Índices de Risco - Cenário Desfavorável

\begin{tabular}{|c|c|c|c|c|c|}
\hline Seq. & $\begin{array}{c}\text { Geração } \\
\text { Disponível } \\
{[\mathrm{MW}]}\end{array}$ & Reserva G & Risk G & $\begin{array}{c}\text { Reserva G-Trans. } \\
\text { Losses }\end{array}$ & Risk GT \\
\hline 1 & 3254,91 & 404,91 & $1,83 \mathrm{E}-04$ & 350,64 & $3,97 \mathrm{E}-03$ \\
\hline 2 & 3271,69 & 421,69 & $1,11 \mathrm{E}-04$ & 366,95 & $3,90 \mathrm{E}-03$ \\
\hline 3 & 3290,00 & 440,00 & $1,11 \mathrm{E}-04$ & 384,71 & $3,87 \mathrm{E}-03$ \\
\hline 4 & 3314,42 & 464,42 & $8,97 \mathrm{E}-05$ & 408,33 & $4,52 \mathrm{E}-04$ \\
\hline 5 & 3285,43 & 435,43 & $1,12 \mathrm{E}-04$ & 380,27 & $3,94 \mathrm{E}-03$ \\
\hline 6 & 3299,16 & 449,16 & $1,02 \mathrm{E}-04$ & 393,57 & $3,96 \mathrm{E}-03$ \\
\hline 7 & 3306,79 & 456,79 & $9,16 \mathrm{E}-05$ & 400,95 & $4,54 \mathrm{E}-04$ \\
\hline 8 & 3309,84 & 459,84 & $8,98 \mathrm{E}-05$ & 403,90 & $4,49 \mathrm{E}-04$ \\
\hline \hline
\end{tabular}

Tabela 10.4: Índices de Risco - Cenário Decrescente

\begin{tabular}{|c|c|c|c|c|c|}
\hline Seq. & $\begin{array}{c}\text { Geração } \\
\text { Disponível } \\
{[\mathrm{MW}]}\end{array}$ & Reserva G & Risk G & $\begin{array}{l}\text { Reserva G-Trans. } \\
\text { Losses }\end{array}$ & Risk GT \\
\hline 1 & 3825,63 & 975,63 & $2,15 \mathrm{E}-08$ & 882,74 & 6,73E-04 \\
\hline 2 & 3776,80 & 926,80 & $4,85 \mathrm{E}-08$ & 840,33 & $5,89 \mathrm{E}-04$ \\
\hline 3 & 3692,87 & 842,87 & $1,01 \mathrm{E}-07$ & 765,75 & 4,67E-04 \\
\hline 4 & 3630,30 & 780,30 & $3,33 \mathrm{E}-06$ & 708,32 & $4,74 \mathrm{E}-04$ \\
\hline 5 & 3557,05 & 707,05 & $3,63 \mathrm{E}-06$ & 639,68 & $3,55 \mathrm{E}-04$ \\
\hline 6 & 3499,07 & 649,07 & $4,02 \mathrm{E}-06$ & 584,95 & $2,94 \mathrm{E}-04$ \\
\hline 7 & 3415,14 & 565,14 & $2,77 \mathrm{E}-05$ & 505,11 & $3,23 \mathrm{E}-04$ \\
\hline 8 & 3297,63 & 447,63 & $1,11 \mathrm{E}-04$ & 392,09 & $3,89 \mathrm{E}-03$ \\
\hline
\end{tabular}

Tabela 10.5: Índices de Risco - Cenário Crescente

\begin{tabular}{|c|c|c|c|c|c|}
\hline \hline Seq. & $\begin{array}{c}\text { Geração } \\
\text { Disponível } \\
{[\mathrm{MW}]}\end{array}$ & Reserva G & Risk G & $\begin{array}{c}\text { Reserva G-Trans. } \\
\text { Losses }\end{array}$ & Risk GT \\
\hline 1 & 3297,63 & 447,63 & $1,11 \mathrm{E}-04$ & 392,09 & $3,87 \mathrm{E}-03$ \\
\hline 2 & 3415,14 & 565,14 & $2,75 \mathrm{E}-05$ & 505,11 & $3,23 \mathrm{E}-04$ \\
\hline 3 & 3499,07 & 649,07 & $3,99 \mathrm{E}-06$ & 584,95 & $2,95 \mathrm{E}-04$ \\
\hline 4 & 3557,05 & 707,05 & $3,65 \mathrm{E}-06$ & 639,68 & $3,59 \mathrm{E}-04$ \\
\hline 5 & 3630,30 & 780,30 & $3,31 \mathrm{E}-06$ & 708,32 & $4,66 \mathrm{E}-04$ \\
\hline 6 & 3692,87 & 842,87 & $1,00 \mathrm{E}-07$ & 765,75 & $4,66 \mathrm{E}-04$ \\
\hline 7 & 3776,80 & 926,80 & $4,87 \mathrm{E}-08$ & 840,45 & $5,90 \mathrm{E}-04$ \\
\hline 8 & 3825,63 & 975,63 & $2,15 \mathrm{E}-08$ & 882,74 & $6,81 \mathrm{E}-04$ \\
\hline
\end{tabular}


11

Apêndice $C$ :

Tempos Computacionais para Avaliar os Cenários GT do Sistema IEEE RTS Wind

Nas tabelas a seguir são apresentados os tempos computacionais para avaliar os cinco cenários de geração do sistema IEEE RTS Wind, considerando falhas na geração e na transmissão.

Tabela 11.1: Tempos computacionais [em segundos] considerando falhas somente na Geração (sem Transmissão)

\begin{tabular}{|c|c|c|c|c|}
\hline \multirow{2}{*}{ Série de Vento } & \multicolumn{4}{|c|}{ Número de Unidades } \\
\cline { 2 - 5 } & 783 & 784 & 785 & 786 \\
\hline S1 & 33,67 & 33,91 & 43,88 & 89,56 \\
\hline S2 & 33,08 & 30,17 & 30,23 & 57,02 \\
\hline S3 & 18,08 & 29,41 & 29,89 & 51,05 \\
\hline S4 & 47,52 & 38,94 & 41,92 & 55,52 \\
\hline S5 & 40,38 & 43,39 & 41,27 & 63,27 \\
\hline Média: & 34,546 & 35,164 & 37,438 & 63,284 \\
\hline
\end{tabular}

Tabela 11.2: Tempos computacionais [em segundos] considerando restrições de transmissão (Falhas, Capacidade e Perdas nas LTs)

\begin{tabular}{|c|c|c|c|c|}
\hline \multirow{2}{*}{ Série de Vento } & \multicolumn{4}{|c|}{ Número de Unidades } \\
\cline { 2 - 5 } & 783 & 784 & 785 & 786 \\
\hline S1 & 41,62 & 47,64 & 51,06 & 56,64 \\
\hline S2 & 17,47 & 31,17 & 33,95 & 37,19 \\
\hline S3 & 15,42 & 15,22 & 34,53 & 36,73 \\
\hline S4 & 47,75 & 51,23 & 54 & 58,14 \\
\hline S5 & 44,39 & 55,66 & 52,25 & 56,95 \\
\hline Média: & 33,33 & 40,184 & 45,158 & 49,13 \\
\hline
\end{tabular}

A média de tempo das avaliações de risco foi de 42,61 segundos (sistema barra única) - Tabela 11.1. Considerando o sistema de transmissão, a média de tempo das avaliações de risco foi de 41,95 segundos - Tabela 11.2. 


\section{Aplicação do Índice de Gini}

O Índice de Gini é usualmente empregado em economia para avaliar numericamente o perfil de distribuição renda de uma população, refletindo se a riqueza acumulada está distribuída ou concentrada em um grupo de indivíduos.

Uma das maneiras de entender o cálculo do índice é por meio da Curva de Lorenz, conforme descrito em [97].

Considere $n$ valores para uma variável $x_{\mathrm{i}}$ ordenados de forma crescente ( $x_{1} \leq$ $x_{2} \leq \ldots x_{\mathrm{n}}$ ). A proporção acumulada (normalizada por $n$ ) da população até a i-ésima pessoa é $p_{\mathrm{i}}=i / n$. Os pares de valores $\left(p_{i} ; \phi_{i}\right)$ correspondem a pontos que formam a "curva de Lorenz". No caso de perfeita equidade a curva de Lorenz corresponde à reta diagonal que une os pontos $(0,0)$ e $(1,1)$. No outro extremo, temos o caso de perfeita desigualdade, no qual um único indivíduo é detentor de toda a renda $\left(x_{\mathrm{j}}=\right.$ $N u$ e $x_{\mathrm{i}}=0$ para $\mathrm{i} \neq \mathrm{j}$ ). Nesta situação, uma parte da curva de Lorenz coincide com o eixo horizontal do gráfico.

A área compreendida entre a linha de perfeita equidade e a curva de Lorenz é a área de desigualdade, indicada por $\alpha$ na Figura 14.1. No caso de perfeita desigualdade, $n$ - 1 pessoas possuem 0 e um único indivíduo possui tudo. A área de desigualdade corresponde à área do triângulo cuja base (no eixo das abscissas) é igual a 1-1/n e cuja altura é igual a 1 . Desta forma, o valor máximo de $\alpha$ para uma distribuição discreta é

$$
\alpha_{\max }=\frac{1}{2}\left(1-\frac{1}{n}\right) \text {, }
$$

À medida que o tamanho da população aumenta $\alpha_{\max }$ tende para $1 / 2$. 


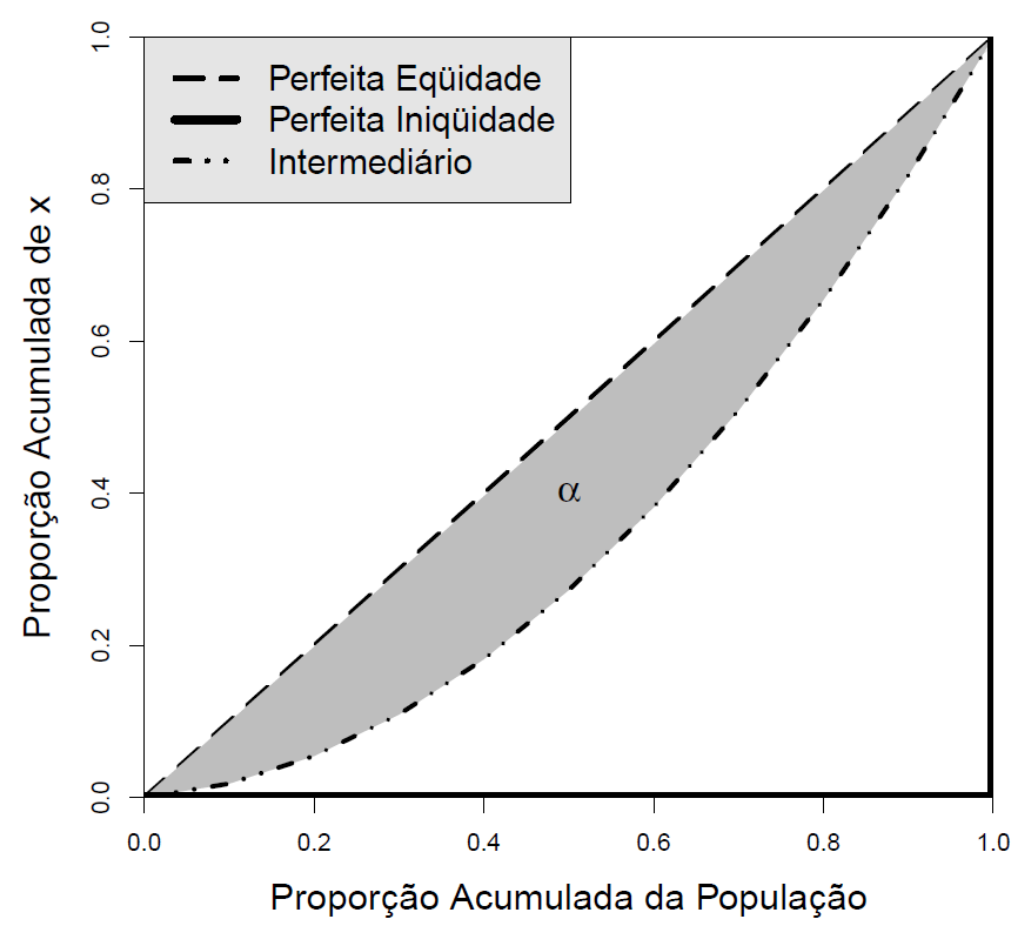

Figura 12.1: Curva de Lorenz e o índice de Gini [97]

O índice de Gini $(\mathrm{G})$ é definido como o quociente entre a área de desigualdade $\alpha$ e o valor de máxima desigualdade $\left(\alpha_{\max }=1 / 2\right.$. $)$,

$$
G=\frac{\alpha}{\lim _{n \rightarrow \infty} \alpha_{\max }}=\frac{\alpha}{1 / 2}=2 \alpha
$$

O índice $\mathrm{G}$ assume valores entre zero e um, $0 \leq G \leq 1$.

O cálculo do Gini de uma distribuição pode ser realizado sem recorrer à curva de Lorenz. Definimos a área entre a curva de Lorenz e o eixo das abscissas por $\beta$. Então, temos $\alpha+\beta=0,5$. É possível decompor a área $\beta$ em $n-1$ trapézios. Sendo $S_{i}$ área do i-ésimo trapézio, cuja altura é igual a $p_{i}-p_{i-1}=1 / n$ e bases maior e menor correspondem a $\phi_{i}$ e $\phi_{i-1}$, respectivamente. Tem-se,

$$
S_{i}=\frac{1}{2}\left(\Phi_{i}-\Phi_{i-1}\right) \times(1 / n)
$$

A área $\beta$ pode ser encontrada através da soma de todos os trapézios, isto é, 


$$
\beta=\sum S_{i}=\frac{1}{2 n} \sum_{i=1}^{n}\left(\Phi_{i}-\Phi_{i-1}\right),
$$

A partir da equação (14.2) e dado que $\alpha=0,5-\beta$, obtem-se a seguinte expressão para o índice de Gini,

$$
G=1-2 \beta=1-\frac{1}{n} \sum_{i=1}^{n}\left(\Phi_{i}-\Phi_{i-1}\right)
$$

12.1.

\section{Aplicação do índice de Gini em sistemas de energia elétrica}

Neste tópico, o índice de Gini será aplicado ao problema da distribuição da reserva operativa entre as áreas elétricas de um sistema de distribuição, analisando o impacto da distribuição da geração em cada área do sistema IEEE RTS.

Tabela 12.1: Riscos no sistema IEEE RTS

\begin{tabular}{|c|c|c|c|c|c|}
\hline NU & $\begin{array}{c}\text { Geração } \\
{[\mathrm{MW}]}\end{array}$ & $\begin{array}{c}\text { Reserva } \\
{[\mathrm{MW}]}\end{array}$ & $\begin{array}{c}\text { Risco G\&T } \\
\text { Sistema }\end{array}$ & $\begin{array}{c}\text { Risco } \\
\text { Área } 230 \mathrm{kV}\end{array}$ & $\begin{array}{c}\text { Risco } \\
\text { Área } 138 \mathrm{kV}\end{array}$ \\
\hline 20 & 2695 & 115 & 0,02019514 & 0,02010961 & 0,02019514 \\
\hline 21 & 3065 & 215 & 0,00579402 & 0,00552295 & 0,00579402 \\
\hline 22 & 3165 & 315 & 0,00556373 & 0,00537317 & 0,00556373 \\
\hline 23 & 3265 & 415 & 0,0003588 & 0,00016051 & 0,00035875 \\
\hline 24 & 3277 & 427 & 0,00034756 & 0,00015107 & 0,00034755 \\
\hline 25 & 3289 & 439 & 0,00034951 & 0,00015108 & 0,00034949 \\
\hline 26 & 3301 & 451 & 0,00031935 & 0,00012054 & 0,00031932 \\
\hline 27 & 3313 & 463 & 0,00031849 & 0,00012026 & 0,00031848 \\
\hline 28 & 3325 & 475 & 0,00031879 & 0,00012003 & 0,00031876 \\
\hline 29 & 3345 & 495 & 0,00030372 & 0,00010659 & 0,0003037 \\
\hline 30 & 3365 & 515 & 0,00027317 & 0,00007462 & 0,00027315 \\
\hline 31 & 3385 & 535 & 0,00027311 & 0,00007538 & 0,00027309 \\
\hline 32 & 3405 & 555 & 0,00023343 & 0,00003529 & 0,0002326 \\
\hline
\end{tabular}


No problema da reserva operativa em sistemas multiárea, pode-se fazer a analogia em que a renda seria o inverso do risco. A montante de geração da área seria análogo à população,

$$
\begin{gathered}
\operatorname{Renda}\left(\mathrm{A}_{i}\right)=1 / \operatorname{RiscoGT}\left(\mathrm{A}_{i}\right) . \\
\operatorname{População}\left(\mathrm{A}_{i}\right)=\mathrm{G}\left(\mathrm{A}_{i}\right)
\end{gathered}
$$

Na Tabela 14.2 está apresentada a "renda" das áreas do sistema, obtidas invertendo o risco da Tabela 14.1.

Tabela 12.2: Renda das áreas do sistema

\begin{tabular}{|c|c|c|c|c|}
\hline $\begin{array}{c}\text { Geração } \\
138 \mathrm{kV}\end{array}$ & $\begin{array}{c}\text { Geração } \\
230 \mathrm{kV}\end{array}$ & $\begin{array}{c}\text { Geração To- } \\
\text { tal }\end{array}$ & Renda 230 & Renda 138 \\
\hline- & - & 2498 & 1 & 1 \\
\hline 304 & 2661 & 2695 & 49,7 & 49,5 \\
\hline 404 & 2661 & 3065 & 181,1 & 172,6 \\
\hline 504 & 2661 & 3165 & 186,1 & 179,7 \\
\hline 604 & 2661 & 3265 & 6230,1 & 2787,5 \\
\hline 604 & 2673 & 3277 & 6619,4 & 2877,3 \\
\hline 604 & 2685 & 3289 & 6619,0 & 2861,3 \\
\hline 604 & 2697 & 3301 & 8296,0 & 3131,7 \\
\hline 604 & 2709 & 3313 & 8315,3 & 3139,9 \\
\hline 604 & 2721 & 3325 & 8331,3 & 3137,2 \\
\hline 624 & 2721 & 3345 & 9381,7 & 3292,7 \\
\hline 644 & 2721 & 3365 & 13401,2 & 3661,0 \\
\hline 664 & 2721 & 3385 & 13266,1 & 3661,8 \\
\hline 684 & 2721 & 3405 & 28336,6 & 4299,2 \\
\hline
\end{tabular}

No cálculo do índice de Gini, a renda e o número de indivíduos da população devem ser normalizados (divididos pelo valor máximo), como apresentado na Tabela 14.3. 
Tabela 12.3: Parâmetros normalizados

\begin{tabular}{|c|c|c|}
\hline $\begin{array}{c}\text { Geração To- } \\
\text { tal } \\
\text { Normalizada }\end{array}$ & $\begin{array}{c}\text { Renda 230 } \\
\text { Normalizada }\end{array}$ & $\begin{array}{c}\text { Renda 138 } \\
\text { Normalizada }\end{array}$ \\
\hline 0,7336 & 0,0000 & 0,0002 \\
\hline 0,7915 & 0,0018 & 0,0115 \\
\hline 0,9001 & 0,0064 & 0,0401 \\
\hline 0,9295 & 0,0066 & 0,0418 \\
\hline 0,9589 & 0,2199 & 0,6484 \\
\hline 0,9624 & 0,2336 & 0,6693 \\
\hline 0,9659 & 0,2336 & 0,6655 \\
\hline 0,9695 & 0,2928 & 0,7284 \\
\hline 0,9730 & 0,2934 & 0,7303 \\
\hline 0,9765 & 0,2940 & 0,7297 \\
\hline 0,9824 & 0,3311 & 0,7659 \\
\hline 0,9883 & 0,4729 & 0,8515 \\
\hline 0,9941 & 0,4682 & 0,8517 \\
\hline 1,0000 & 1,0000 & 1,0000 \\
\hline
\end{tabular}

Empregando as equações 14.5 a 14-7, calcula-se $\beta$, como apresentado na Tabela 14.4.

Tabela 12.4: Parâmetros da curva de Lorenz

\begin{tabular}{|c|c|c|c|c|c|c|c|}
\hline \multicolumn{4}{|c|}{ Área 230} & \multicolumn{4}{|c|}{ Área 138} \\
\hline$n$ & $\Phi_{i}$ & $\Phi_{i-1}$ & $S_{i}$ & $n$ & $\Phi_{i}$ & $\Phi_{i-1}$ & $S_{i}$ \\
\hline 0,0579 & 0,0018 & 0,0000 & $5,18 \mathrm{E}-05$ & 0,0579 & 0,0115 & 0,0002 & $3,40 \mathrm{E}-04$ \\
\hline 0,1087 & 0,0064 & 0,0018 & $4,43 \mathrm{E}-04$ & 0,1087 & 0,0401 & 0,0115 & $2,81 \mathrm{E}-03$ \\
\hline 0,0294 & 0,0066 & 0,0064 & $1,90 \mathrm{E}-04$ & 0,0294 & 0,0418 & 0,0401 & $1,20 \mathrm{E}-03$ \\
\hline 0,0294 & 0,2199 & 0,0066 & $3,32 \mathrm{E}-03$ & 0,0294 & 0,6484 & 0,0418 & $1,01 \mathrm{E}-02$ \\
\hline 0,0035 & 0,2336 & 0,2199 & 7,99E-04 & 0,0035 & 0,6693 & 0,6484 & $2,32 \mathrm{E}-03$ \\
\hline 0,0035 & 0,2336 & 0,2336 & $8,23 \mathrm{E}-04$ & 0,0035 & 0,6655 & 0,6693 & $2,35 \mathrm{E}-03$ \\
\hline 0,0035 & 0,2928 & 0,2336 & $9,27 \mathrm{E}-04$ & 0,0035 & 0,7284 & 0,6655 & $2,46 \mathrm{E}-03$ \\
\hline 0,0035 & 0,2934 & 0,2928 & $1,03 \mathrm{E}-03$ & 0,0035 & 0,7303 & 0,7284 & $2,57 \mathrm{E}-03$ \\
\hline 0,0035 & 0,2940 & 0,2934 & $1,04 \mathrm{E}-03$ & 0,0035 & 0,7297 & 0,7303 & $2,57 \mathrm{E}-03$ \\
\hline 0,0059 & 0,3311 & 0,2940 & $1,84 \mathrm{E}-03$ & 0,0059 & 0,7659 & 0,7297 & 4,39E-03 \\
\hline 0,0059 & 0,4729 & 0,3311 & $2,36 \mathrm{E}-03$ & 0,0059 & 0,8515 & 0,7659 & $4,75 \mathrm{E}-03$ \\
\hline 0,0059 & 0,4682 & 0,4729 & $2,76 \mathrm{E}-03$ & 0,0059 & 0,8517 & 0,8515 & $5,00 \mathrm{E}-03$ \\
\hline 0,0059 & 1,0000 & 0,4682 & $4,31 \mathrm{E}-03$ & 0,0059 & 1,0000 & 0,8517 & $5,44 \mathrm{E}-03$ \\
\hline & & $\mathrm{B}_{1}$ : & 0,020 & & & $\beta_{2}:$ & 0,046 \\
\hline
\end{tabular}


O índice de Gini pode ser então estimado $(\mathrm{G}=1-2 \beta)$, conforme Tabela 14.5.

Tabela 12.5: Índice de Gini das áreas

\begin{tabular}{|c|c|c|}
\hline & Área $230 \mathrm{kV}$ & Área $138 \mathrm{kV}$ \\
\hline$\beta$ & 0,020 & 0,046 \\
\hline $\mathrm{G}$ & 0,960 & 0,907 \\
\hline
\end{tabular}

É possível perceber que o índice de Gini da área $230 \mathrm{kV}$ é menor que o da área de $138 \mathrm{kV}$. Quanto mais próximo de zero maior o nível de igualdade de distribuição. Desta forma, percebe-se que, despachando reserva operativa pela ordem de mérito, a área $138 \mathrm{kV}$ tem melhor distribuição da geração que a área $230 \mathrm{kV}$ (aparentemente já "saturada", uma vez que as máquinas já haviam sido despachadas na base).

Analisando o comportamento do Índice de Gini percebe-se que é possível empregá-lo para avaliar a distribuição da geração entre áreas de um sistema elétrico. A área de $230 \mathrm{kV}$ apresenta melhor perfil de geração $\mathrm{G}_{230 \mathrm{kV}}>\mathrm{G}_{138 \mathrm{kV}}$. Caso se desejasse uma distribuição mais igualitária, a área de $138 \mathrm{kV}$ seria mais propícia à alocação de reserva. 